\title{
Early detection of cancer: the development and evaluation of computer-tailored health education
}

Citation for published version (APA):

de Nooijer, J. M. (2001). Early detection of cancer: the development and evaluation of computer-tailored health education. [Doctoral Thesis, Maastricht University]. Universiteit Maastricht. https://doi.org/10.26481/dis.20011012jn

Document status and date:

Published: 01/01/2001

DOI:

10.26481/dis.20011012jn

Document Version:

Publisher's PDF, also known as Version of record

\section{Please check the document version of this publication:}

- A submitted manuscript is the version of the article upon submission and before peer-review. There can be important differences between the submitted version and the official published version of record.

People interested in the research are advised to contact the author for the final version of the publication, or visit the DOI to the publisher's website.

- The final author version and the galley proof are versions of the publication after peer review.

- The final published version features the final layout of the paper including the volume, issue and page numbers.

Link to publication

\footnotetext{
General rights rights.

- You may freely distribute the URL identifying the publication in the public portal. please follow below link for the End User Agreement:

www.umlib.nl/taverne-license

Take down policy

If you believe that this document breaches copyright please contact us at:

repository@maastrichtuniversity.nl

providing details and we will investigate your claim.
}

Copyright and moral rights for the publications made accessible in the public portal are retained by the authors and/or other copyright owners and it is a condition of accessing publications that users recognise and abide by the legal requirements associated with these

- Users may download and print one copy of any publication from the public portal for the purpose of private study or research.

- You may not further distribute the material or use it for any profit-making activity or commercial gain

If the publication is distributed under the terms of Article $25 \mathrm{fa}$ of the Dutch Copyright Act, indicated by the "Taverne" license above, 
EARLY DETECTION OF CANCER: THE DEVELOPMENT AND EVALUATION OF COMPUTER-TAILORED HEALTH EDUCATION 


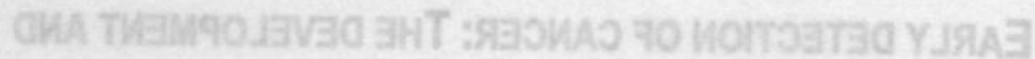

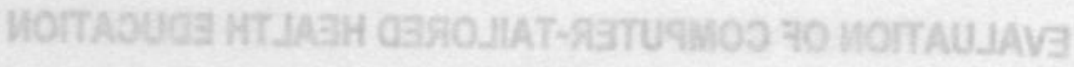




\section{EARLY DETECTION OF CANCER: THE DEVELOPMENT AND EVALUATION OF COMPUTER-TAILORED HEALTH EDUCATION}

PROEFSCHRIFT

ter verkrijging van de graad van doctor aan de Universiteit Maastricht, op gezag van de Rector Magnificus, Prof. Dr. A.C. Nieuwenhuijzen Kruseman, volgens het besluit van het College van Decanen, in het openbaar te verdedigen op vrijdag 12 oktober 2001 om 12.00 uur

door

Jacqueline Mary de Nooijer geboren te Dordrecht op 5 maart 1970 


\section{PROMOTOR:}

Prof. Dr. H. de Vries

\section{COPROMOTOR:}

Dr. E.H.S. Lechner

\section{BEOORDELINGSCOMMISSIE:}

Prof. Dr. N.K. de Vries (voorzitter)

Prof. Dr. Ir. J. Brug

Dr. E.P.E. Mesters

Prof. Dr. C.P. van Schayck

Prof. Dr. E.R. Seydel (Universiteit Twente)

ISBN: 90-5681-113-4

Printed by: Unigraphic, Maastricht

The study presented in this thesis was performed at the Mastricht Health Research Institute for Prevention and Care (HEALTH), which participates in the Netherlands School of Primary Care Research (CaRe), acknowledged in 1995 by the Royal Dutch Academy of Science (KNAW).

All studies were conducted with financial support from the Dutch Cancer Society. 


\section{CONTENTS}

General introduction

Chapter 1 Early detection of cancer

Chapter 2 Anderson's model of total patient delay: A qualitative study on detecting cancer symptoms and seeking medical help

Chapter 3 Help-seeking behavior for cancer symptoms: Perceptions of patients and physicians

Chapter 4 Early detection of cancer: Knowledge and behavior among Dutch adults

Chapter 5 Social psychological correlates of paying attention to cancer symptoms and seeking medical help

Chapter 6 Tailored versus general information on early detection of cancer:

A comparison of the reactions of Dutch adults and the impact on attitudes and behaviors

Chapter 7 A randomized controlled study of short-term and long-term effects of tailored information versus general information on determinants and behaviors related to early detection of cancer

Chapter 8 General conclusions, discussion and implications

References

Summary

Samenvatting 


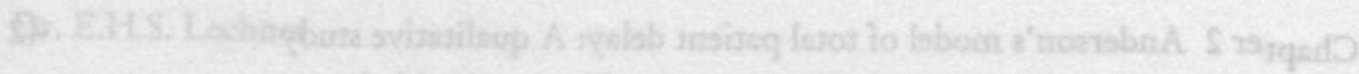

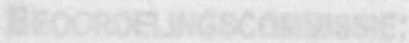

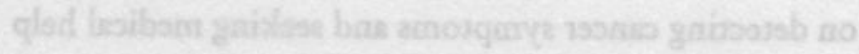

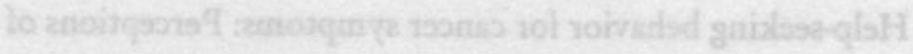

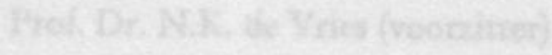

zanizizydo bos zansisse

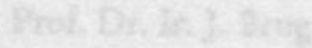

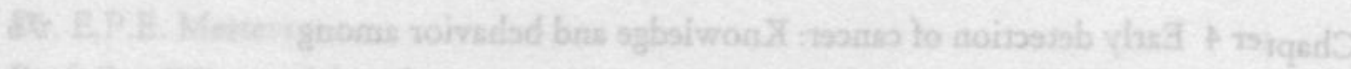

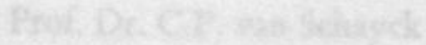

aluhis doma

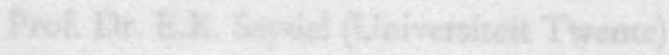

se

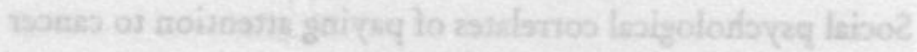

27syando

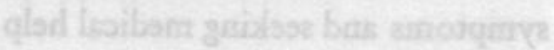

$\$ 01$

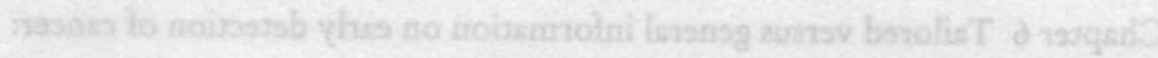

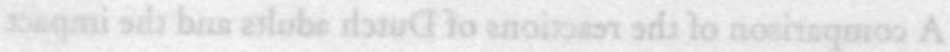

noiventad bess wabusins no

SPI

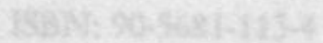

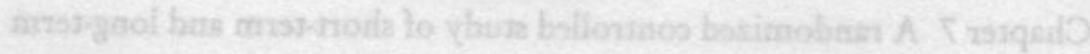

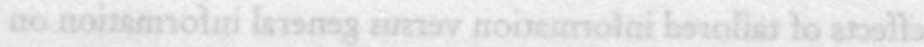

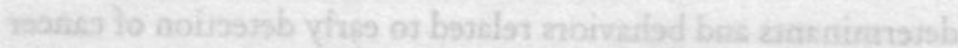

OSt

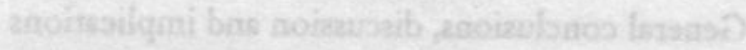

8 zasgadis

PGated by: Unigraphic, Mantrichr

nomostats

deIl

kiammu?

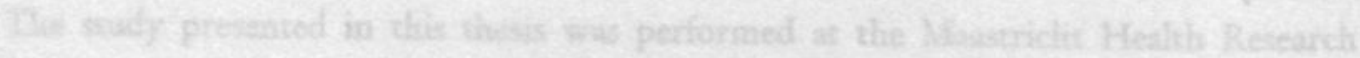

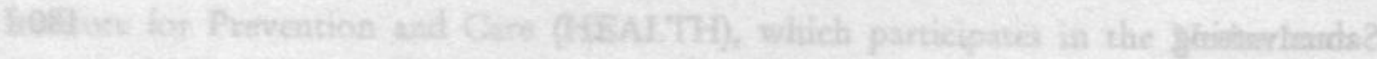

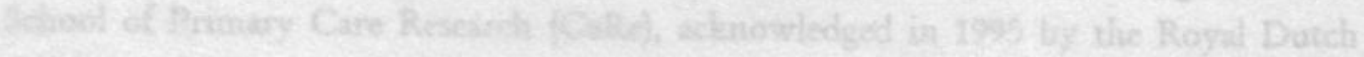

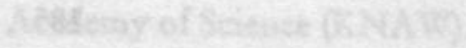
anampgostwomato 


\section{GENERAL INTRODUCTION}

It is generally accepted that more cancers could be cured if they were detected at an earlier stage. It has been unequivocally established that localized disease has a better chance of successful treatment and survival than cancers diagnosed at advanced stages (Ruwaard \& Kramers, 1997; American Cancer Society, 2000b).

Detection of cancer or precancerous tissues at an early stage, also called secondary prevention, is of major importance. Although advanced medical technologies may achieve a decrease in mortality and morbidity from cancer, not all forms of cancer can be prevented. And in view of the aging population, absolute rates of mortality and morbidity due to cancer are expected to rise over the next decades (Ruwaard \& Kramers, 1997). Furthermore, there are many forms of cancer in which no effective treatment is available for advanced tumors or chances of successful treatment are poor. Besides, reduction of the incidence of the disease (primary prevention), often done by promoting healthy behavior, is not possible for all forms of cancer. Whereas morbidity and mortality from lung cancer are obviously associated with smoking (United States Department of Health and Human Services, 1988), the development of other types of cancer is associated with factors that are less easily influenced, for example breast cancer associated with the mothers' age when they first give birth (Kelsey \& Gammon, 1991), or testicular cancer associated with cryptorchidism (i.e. undescended testes) (Austoker, 1994). Thus, for some types of cancer, factors that cause the disease cannot be influenced, or attempts to influence them might be regarded as unethical, for instance encouraging women to become pregnant at a young age to prevent the development of breast cancer. If no modifiable behavioral or environmental factor is associated with the development of a disease, opportunities to prevent its occurrence are limited, and early detection of the disease becomes necessary in order to reduce the burden of illness. Detection of cancer or precancerous tissues at an early stage, is necessary to ensure that treatment is started as early as possible.

Cancer can greatly affect someone's quality of life (Van Duijn et al., 2000). Cancer treatment, such as surgery, radiotherapy or chemotherapy, has a great impact on the patient's physical, social and emotional life (De Haes \& Van Knippenberg, 1989). A better prognosis, which is often associated with detection at an earlier stage, may result 
in improved quality of life (Greimel \& Popper, 1998; Ringdal, Ringdal, Kvinnsland \& Gotestam, 1994). Thus, in the absence of effective primary prevention strategies and effective treatment for most forms of cancer, especially at the advanced stages, secondary prevention of cancer is essential. Therefore, this thesis discusses the development and evaluation of a health education intervention to encourage people to engage in early detection behaviors.

\section{OUTLINE OF THE THESIS}

This thesis focuses on factors associated with early detection of cancer, as well as the development and evaluation of a computer-tailored health education intervention to encourage the general public to engage in behaviors related to the early detection of cancer. In the first chapter a systematic approach is used to obtain insight into the behaviors and behavioral factors related to early detection of cancer, and an overview of the literature on early detection is provided.

The empirical studies described in Chapters 2 to 7 can be divided into three parts. The first part (Chapters 2 and 3) deals with the experiences of patients and physicians with cancer detection. Chapter 2 describes the results of a qualitative study among cancer patients on the process of detecting possible cancer symptoms and the decision to consult a physician with these symptoms. Stimulating and impeding factors in this process are identified. The third chapter includes the results of a qualitative study of the perceptions of patients and physicians about help-seeking behavior for cancer symptoms. This chapter focuses on the role of knowledge and interpretation of symptoms, fear and trust on the one hand, and the decision to consult a physician on the other, and considers the issues from the perspectives of patients and physicians.

The second part of the thesis (Chapters 4 and 5) focuses on two quantitative studies on early detection behaviors among the general public. In the fourth chapter, data from two studies are used to describe knowledge of cancer symptoms and performance of early detection behaviors among Dutch adults. The fifth chapter presents the results of a longitudinal study describing the correlations between social psychological factors and early detection behaviors.

The last part of the thesis (Chapters 6 and 7) presents the evaluation of a computertailored intervention for early detection behaviors. The computer-tailored intervention is described in Chapter 6. This includes a comparison of tailored information and nontailored information with respect to the effects on attitudes and early detection behaviors 
shortly after the intervention. This chapter also describes the accompanying process evaluation of the intervention. Chapter 7 looks at the results of a randomized controlled study of the effect of the tailored information on detection behaviors compared to general information or no information.

The thesis ends with the main findings of the various studies, a discussion of the methodology used in the studies and implications for future research and interventions on early detection of cancer (Chapter 8). The various studies undertaken, with their sample sizes, study designs, data collection methods and main objectives, are listed in Table 1.

Table 1 Overview of the various studies described in this thesis.

\begin{tabular}{|c|c|c|c|c|c|}
\hline Chapter & Sample & $\mathbf{N}$ & Design & $\begin{array}{l}\text { Method of data } \\
\text { collection }\end{array}$ & Main objective of the study \\
\hline 2 & $\begin{array}{l}\text { patients with breast, } \\
\text { testicular, colon } \\
\text { cancer and } \\
\text { melanoma }\end{array}$ & 23 & cross-sectional & $\begin{array}{l}\text { face-to-face } \\
\text { interviews }\end{array}$ & $\begin{array}{l}\text { factors influencing the process of } \\
\text { detecting cancer symptoms and } \\
\text { seeking medical help }\end{array}$ \\
\hline 3 & $\begin{array}{l}\text { patients and } \\
\text { physicians }\end{array}$ & $23+10$ & cross-sectional & $\begin{array}{l}\text { face-to-face } \\
\text { interviews }\end{array}$ & $\begin{array}{l}\text { role of knowledge and interpreta- } \\
\text { tion, fear and trust in the decision to } \\
\text { seek help for cancer symptoms }\end{array}$ \\
\hline 4 & $\begin{array}{l}\text { random samples of } \\
\text { Dutch adults }\end{array}$ & $431+1778$ & cross-sectional & $\begin{array}{l}\text { telephone and } \\
\text { written } \\
\text { questionnaire }\end{array}$ & $\begin{array}{l}\text { knowledge of cancer symptoms and } \\
\text { early detection behaviors }\end{array}$ \\
\hline 5 & $\begin{array}{l}\text { random sample of } \\
\text { Dutch adults }\end{array}$ & 534 & longitudinal & $\begin{array}{l}\text { written } \\
\text { questionnaire }\end{array}$ & $\begin{array}{l}\text { correlates of early detection } \\
\text { behaviors }\end{array}$ \\
\hline 6 & $\begin{array}{l}\text { random sample of } \\
\text { Dutch adults }\end{array}$ & 1576 & longitudinal & $\begin{array}{l}\text { written } \\
\text { questionnaire }\end{array}$ & $\begin{array}{l}\text { process evaluation and short term } \\
\text { effects of the tailored intervention } \\
\text { on attitudes and behavior }\end{array}$ \\
\hline 7 & $\begin{array}{l}\text { random sample of } \\
\text { Dutch adults }\end{array}$ & 1358 & longitudinal & $\begin{array}{l}\text { written and } \\
\text { telephone } \\
\text { questionnaire }\end{array}$ & $\begin{array}{l}\text { effects of the tailored intervention } \\
\text { on determinants, intentions and } \\
\text { behaviors after } 3 \text { weeks and } 6 \\
\text { months }\end{array}$ \\
\hline
\end{tabular}




\section{EARLY DETECTION OF CANCER}

\section{INTRODUCTION}

Cancer is an important cause of death and illness in the Netherlands (Van Leer, Cleton \& Van Leeuwen, 1999). Early cancer detection can improve survival rates and chances of a more successful treatment (Ruwaard \& Kramers, 1997; American Cancer Society, 2000b). Therefore, unnecessary delays in cancer diagnosis should be prevented as much as possible. To encourage people to engage in early detection a health education intervention was developed and evaluated based on the $\mathrm{ABC}$ planning model. In this chapter the planning model will be explained and applied to the early detection of cancer.

Health education programs should be systematically planned if they are to be effective (Green \& Kreuter, 1991). A model that can be used to systematically develop and evaluate interventions is the ABC planning model (De Vries, 1998; De Vries, Dijkstra \& Kok, 1991, 1992; De Vries \& Kok, 1996). This model is based on the PRECEDEPROCEED model (Green \& Kreuter, 1991), Kok's model of behavioral change (1985), Rogers' theory of diffusion of innovations (1983) and the model of community organization developed by Bracht (1990). The ABC planning model consists of three main phases, Analysis - Behavioral change - Continuation.

The first phase consists of five steps. The first step analyzes the problem in terms of quality of life. This step provides insight into the problems that threaten the quality of life of groups of persons, and evaluates the seriousness of the problem. The second step in this phase is to analyze the extent to which the health problem is linked with behavioral or environmental factors. If human behavior influences the problem, it should be possible to influence the problem by changing the behavior. The third step is the identification of the relevant target group. For instance, the target group for early detection of breast cancer includes all adult women, while the promotion of testicular self-examination should address only the high-risk group for testicular cancer, i.e., men aged 15 to 35 . The fourth step of the first phase involves an analysis of determinants of 
the behavior, which provides information about the motives of the target group for engaging in early detection behaviors. The last step consists of an access point analysis to identify which methods can be used to motivate the target group to change their behavior.

The second phase in the planning model is behavioral change. This involves planning an intervention, based on the results of the problem analysis in the first phase. Depending on the targets of an intervention, several methods can be used, e.g. public campaigns or an individual approach. For instance, if the target of the intervention is to inform all women over the age of 18 years about the advantages of breast self-examination, the method may be different from an intervention which aims to induce women with a family history of breast cancer to perform breast self-examination regularly and accurately. The first target may be approached by a mass media campaign for all women, while the second focuses on a specific part of the population and probably requires a more individual approach. In the next step of the second phase, the intervention is developed and tested among members of the target population in order to see whether the messages are understood as intended. The last step in this phase is the evaluation of the intervention for its effectiveness.

Continuation of the intervention, if effective, on a larger scale is the object of the third phase of the planning model. A successful implementation of interventions is enhanced by an intersectoral approach, since health education interventions, diffusion strategies, and policies and legislative measures to support the diffusion involve many different sectors.

Green and Kreuter (1991) describe two different approaches that can be used to address a specific health problem. The first approach is called the reductionist approach, and identifies the level of priority of health problems. In the second approach, the expansionist approach, the health problem has already been identified, and how the health problem fits into a larger context has been assessed. The latter is the approach chosen in the present thesis. The Dutch Cancer Society has designated early detection of cancer as one of its main topics of interest and has initiated research on early detection behaviors among Dutch adults. This chapter provides an overview of early detection of cancer, using the $\mathrm{ABC}$ planning model. 


\section{PHASE 1 ANALYSIS OF THE HEALTH PROBLEM}

\section{Step 1.1 Problem analysis and quality of life}

The first step in the planning model addresses the health problem, as well as the quality of life of the population. This is followed by a description of the problem, the severity of the problem, the extent to which the problem affects the Dutch population, the importance of early detection in terms of mortality rates, and its impact on the quality of life of those who are affected.

Cancer is a major cause of illness and death in the Netherlands (Van Leer et al., 1999; Visser, Coebergh, Schouten \& Van Dijck, 2000), as well as in other European countries and North America, surpassed only by coronary heart diseases (Bailar \& Gornik, 1997). In 1996, approximately 58,000 new patients were diagnosed with cancer in the Netherlands, and in the same year approximately 37,000 persons died of cancer (Visser et al., 2000).

In the Netherlands, the highest incidence and mortality rates per type of cancer for men are those for lung cancer, prostate cancer, and colorectal cancer (Van Leer et al., 1999). For women, breast cancer, colorectal cancer, and lung cancer are the most frequent forms. This is consistent with the most common forms among men and women in the United States (Greenlee, Murray, Bolden \& Wingo, 2000). Table 1.1 lists the 1996 incidence and mortality figures in the Netherlands. Two comments should be made about the interpretation of these rates. First, the incidence rates refer to the number of tumors, while the mortality rates refer to the number of patients. Second, the incidence and mortality rates do not necessarily refer to the same cases, since the diagnosis and death often do not occur in the same year.

Despite an increase in cancer incidence in recent years, mortality rates from all forms of cancer together have not increased, which is probably due to improved treatment, early diagnosis resulting in cure, and a reduction in tobacco use (Bailar \& Gornik, 1997; Van Leer et al., 1999). Between 1989 and 1996, the number of new cases of cancer detected increased by approximately 9,000 , due to the aging population, the introduction of screening programs for breast cancer among women aged between 50 and 75 years, and changes in the detection methods of prostate cancer (increased use of the prostatespecific antigen). This is an increase of more than 1,000 new cases each year, (Visser et al., 2000).

Cancer affects mostly older people. Approximately two-thirds of all women with cancer and three-quarters of all men with cancer are older than 60 years. Just $9 \%$ of all cancers affect people younger than 45 years (Visser et al., 2000). 


\begin{tabular}{|c|c|c|c|c|c|}
\hline \multicolumn{3}{|c|}{ Men } & \multicolumn{3}{|c|}{ Women } \\
\hline & Incidence 1996 & Mortality 1996 & & Incidence 1996 & Mortality 1996 \\
\hline Lung & 6872 & 6766 & Breast & 9942 & 3552 \\
\hline Prostate & 6539 & 2458 & Colorectal' & 4078 & 2134 \\
\hline Colorectal' ${ }^{1}$ & 4351 & 2042 & Lung & 1942 & 1800 \\
\hline $\begin{array}{l}\text { Skin cancer } \\
\text { (non-melanoma) }\end{array}$ & 1932 & $31^{2}$ & Endometrium & 1428 & $307^{2}$ \\
\hline Urinary bladder & 1653 & 750 & Ovary & 1376 & 1058 \\
\hline Stomach & 1368 & 1175 & $\begin{array}{l}\text { Skin cancer } \\
\text { (non-melanoma) }\end{array}$ & 1252 & $36^{2}$ \\
\hline $\begin{array}{l}\text { Non-Hodgkin's } \\
\text { lymphoma }\end{array}$ & 1145 & 587 & Melanoma & 1221 & $190^{2}$ \\
\hline Kidney & 851 & 504 & $\begin{array}{l}\text { Non-Hodgkin's } \\
\text { lymphoma }\end{array}$ & 933 & 516 \\
\hline Melanoma & 828 & 237 & Stomach & 812 & 751 \\
\hline Leukemia & 726 & 579 & Pancreas & 691 & 909 \\
\hline
\end{tabular}

Source: Incidence of cancer in the Netherlands 1996 (Visser et al., 2000).

1 'Including cancer of the colon, recto-sigmoid, rectum and anus/anus canal.

${ }^{2}$ Because of the relatively good prognosis, skin cancer (non-melanoma), melanoma and endometrium cancer are three of the ten most common forms of cancer in the Netherlands, but do not contribute to the mortality rates from cancer.

Five-year relative survival rates are important sources of statistics to monitor progress in the early detection and treatment of cancer (Parker, Tong, Bolden \& Wingo, 1996). Five-year relative survival rates include persons who are alive five years after the diagnosis, whether in remission, disease-free, or under treatment. This rate is adjusted to normal life expectancies (caused by factors such as dying from coronary heart diseases, accidents etc.), which means that the five-year survival rates for cancer patients are divided by the five-year survival rates for a reference group (one that is similar to the patient group with respect to age, gender, race etc.) in the general population.

It is true for all forms of cancer that the highest five-year relative survival rates are achieved for those cancers detected at an early, localized stage. These rates decline dramatically if the cancer is diagnosed at a more advanced stage (American Cancer Society, 2000b). Advanced stages are divided into a regional stage, which is defined as the involvement of regional lymph nodes or nearby tissues, and a distant stage, referring to the presence of distant metastases. Figure 1.1 shows the five-year relative survival rates over the period 1989-1995 for the most common forms of cancer in men and women (American Cancer Society, 2000b). Breast and colon cancer and melanoma in particular have an excellent prognosis if detected early: the five-year survival rates exceed $90 \%$. 
However, the proportion of cancers that are discovered at an early stage vary per cancer. Thus, $82 \%$ of melanomas are discovered at the localized stage, against $37 \%$ of colon cancers, $25 \%$ of ovarial cancers, and only $15 \%$ of lung cancers (American Cancer Society, 2000b).

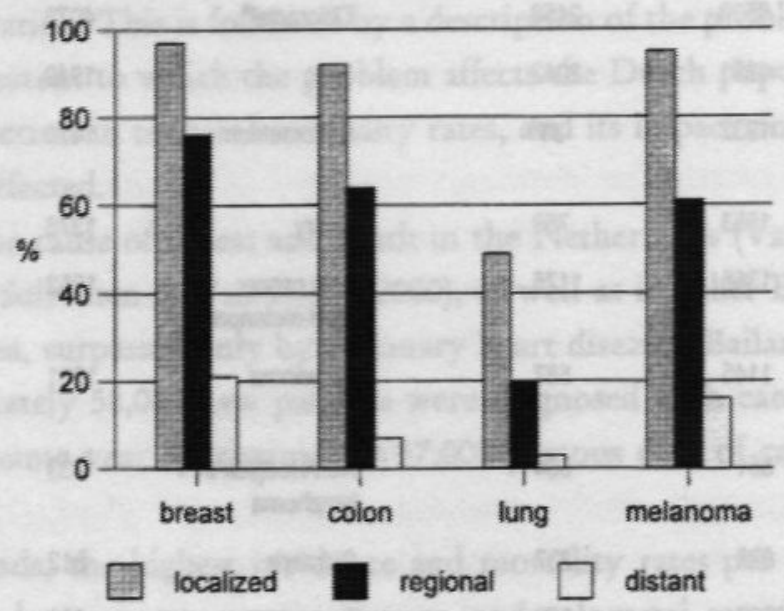

Figure 1.1 Five-year relative survival rates. Percentage at stage of diagnosis for the most common forms of cancer in men and women (American Cancer Society, 2000b).

In considering a health problem such as cancer, the quality of life of those people who are affected by the disease and their environment should be taken into account. Quality of life is defined by Felce \& Perry as "an overall well-being that comprises objective descriptors and subjective evaluations of physical, material, social, and emotional wellbeing together with the extent of personal development and purposeful activity, all weighted by a personal set of values" $(1995, \mathrm{pp} .60)$. The concept is a multidimensional, subjective construct. Each stage of the disease, including the diagnostic stage, the curative stage, the disease-free stage and the palliative stage, has its own medical, psychological and social aspects influencing the patient's life (Van Duijn et al., 2000). Several studies have found that survivors reported fear of death, metastasis, recurrence or a second cancer (Corney, Everett, Howells \& Crowther, 1992; Ersek, Ferrell, Dow \& Melancon, 1997; Ferrell, Grant, Funk, Otis-Green \& Garcia, 1997; Muzzin, Anderson, Figueredo \& Gudelis, 1994), as well as feelings of depression (De Boer, 1998; Ersek et al., 1997; Ferrell et al., 1997; Giovagnoli, 1999; Li, Samsioe \& Iosif, 1999), family distress (Ersek et al., 1997; Ferrell et al., 1997), and problems with sexuality (Corney et al., 1992; Ferrell et al., 1997; Gascoigne, Mason \& Roberts, 1999). Physical symptoms, such as fatigue, were 
often mentioned as aspects severely affecting the patient's life (De Boer, 1998; Ersek et al., 1997; Ferrell et al., 1997).

In sum, cancer is a disease that affects large parts of the population and has a great impact on the patients' quality of life.

\section{Step 1.2 Behavioral analysis}

The second step of the first phase in the planning model, the behavioral analysis, considers to what extent the health problem is linked with behavioral or environmental factors. This implies that if behavior influences the problem, the problem can be influenced by changing the behavior. The following section describes an overview of behaviors related to early detection of cancers.

\section{Early detection of cancer}

To indicate which cancers can be self-detected and which cancers can only be detected by medical tests, cancers can be classified into three anatomical categories (Qin, Wang, Zhang, Zuo \& Yuan, 1996). The first category includes cancers of the superficial organs, which are the organs located on the surface of the body, like the skin, oral cavity, the breast and the testes. Symptoms of these kinds of cancer can be detected by looking for a lump, ulceration or mole. The second category includes cancers of the hollow organs, referring to organs with a cavity opening to the outside, such as the throat, the lung, the stomach, the urinary bladder, and the intestines. Malignant growths in these organs often cause symptoms like blood excretion. The third category includes cancers of the deep solid organs, that are out of reach by palpation and invisible. Malignancies of these organs rarely give symptoms in the early stages, and can only be detected by medical tests, such as X-ray, CT scans, and blood tests. Examples are the bones, the brain, the liver, the ovary, and the pancreas.

This implies that cancers of superficial organs and those of the hollow organs can be detected by awareness of suspicious symptoms or by specific actions undertaken by individuals, including self-examination or participating in screening programs or medical check-ups. This is in accordance with the opinion of the American Cancer Society (2000b), which postulates that cancers of the breast, colon, rectum, cervix, prostate, testis, oral cavity, and skin can be detected in asymptomatic people by means of selfexamination, physical examinations or medical tests. A combination of two or more strategies is expected to be most effective. Since survival rates rapidly decrease when a malignancy is at an advanced stage, early detection of cancer is an important tool. 
The development of malignancies can be indicated by various symptoms, some of which are specifically associated with a particular type of cancer, like a lump in a breast. Other symptoms are more general, like changes in bowel habits, and may be caused by several types of cancer or other diseases. The Dutch Cancer Society (1996) has identified eight symptoms which may be caused by cancer (Table 1.2) and recommends that a physician should be consulted once such symptoms are detected. These symptoms are obvious changes in warts or moles, swellings or lumps in breast or elsewhere, usual bleeding or discharge, nagging cough or hoarseness, sores that do not heal, indigestion or difficulty swallowing, changes in bowel or bladder habits, and unusual weight loss. It recommends consulting a physician with these symptoms immediately or within a few weeks if symptoms do not heal spontaneously, or return from time to time. Other international guidelines, like those of the American Cancer Society, the National Cancer Institute and the Cancer Research Campaign, include the same symptoms as the Dutch inventory, except for the unusual weight loss. The European Code Against Cancer recommends that people see a doctor for the same symptoms as the Dutch Cancer Society does (Boyle et al., 1995).

Table 1.2 Warning signs of cancer and the time within which a physician should be consulted.

\begin{tabular}{ll}
\hline \hline One week & Four weeks \\
\hline Obvious changes in warts or moles & Nagging cough or hoarseness \\
Swellings or lumps in breast or elsewhere & Sores that do not heal \\
Unusual bleeding or discharge & Indigestion or difficulty swallowing \\
& Changes in bowel or bladder habits \\
& Unusual weight loss \\
\hline
\end{tabular}

Source: Dutch Cancer Society, 1996.

\section{Behaviors related to early detection of cancer}

Merely detecting a cancer symptom is pointless if it is not followed up by seeking medical help. This section describes the process of detecting symptoms and seeking medical help for symptoms. This section starts with a description of a model to describe the prediagnostic period.

\section{Model of total patient delay}

A helpful model to describe the process of detecting cancer symptoms and consulting a physician is the 'model of total patient delay' (Andersen, Cacioppo \& Roberts, 1995), which originated in the work of Safer and colleagues (Safer, Tharps, Jackson \& Leventhal, 1979). This model distinguishes six stages in the pre-diagnostic period in which 
delays may occur (Figure 1.2). Each stage is dichotomous and a move to the next stage is determined by decisions and interpretations in the previous stage.

First, an unexplained symptom, possibly a cancer symptom, is detected. Hence, when a person notices a symptom, he/she has to interpret the symptom as a cancer symptom, or at least as a symptom serious enough to seek medical help. If a symptom is detected, but the person does not infer illness, 'appraisal delay' occurs. If a person infers illness, but decides to postpone seeking medical attention, this is called 'illness delay'. Illness delay refers to the time needed for the decision to seek professional help for the complaint. When a person realizes that the symptom will not disappear spontaneously, and decides to seek help, the move to the next stage is made. The time elapsing between the decision to act upon the unexplained symptom by seeking professional help and the moment when he/she actually makes an appointment with a professional is called 'behavioral delay'. Subsequently, when an appointment can not be made immediately, 'scheduling delay' occurs. Scheduling delay is either due to the patient, for instance when it takes a while before a convenient time for the patient occurs, or due to the professional, for instance if there is a waiting list, or if it is impossible to make an appointment within a certain time. The last stage in the model of total patient delay is 'treatment delay', which refers to the time elapsing between the moment when a person receives the first medical attention and the beginning of treatment. This type of delay will not be discussed in this thesis, since treatment delay is caused by medical professionals and not by potential patients themselves. This thesis focuses on the potential patients.

As was mentioned above, the starting point in the model of total patient delay is the detection of unexplained symptoms. As a consequence, the model of total patient delay focuses on delay after symptoms are detected, but does not include the actual detection process. However, if symptoms are not detected at an early moment, the whole process is delayed. Moreover, the model of total patient delay solely concern the detection of symptoms by individuals, that is, not via screening programs or medical check-ups by physicians. However, detection of cancer symptoms can be done in two ways: 1) by the persons themselves, or 2) by health care providers, for instance during a screening program or a medical check-up. The first category is the main focus of this thesis.

A person can contribute to early detection by actively performing particular actions, like breast self-examination, testicular self-examination, or examination of the skin. These concrete actions undertaken to detect changes in the body can be referred to as active detection. However, a person can also detect possible cancer symptoms by becoming aware of bodily changes without having undertaken any specific action. This can be called passive detection, and may involve becoming aware of changes in moles, 


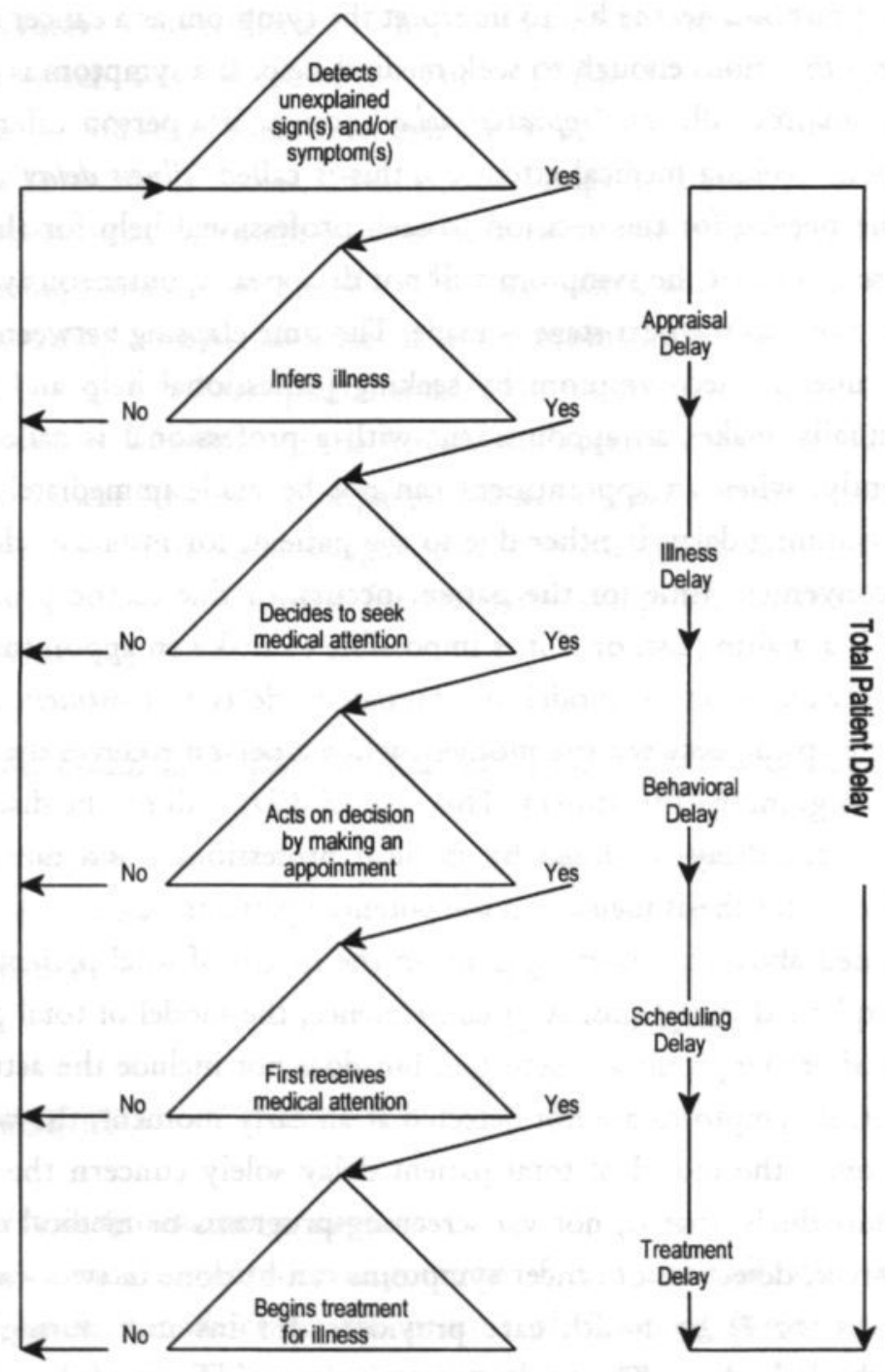

Figure 1.2 Andersen's model of total patient delay (Andersen et al., 1995). 
changes in bowel habits and so on without actively searching for these symptoms. A major problem with the interpretation of these symptoms is the non-specific nature of many of the warning signals in apparently healthy people. Hence, possible cancer symptoms may be easily attributed to common diseases. Obviously, early detection of cancer cannot be defined as one particular behavior, but consists of several different behaviors. Thus, a complete model of total patient delay should include active or passive detection of cancer symptoms in addition to inferring illness, deciding to seek medical attention, visiting a health care provider with symptoms or participating in screening programs. Although some of these stages occur simultaneously, different behaviors may be expected to be related to different social psychological determinants.

Thus, in the different stages of the process of detecting a cancer symptom and seeking medical help, various behaviors are conducive to early detection of cancer detection behaviors. The next section describes the behaviors, including passive detection behavior, active detection (breast self-examination, testicular self-examination, and skin selfexamination) and participating in population screening programs, as well as the recommendations of the Dutch Cancer Society to perform these behaviors and the relevance of such behaviors in relation to mortality from cancer and the prevalence of the detection behaviors.

\section{Passive detection behavior}

Passive detection behavior includes awareness of changes in the body, but does not require any concrete actions. The Dutch Cancer Society recommends being attentive to cancer symptoms and appropriate help seeking behavior (Table 1.2). Obviously, being attentive to cancer symptoms as a behavior is very difficult to measure and assessment is threatened by self-report bias. Therefore, studies of the effectiveness of passive detection behaviors related to mortality and morbidity have been rare or difficult to interpret.

A literature search yielded three studies on awareness with respect to melanoma. One of these studies tested the effects of posters and leaflets illustrating the features of early malignant melanoma and encouraging the public to consult a physician if they recognize such symptoms (Doherty \& MacKie, 1986). This resulted in an increase of almost $25 \%$ in the detection of primary lesions of $1.5 \mathrm{~mm}$ or less, lesions which have an excellent prognosis. In a second study (Berwick, Begg, Fine, Roush \& Barnhill, 1996) casual awareness (i.e., informal skin self-examination) was measured by asking subjects if they ever thought about their skin, what it looked like and whether they had noticed any changes or abnormalities. About $62 \%$ of the respondents were aware of their skin. A third study investigated the relationship between patient knowledge, skin awareness and 
delay in seeking medical attention for melanoma (Oliveria et al., 1999). Awareness was assessed in the same way as in Berwick's study. It was concluded that awareness of changes in the skin was associated with a reduced delay in melanoma diagnosis, adjusted for age, gender, prior history of cancer, and skin self-examination practices $(O R=0.30$, 95\% $\mathrm{CI}=0.12-0.71)$.

The literature also includes one study on the awareness of signs of fecal blood (Hakkinen, Nylamo \& Soderstrom, 1997). In a Finnish city a newspaper campaign was used to encourage all persons over the age of 50 to act on signs of fecal blood and to visit a medical professional for an examination. Over 1,600 persons requested screening. Eighteen colorectal cancers were found, of which $28 \%$ were diagnosed at an early stage.

So far, no studies have tried to assess healthy people's (passive) awareness of other cancer symptoms. This will be the main focus of this thesis.

\section{Breast self-examination}

Breast cancer is the most common form of cancer among women in the Netherlands. Almost 10,000 new cases were diagnosed in 1996 (Visser et al., 2000), about 5,600 of which affected women aged between 45 and 70 . Breast self-examination is one way to detect breast cancer in the early stages and is done by inspection and palpation of the breasts and the armpit to search for changes in the breasts and the axillary nodes. To be able to detect abnormalities in the breast or nodes, women should become familiar with their breasts. Therefore, monthly breast self-examination is recommended by the Dutch Cancer Society (1996) to women aged 18 years and over. Other Cancer Societies also recommend breast self-examination for the female population, although the recommendations differ with respect to the age at which with breast self-examination should be started (Shapiro et al., 1998; American Cancer Society, 2000b; Wardle et al., 1995).

Breast cancer is in many cases $(32-88 \%)$ detected by women themselves, either accidentally or through breast self-examination (Baines, 1983; Benedict, Williams \& Hoomani, 1996; Cope, 1992; Kuroishi et al., 1992; Maibenco, Daoud, Phillips \& Saxe, 1999; Shugg, Hill, Cooper \& Shepherd, 1990; Smith \& Burns, 1985). Nevertheless, in one study only $8 \%$ of the women who performed self-examination regularly detected breast cancer by means of breast self-examination (Auvinen, Elovainio \& Hakama, 1996). The practice of breast self-examination among healthy women has been the focus of many studies. In several studies, the majority of the women $(50-90 \%)$ reported that they performed breast self-examination (Auvinen et al., 1996; Cope, 1992; Friedman, Nelson, Webb, Hoffman \& Baer, 1994; Kreitler, Chaitchik, Kreitler \& Weissler, 1994; Newcomb et al., 1991; Persson, Johansson \& Ek, 1995; Shugg et al., 1990). However, only 10 to $44 \%$ of the 
women said they performed breast self-examination each month (Budden, 1995; Cope, 1992; Fink, 1991; Friedman et al., 1994; Newcomb et al., 1991; Persson et al., 1995; Shugg et al., 1990). Of Dutch women aged 17 to 30 just $6 \%$ reported that they performed breast self-examination at least 10 times a year (Wardle et al., 1995). The frequency with which these women performed breast self-examination was the lowest in Europe, together with the Spanish and Italian young women.

Results of studies on the effectiveness of breast self-examination on breast cancer mortality are limited and inconsistent. Japanese and American studies have shown better survival rates 5 years after the diagnosis among women who performed breast selfexamination compared to women who did not: $94.4 \%$ vs $85.7 \% \mathrm{p}<.001$ in the Japanese study (Kuroishi et al., 1992), and $76.7 \%$ vs $60.9 \%, \mathrm{p}<.0001$ in the American study (Huguley, Brown, Greenberg \& Clark, 1988). Only the Japanese study measured survival rates ten years after the diagnosis, and at that time, differences in survival rates between women who performed breast self-examination and women who did not were no longer significant (Kuroishi et al., 1992). Some studies have provided evidence that breast self-examination was associated with the likelihood of patients finding their own tumors (Foster \& Constanza, 1984; Smith \& Burns, 1985), with smaller tumors and with fewer axillary node metastases (Foster \& Constanza, 1984; Huguley et al., 1988; Philip et al., 1984; Shugg et al., 1990). Some studies, however, have found that breast self-examination was unrelated to breast cancer mortality (Auvinen et al., 1996; Holmberg, Ekbom, Calle, Mokdad \& Byers, 1997; Philip et al., 1984; Thomas et al., 1997). Hence, conclusions on the effectiveness of breast self-examination should be drawn with caution, also because most studies used a retrospective design (Foster \& Constanza, 1984; Kuroishi et al., 1992; Shugg et al., 1990; Smith \& Burns, 1985). There have, however, also been studies with a prospective design (Auvinen et al., 1996; Holmberg et al., 1997; Huguley et al., 1988; Thomas et al., 1997), in which bias due to self-reported behavior is limited. However, these studies have showed less positive results in favor of breast self-examination. Another factor that limits the value of the conclusions are the differences in outcome measures, such as incidence, tumor size, etc.

\section{Testicular self-examination}

Although testicular cancer is a rare form of cancer, it is the most frequent cancer in young men aged 15-35 (Visser et al., 2000). In 1996, 463 new cases were diagnosed in the Netherlands, of which 261 occurred in the high risk group (15-35 years old males). Only six cases of testicular cancer occurred among males younger than 15, and the remaining cases occurred among men aged 35 and older. Testicular self-examination is done by 
rotating the testicles between the fingers to search for lumps or changes. The Dutch Cancer Society is not as explicit in its recommendations on testicular self-examination as it is on breast self-examination, although it suggests that men up to the age of 35 should perform such examinations.

Several studies have shown that young men are unaware of the risk of cancer of the testes or of the value of testicular self-examination (Cummings, Lampone, Mettlin \& Pontes, 1983; Ganong \& Markovitz, 1987; Goldenring \& Purtell, 1984; Katz, Meyers \& Walls, 1995; Neef, Scutchfield, Elder \& Bender, 1991; Ostwald \& Rothenberger, 1985; Reno, 1988; Thornhill et al., 1986; Vaz, Best \& Davis, 1988). Self-reported prevalence of testicular self-examination among the target population was found to be extremely low, with $0-21 \%$ reporting that they practiced testicular self-examination regularly (Cummings et al., 1983; Ganong \& Markovitz, 1987; Goldenring \& Purtell, 1984; Katz et al., 1995; Lechner, Oenema \& De Nooijer, in press; Moore, Barling \& Hood, 1998; Reno, 1988; Steffen \& Gruber, 1990; Thornhill et al., 1986; Vaz et al., 1988; Wardle et al., 1994).

Few studies have assessed the effectiveness of testicular self-examination. Five-year relative survival rates of testicular cancer are high (99\%) when detected early, and due to advances in treatment (chemotherapy), even patients with metastatic disease have fiveyear relative survival rates of $75 \%$ (Ries et al., 2000). Hence, early diagnosis of testicular cancer is associated with a reduction in mortality, and is likely to be associated with simpler and less toxic treatment (Austoker, 1994). So far, no randomized controlled trials have provided evidence on the effectiveness of testicular self-examination. Hence, the United States Preventive Services Task Force (1996) concluded that there is insufficient evidence to recommend or discourage examination by a physician. However, young men should be advised to consult a physician with abnormalities in the testicles.

\section{Skin self-examination}

In 1996, more than 2,000 new cases of melanoma and almost 3,200 cases of other skin cancers were diagnosed in the Netherlands (Visser et al., 2000). Skin cancer can be detected by means of skin self-examination. This can be done by inspecting the skin in front of a mirror, to search for new moles, changes in existing moles and other irregularities in the skin. The American Cancer Society, the American Academy of Dermatology and the National Institutes of Health advocate the practice of skin self-examination. The recommended strategy is to look for the $A B C D$ 's of skin cancer: Asymmetry of lesions; Border irregularity; Color variation; and Diameter change (Cummings, Tripp \& Herrman, 1997; Friedman, Rigel \& Kopf, 1985). In the Netherlands, no specific recommendations about skin self-examination are currently being given to the general public, 
except to be aware of changes in moles or the appearance of new moles (Dutch Cancer Society, 1996). However, this may well change in the future, since there is still an increase in mortality from melanoma of $3 \%$ per year among men (Van Leer et al., 1999). Mortality from melanoma among women does not seem to have increased recently (Van Leer et al., 1999). Furthermore, due to increased leisure time and vacations to tropical countries, Dutch people are more exposed to UV radiation, a risk factor for all forms of skin cancer. Hence, it is not unlikely that the incidence of all forms of skin cancer will increase. So far, education on skin cancer prevention in the Netherlands has been mainly focused on primary prevention (e.g., through a mass media campaign to encourage parents to protect their children against UV radiation) rather than secondary prevention (e.g., raising awareness of changes in the skin), since most cases of skin cancer are due to behavioral factors, such as exposure to UV radiation (The Skin Cancer Foundation, 1992).

Most studies on skin self-examination have been performed in the United States or Australia, countries were skin cancer is a much more serious health threat than it is in the Netherlands. Skin self-examination was found to be performed by $15-80 \%$ of all subjects at least once a year (Berwick et al., 1996; Friedman, Webb, Bruce, Weinberg \& Cooper, 1995; Robinson, Rigel \& Amonette, 1998). One study showed that $53 \%$ of all skin cancers were found by the patients themselves, and $17 \%$ were found by family members (Koh et al., 1992). Unfortunately, prevalence of skin self-examination and skin awareness has hardly been studied among the Dutch population.

The relationship between skin self-examination and morbidity or mortality from skin cancer has not yet been established. Early detection and treatment have been associated with less morbidity and local tissue destruction for patients with basal cell carcinomas (BCC) and squamous cell carcinomas (SCC) (United States Preventive Services Task Force, 1996). While BCC and SCC rarely metastasize, melanoma does. In any case, detection at an early stage remains important for all forms of skin cancer, either to prevent melanoma from metastasizing, or to reduce disfigurement (Rhodes, 1995). No randomized controlled trials have been reported on the effectiveness of early detection of skin cancer or screening in preventing mortality from melanoma. In a population-based case-control study among 650 recently diagnosed melanoma patients and 549 matched subjects from the general population the association between early detection through skin self-examination and the risk of melanoma (in terms of the presence of advanced disease and mortality) was investigated (Berwick et al., 1996). The results showed that skin self-examination was associated with a reduced risk of advanced disease among melanoma patients. 


\section{Participating in population screening programs}

Early detection of cancer can also be done by a medical professional, for instance during a screening program. As a general rule, a screening program in a population for certain types of cancer requires that the disease must be an important public health problem, that it must be possible to detect the disease at an early stage in large parts of the population, and that treatment of the disease at an early stage must result in significantly improved survival rates compared to treatment of the disease at the advanced stages (Buetow, 1996). Furthermore, a suitable screening program should be sensitive, specific, and have a high predictive value. Sensitivity refers to the likelihood that a positive test (i.e., indicating the presence of the disease) means that the person tested actually has the disease; a highly sensitive screening test has a small proportion of false negative test results (Soost, Lange, Lehmacher \& Ruffing-Kullmann, 1991). In contrast, specificity is related to false positive test results, that is, it reflects the likelihood of a negative test result (i.e., indicating the absence of the disease) in persons who do not have the disease. The predictive value of a screening test is a measure of the prevalence of actual disease cases among persons who have a positive test result compared to the number of persons with the disease in the entire population. Moreover, the benefits of a screening test for each person should outweigh the possible harms, such as anxiety, inconvenience, and undergoing unnecessary medical procedures (Marteau, 1989).

This subsection briefly evaluates the effectiveness of screening programs for types of cancer for which screening programs are available in the Netherlands, including breast and cervix cancer. Other countries also have screening programs for cancer of the colon, skin cancer and prostate cancer, but this is not common in the Netherlands. Therefore, these screening programs are beyond the scope of this thesis.

The principal screening test for breast cancer is mammography (Shapiro et al., 1998). Breast cancer is an important health problem, since it is the most common form of cancer among women in the Netherlands (Visser et al., 2000), and it is expected that one out of ten women will be diagnosed with breast cancer at some point in her life. Mammography can detect very small tumors, even when physical symptoms have not yet developed (Benedict, 1996; American Cancer Society, 2000a, 2000b; Tabar et al., 1985). Fletcher and colleagues compared randomized controlled trials on the effects of breast cancer screening and found evidence of the benefits of screening for breast cancer for women aged 50-69. The mortality rates were found to decrease by 30\% 10-12 years after study entry. Sensitivity of breast cancer screening varied form $63-88 \%$, specificity ranged from $82-98 \%$, and the positive predictive value varied from from $4-22 \%$ (Fletcher, Black, Harris, Rimer \& Shapiro, 1993). A clinical breast examination is often part of the 
screening. In the Netherlands, a nationwide breast cancer screening program was introduced in 1989, inviting all women aged 50-75 to have a free mammography every two years.

Cervical cancer is far less common than breast cancer: in 1996, 710 cases of cervical cancer were diagnosed in the Netherlands (Visser et al., 2000). Cervical cancer and its precursors can be detected by means of a Papanicolaou smear test, which is moderately sensitive (80\%) and highly specific (99\%) (Soost et al., 1991; United States Preventive Services Task Force, 1996). A national screening program in the Netherlands was started in 1988 (De Koning \& Ballegooijen, 1997). All women aged 30-60 receive an invitation every five years to have a free Pap test at their family physician.

Attendance of screening programs is being recorded by official registrations. For breast cancer, several studies have shown that attendance was high during the first round, but declined in the course of the program (Baker, 1982; Collette, Rombach, De Waard \& Collette, 1988; Vernon, Lavill \& Jackson, 1990). Attendance rates for cervix cancer screening are lower than those for breast cancer screening.

The above behaviors can be regarded as part of the first step in the model of total patient delay. Some of these symptoms will be detected by coincidence, while other symptoms require a specific action, i.e., breast or testicular self-examination or participating in a screening program. This should then be followed by seeking medical attention. If a possible cancer symptom is not followed by medical consultation, the detection is in fact useless, and the cancer detection process will be delayed. With respect to delay in helpseeking behavior for cancer symptoms, Andersen and colleagues (1995) claimed that about $60 \%$ of the delay for breast cancer symptoms is due to appraisal delay, a figure which rose to $80 \%$ for gynecological cancer. Although most studies do not distinguish between the various stages of delay, most do distinguish between patient delay and doctor delay. Doherty and MacKie (1986) have shown that among the 105 cases of patients in their study waiting longer than three months between first noticing a new or changing pigmented lesion and surgical excision, delay was due to the patient in 102 cases. The mean delay was fifteen months. Krige et al. (1991) also concluded that the mean delay of more than eleven months they found was predominantly caused by the patient (9.8 months). Cassileth et al. (1988) found similar results: approximately six months elapsed between the moment when a patient first noticed a new mark or a change in an existing mark and the time that they became suspicious about it. An additional 2.6 months elapsed between the suspicion and seeking medical attention. Delay due to the physician was on average 3.9 months. In a study by Oliveria and 
colleagues (1999), the mean delay time for melanoma symptoms was two months, although it ranged from 0.5 to as much as 22 months. Gascoigne et al. (1999) found long (six weeks to twelve months) delays in patient with symptoms of testicular cancer. Delay in seeking medical help for other forms of cancer has also been studied. Mor et al. (1990) found that one-quarter of the patients waited longer than three months with symptoms of breast, lung and colorectal cancer. Cochran and colleagues (1986) asked women about their delay after detecting symptoms of endometrial cancer (usually abnormal bleeding) and found that women postponed medical consultation for between one and four months.

In sum, serious patient delays do occur. If we want to minimize the time elapsing between the appearance of a symptom and it's detection and the time elapsing between the moment when a person first becomes aware of a possible cancer symptom and the first medical consultation, we need insight into factors influencing the decisions to go through the several phases of total patient delay.

\section{Step 1.3 Target group}

The previous section showed that cancer is an important health problem affecting all parts of the population, although some forms of cancer occur more often among particular groups of the population than others. It has become clear that detection behaviors may contribute to the early detection of cancer, which in turn improves the chances of successful treatment and survival. Research has provided some indications of the extent to which the general public currently engage in these behaviors. Some behaviors related to the early detection of cancer are of concern to the population as a whole, for instance, being attentive to possible cancer symptoms, such as changing bowel habits or unusual weight loss, and seeking medical help if these symptoms are detected. Other behaviors, such as breast or testicular self-examination and participating in screening programs, concern only a specific segment of the general population. Although health care professionals also form an important target group to encourage action directed at the early detection of cancer, this thesis focuses mainly on the general public.

\section{Step 1.4 Analysis of determinants}

In developing successful health education interventions, it is necessary to find out what the existing motives of the target group are to engage in or sustain the behavior (Green \& Kreuter, 1991). In order to encourage people to engage in early detection behaviors, the factors that determine why people do or do not engage in such behaviors must be 
identified. Furthermore, shortening patient delay requires knowledge of the factors that influence the process of deciding to seek help for possible cancer symptoms.

There are three main strategies to determine the factors influencing decisions and actions on health (Kreuter, Farrell, Olevitch \& Brennan, 2000): reviewing applicable theories and models, reviewing previous research, and collecting original data. This subsection describes the results of the first two methods, while Chapters 2 to 5 report on the results of additional data collection. The following subsection describes the determinants of the various early detection behaviors and help-seeking behavior, using the ASE model (De Vries, Backbier, Kok \& Dijkstra, 1995; De Vries, Dijkstra \& Kuhlman, 1988; De Vries \& Mudde, 1998) and the Health Belief Model (Becker \& Rosenstock, 1984; Strecher \& Rosenstock, 1996) as the most important theoretical frameworks.

\section{The ASE model}

Social psychological models are often used to study the underlying factors influencing healthy or unhealthy behavior. Many Dutch studies searching for the underlying factors of behaviors with respect to primary and secondary prevention of chronic diseases are based on the Attitude - Social influence - self Efficacy model (ASE) (De Vries et al., 1995; De Vries et al., 1988). In the international literature similar models are often used, such as the Theory of Reasoned Action (TRA) (Ajzen \& Fisbein, 1970) and its successor the Theory of Planned Behavior (TPB) (Ajzen, 1991). Godin \& Kok (1996) provide an overview of several health related behaviors, confirming the value of the TPB. The following paragraphs describe the ASE model, the TRA and the TPB. The main differences between these models are related to the assessment of the central concepts, as will be explained below. An overview is given of applications of the ASE model, the TRA and the TPB to behaviors related to the early detection of cancer. It should be noted that most of the literature used refers to active detection behaviors, such as breast self-examination and testicular self-examination, and participating in screening programs.

The ASE model describes three major determinants influencing someone's motivation, or intention, to engage in a behavior, namely attitudes, social influences and self-efficacy (Figure 1.3). The model assumes that distal factors, such as psychological, biological, social and cultural factors, influence the behavioral intention through the central concepts, and that, in turn, intention influences actual behavior. The TRA and the TPB also assume that intention is the proximal determinant of behavior (Ajzen, 1991; Conner \& Sparks, 1995). Evidence for the relationship between intention and behavior has been found in several studies regarding participation in screening programs (Calnan, 1984; Lechner et al., 1997; Rakowski et al., 1992). 
The first determinant of intention, attitude, refers to the beliefs a person has toward that behavior, for instance about the advantages or disadvantages of that behavior or its consequences. Knowledge is often regarded as a prerequisite to develop attitudes. Knowledge of cancer symptoms and detection techniques has been found to be associated with early detection behaviors (Amsel, Grover \& Balshem, 1985; Barling \& Lehman, 1999; Champion, 1991; Friedman, 1995; Miller et al., 1996; Reno, 1988; Savage \& Clarke, 1996) and intentions (Steffen, 1990), whereas lack of knowledge was associated with the absence of early detection behaviors, such as breast self-examination and testicular selfexamination (Katz et al., 1995; Lechner et al., in press; Murray \& McMillan, 1993; Wardle et al., 1994). Studies have shown that knowledge of cancer warning signs and detection techniques was poor (Ali \& Khalil, 1996; Bostick et al., 1993; Myhre, Li, Guan \& Wang, 1996; Nichols, Misra \& Alexy, 1996). Two studies found that subjects could mention an average of 3 of the 7 cancer warning signs (Ali \& Khalil, 1996; Nichols et al., 1996). In another study, $61 \%$ of all subjects listed three warning signs (Bostick et al., 1993). Thornhill et al. (1986) showed that only $19 \%$ of the subjects could identify a lump or a swelling as an important possible symptom of testicular cancer. Women were significantly more knowledgeable about cancer symptoms than men (Ali \& Khalil, 1996; Bostick, 1993; Miller et al., 1996), especially as regards knowledge of the clinical signs of early melanoma (e.g., bleeding, change in color and shape) (Jackson, Wilkinson \& Pill, 1999).

With respect to attitudes toward the early detection of cancer, several studies have shown that persons with favorable attitudes toward a certain behavior are more likely to perform that behavior or to have positive intentions to perform, for instance, breast selfexamination (McCaul, Sandgren, O'Neill \& Hinsz, 1993; Moore et al., 1998; Van Ryn, Lytle \& Kirscht, 1996; Wardle et al., 1995), testicular self-examination (Brubaker \& Wickersham, 1990; Lechner et al., in press; McCaul et al., 1993; Moore et al., 1998; Wardle et al., 1994), or participate in screening programs for breast cancer (Champion, 1994; Crooks \& Neutens, 1993; Lechner et al., 1997; Montano \& Taplin, 1991). ASE, TRA, and TPB differ in the method by which attitudes are assessed. ASE assesses attitude on the basis of people's beliefs, while TRA and TPB assess them by means of a multiplicative function of someone's beliefs and the evaluation of these beliefs (Ajzen \& Fisbein, 1980).

Social influences, the second determinant of intention in the ASE model, include the subjective norm, social pressure and modeling. Subjective norm refers to the impression a person has of the feelings of important others about his or her performing a particular behavior. Social pressure or social support refers to the reactions a person perceives from 
others about performing the healthy or unhealthy behavior, and that may have either a positive or a negative influence on the desired behavior. Modeling means learning from others by observing them performing the behavior. If many people in the environment perform a particular behavior, it becomes more likely that the person will also perform the behavior. The ASE model differs from the TRA and TPB in the social influence component. Whereas the ASE model distinguishes between three kinds of social influence, the TRA and TPB use a multiplicative function of the subjective norm and the motivation to comply, which is similar to the way they assess attitude. A study among Dutch adolescents has shown that adding social pressure and modeling significantly increases the predictive value of the model as applied to future smoking behavior (De Vries et al., 1995). As regards the early detection of cancer, the subjective norms of partners, family, friends and medical professionals were found to have a positive influence on the intention to engage in early detection behaviors, such as breast selfexamination, testicular self-examination and mammography (Baines, To \& Wall, 1990; Champion, 1991; McCance, Mooney, Field \& Smith, 1996; Montano \& Taplin, 1991; Moore et al., 1998; Van Ryn et al., 1996). Also a significant effect of social support was found on the frequency of performing breast self-examination (Wagle, Komorita \& Lu, 1997). Furthermore, knowing a woman who has had mammography was found to be positively associated with the intention to have mammography (Savage \& Clarke, 1996). The third determinant of intention is self-efficacy, which assesses one's ability to perform the behavior in question. Self-efficacy, a concept from Bandura's social cognition theory (Bandura, 1986) is to some extent comparable to the perceived behavioral control in the TPB. The concept of perceived behavioral control was added to the original TRA in order to overcome its limitations in predicting behaviors which are not completely under someone's volitional control (Ajzen, 1991). Whereas perceived behav-

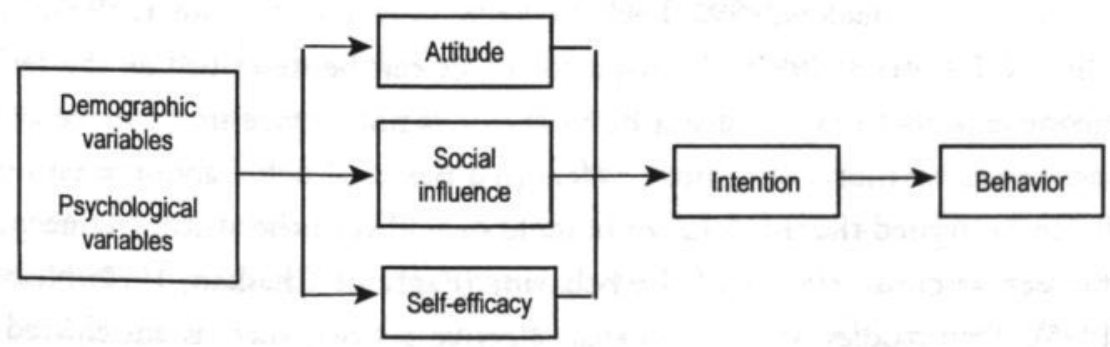

Figure 1.3 The ASE model (De Vries et al., 1995). 
ioral control refers to 'the perceived ease or difficulty of performing the behavior' (Ajzen, 1988, p.132), self-efficacy refers to 'people's judgements of their capabilities to organize and execute the courses of action required to attain designated types of performances' (Bandura, 1986, p. 391). The main difference in the self-efficacy concept between ASE and TPB lies in the operationalization of the concepts. According to Bandura, self-efficacy varies along three dimensions: magnitude (i.e., the perceived difficulty of skills needed to perform the behavior), generality (i.e., the perceived problems of the same behavior in different situations) and strength (i.e., the level of confidence required to perform the behavior). In measuring someone's self-efficacy, all three dimensions should be assessed. To assess self-efficacy, the TPB multiplies someone's control beliefs by the perceived power of the particular control factor to facilitate or impede performance of the behavior. In the ASE model, self-efficacy is operationalized as someone's self-efficacy to perform a healthy behavior or to refrain from an unhealthy behavior in a set of given situations. Both concepts have been used in the literature on behaviors related to the early detection of cancer. High levels of self-efficacy have been associated with performing breast selfexamination, testicular self-examination and skin self-examination (Barling \& Lehman, 1999; Champion, 1991; Friedman et al., 1994, 1995; Murray \& McMillan, 1993), as well as participation in a colorectal cancer screening program (McEvoy-DeVellis, Blalock \& Sandler, 1990) and intentions to engage in early detection behaviors (Allen, Sorensen, Stoddard, Colditz \& Peterson, 1998; Lechner et al., 1997; Lechner et al., in press; Savage \& Clarke, 1996).

Those with a positive attitude, positive social influences and high self-efficacy expectations are expected to have positive intentions to engage in the behavior under study. Positive intentions toward the behavior are more likely to result in its actual performance.

It has recently been proposed that certain factors should be added to these cognitive models as potential predictors of behaviors, viz. anticipated regret and personal norm (Ajzen, 1991; Eagly \& Chaiken, 1990; Lechner, 1998; Norman \& Conner, 1995; Richard, Van der Pligt \& De Vries, 1995). Anticipated regret can be described as the feeling of regret someone expects to experience if he or she does not engage in a particular behavior. Personal norm, or moral obligation, refers to a personal belief about what ought to be done. It can be argued that both factors should be added to the attitude concept, since they can be seen as consequences of the behavior (Eagly \& Chaiken, 1990; Norman \& Conner, 1995). Two studies have found that affective factors, such as anticipated regret and moral obligation, play a role in the decision whether or not to participate in a screening program for breast cancer or to perform testicular self-examination (Lechner $e t$ 
ioral control refers to 'the perceived ease or difficulty of performing the behavior' (Ajzen, 1988, p.132), self-efficacy refers to 'people's judgements of their capabilities to organize and execute the courses of action required to attain designated types of performances' (Bandura, 1986, p. 391). The main difference in the self-efficacy concept between ASE and TPB lies in the operationalization of the concepts. According to Bandura, self-efficacy varies along three dimensions: magnitude (i.e., the perceived difficulty of skills needed to perform the behavior), generality (i.e., the perceived problems of the same behavior in different situations) and strength (i.e., the level of confidence required to perform the behavior). In measuring someone's self-efficacy, all three dimensions should be assessed. To assess self-efficacy, the TPB multiplies someone's control beliefs by the perceived power of the particular control factor to facilitate or impede performance of the behavior. In the ASE model, self-efficacy is operationalized as someone's self-efficacy to perform a healthy behavior or to refrain from an unhealthy behavior in a set of given situations. Both concepts have been used in the literature on behaviors related to the early detection of cancer. High levels of self-efficacy have been associated with performing breast selfexamination, testicular self-examination and skin self-examination (Barling \& Lehman, 1999; Champion, 1991; Friedman et al., 1994, 1995; Murray \& McMillan, 1993), as well as participation in a colorectal cancer screening program (McEvoy-DeVellis, Blalock \& Sandler, 1990) and intentions to engage in early detection behaviors (Allen, Sorensen, Stoddard, Colditz \& Peterson, 1998; Lechner et al., 1997; Lechner et al., in press; Savage \& Clarke, 1996).

Those with a positive attitude, positive social influences and high self-efficacy expectations are expected to have positive intentions to engage in the behavior under study. Positive intentions toward the behavior are more likely to result in its actual performance.

It has recently been proposed that certain factors should be added to these cognitive models as potential predictors of behaviors, viz. anticipated regret and personal norm (Ajzen, 1991; Eagly \& Chaiken, 1990; Lechner, 1998; Norman \& Conner, 1995; Richard, Van der Pligt \& De Vries, 1995). Anticipated regret can be described as the feeling of regret someone expects to experience if he or she does not engage in a particular behavior. Personal norm, or moral obligation, refers to a personal belief about what ought to be done. It can be argued that both factors should be added to the attitude concept, since they can be seen as consequences of the behavior (Eagly \& Chaiken, 1990; Norman \& Conner, 1995). Two studies have found that affective factors, such as anticipated regret and moral obligation, play a role in the decision whether or not to participate in a screening program for breast cancer or to perform testicular self-examination (Lechner $e t$ 
times suggested is someone's health motivation, that is, their readiness to be concerned about health matters. People may differ in their beliefs about the importance of health behaviors, and hence show smaller or greater inclination to engage in these behaviors. Beliefs about susceptibility and severity determine how threatened someone will feel about health or health behavior, while beliefs about the benefits and barriers form the behavioral evaluation. Some of the constructs of the Health Belief Model are comparable to some of the constructs of the ASE, TRA and TPB. For instance, the perceived threat (i.e., a combination of susceptibility and severity) would be seen as an attitudinal belief in the ASE model. It is therefore less important to select a specific model than it is to incorporate appropriate constructs to analyze a health problem.

Studies using the Health Belief Model have shown that perceived susceptibility was related to breast self-examination (Champion, 1991; Millar, 1997). Perceived susceptibility, perceived barriers, benefits and cues to action were effective predictors of future intentions to undergo mammography (Stein et al., 1992). Health motivation was also found to be related to breast self-examination, mammography and professional breast examination (Champion, 1991).

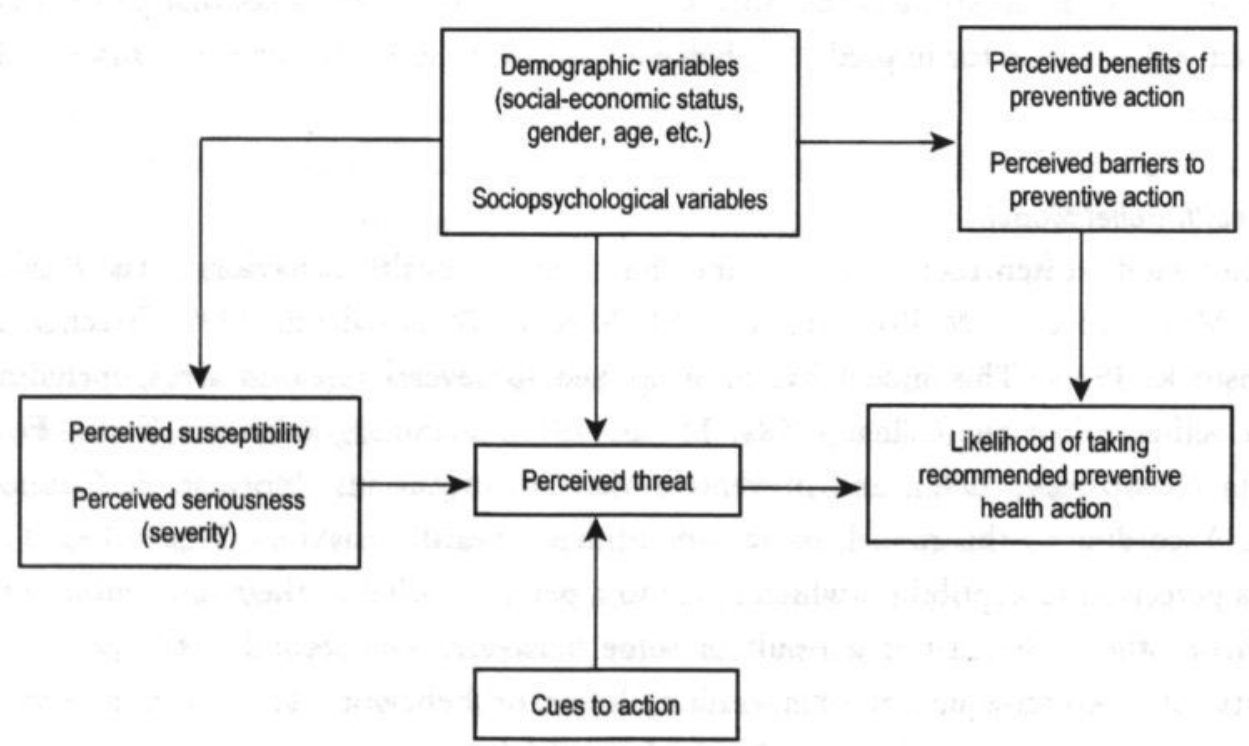

Figure 1.4 The Health Belief Model (Janz \& Becker, 1984). 


\section{Determinants of seeking medical help for cancer symptoms}

In the literature on determinants of help-seeking behavior for (cancer) symptoms, the various stages in patient delay are not regarded as separate stages. However, many studies provide information on why potential patients postponed seeking medical help.

One frequently mentioned factor influencing delay is knowledge, which is necessary to interpret symptoms correctly. For instance, people need to know whether a symptom is a cancer related symptom, and when a symptom is serious enough to require medical attention. The perception that the symptom is not serious enough to require medical attention, or that it would clear up by itself was found to be a factor increasing delay (Byles, Redman, Hennrikus, Sanson-Fischer \& Dickinson, 1992; Cassileth et al., 1988; Hennrikus, Girgis, Redman \& Sanson-Fisher, 1991; Van de Kar, Knottnerus, Meertens, Dubois \& Kok, 1992). Lack of knowledge and the resulting tendency to attribute symptoms to common illnesses has been associated with increased delay (Cochran et al., 1986; Doherty \& MacKie, 1986; Gascoigne et al., 1999; Mor et al., 1990; Oliveria et al., 1999; Salander, Bergenheim, Hamberg \& Hendriksson, 1999). Conversely, attributing symptoms to cancer or other serious problems that should be checked was associated in various studies with less delay (Cochran et al., 1986; Hackett, Cassem \& Raker, 1973; Hennrikus et al., 1991).

Detecting cancer symptoms is often associated with fear (Andersen et al., 1995; Gascoigne et al., 1999; Leventhal, 1970; Safer et al., 1979; Wool, 1986), which was found to be either a stimulating or an impeding factor in seeking help for cancer symptoms. Fear caused by the nature of the symptoms is likely to decrease delay, while fear caused by the possible diagnosis of cancer is likely to increase delay. For certain check-ups, such as colorectal examination, embarrassment about the test itself may lead to delay (Byles et al., 1992).

Another factor in the process of detecting cancer symptoms and seeking medical attention is discussing symptoms with others. Many studies have shown that communication about (cancer) symptoms leads to shorter pre-diagnostic periods (Cameron, 1993; Gascoigne et al., 1999; Van de Kar et al., 1992). One study showed that reduced delay was associated with the influence of others who insisted on their consulting a physician with particular symptoms (Hennrikus et al., 1991). Having a relative or friend with cancer is also associated with less delay (Hackett et al., 1973) (Lauver, 1994), although Wool did not find a relationship between these variables (Wool, 1986).

In addition to cognitive and affective factors influencing the process of symptom detection and help-seeking, other factors were also found to play a role. In general, women consult health care professionals more often than men and they experience more 
ill health than men (Corney, 1990; Ingham, 1986). Moreover, some people simply experience more symptoms than others, because they are more alert to bodily symptoms than others (Pennebaker, 1982). People also differ in their coping styles in relation to the detection of symptoms. Whereas one person tries to seek out threat-relevant information, described as a monitoring coping style, another person would avoid threat-relevant information, which is called a blunting coping style (Miller, 1980). The former is more common among anxious people and those who are alert to physical complaints than the latter (Muris \& Van Zuuren, 1992). In a study by Van Zuuren, a monitoring coping style, seeking information about health threats, was modestly associated with disease detection, such as examining the skin and monitoring body weight (Van Zuuren \& Dooper, 1999). A final factor mentioned in the literature is the effectiveness of the action that is likely to be undertaken by the medical professional when consulted. More trust in the medical professional's action was associated with greater use of medical services (Egan, 1987; Ingham \& Miller, 1983; Van de Kar et al., 1992).

In sum, an analysis of determinants is a prerequisite for program development. So far, not much is known about the motives for engaging in early detection behaviors and the performance of these behaviors among the general population in the Netherlands. Therefore, additional research was conducted to investigate what Dutch adults know about cancer symptoms and detection methods, what they think about these behaviors, and to what extent they actually perform these behaviors. The results of these studies are described in Chapters 2 to 4 of this thesis.

\section{Step 1.5 Access point analysis}

The previous sections discussed the behaviors associated with early detection of cancer and the social psychological determinants that influence these behaviors. Another aspect is that health education aiming at passive detection and help-seeking behaviors should target the general population, while specific segments of the general population should be targeted for active detection behaviors and participating in screening programs. The final step in the problem analysis, the access point analysis, is an assessment of how these target groups can be reached.

From an educational point of view, it is not easy to formulate one simple and clear message about early detection of cancer for the whole population. To prevent the target group from being given redundant information, it is desirable to adjust information to the features of the individual. For instance, a woman who has always participated in a screening program for cervix cancer may need different information than a woman who is receiving an invitation for the first time and is not yet convinced of the advantages of a 
Pap smear. Similarly, a person who is extremely worried about cancer needs information to reduce fears, while someone who denies the dangers of particular risk behaviors needs more information on the severity and risks related to cancer. It is to be expected that someone who receives information which is adapted to his or her needs, interests, and characteristics and thus contains no redundant information is more likely to read and accept this information. This kind of information is more personally relevant and therefore more likely to be attentively considered (De Vries \& Brug, 1999; Petty \& Cacioppo, 1986). Additionally, this is thought to be more effective than generic information in changing attitudes, and hence behaviors.

Health education about early detection of cancer should on the one hand take individual characteristics into account, and on the other hand address the general population, since the detection of cancer at an early stage is important for the general population. Since previous research showed that multiple factors (demographic and social psychological variables) are likely to determine the considerable variation in detection behaviors across the intended audience, tailored health messages seem to be the most appropriate method to obtain access to all segments of the population. This strategy was elaborated in the development of a tailored intervention described below.

\section{Phase 2 Changing early detection behaviors}

The previous section mapped behaviors and social psychological determinants related to early detection of cancer. In the second phase of the planning model, the main focus is to formulate goals and objectives, which should be translated into an intervention. This phase also includes evaluating the intervention for its effectiveness. Since there have been few examples of the development and evaluation of interventions on passive detection behavior and the possible resulting help-seeking behavior, the development of the intervention described in this thesis focused on these aspects.

\section{Step 2.1 Objectives of the intervention}

The overall goal of an intervention targeted at the general population and focused on early detection of cancer is usually a reduction of patient delay in the process of detecting cancer symptoms and seeking help, and in the long term a reduction in morbidity and mortality from cancer. Studying this requires a large study population and a very long period of data collection, neither of which was available for the present research project. Therefore, the goal of the intervention was to encourage people to engage in early 
detection behaviors and to maintain or create positive motivational determinants toward the early detection of cancer.

Although additional information on behaviors and determinants of passive detection and help seeking behavior for cancer symptoms is described in Chapters 2 to 5 , the considerations presented in the preceding section allows several objectives for the intervention to be formulated. First, recipients of the information should practice passive detection behaviors, that is, be attentive to cancer symptoms, and seek medical help according to the recommendations of the Dutch Cancer Society (1996) as described above. Second, recipients of the information should obtain or maintain knowledge of cancer symptoms and develop positive social psychological determinants (attitudes, social influences and self-efficacy expectations) and intentions tending toward passive detection and help-seeking behavior. Third, recipients of the information should not experience adverse side-effects of the intervention, such as increased fear of cancer or more fatalistic attitudes toward cancer.

\section{Step 2.2 Developing a tailored intervention}

Based on the outcomes of the problem analysis of the first phase in the planning model and the additional analyses of determinants and behavior described in Chapters 2 to 5 , an intervention was developed.

The literature and the analysis of the health problem have so far revealed that one simple message to encourage people to engage in early detection behaviors would not be feasible. Messages can target specific groups or the general population as a whole. Much attention has been paid to the development of programs aimed at active detection behavior, such as breast and testicular self-examination and participating in screening programs (see for instance Assaf, Cummings, Graham, Mettlin \& Marshall, 1985; Best, Davis, Vaz \& Kaiser, 1996; Friman, Finney, Glasscock, Weigel \& Christophersen, 1986; Paskett et al., 1998; Rakowski et al., 1998; Skinner, Strecher \& Hospers, 1994; Solomon et al., 1998; Strickland et al., 1997). Far less is being done to promote passive detection behaviors. Therefore, the intervention described in the present thesis mainly focused on passive detection of cancer symptoms and on stimulating appropriate responses to the detection of such a suspicious symptom.

Intervention studies focusing on the encouragement of passive detection behavior are rare. In a Swedish study attempting to shorten patient delay, community inhabitants were informed by letter about cancer symptoms and common forms of cancer (Månsson, Marklunc, Bengtsson \& Fridlund, 1999). They were invited to visit health care centers if they noticed any of the symptoms described in the letter. More than 200 visits followed, 
and 15 cancers were detected, 13 of which were at a localized stage. In another study on the detection of melanoma, the general public was informed about the features of early melanoma by several mass media channels and people were encouraged to consult a physician if they recognized such lesions on their skin (Doherty \& MacKie, 1986). The results over the first six months were promising: the proportion of patients judged to have a 'good prognosis' increased from $38 \%$ to $62 \%$, while the proportion of patients with 'poor prognosis' decreased from $34 \%$ to $15 \%$. Unfortunately, none of the studies included control groups, limiting any conclusions about shorter patient delay or better prognosis.

In the Netherlands, a few interventions have been implemented to inform the general public about cancer symptoms and to encourage early detection behaviors. The Dutch Cancer Society published several brochures, including one about early detection of cancer symptoms (Dutch Cancer Society, 1996). A mass media campaign about cancer among men was launched in the framework of the European Week Against Cancer, stimulating men to be attentive to cancer symptoms (Dutch Cancer Society, 1998). Unfortunately, these interventions were not evaluated for their effectiveness.

It is assumed that interventions stimulating the public to be attentive to cancer symptoms may result in increased fear. Fear may lead to different coping styles, for instance avoiding the threatening situation (Sarafino, 1998). It is possible that people who cannot cope with the fear associated with the detection of cancer, and who have little trust in the effectiveness of medical treatment, respond with fatalistic opinions about cancer, such as 'if you find a cancer symptom, it is too late to do anything about it' and hence do not engage in early detection behaviors (Olson \& Morse, 1996). This assumption was not confirmed in a study encouraging attentiveness to cancer symptoms nor in other studies in which breast and testicular self-examination were encouraged (Best et al., 1996; Hobbs, Haran, Pendleton, Jones \& Posner, 1984; Månsson et al., 1999; Weist, 1996). Nevertheless, in developing health education interventions on early detection of cancer, possible adverse side-effects such as arousing fear of cancer should be very carefully taken into consideration.

The last decade has seen the introduction and growing popularity of computer-tailored communication, which enables a combination of the advantages of mass media and interpersonal communication (De Vries \& Brug, 1999; Dijkstra \& De Vries, 1999b; Kreuter, Farrell, Olevitch \& Brennan, 2000; Kreuter, Strecher \& Glassman, 1999). Tailoring is defined as 'any combination of strategies and information intended to reach one specific person, based on characteristics that are unique to that person, related to the outcome of interest, and derived from an individual assessment' (Kreuter et al., 2000; Kreuter \& 
Skinner, 2000; Kreuter et al., 1999). Tailored messages can be distinguished from traditional health messages in that the messages are intended for a particular person rather than a group (focused on individuals) and in that these messages are based on individual factors related to the health or behavior outcome (assessment-based). Hence, tailoring goes a step beyond generic, targeted or personalized communication and is close to interpersonal communication. Moreover, compared to expensive and time-consuming interpersonal communication, computerized tailoring allows health educationists to reach large target groups at relatively low cost.

Computer-tailoring requires three interrelated elements: a screening questionnaire, a message library and tailoring algorithms. Each of these elements will be described briefly below. The first element is the screening instrument, which can be administered by telephone interviews, by self-administered written questionnaires, and recently also by interactive computer programs. This screening questionnaire should address all important determinants of change in a valid way, and will be primarily used to enable personal feedback (Dijkstra \& De Vries, 1999b; Kreuter et al., 2000). The tailoring assessment questionnaire encompasses mostly closed questions, enabling the creation of a message library covering all possible answers provided by the participant (Kreuter et al., 2000). Three of the categories could also allow open-ended questions. These include questions on personal identification information (i.e., address etc.), questions which require numerical responses (for instance, age, number of health care visits during the last month etc.), and questions to gather data that will be used to revise the current program (for instance, by creating the option 'other, please specify' in an otherwise closed question). The tailoring assessment questionnaire should be pre-tested among members of the target population to ensure that the questions are easily and unequivocally understood by the participants and that it provides appropriate response options. The data is then entered into a data file, which is later linked with the message library.

The message library contains feedback messages tailored to all possible answers or combinations of answers from the tailoring assessment questionnaire. These tailored messages can be given at various levels, for instance at the behavioral level, at the level of behavioral determinants, or even more specific, at the level of someone's beliefs about particular issues. Seven types of feedback can be distinguished (Dijkstra \& De Vries, 1999b). The first is feedback on cognitive behavioral states, which should enhance selfmonitoring. The second type involves normative feedback, allowing comparisons between individual responses and responses of a reference group. The third type is positive feedback, to reinforce desired states, while the fourth involves feedback on personal characteristics, which enhances curiosity and involvement. The fifth type uses a 
personal tone and empathy to enhance commitment, whereas the sixth uses ipsative feedback to provide information on a person's progress relative to a previous assessment, and enhances self-monitoring. The seventh type of feedback stimulates attentional change processes, or 'cues to action'. The last two types of feedback are only applicable in multiple tailoring.

The third element of computer-tailored communication is the set of decision rules which evaluates the tailoring assessment questionnaire. Developing these tailoring algorithms starts by coding the assessment questionnaire and the messages, so that each response or combination of responses can be linked with the corresponding message or messages from the message library. These algorithms mainly consist of logical statements ('if this, then that'). Subsequently, the tailoring algorithms are translated into a computer program that selects and generates the messages tailored to the individual. Finally, these messages are delivered to the individual in a clear and attractive way, for instance in a letter, or via a computer screen.

Over the last decade many studies have tested the effectiveness of computer-tailored interventions. Most of these studies were related to primary prevention behaviors, such as smoking cessation, and nutrition habits. Evaluations of these studies showed that computer-tailored interventions were effective in changing intentions and behaviors, such as motivating people to reduce fat intake and increase their fruit and vegetable intake (Brug, Campbell \& Van Assema, 1999; Brug, Steenhuis, Van Assema \& De Vries, 1996; Campbell, 1994), to stop smoking (Dijkstra, De Vries \& Roijackers, 1998; Strecher et al., 1994), and to lose weight (Kreuter, Bull, Clark \& Oswald, 1999). With regard to secondary prevention behaviors, two studies evaluated an intervention stimulating people to engage in mammography screening (Rakowski et al., 1998; Skinner et al., 1994). Skinner and colleagues have provided an extensive review of the effectiveness of computer-tailored printed communication (Skinner, Campbell, Rimer, Curry \& Prochaska, 1999). They concluded that, compared to non-tailored information, tailored printed communications have been found to be consistently better remembered, read, and perceived as relevant and/or credible, and to be more effective in changing health behaviors. They recommended research to assess what factors are responsible for the effects of tailoring.

\section{Step 2.3 Program evaluation}

After implementation, a program should be evaluated. Such an evaluation should consist of two parts. The first is the process evaluation, which involves an analysis of the acceptability of the intervention for the recipients in terms of use, format and content. 
The second part, the effect evaluation, tries to gain insight into the effectiveness of the tailored intervention in influencing early detection of cancer. Whereas the effect evaluation data provides information on whether the intervention works, the process evaluation data seeks explanations for program effects and reveals strong and weak points of the intervention, which can be used to improve the intervention. The program evaluation should take the form of an experimental study design, which should encompass five elements: a representative sample of the target population, one or more pretests, an unexposed group for comparison, random assignment of the sample to the different study groups, and one or more posttests to measure effects after the experimental group(s) has/have received the intervention (Green \& Lewis, 1986).

Primary endpoints to determine whether an intervention is effective or not can be identified at different levels: early detection behaviors (passive and active detection behavior, help-seeking behavior), intentions to engage in these behaviors, and the social psychological determinants of these behaviors. In the research project reported on in the present thesis, the sample size was calculated on the assumption that a power of 0.90 and an alpha of .05 would be sufficient. One-sided statistical analyses were used, since the intervention was expected to have a positive effect on behaviors, intentions and social psychological determinants. Effect sizes were computed on the basis of previous studies. Power analysis revealed that, based on a power of 0.90 and $\alpha=.05,390$ respondents per group were required at the second posttest (Lipsey, 1990). Subsequently, it was assumed that there would be a response rate of $80 \%$ at the pretest and a drop-out rate of $10 \%$ for each posttest (Swanborn, 1987), which meant that at the start of the project 600 participants for each group should be included. Chapters 6 and 7 describe the process and effect evaluation of the intervention in detail.

\section{Phase 3 Continuation}

The last phase of the planning model concerns large-scale implementation and dissemination of the effective health education intervention. This phase emphasizes the intersectoral collaboration required to increase the likelihood of successful implementation by developing diffusion strategies and supportive policies. The intervention described in this thesis should first be tested for its effectiveness, before implementation and dissemination strategies can be considered. Since this final phase is beyond the scope of this thesis, however, only some general theoretical aspects of continuation are briefly described here. 
The process of diffusion of new programs has been described by Rogers (1983). According to Rogers, successful continuation depends on several factors, such as intersectoral collaboration, diffusion analysis and strategies, and structural measures to increase the probability of actual utilization of the intervention. Intersectoral collaboration refers to identification of and collaboration with all important participants in the implementation, or 'stakeholders' (linkage approach). These important others include several parties: a research group responsible for evaluating the intervention, a resource group to provide and develop the materials, an intermediary group representing program providers, the target group, a support group, and the financiers of the program. All stakeholders should be convinced of the advantages of participating in the intervention, and consensus should be reached about the extent of involvement. An analysis of determinants of diffusion should then be used to gain insight into the perceived advantages and disadvantages of the intervention. Based on these results, an appropriate diffusion strategy can be developed. The last factor involves the creation of policies and legislation to increase the chances that the successful intervention will be used.

Since the intervention described in the present thesis still has to be developed and evaluated for its effectiveness, it is too early and irrelevant to speculate about its continuation. The final chapter of this thesis discusses the implications of the computer-tailored intervention on early detection of cancer. 


\section{ANDERSEN'S MODEL OF TOTAL PATIENT DELAY: A QUALITATIVE STUDY ON DETECTING CANCER SYMPTOMS AND SEEKING MEDICAL HELP}

\section{ABSTRACT}

Patient delay is the interval between the day someone first becomes aware of an unexplained symptom and the day he/she seeks medical consultation. This pre-diagnostic period is comprised of several stages which may involve delay on the part of the individwal. This study invertigated factors influencing the process of detecting cancer symptoms and consulting a physician. Twentylhree patients were interviewed about their experiences during this process. Among factors stimulating the process of detection and consultation were associating symptoms with cancer, and discussing symptoms with others. Being ashamed or embarrassed about the symptoms and attributing symptoms to common ailments were among the impeding factors. The findings of the present study suggest that future health edvcation about early detection of cancer should focus on increasing knowledge and providing positive information about early detection of cancer. It is recommended to disseminate educational materials for the general public via more channels, induding non-medical ones.

\section{Published as:}

De Nacijer, I., Lechner, L. E De Vries, H. (2001). Andersen's model of total patient delay: a qualitative study on detecting cancer symptoms and seeking medical help. Patient Education and Cownseling 42, 145 157. 


\section{INTRODUCTION}

Cancer is the second important cause of death and illness in the Netherlands (Van Leer, 1999). Early detection of particular cancer sites can decrease mortality rates and can improve the chance of successful treatment (American Cancer Society, 1998). Early detection of cancer can be achieved in two ways: 1) by a medical health care provider, for instance during a screening program or a medical check-up, or 2) by the persons themselves, who should be on the alert for cancer symptoms, such as changes in the breast, changes in bowel habits or a nagging cough. These symptoms are also known as the 'warning signs of cancer' (Table 2.1) (Dutch Cancer Society, 1996). Other international guidelines from the Cancer Research Campaign, the National Cancer Institute and the American Cancer Society include the same symptoms, except the unusual weight loss. It should be emphasized that these symptoms may indicate cancer, but in most cases they are caused by other medical problems.

\section{Table 2.1 Warning signs of cancer.}

\begin{tabular}{ll}
\hline \hline 1 & Nagging cough or hoarseness \\
2 & Sores that do not heal \\
3 & Obvious changes in warts or moles \\
4 & Indigestion or difficulty swallowing \\
5 & Swellings or lumps in breast or elsewhere \\
6 & Unusual bleeding or discharge \\
7 & Changes in bowel or bladder habits \\
8 & Unusual weight loss \\
\hline
\end{tabular}

Source: Dutch Cancer Society, 1996.

A person can contribute to early detection by actively performing particular actions, like breast self-examination (BSE), testicular self-examination (TSE), or checking the skin. These conscious actions to detect changes in the body can be referred to as active detection. Baines (1983) and Cope (1992) showed that around $70-80 \%$ of all new cases of breast cancer are detected by the woman herself. In many Western countries the female adult population is encouraged to perform BSE, whereas the male population younger than 35 years is encouraged to perform TSE (American Cancer Society, 1991; Dutch Cancer Society, 1996). However, several studies have shown that BSE is performed on a monthly basis by only about $25 \%$ of all women (Budden, 1995; Cope, 1992; Fink, 1991; Friedman et al., 1994; Hallal, 1982) and that only some of the women who practice BSE 
do so correctly (Pinto \& Fuqua, 1991). In contrast to BSE, which is familiar to most women, TSE is hardly known at all among the target group and therefore rarely performed (Thornhill, 1987; Wardle et al., 1994).

If a person becomes aware of a cancer symptom without a conscious action, this may be called passive detection. This may involve becoming aware of changes in moles, changes in bowel habits and so on. However, a major problem with these symptoms is the non-specific nature of many of the warning signals in apparently healthy people. Obviously, early detection of cancer is not one particular behavior, but consists of several separate behaviors. Persons have to detect a symptom, infer illness, decide to seek medical attention, visit a health care provider with symptoms or participate in screening programs. Although some of these behaviors overlap, it can be expected that different behaviors require different knowledge, attitudes, and skills.

Several studies have shown that delay in seeking medical consultation is common (Byles et al., 1992; Cochran et al., 1986; Facione, 1993; Lauver, 1993; Mor et al., 1990). The interval between the day a person first becomes aware of an unexplained symptom and the day (s)he seeks medical consultation has been described by Andersen and colleagues (1995). Their 'model of total patient delay' is based on early work by Safer and colleagues (1979) and is applicable to a variety of physical disorders. The model describes the pre-diagnostic period to be comprised of six stages in which delay can occur (Figure 2.1). Each stage is dichotomous and a move to the next stage is determined by decisions and interpretations in the previous stage. The time between the moment that a person first detects an unexplained symptom and infers illness is called appraisal delay. This means that a person has to interpret a complaint as a cancer symptom or at least as a serious symptom that needs attention. The next step, making a choice between seeking medical attention and self-treating the illness, is referred as illness delay. Illness delay occurs when a person decides to postpone seeking medical help. The move to the next step occurs when the person realizes the symptom does not disappear spontaneously and decides to seek medical help. The time elapsing between this decision and the act of making an appointment is called behavioral delay. The time between the making of an appointment and the first medical consultation is called scheduling delay. Scheduling delay can be due to the medical specialist (when it is impossible to make an appointment within a certain time) or to the patient (when it takes a while before a convenient time for the patient occurs). Treatment delay refers to the time between the moment when a person first receives medical attention and the beginning of the treatment. Since this type of delay is due to the medical specialist and not to the potential patients themselves, this delay is not discussed any further in this chapter. 

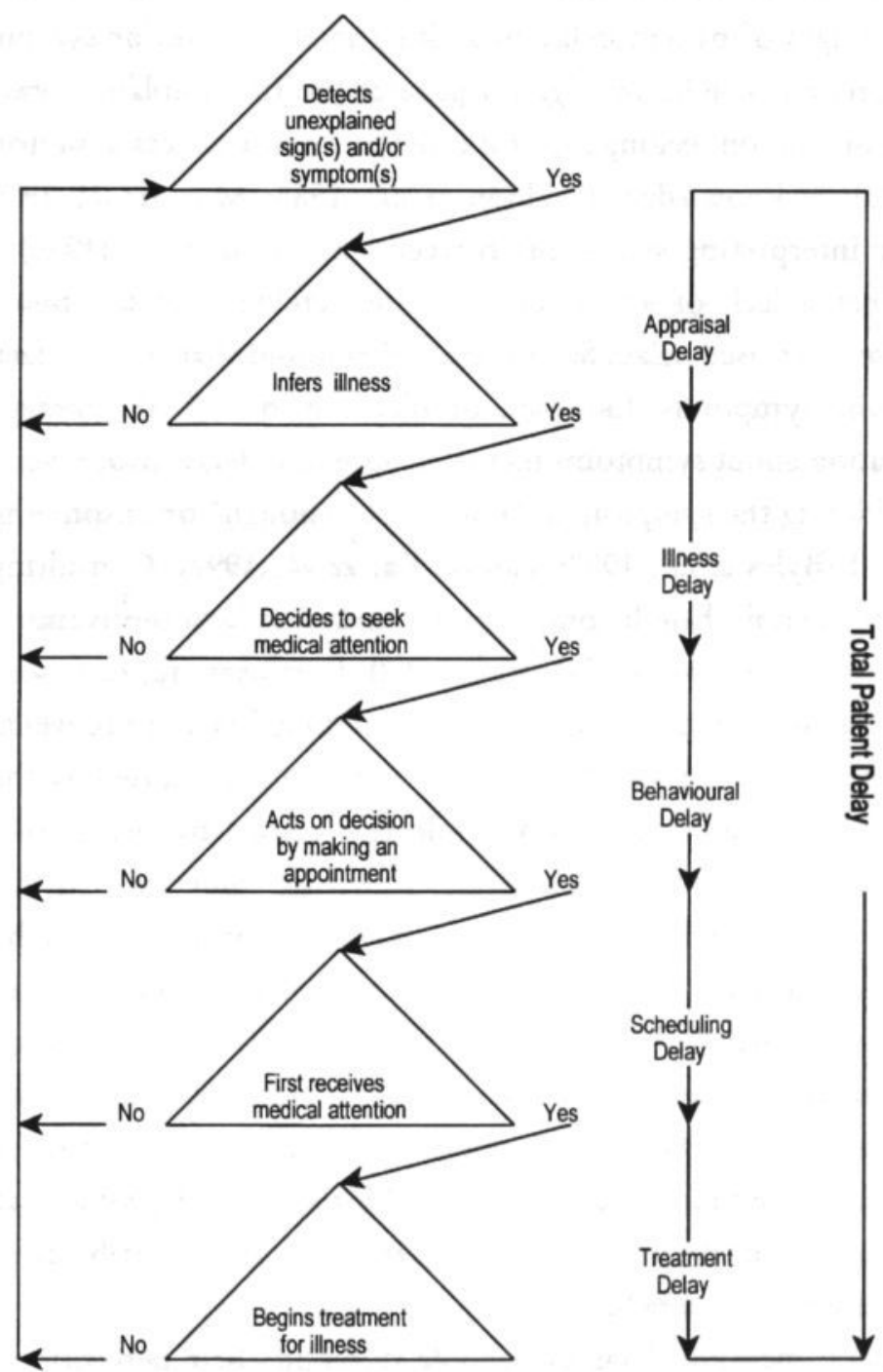

Figure 2.1 The model of total patient delay (Andersen et al., 1995). 
Several studies have identified determinants of seeking medical consultation for several health complaints. However, these studies considered total patient delay and did not distinguish between the various stages of Andersen's model. So far, few studies have considered the stages of patient delay in seeking medical care for symptoms related to cancer. Therefore, current knowledge on general health complaints was being used to gain more information on seeking medical care for specific cancer symptoms. One factor influencing delay is knowledge (Cochran et al., 1986; Mor et al., 1990), which is a prerequisite for interpreting symptoms correctly. Cochran et al. (1986) and Mor et al. (1990) found that a lack of knowledge and the tendency to attribute symptoms to common illnesses increased delay. Safer et al. (1979) found that sensory factors relating to the nature of the symptoms, like pain or bleeding, decreased appraisal delay, while seeking information about symptoms increased appraisal delay. Moreover, delay was also caused by considering the symptom as "not serious enough" or as something that would clear up by itself (Byles et al., 1992; Van de Kar et al., 1992). Consulting others about what to do with a certain health complaint was found to be a motivating factor for care seeking (Cameron, 1993; Van de Kar et al., 1992). Furthermore, fear was found to be a stimulating as well as an impeding factor in help seeking behavior (Leventhal, 1970; Mor et al., 1990; Safer et al., 1979; Wool, 1986). For instance, fear caused by the nature of the symptoms is likely to result in action, while fear caused by being told the diagnosis would be cancer is likely to result in delay. Knowing someone with cancer might be related to delay if the personal experience was traumatic, or if it is thought that cancer is hereditary and therefore unavoidable (Hackett et al., 1973). However, Wool (1986) found no relation between delay and having relatives or close friends with cancer. In addition, competing problems in the current life situation increased delay (Safer et al., 1979). Barriers between the physician and the patient, such as lack of trust or communication problems, have also been found to cause delay (Mor et al., 1990; Safer et al., 1979; Wool, 1986). Furthermore, the efficacy of the physician's care also contributed to help seeking behavior (Van de Kar et al., 1992).

Beside the above mentioned factors people differ in their perception of symptoms. Some people simply have more symptoms than others or they differ in the sensation they experience from the same symptom. According to Pennebaker, some people are more focused on bodily symptoms than other people leading to increased reports of symptoms (Pennebaker, 1982). Furthermore, it is likely that people differ in their response on newly detected symptoms. Miller (1980) had distinguished two coping styles on a threatening situation: monitoring, i.e. the extent to which persons seek out threatrelevant information and blunting, i.e. the extent to which persons avoid threat-relevant 
information. Research suggests that people using a monitoring coping style are more anxious than people using a blunting coping style and that they are more aware of physical complaints (Muris \& Van Zuuren, 1992). Moreover, a monitoring coping style is modestly associated with disease detection, such as checking unusual birthmarks on the skin and checking changes in body weight (Van Zuuren \& Dooper, 1999).

As indicated above, each move to the next stage in the model of patient delay is attended by decisions. However, the factors influencing these decisions when a person is confronted with cancer symptoms are not entirely clear. Further insight into these factors is very important if we wish to minimize the time elapsing between the moment persons first become aware of cancer symptoms and the first medical consultation. Therefore, the present study aimed at identifying the stimulating and impeding factors influencing the transition to the next stage in the process described by Andersen of detecting cancer symptoms and seeking medical help. The stages in which delay due to the patient might occur are studied, while delay due to a medical specialist is not studied. The qualitative study described below was part of a wider study focusing on developing interventions to encourage early detection of cancer. This article describes the patient's point of view about the period between detecting cancer symptoms and the first medical consultation.

\section{METHODS}

\section{Sample}

Patients were recruited by contact persons of regional patient groups for four different forms of cancer. Each contact person was asked to recruit about six patients. After patients agreed to participate in an interview, they were approached by the researcher to make an appointment. Twenty-five volunteers were selected by the contact persons. However, at the time of data collection, 2 patients were not able to participate because of unexpected circumstances. The study thus included 23 patients (Table 2.2); 6 patients had been diagnosed with breast cancer, 5 patients with testicular cancer, 6 patients with colon cancer, and 6 patients with melanoma. These particular cancer sites were chosen to include cancer sites that can be detected passively (colon cancer) and those that have to be detected actively (breast and testicular cancer). Melanoma can be detected both passively and actively. By choosing these particular cancer sites we hoped to encompass a more complete range of variables we expected to be relevant to the issue. One criterion for including breast cancer patients was that the lump had been self-detected and not 
detected by participation in a screening program. No other inclusion or exclusion criteria were used.

Table 2.2 Characteristics of the patients.

\begin{tabular}{|c|c|c|c|c|}
\hline No. & Patient & Cancer site & Time interval & Symptoms' \\
\hline 1 & male, 45 & testicular & 2 weeks & fatigue, losing small amounts of urine \\
\hline 2 & male, 33 & testicular & 2 weeks & $\begin{array}{l}\text { fever, sweating, diarrhoea, weight loss, fatigue, pain, swollen } \\
\text { scrofula }\end{array}$ \\
\hline 3 & male, 32 & testicular & 5-6 months & fatigue, swollen testicle, swollen chest, pain in chest \\
\hline 4 & male, 24 & testicular & 3-4 days & fatigue, lack of appetite, weight loss, pain in testicle, lump in testicle \\
\hline 5 & male, 32 & testicular & 1 month & back pain, fatigue, weight loss, swollen scrofula \\
\hline 6 & female, 41 & breast & $1-2$ days & fatigue, inverted nipple, two lumps \\
\hline 7 & female, 45 & breast & 1 day & inverted nipple, lump \\
\hline 8 & female, 45 & breast & 1 month & fatigue, pain in arm, pain in breast, change in breast \\
\hline 9 & female, 35 & breast & 9 hours & lump \\
\hline 10 & female, 49 & breast & 2 weeks & fatigue, pain when lying down, small string of lumps \\
\hline 11 & female, 51 & breast & 3-4 months & swelling in the breast, weight loss, fatigue, back pain, inverted nipple \\
\hline 12 & male, 61 & colon & 10 months & fatigue, weight loss, lack of appetite, rectal bleeding \\
\hline 13 & male, 39 & colon & a few hours & $\begin{array}{l}\text { diarthea, abdominal pain, rectal bleeding, fatigue, loss of sphincter } \\
\text { control }\end{array}$ \\
\hline 14 & male, 39 & colon & a few hours & fatigue, itchy anus, swelling near the anus \\
\hline 15 & female, 41 & colon & 4 months & $\begin{array}{l}\text { fatigue, change in bowel habits, rectal bleeding, weight loss, } \\
\text { dizziness }\end{array}$ \\
\hline 16 & female, 75 & colon & 3 days & pain in anus, hemorrhoids, itchy anus, fatigue \\
\hline 17 & male, 52 & colon & 3 months & change in bowel habits \\
\hline 18 & female, 52 & melanoma & $4-5$ months & fatigue, new mole, itchy and bleeding moles \\
\hline 19 & female, 38 & melanoma & 3 weeks & fatigue, new mole, change in color, bleeding \\
\hline 20 & female, 37 & melanoma & $2-3$ months & fatigue, new mole, bleeding \\
\hline 21 & female, 38 & melanoma & 2 years & fatigue, lesion, irregularity of contour, color, thickness of the lesion \\
\hline 22 & male, 37 & melanoma & several years & dark mole, growing mole, fatigue \\
\hline 23 & female, 48 & melanoma & 2 years & none \\
\hline
\end{tabular}

The symptom which induced the patient to consult the physician is underlined. 


\section{The interview}

A qualitative data collection method was chosen. Such methods are useful to gain insight into the complexity of the issue and to provide specific information about the patients' experiences of discovering cancer symptoms. Semi-structured, in-depth interviews with open-ended questions were conducted, based on the 'model of total patient delay' (See Table 2.3) (Andersen et al., 1995).

The patients were interviewed at home, to create a more intimate atmosphere. Each interview took about 30 to 45 minutes. At the beginning of the interview, the patients were invited to tell the story of how they went through the process of detecting cancer symptoms. Subsequently, more specific questions were asked to gain insight into each separate stage. These questions were based on the literature.

With regard to appraisal delay, patients were asked to list the physical complaints they had suffered from in the pre-diagnostic period. Patients with breast and testicular cancer were asked if and how they had performed self-examination. Furthermore, knowledge of the warning signs of cancer was assessed by asking which cancer-related symptoms they could recall. The interview also included questions about the interpretation of the symptoms, that is, what explanations patients had for the complaints and to whom they had talked about them. Regarding illness delay, patients were asked what particular reasons they had had to seek medical help for one complaint but not for another, and whether the decision had been influenced by important others in their immediate environment. Behavioral delay contained questions regarding the reasons to postpone consulting a physician. The final stage, scheduling delay, included questions about the first medical consultation.

Table 2.3 Interview route.

\begin{tabular}{ll}
\hline \hline Stage & Important questions \\
\hline Appraisal delay & What symptoms did you detect? \\
& Did you perform self-examination? \\
& What was your reaction on the symptoms detected? \\
& What was your explanation of the symptoms? \\
& Did you consult others about your symptoms? \\
& Did you know the eight warning signs of cancer? \\
IIIness delay & What were the reasons to consult the physician? \\
& Was your decision to consult the physician influenced by others? \\
Behavioral delay & What were the reasons to postpone your consult? \\
Scheduling delay & How was the first appointment with the physician?
\end{tabular}


With the participants' consent, the interviews were recorded on tape in order to collect data without being selective in taking notes during the interview and in order to enable transcription.

\section{Data analysis}

The oral data recorded on tape were transcribed in written form. Two independent researchers read each transcript several times to familiarize themselves thoroughly with the data. Moreover, they studied and double-checked the interpretation of the data in order to ensure the objectivity of the results. The texts were categorized according to the stages of patient delay (Andersen et al., 1995). The interview route, and hence the stages of patient delay, served as the framework for data analysis. In each stage, segments of the data were identified based on key concepts of the questionnaire. Ten themes were identified as important factors in passing through the different stages of delay. These themes are discussed below.

\section{Results}

Table 2.2 presents the characteristics of the participants, as well as the symptoms they had experienced during the pre-diagnostic period. The symptoms which had finally led to medical consultation at a later stage have been underlined. The time interval refers to the reported time between the day patients first discovered unexplained symptoms and the day they had the first contact about this with their physician. Table 2.4 presents the stimulating and impeding factors influencing the transition from stage to stage in the process of detecting cancer symptoms and seeking medical consultation, including a list of the patients against the factors involved in their case.

\section{Appraisal delay}

Patients reported to have detected both specific localized symptoms (e.g. a swollen testicle or a lump in a breast) and non-specific symptoms (e.g. change in bowel habits or weight loss) (Table 2.2). In most cases, symptoms leading to the diagnosis of colon cancer, melanoma, breast and testicular cancer were detected passively $(n=20)$. In two cases of melanoma, other people became aware of cancer symptoms in the patients and drew their attention to the symptoms $(n=2)$. Breast cancer symptoms were mostly detected by just becoming aware of a lump or other discomfort in the breast $(n=4)$. Although five women said they had practiced BSE, abnormalities in the breast had been 
detected by BSE in only two cases. With regard to TSE, this had not been practiced prior to the diagnosis by any of the patients with testicular cancer. One patient with testicular cancer had visited his physician with a symptom not related to the final diagnosis, so cancer was detected by coincidence. One salient general symptom for most patients was fatigue. Table 2.2 shows that the majority of the patients remembered to have felt fatigued during the pre-diagnostic period $(\mathrm{n}=19)$.

(1) Knowledge. Patients were asked which warning signs of cancer they had known about before they were diagnosed. Many patients were able to indicate one or more cancer symptoms $(n=17)$. Changes in the breast and changes in moles were known to the majority of the patients. A nagging cough or hoarseness, and difficulties swallowing were less well known. Lack of appetite and tiredness were often $(n=12)$ mentioned, even though these complaints are not specific warning signs of cancer. Some patients said they did not remember whether they had known about the warning signs before cancer was diagnosed or afterwards. However, knowledge can be regarded as a stimulating factor in inferring illness, since it is a prerequisite for interpreting symptoms.

(2) Reactions to the detection of unexplained symptoms. Several reactions were reported after patients had first noticed abnormalities. Three patients reported reacting immediately with panic, or were extremely alarmed or anxious, which resulted in consulting a physician within a few hours (Table 2.2). One of them had detected a lump in her breast, one had become aware of a tumor near the anus and one had detected rectal bleeding. Other patients reported that they had not been worried at the initial moment when they discovered an abnormality $(n=8)$. However, when symptoms did not disappear spontaneously, when symptoms got worse or when additional symptoms appeared, they realized that something could be wrong. For example bleeding was considered alarming in two cases of melanoma, while changes in the circumference, color or thickness of a mole were not. Two patients reported to have been ashamed of or embarrassed by the symptoms. One of these patients had hemorrhoids and one had a swollen testicle.

Thus, reactions to the detection of symptoms seemed to be associated with the nature of the symptom(s) and led to shortened or prolonged appraisal delay. Specific localized symptoms relating to cancer, like rectal bleeding, a lump in the breast or in the testicle, or a bleeding mole were often attended by emotional reactions like panic or embarrassment. By contrast, non-specific symptoms such as weight loss or diarrhea produced only a mild reaction. In turn, panic stimulated the patients to infer illness and therefore shortened appraisal delay. Shame or embarrassment and lack of worry about the nature of the symptom appeared to be impeding factors (Table 2.4). 
Table 2.4 Stimulating, impeding and ambiguous factors for transition to the next stage.

\begin{tabular}{|c|c|}
\hline Stimulating factors & Patient \\
\hline \multicolumn{2}{|l|}{ Appraisal delay } \\
\hline Knowledge & $\mathrm{n}=17(1,2,4-7,9-11,16-23)$ \\
\hline Reaction to symptoms is panic & $n=2(9,14)$ \\
\hline Interpretation of symptoms (association with cancer) & $\mathrm{n}=10(2,4,6-9,13,18,20,23)$ \\
\hline Consulting others & $\mathrm{n}=22$ (all, except 11) \\
\hline \multicolumn{2}{|l|}{ Illness delay } \\
\hline Fear, leading to action & $n=6(2,6,7,9,10,14)$ \\
\hline Relevance of consulting a physician & $n=17(1-5,10-12,14-20,22,23)$ \\
\hline Consulting others & $n=22$ (all, except 11) \\
\hline Impeding factors & Patient \\
\hline \multicolumn{2}{|l|}{ Appraisal delay } \\
\hline Reaction to symptoms is not being worried & $n=8(2,4,12,13,15,16,19,20)$ \\
\hline Reaction to symptoms is being ashamed/embarrassed & $n=2(3,16)$ \\
\hline Interpretation of symptoms (attribution to common ailments) & $\mathrm{n}=13(1,3,5,10,11,12,14-17,19,21,22)$ \\
\hline Interpretation of symptoms (unawareness of being at risk) & $\mathrm{n}=5(1,4,5,12,22)$ \\
\hline \multicolumn{2}{|l|}{ Illness delay } \\
\hline Fear, denied & $n=2(18,20)$ \\
\hline \multicolumn{2}{|l|}{ Behavioral delay } \\
\hline Reasons for postponing a visit to the physician (other events/ emotions) & $\mathrm{n}=3(7,8,11)$ \\
\hline Ambiguous factor & Patient \\
\hline \multicolumn{2}{|l|}{ IIIness delay } \\
\hline Knowing others who suffer from cancer & $n=19(1-11,13,15,17-20,22,23)$ \\
\hline \multicolumn{2}{|l|}{ Scheduling delay } \\
\hline Fear because of link between symptoms and cancer & $n=6(4,7-9,13,20)$ \\
\hline
\end{tabular}

(3) Interpretation of the symptom(s). Symptoms were either interpreted immediately as cancer symptoms or attributed to common ailments (misinterpretation). Some patients reported that when they had first detected an abnormality they had immediately associated it with cancer $(n=10)$. These symptoms were generally well-known warning signs of cancer. When symptoms were attributed to common ailments, like rectal bleeding to hemorrhoids or weight loss to a diet, patients did not link the symptoms directly to cancer or did not consider the symptoms to be serious $(n=13)$. Another factor associated with the interpretation of symptoms was unawareness of being at risk. Five male patients thought cancer was something that would never happen to them.

The findings suggest that a patient it is likely to infer illness when an obvious cancer symptom is detected. Delay due to misinterpretation of symptoms or thinking that 'cancer never happens to me' results in delayed inference of illness (Table 2.4). However, when additional symptoms appear, existing symptoms get worse, or symptoms do not 
disappear, reinterpretation of symptoms takes place, which finally results in inferring illness.

(4) Consulting important others about symptom(s). Another factor which can help persons to interpret the symptoms is discussing the symptoms or the discovery of the symptoms with several others. The majority of the patients said they had spoken to others about the unexplained symptom(s) $(n=22)$, although not always extensively. Some patients said they just had informed others about the complaint, but had not discussed its possible causes or consequences $(n=3)$. Some patients reported that they had talked to others in order to get advice $(n=5)$. One patient said she had only talked to her son about hemorrhoids, because she knew he had the same complaint, but discussing it with others had made her feel embarrassed. Communicating symptoms with others was a 'cue to action' which resulted in deciding to seek medical attention. Just two patients sought information in other sources, such as a medical encyclopedia or other literature.

Two patients had only spoken about their complaints after a few months. Reasons for not (or only superficially) discussing abnormalities with others were embarrassment about the nature of the symptoms or ignoring the symptom. However, once patients were willing to take action, they began to communicate with others, which was then a mediating factor in acting on the decision. Three of the patients who did not discuss their complaints waited three to ten months before seeking medical help. Therefore, discussing symptoms with others may be a stimulating factor in the move to the next stage, i.e., inferring illness (Table 2.4).

(5) Fear. Fear was mostly related to the nature of the symptoms. When complaints were very obvious cancer symptoms, patients had more often experienced fear than when symptoms were non-specific. Almost half of the patients had experienced the symptoms as life-threatening or very serious $(n=10)$, often because they knew their complaints could be related to cancer $(n=7)$. Fear also existed with regard to relatives. One patient reported worrying more about his wife and children than about the treatment or the seriousness of the disease.

Fear seemed to play an important role both in seeking help and in delay. Different patients coped with fear differently. Fear was either an incentive to action, meaning that they decided to consult a physician $(n=11)$, or denied, resulting in delay $(n=4)$. Four patients (one colon cancer patient and three patients with breast cancer) sought help immediately after discovering a patently obvious cancer symptom which frightened them. The delay time varied from a few hours to one or two days. In two cases (one patient with breast cancer, one patient with testicular cancer) fear was caused by uncertainty about their health, causing them to seek help after two weeks in order to 
take away the uncertainty and to make the health complaints explicit. Two patients reported to have experienced fear caused by the suspicion that the diagnosis would be cancer and had therefore tried to deny the symptoms. They both had melanoma and delayed actions by $2-3$ and $4-5$ months, respectively.

\section{IIIness delay}

(6) Relevance of consulting the physician. In many cases patients had expected the physician to resolve the complaint or to refer the patient to a medical specialist $(n=17)$. Four breast cancer patients did not expect the physician to be able to do anything. However, this was no reason for delay, since they knew they had to get a referral to a medical specialist from the physician. Two patients had decided to seek no medical help because they expected a physician could do nothing about their complaints. Thus illness delay was shortened when patients considered role of the physician as relevant (Table 2.4).

(7) Consulting important others about the decision to seek medical consultation. Almost all patients had discussed the decision to consult the physician with important others $(n=22)$. Seven patients reported that they had sought medical consultation because others in their environment, like spouses, other relatives, colleagues, were insisting on their seeking help.

Patients who had not initially discussed the decision with others or had ignored other people's advice seemed to have postponed the decision to consult a medical care provider for a longer period (ranging from 4-5 months to several years) than patients who had talked with others about deciding to seek help and had perhaps followed their advice.

(8) Knowing important others suffering from cancer. The majority of the patients knew at least one important other who suffered from cancer $(n=19)$. However, the consequences for their own help-seeking behavior varied from case to case. Some said the experience had influenced their own help seeking behavior $(n=4)$, while others said it had not $(n=15)$. Two patients had associated cancer with older people, and therefore being familiar with the disease had not resulted in prompt help seeking behavior.

\section{Behavioral delay}

(9) Reasons for postponing visits to the physician. Three breast cancer patients had decided to seek medical attention but still postponed acting on the decision. One patient had given priority to a holiday and delayed 3-4 months (Table 2.4). Two patients had realized they had to act promptly but had postponed the actual consultation because of emotional reactions. One of them had made an appointment with the physician for the next day, although she could have had it on the same day, but said she had needed time to 
come to terms with the idea. The other patient was quite frightened to consult the physician, but her husband supported her. Delay due to emotional reactions was shorter (1 day to 1 month) than delay due to giving priorities to other events (3-4 months).

\section{Scheduling delay}

(10) Fear during first medical consultation. Some patients said they had had feelings of fear when they first went to the physician $(n=9)$. In most cases the principal reason for their feelings was the link between the symptoms and cancer $(n=6)$, and their fear of being told they had cancer $(n=8)$. In addition, two patients reported that fear during the first medical consultation had been caused by being afraid of making fools of themselves in the doctor's opinion. Fear during the first medical consultation had sometimes resulted in delay; for instance, one patient explicitly said that her fear had almost made her cancel her appointment. Half of the patients who reported not to have had feelings of fear did relate their symptoms to cancer $(n=14)$. The most important reason for not being anxious was their expectation that the physician could be of help.

\section{CONCLUSIONS}

The aim of the present study was to identify relevant factors influencing the transition through the stages in the process of detecting possible cancer symptoms and seeking medical consultation for it. Twenty-three cancer patients were interviewed in depth. The relevance of using qualitative interviews to deal with this topic is that studying the process of detecting cancer requires individually based and contextualized knowledge. However, we are aware of the limitations of the procedure we used. One of these limitations could be that selection bias might have occurred because patients were interviewed retrospectively. This meant that only patients were involved whose disease had taken a relatively good course. It is possible therefore, that we interviewed mostly patients who had acted more adequately on changes in their body and not those who delayed longer and whose disease may have taken a more serious course. However, the periods of delay in our patient population ranged from a few hours to several years, which is a rather comprehensive range. In future studies it would be interesting to include patients who detected cancer symptoms, but never followed them up to find out whether the same psychological processes were prominent in these cases. This group can be reached for instance by including patients who were diagnosed by a screening program. 
Another obvious limitation of the data presented here is that they consisted of retrospective reports about the pre-diagnostic time. Recall of the events and considerations in deciding to seek medical consultation may have differed. Some patients admitted they did not remember all aspects of the pre-diagnostic period, since it was especially the time after the diagnosis that had influenced their lives. An emotional crisis caused by being diagnosed with cancer may also have influenced the accuracy of recall. In addition, patients might have given their own interpretation of their story, because they may have had feelings of regret about the delay, or they may have felt ashamed about not having had enough knowledge at the time to interpret the complaints as cancer symptoms. However, the only way to cope with this limitation would be a prospective study, which for practical reasons would be impossible to conduct.

The 'model of patient delay' (Andersen et al., 1995) describes separate stages of patient delay which are passed through successively, each move being attended by a balanced decision. Andersen and colleagues found that these delay intervals did not correlate, indicating that they are independent (Andersen et al., 1995). However, our findings suggest that in practice the stages do sometimes overlap. For example, detecting a symptom and inferring illness can be compressed into one stage if symptoms are known to be warning signs of cancer. Appraisal delay will then not occur. For instance, all women who detected a lump in the breast immediately associated this symptom with cancer. Thus, there was not really a process of deciding that they were ill, but more a critical state. Furthermore, a variety of reasons may be significant in deciding to seek medical help, such as the interpretation of the symptom, knowledge, and discussing the symptom with others. Deciding to seek medical help and acting on the decision cannot always be separated. When the decision to consult a physician was based on the nature of the symptom, for instance an acute symptom, the decision to seek help promptly seemed to be an affective reaction on impulse. The decision was based on emotions which led to an immediate reaction. In contrast when symptoms appeared gradually the decision to consult a physician was a long-considered decision rather than an immediate reaction based on panic, which resulted in delay. In contrast to the 'model of total patient delay', these findings imply that stages are not always independent.

Furthermore, Andersen's model implies that all individuals are delayers (Andersen et al., 1995). However, the results of the present study suggest that there is not always a real delay between detecting cancer symptoms and seeking medical consultation since six patients reacted within 3 days by consulting a medical professional. Therefore, we would prefer to speak of stages in the process of detection and seeking medical help, rather than of stages of delay. 
Overall, it appeared to be impossible to assess the duration of each stage in the process of detecting cancer symptoms and consulting a physician. The various stages of the model form a useful framework to structure the process, but they do not exist as such in the minds of the patients. The time required to pass through the entire process differed from case to case. The results of the interviews suggest that the pre-diagnostic time is influenced by a number of stimulating or impeding factors in the process of detection of cancer. Our findings suggest that the impact of the first symptom detected, in particular on symptom appraisal, is highly relevant. If the first symptom detected is not a specific cancer signal, this seems to increase appraisal delay. As soon as the non-specific symptom changed into a specific cancer symptom, most patients inferred illness. These findings have also been reported by others (Cassileth et al., 1988; MacArthur \& Smith, 1981; Rampen \& Rumke, 1984). Furthermore, well-known warning signs of cancer were immediately associated with being ill and therefore often led to immediate action. By contrast, vague symptoms attributed to common illnesses led to prolongation of the decision taking process in appraisal delay and illness delay. Other studies have also indicated that delay is associated with the attribution of vague symptoms to common ailments (Cochran et al., 1986; Mor et al., 1990). Although we did not identify the duration of each stage of delay, we could say that the factors influencing appraisal delay have a great impact on the total patient delay, since much of it relates to the specificity of the symptoms and the interpretation of the symptom detected. This suggestion is in line with findings by Andersen et al. (1995), who reported that about $60 \%$ of the total delay was due to appraisal delay.

The results of the interviews showed that two different types of coping strategy were used by the patients to deal with fear. Fear could lead to either help-seeking behavior or to delay, depending on the cause of fear and the way people coped with it. Fear caused by the illness itself, for instance by the detection of specific localized cancer symptoms, led to action. Presumably, the individual is convinced that cancer cannot be cured spontaneously and necessitates treatment. This kind of coping with fear can be explained by Leventhal's danger control theory (Leventhal, 1970), which states that being aware of a danger (a cancer symptom) and the existence of an effective remedy (consulting a physician) will lead to acceptance of the remedy. On the other hand, our findings also show that patients delayed actions because of fear, for instance fear of being told that the diagnosis is cancer. One reaction could be that symptoms are ignored. This mechanism for coping with fear, avoidance, is the result of a patient's focus on emotions experienced instead of on the danger perceived. This process has been described by Leventhal as fear control (Leventhal, 1970), which is a short term effort to minimize unpleasant affects. It 
should be noted that there is huge variety in the nature of fear and that its effect on delay also varies. Obviously, the influence of fear on help-seeking behavior is still ambiguous and needs further research (cf. Facione, 1993).

According to Muris and colleagues (Muris, Van Zuuren, De Jong, De Beurs \& Hanewald, 1994) a characteristic of a monitoring coping style is seeking information by asking others about the threatening situation or by reading books or magazines. In our study all patients consulted others about their symptoms or about the decision to seek medical consultation, but most patients did not seek information in other sources. Moreover, in our study it is impossible to identify people with a monitoring or a blunting coping style. Muris et al. (1994) concluded that during preparation of medical procedures, 'monitors' are more helped by a high level of information, while 'blunters' are more availed by less information. It should be interesting to incorporate the monitoringblunting concepts in future research to assess how much information a person should get to encourage early detection of cancer and seeking medical help for cancer symptoms.

In the design of the present study and of the interview protocols we decided to distinguish between active and passive detection of cancer. However, the results show that although some symptoms are supposed to be detected by conscious actions, like a lump or swelling by BSE or TSE, these symptoms were in fact mostly detected by chance. For instance, none of the respondents with testicular cancer knew they were supposed to do monthly TSE. This is consistent with other findings (Thornhill, 1987; Wardle et al., 1994). Furthermore, breast cancer was detected by chance in four cases. Although most of the interviewed breast cancer patients said they practiced BSE, they indicated that they did not always follow the instructions consistently (cf. Pinto \& Fuqua, 1991).

\section{PRACTICAL IMPLICATIONS}

Based on the retrospective interviews with cancer patients about detection of cancer, some recommendations can be made for future education about early detection of cancer and seeking medical help. These recommendations concern the contents as well as the dissemination of the educational materials.

One of the stimulating factors in the process of symptom detection and consulting a physician is knowledge. The results of the interviews showed that not all patients were familiar with cancer symptoms and that symptoms were not always interpreted correctly. In addition, relations between different symptoms were not recognized. Increased 
knowledge about the early detection of cancer and correct interpretation of symptoms may lead to a shorter process of inferring illness and deciding to seek medical attention. Therefore, more information should be given to the general public about what they can do to detect cancer in an early stage and how to react upon the detection of cancer symptoms. Education must also emphasize that the combination of certain symptoms may indicate the possibility of cancer. Although increasing knowledge of symptoms is one element in reducing delay (in particular appraisal delay), emotional reasons for delay, such as fear, should be taken into account in future education as well. Positive information about treatment and survival chances and anticipation of feelings of fear might reduce fear and stimulate people to seek help. Additionally, stimulating people to discuss the detection of symptoms and the decision to seek medical help with others may also lead to less delay.

As regards the dissemination of educational materials, it was found that some patients seldom visited the physician and were unaware of the risk of getting cancer. This was especially true for young, healthy people. As a result, this section of the general public is not exposed to health education which is disseminated via the waiting rooms at primary health care services. Health education materials on early detection of cancer for the general public should in future be disseminated via other, more general and non-medical media in order to reach the young population as well. Different channels tailored to different sections of the population should be taken into account. 


\section{ChAPTER 3}

\section{HELP-SEEKING BEHAVIOR FOR CANCER SYMPTOMS: PERCEPTIONS OF PATIENTS AND PHYSICIANS}

\section{ABSTRACT}

The aim of this study is to increase our understanding of the relationship between knowledge and interpretation of symptoms, fear and trust on the one hand, and the decision to consult a physician for cancer symptoms on the other. Qualitative interviews were used to evaluate the various factors. Twenty-three patients and ten physicians were interviewed. A number of factors were found to play different roles for different patients groups, i.e., patients that consult their doctor prematurely, at the right time, or those that delay. A lot of the findings can be tested using various concepts of social psychological theories. Further research should provide an improved understanding of the way these models can be applied to help-seeking behavior. In terms of implications for health education, we conclude that each patient group has different needs and requires different information.

\section{Accepted for publication as:}

De Nooijer, J., Lechner, L. \& De Vries (2001). Help-seeking behaviour for cancer symptoms: Perceptions of patients and general practitioners. Psycho-Oncology 


\section{INTRODUCTION}

Early cancer detection can improve survival rates and chances of a more successful treatment (Bailar \& Gornik, 1997; Ruwaard \& Kramers, 1997; American Cancer Society, 1998; Tabar et al., 1985). Therefore, unnecessary delays in cancer diagnosis should be prevented as much as possible. Dutch health education regarding the early detection of cancer focuses on highlighting eight warning signals that a person should pay attention to and which, if detected, should induce that person to see a physician. Depending on the symptom detected, a physician should be consulted at once (in the case of unusual bleeding, a lump in the breast or elsewhere, obvious changes in a wart or mole), or within a few weeks (in the case of a nagging cough or hoarseness, a sore that does not heal, indigestion or difficulty swallowing, changes in bowel or bladder habits and unusual weight loss) (American Cancer Society, 1998; Dutch Cancer Society, 1996). In the Netherlands, it is normal procedure to go to the family physician first for any medical advice. The family physician is also the link between the patient and other medical professionals, such as specialists.

Not all individuals respond in the same way to suspicious symptoms (De Nooijer, Lechner \& De Vries, 2001). Some people frequently visit their physicians with minor complaints, while others avoid visiting a physician even with obvious cancer symptoms. Individuals might be divided into three groups with respect to consultation behavior. The first group may be defined as the 'worried well' and consists of persons who seek medical help for cancer after experiencing non-cancer symptoms, i.e., the needless use of health services. This includes, for instance, someone who visits a physician after two days of coughing. These persons tend to present abundant symptoms, but seldom suffer from major illnesses. A lot of people would ignore these types of symptoms, or would not act upon them (Robinson \& Granfield, 1986). The second group is composed of people that detect changes in their body and act appropriately; they are able, for instance, to notice changes in the skin. The people in this group do not visit a physician too early or too late, but at the right time. Even though the diagnosis may not be cancer, they still showed an appropriate response to the occurrence of the symptom. These patients may be called the 'appropriate actors'. The third group, the 'delayers', consists of people who have the opportunity to notice and to respond to cancer symptoms but who delay seeking medical help for various reasons, even though their complaints require medical attention. These persons postpone seeing a physician for a number of reasons, such as ideas or beliefs about the treatment of illnesses, social factors and emotional factors (Beukema-Siebenga, 1997; Byles et al., 1992; Smith \& Anderson, 1985). 
By delaying to seek medical help for cancer symptoms, these people may unnecessarily endanger their health.

Andersen and colleagues have developed a model of 'total patient delay' indicating various stages of perceiving, interpreting and responding to unexplained symptoms (Andersen et al., 1995). One of the impeding factors in this process of detecting cancer symptoms and inferring illness is the attribution of possible cancer symptoms to common diseases (Cochran et al., 1986; De Nooijer et al., 2001; Mor et al., 1990). For example, changes in bowel habits could be caused by certain food ingredients, or abnormal vaginal bleeding might be related to menopause. Although these symptoms are often harmless, they might be caused by cancer. In any case, such health problems need medical attention.

Several factors have been found to influence the decision to consult a physician with symptoms of bad health, including knowledge, the interpretation of symptoms, fear and trust in medical treatment. These factors were therefore the main focus of the present study. Knowledge, the first factor, is a necessary prerequisite to interpret symptoms as cancer signals or as 'serious' symptoms requiring medical attention. It can be hypothesized that if people have insufficient or incorrect knowledge, it is impossible to interpret suspicious symptoms correctly. Thus, if people regard the symptoms as self-treatable, delay is more likely to occur (Beukema-Siebenga, 1997; Byles et al., 1992; Cochran et al., 1986; Van de Kar et al., 1992). The second factor often mentioned is fear, although its influence on help-seeking behavior is still ambiguous. Some studies have suggested that fear is associated with immediate help-seeking behavior (Hackett et al., 1973; Lauver \& Chang, 1991), while other studies have found fear to be related to delay (BeukemaSiebenga, 1997; Gascoigne et al., 1999; Mor et al., 1990; Smith \& Anderson, 1985). The third factor associated with consultation behavior is trust in medical treatment. It was found that delays are more common among people who do not believe that the physicians' action will be beneficial to them (Beukema-Siebenga, 1997; Egan, 1987; Ingham \& Miller, 1983; Van de Kar et al., 1992).

Clearly, laymen and professionals differ in their ideas about interpreting and responding appropriately to symptoms. For instance, it is difficult or impossible for a lay-person to assess whether a particular symptom is indeed related to cancer or just a harmless symptom that has nothing to do with cancer. Moreover, physicians may wonder why people visit them with one complaint, but not with another. Qualitative data is needed to help identify the gaps in our knowledge of the ideas of patients and physicians concerning the process of detecting cancer symptoms and seeking medical help. 
So far, little is known about the relationship between knowledge, fear and trust in medical treatment in the decision to seek medical attention for cancer symptoms. Therefore, in order to obtain a better understanding of patients' help-seeking behavior for cancer symptoms, the purpose of the present study was to gain insight into the relationship between knowledge, fear and trust in medical treatment on the one hand, and the decision to consult a physician when facing possible cancer symptoms on the other. In the present study, patients and physicians were interviewed retrospectively to gather information about the three categories of individuals mentioned above. The patients supplied information about people acting appropriately or delaying, while the physicians also provided information about the 'worried well'.

\section{METHODS}

\section{Respondents and procedures}

The influence of the various factors from the perspectives of patients and physicians was assessed using semi-structured, in-depth interviews among 23 cancer patients and 10 physicians. Semi-structured interviews were used to enable interviewees to freely express themselves and enable the researcher to find answers to specific questions. The method used could be described as a quantitative method to embellish a primarily qualitative study (Steckler, McLeroy, Goodman, Bird \& McCormick, 1992). We chose this method because of the lack of understanding of the relationship between the different aspects of seeking medical help for cancer symptoms from the perspectives of both the patient and the physician, and hoped that the results will enable us to gain insight into these different aspects.

Patients were recruited by the contact persons of regional patient groups for four different forms of cancer. Each contact recruited six patients that were willing to participate. One criterion for selection was that the diagnosis had been established recently with the purpose of optimal recall of the pre-diagnostic period. Patients willing to participate in the study were approached by the researcher. The study included six patients with melanoma, six patients with colon cancer, six with breast cancer, and five with testicular cancer (Table 3.1). Colon cancer was chosen because it can be detected passively by paying attention to possible symptoms; the three other types of cancer can be detected actively by performing a conscious action in the early stages of the disease (breast, testicular and skin cancer). One criterion for including breast cancer patients was 
that the symptoms had to be detected by the patients themselves rather than in a screening program. No other criteria were used.

In addition, a random sample of 40 physicians was assembled from six Dutch cities. The physicians were approached by letter and telephoned after one week. The first ten physicians who indicated that they were willing to participate were included in the study. At that time, a total of seventeen physicians had been contacted. Of the seven physicians that refused to participate, four were not interested, two were not available during the period of data collection, and one had retired.

Prior to the start of the interviews, the patients and physicians were informed about the aim of the interview and were asked whether they still wanted to participate and whether they objected to the interview being tape-recorded.

\section{The interviews}

We asked the patients about their experiences during the time they became aware of possible cancer symptoms and the moment they first sought medical help. The patient interviews were based on the model of patient delay (Andersen et al., 1995). With regard to appraisal delay, we asked patients to list the physical disorders they had experienced in the pre-diagnostic period. Patients with breast and testicular cancer were asked if and how they had performed self-examination. Knowledge of the warning signs of cancer was assessed by asking which cancer-related symptoms they were able to recall. The interview also contained questions about the interpretation of the symptoms, the person(s) they had discussed the symptoms with, and whether they had experienced fear. With regard to illness delay, patients were asked what particular reason they had to seek medical help for one complaint but not for another, and whether the decision had been influenced by important other people in their immediate environment or by fear. Behavioral delay was assessed by means of questions about the reasons to postpone seeing a physician. The last stage, scheduling delay, was evaluated by means of questions about the first medical advice. Each interview lasted about 35 to 50 minutes.

The interviews with the physicians took about 20 minutes and focused on their experiences with patients seeking medical help as a result of the discovery of what they thought were cancer symptoms. We asked the physicians what, in their opinion, were the reasons for each group of patients with cancer symptoms (the worried well, the appropriate actors, and the delayers) to visit a physician. 


\section{Data analysis}

Interviews were recorded on tape and transcribed. The researchers read each transcript several times to familiarize themselves thoroughly with the data. Two independent researchers studied and double-checked the interpretation of the data in order to ensure objectivity of the results. Moreover, data was obtained from two different sources in order to obtain a broad insight into the whole spectrum of help-seeking behavior. On the basis of the patient interviews, patients were categorized as 'delayers' or 'appropriate actors', using the guidelines issued by Cancer Societies about the appropriate time intervals between the initial detection of a cancer symptom and the first medical consultation (American Cancer Society, 1998; Dutch Cancer Society, 1996). Acting appropriately was defined as consulting a physician within a week for obvious changes in warts or moles, thickening or lumps in the breast or elsewhere and unusual bleeding, and consulting within four weeks for other symptoms. Patients exceeding these periods were classified as 'delayers'.

For both interviews, the interview route served as the framework for data analysis. A content analysis was based on key concepts of the questionnaire. Each researcher identified the most important aspects of each interview. These aspects were compared and consensus was reached about the various aspects. The focus of the present paper is to elaborate on the relationship between knowledge and interpretation of symptoms, fear and trust in medical treatment. These factors appeared to be most important in the appraisal, illness and behavioral delay stages of the model of total patient delay (De Nooijer et al., 2001).

\section{RESULTS}

Table 3.1 presents the characteristics of the patients, the time elapsed between symptom detection and seeking medical help, and the symptom that induced the patient to consult the physician. The influence of the various factors on consultation behavior from the patients' perspective is shown in Table 3.2, while Table 3.3 presents the perspective of the physicians. Based on the self-reported time between the moment patients detected a cancer symptom and the first medical consultation, fourteen patients had delayed, while eight had acted appropriately on cancer symptoms (Tables 3.1 and 3.2). Four patients (nrs. 4, 5, 6, 18) went to the physician because others people insisted they did, all of them delayed. One patient (nr. 19) had consulted a physician with a non-cancer symptom which finally led to a diagnosis of cancer. This patient was not included in the analyses. 
Table 3.1 Characteristics of the patients.

\begin{tabular}{|c|c|c|c|}
\hline Type of cancer & Patient (age) & Time interval & Symptom $^{1}$ \\
\hline \multirow[t]{6}{*}{ Melanoma } & 1. Female, 52 & $4-5$ months & itchy and bleeding moles \\
\hline & 2. Female, 38 & 3 weeks & bleeding mole \\
\hline & 3. Female, 37 & $2-3$ months & bleeding mole \\
\hline & 4. Female, 38 & 2 years & $\cdot$ \\
\hline & 5. Male, 37 & several years & $\cdot$ \\
\hline & 6. Female, 48 & 2 years & $\cdot$ \\
\hline \multirow[t]{6}{*}{ Colon cancer } & 7. Male, 61 & 10 months & rectal bleeding \\
\hline & 8. Male, 39 & a few hours & rectal bleeding \\
\hline & 9. Male, 39 & a few hours & swelling near the anus \\
\hline & 10. Female, 41 & 4 months & rectal bleeding \\
\hline & 11. Female, 75 & 3 days & haemorrhoids \\
\hline & 12. Male, 52 & 3 months & change in bowel habits \\
\hline \multirow[t]{6}{*}{ Breast cancer } & 13. Female, 41 & $1-2$ days & inverted nipple, two lumps \\
\hline & 14. Female, 45 & 1 day & inverted nipple, lump \\
\hline & 15. Female, 45 & 1 month & pain in breast, changes in breast \\
\hline & 16. Female, 35 & 9 hours & lump \\
\hline & 17. Female, 49 & 2 weeks & pain in breast when lying down \\
\hline & 18. Female, 51 & 3-4 months & $\cdot$ \\
\hline \multirow[t]{5}{*}{ Testicular cancer } & 19. Male, 45 & 2 weeks & losing small amounts of urine \\
\hline & 20. Male, 33 & 2 weeks & diarthoea \\
\hline & 21. Male, 32 & 5-6 months & pain in chest \\
\hline & 22. Male, 24 & $3-4$ days & pain and lump in testicle \\
\hline & 23. Male, 32 & 1 month & back pain \\
\hline
\end{tabular}

Symptom that induced the patient to consult the physician.

\section{Knowledge and symptom interpretation}

Patients

The interviews with both patients and physicians show that knowledge and interpretation of symptoms seemed to represent an important factor influencing the process of detecting symptoms and consulting a physician. If a person is expected to interpret certain symptoms as cancer signals, this person has to know what these warning signals are. Sixteen patients were able to mention one or more cancer warning signs. Some 
symptoms, such as lack of appetite and tiredness, were mentioned by some patients as cancer signs $(\mathrm{n}=12)$, while in fact these are not among the eight established cancer signs.

Sufficient knowledge is a prerequisite for a correct interpretation of symptoms. Eleven patients reported that as soon as they had detected an abnormality they had immediately associated it with cancer, and six had taken immediate action (Table 3.2). All patients who had acted adequately had obvious cancer symptoms, such as a lump in the breast, which they had recognized correctly $(n=6)$. Four patients who had delayed had experienced vague symptoms, such as changes in bowel habits, before they had noticed more specific symptoms. Eleven patients reported that they did not directly link the symptoms to cancer or did not consider the symptoms as being serious, and nine of them had postponed consultation: "I just thought I had an upset stomach. It wasn't that I had this all the time, only now and then. After a while, when it didn't get any better, I thought I should see a doctor. But I never thought of cancer. "(Patient nr. 12).

Two other patients had acted appropriately since the moment they had noticed the complaints. Unawareness of being at risk has also led to delays. Five patients reported that they had thought cancer was something that would never happen to them, because they had considered cancer to be a disease that happened only to older people or had not perceived themselves to be at risk. The patient interviews showed that, in general, knowledge and a correct interpretation of symptoms are factors influencing the inference of illness and therefore the consultation behavior.

Table 3.2 Patients' perspectives of factors relating to acting appropriately or delaying.

\begin{tabular}{|c|c|c|}
\hline Factor & $\begin{array}{l}\text { Appropriate actors } \\
n=8\end{array}$ & $\begin{array}{c}\text { Delayers } \\
n=14\end{array}$ \\
\hline \multicolumn{3}{|l|}{ Knowledge \& interpretation of symptoms } \\
\hline - Associating symptom with cancer & 6 & 5 \\
\hline - Not associating symptom with cancer or serious disease & 2 & 9 \\
\hline - Unawareness of being at risk & & 5 \\
\hline \multicolumn{3}{|l|}{ Fear } \\
\hline - Associating symptom with cancer but avoiding confirmation of expectations & 5 & 3 \\
\hline - Coping with fear: - active coping & 6 & \\
\hline - avoidance & & 2 \\
\hline \multicolumn{3}{|l|}{ Trust in medical consultation } \\
\hline $\begin{array}{l}\text { - Expecting a physician to solve the problem, but not seeing the need to consult } \\
\text { a physician with symptoms not associated with cancer }\end{array}$ & & 9 \\
\hline - Expecting a physician to solve the problem & 2 & \\
\hline - Expecting to be referred to a specialist & 3 & \\
\hline
\end{tabular}




\section{Physicians}

The physicians mentioned lack of knowledge not only as a reason for delay $(n=4)$, but also as a reason for seeking medical help by the worried well, i.e., prematurely $(n=3)$ (Table 3.3). According to these physicians, the worried well are not well-informed, do not participate in thinking about solutions, and are insecure about their health. One physician said: "These patients know a little about cancer, but not enough. They are worried because they heard some stories from their neighbors, or read something in a magazine. And then they come with complaints I think can be easily solve by oneself. "In their view, lack of information can cause misinterpretation and fear. Patients who delay as a result of a lack of information are probably unaware of cancer signals or misinterpret symptoms, in particular the non-specific complaints. Additionally, they may have misconceptions about the consequences of the disease, for instance "once you have cancer, you will certainly die" and will therefore delay. According to four physicians, too much information about cancer symptoms could result in overreacting. Two physicians referred to the example of the skin cancer prevention campaign, which resulted in a rise in the number of people consulting their doctor with non-malignant changes in moles or warts. However, both of them said that it is difficult for laymen to assess whether some symptoms are cancer signals, in particular the non-specific symptoms, and that although people are aware of cancer symptoms, medical examination is often required to arrive at a diagnosis. Two physicians added that they would rather see a patient too often than too late. According to three physicians, patients acting appropriately base their interpretation of the complaint on past experience. In their opinion, patients who experienced the same symptoms in the past more often view such symptoms as more serious, while recurrence of symptoms also leads patients to conclude that medical attention is needed.

Table 3.3 Perspectives of physicians on factors relating to not acting appropriately by the worried well and delayers.

\begin{tabular}{lcc}
\hline \hline Factor & Worried well & Delayers \\
\hline Knowledge \& interpretation of symptoms & & 4 \\
- Lack of knowledge & 3 & 10 \\
Fear & 9 & \\
- Aroused by others & 3 & 4 \\
- Anxious by nature & 3 & 4 \\
- Suspicions being confirmed & \\
- Avoidance & \\
Trust in medical consultation & \\
- Lack of trust & \\
\hline Note. The numbers do not comprise the total numbers of subjects, but only those subjects that mentioned anything relevant to the \\
issue.
\end{tabular}




\section{Fear}

Patients

Fear is another important factor that influences consultation behavior. It was found to be related to various aspects, including unpleasant treatment, the seriousness of the disease, dying or leaving relatives behind. The awareness that a symptom could be related to cancer was mentioned as a reason for anxiousness by eight patients: "I was extremely scared. But at the same time, you need to take action to survive. You need to know for sure whether it's cancer or not. And to live with this uncertainty is also destructive." (Patient nr. 15). Three of these patients delayed because they did not want the physician to confirm their expectations of having cancer. A number of patients did not associate their symptoms with cancer and did not report feelings of fear $(n=9)$. All of these patients delayed. Response to fear led to either delay $(n=2)$ or prompt action $(n=6)$. Patients who acted promptly reported that they had consulted the physician because they expected the physician to be able to take away the fear or to refer them to a specialist. The other patients did not comment on the way they had coped with fear.

\section{Physicians}

We also asked the physicians about the role of fear in consultation behavior. Fear was mentioned as the most important factor for both consulting and delaying; nine physicians mentioned fear as a possible reason for the worried well to seek medical advice, and all physicians mentioned fear as a possible reason for delayers (Table 3.3). According to six physicians, the worried well may also consult a doctor because of fear triggered by external factors, such as television programs or people in the immediate social environment who have been diagnosed with cancer. Three physicians said that people who frequently visit their doctors are often anxious by nature. According to four physicians, patients with cancer signals who delay seeing a doctor are often afraid of having their suspicions confirmed or do not want to hear bad news: "When patients notice that they lose weight, and that they also have other complaints, they think they have cancer. They fear that I will confirm their suspicions. " Some physicians mentioned 'hiding one's head in the sand' as the way potential patients respond to their fear $(n=4)$. Two of these physicians said that when patients avoid responding to cancer symptoms, they apparently have enough knowledge to interpret the symptoms correctly. Potential cancer patients who act appropriately were characterized by nine physicians as down-to-earth and knowing how to act on unexplained symptoms. 


\section{Trust in medical treatment}

\section{Patients}

A third factor influencing consultation behavior is trust in the physician, or the expected relevance of consulting a physician when facing cancer signals. Most patients had expected their doctor to solve their complaints or to be able to refer them to a medical specialist $(n=16)$ : Twelve of these patients had delayed. Nine patients had not associated their complaints with cancer, but did expect the physician to be able to help. These patients did not think it was necessary to consult their doctor with common symptoms and therefore delayed (Table 3.2). Two patients had not attributed their symptoms to cancer, but had seen the physician because the complaints were bothering them. They had expected the physician to be able to solve their complaints quickly, and thus had not delayed. "They were just two moles. I thought the doctor would remove them, nothing to worry about." (Patient nr. 2). Some patients had not expected the physician to be able to solve the complaint, but had expected to be referred to a medical specialist, since they had related their symptoms to cancer $(n=3)$. These patients had not delayed. One patient with breast cancer, who consulted her physician within two days, explained: "I thought it could be cancer, or a tumor. I realized it didn't make sense to keep going with it, it wouldn't disappear by itself, so I knew I had to see the doctor." (Patient nr. 14).

\section{Physicians}

According to some physicians, a good relationship between patients and their physician is a prerequisite for communicating complaints $(n=4)$. With regard to people who do not act appropriately, a lack of trust in the physician was mentioned by four physicians as a reason for delay (Table 3.3). They had noticed that these patients might go straight to the medical specialist. One physician said she did not know whether patients who delay had faith in the physician, because she did not know what happened to the patients who had not consulted her.

\section{DISCUSSION}

The main goal of this study was to improve our understanding of the relationship between three important factors related to help-seeking behavior, i.e., knowledge, correct interpretation of symptoms, fear, and trust in medical treatment. For this purpose, we interviewed both patients and physicians. The interviews with patients provided information about those who acted appropriately and those who delayed their 
visit to the physician, but not about those who consult the physician for non-cancer symptoms (and who are thus not diagnosed with cancer), i.e., the worried well. Physicians $^{*}$ views were based on retrospective experience with patients who had acted appropriately or otherwise, but the interviews with physicians have not produced information on what happens before patients with cancer symptoms first visit the physician. The interviews with the patients and physicians enabled us to gain information about the entire patient population and their responses to symptoms. A large number of studies have focused on patient delay and on identifying what diseases cause patients to consult a physician (Byles et al., 1992; Cochran et al., 1986; Mor et al., 1990; Smith \& Anderson, 1985). Yet only few studies have focused on the entire spectrum of help-seeking behavior. Initially, we divided the patients into three groups on the basis of their consultation behavior in order to obtain insight into how different patient groups pass through the process of patient delay as described by Andersen and colleagues (1995). Our results suggest, however, that patients who delayed seeing a physician could be divided into two groups: those who delayed because of a lack of knowledge (or misinterpretation of symptoms) and those who delayed because of fear. Hence, on the basis of these results we can categorize patients into four groups: 1) patients that consult a physician for cancer with non-cancer symptoms (the worried well group); 2) patients that act appropriately; 3) patients that delay because of fear; and 4) patients that delay because of a lack of knowledge. Knowledge and correct interpretation of symptoms, fear and trust in medical treatment were found to play different roles in each group (Table 3.4), as will be explained below. It should be noted that this conclusion is based on our interpretation of the results, and requires further investigation.

Table 3.4 The role of knowledge, fear and trust in medical treatment among different patients.

\begin{tabular}{lccc}
\hline \hline Patients & Knowledge \& interpretation & Fear & Trust \\
\hline Worried well & - & - & + \\
Appropriate actors & + & + & + \\
Delayers because of fear & + & + & - \\
Delayers because of lack of knowledge & - & 0 & 0 \\
\hline
\end{tabular}

Note. +: correct; $-:$ incorrect; 0 :neutral

The results indicate that the first group of patients, the worried well group, had insufficient knowledge or misinterpreted their complaints. The physicians said that certain aspects of cancer, such as fear of knowing the cause of the symptoms, represented the most important reason for this group of patients to consult their doctor prematurely. 
However, their fear is not based on accurate knowledge and interpretation of symptoms. These patients had a certain level of trust in medical consultation, and hoped that the physician was able to do something to relieve the symptoms. This finding is supported by those of other researchers (Egan, 1987; Ingham \& Miller, 1983; Van de Kar et al., 1992). Furthermore, a variety of external factors, for instance a friend who had previously discovered a lump in her breast, might prompt a person to consult a physician. This 'cue to action', which has been described by Becker \& Rosenstock (1984) as a reminder of a potential health problem, increasing the likelihood of perceiving a threat and taking action, could be related to fear. This fear might be situationally determined, because it would not have been triggered if the friend had not detected a lump in her breast. This type of fear could be compared to Spielberger's (1979) state anxiety, which refers to an individual's temporary emotional condition, marked by perceived feelings of tension. A limitation of our study was that we did not interview the worried well group. In further research it would be interesting to study patients who detected possible cancer symptoms, but were not diagnosed with cancer, and whether this group differed from other patient groups in the process of detecting symptoms and help-seeking behavior.

The second group of patients, those responding appropriately to possible cancer signals, possessed sufficient knowledge of cancer signals to interpret changes in the body correctly. These patients apparently were alarmed when they interpreted complaints as being different from or more severe than previous complaints. Their fear, caused by the detection of a symptom and their interpretation as a serious or potential cancer signal, was warranted. They coped with their fear by seeking medical advice rather than ignoring the complaints. A possible explanation for prompt action might be that the patient is aware that cancer does not cure spontaneously and requires further treatment. Hence, consulting a physician is relevant, either to reduce fear or to reduce the danger by, for instance, being referred to a medical specialist.

Patients who delayed because of fear, the third group, seemed to have adequate knowledge of cancer signals to interpret body changes correctly. These patients nevertheless decided not to seek immediate medical advice. A plausible reason for this delay might be that these patients are fearful to the extent that it blocks further information processing (Janis \& Mann, 1977; Petty \& Cacioppo, 1986) and/or that they think cancer is incurable. Consequently, instead of acting appropriately, they seem to ignore the symptoms. These patients may not be convinced that a physician might be able to help and are therefore likely to delay. This kind of fear may be more closely related to trait anxiety, which is the inherent tendency of an individual to be anxious (Spielberger, 1979). 
Patients who delayed due to a lack of knowledge were unable to interpret their complaints as cancer signals. Therefore, they did not regard their symptoms as a serious health threat and did not think they required medical attention. Even though they may have feared they had cancer and trusted the physician's abilities, this did not lead to the right response to the detection of a cancer symptom.

In future studies, the precise relationships between knowledge and interpretation of symptoms, fear and trust in medical consultation can be tested using various concepts of social psychological theories. Based on Leventhal's concepts (1970) of fear and danger control, we assume that people cope with fear as a result of the discovery of an unexplained cancer symptom by either reducing the danger or reducing the fear. Thus, when people become aware of a danger (e.g., an unexplained cancer symptom) and know that there is an effective remedy (i.e., consulting a physician) people accept the remedy and consult the physician; this is called danger control. We believe that people who use this coping strategy will either act appropriately or consult the physician for cancer with non-cancer symptoms. By contrast, fear control, a short-term effort to minimize unpleasant stimuli, might occur when patients focus on the emotions they are experiencing (i.e., fear of having their expectations confirmed) rather than on the perceived danger, by ignoring symptoms and therefore endangering health. We assume that these people with cancer symptoms delay consulting a physician. Thus, patients who delay as a result of fear seem to use fear control as a coping strategy, while others seem to use danger control. Moreover, fear might be intensified or reduced by the type of symptom. For instance, unusual bleeding was found to be alarming, while changes in bowel habits were not (De Nooijer et al., 2001). This seems to suggest that help-seeking behavior is also related to other factors and that we are not fixed in our help-seeking behaviors.

The balance between the perceived benefits of being treated (i.e., trust in consulting a physician in order to be reassured about one's health and to reduce fear) and the perceived barriers (i.e., fear that cancer expectations will be confirmed) in the Health Belief Model (Becker \& Rosenstock, 1984) might help us understand why people with cancer symptoms consult a physician or refrain from doing so. Those patients who experience fear because of unexplained symptoms, but believe that the benefits of consultation outweigh the barriers, are more likely to consult their physician. Similarly, according to the Attitude-Social influence-self Efficacy (ASE) model (De Vries et al., 1988; De Vries \& Mudde, 1998), seeking medical advice for cancer symptoms can be explained by advantages versus disadvantages, together with the perceived social support and the perceived ability to implement the behavior under various circumstances. For instance, patients are more likely to seek medical advice for cancer symptoms when they expect a physician to 
be able to help (advantage), when they are stimulated by their spouses to consult a physician (social influence), and if they are able to actively cope with their fear (selfefficacy). Further research is needed to shed more light on how these models can be used to explain help-seeking behavior.

The use of such social psychological theories in further research enables us to obtain quantitative data and to investigate whether there are differences in responses to cancer symptoms between different types of cancer or between different demographic groups.

\section{IMPLICATIONS FOR HEALTH EDUCATION}

Although the data are preliminary and it has been derived from exploratory research, we should consider a number of implications for designing interventions for the general public on early detection of cancer. First, a contribution to the early detection of cancer may be expected when health education focuses on improving knowledge and interpretation of cancer symptoms, decreasing feelings of unrealistic fear, helping patients to cope with realistic fear, and convincing patients of the relevance of consulting a doctor. As indicated previously, a variety of issues should be addressed in health education for the different patient groups. For instance, the first group of patients, the "worried well", would benefit from information about the nature of cancer symptoms and about how to interpret a cancer symptom correctly. Fear of cancer, which might be unrealistic, can be prevented by providing clear information on cancer symptoms. This may lead to a decrease in the unnecessary burden of physicians. The second group, those who responded appropriately, possess the right knowledge on cancer symptoms, but might be helped with information about how to deal with their fear and by stressing that consulting a physician in case of a possible cancer symptom is the correct action. The third group, those who delayed because of fear, should be given information about their fear and the relevance of consulting a physician. They should be made aware that delay may lead to more fear and does not solve the health problem. The last group, those who delay because of a lack of knowledge, are in need of information on the nature of cancer symptoms and that if (one of) such symptoms are detected, medical advice should be sought. However, it should be noted that it is not easy to classify patients into one of these four groups in advance, so it would be difficult to give patients the information they are in need of. Therefore, generic information should be used to address the general population. 
Secondly, health education stimulating people to detect cancer at an early stage should not be done exclusively by means of mass media campaigns, which, after all, reach not only those who delay, but also those who consult too early. Therefore, the mass media should provide information that is more tailored to the various patients groups or to their characteristics, in order to induce patients to respond appropriately to cancer signals. 


\section{CHAPTER 4}

\section{EARLY DETECTION OF CANCER: KNOWLEDGE AND BEHAVIOR AMONG DUTCH ADULTS}

\section{ABSTRACT}

This paper reports on knowledge and behavior among Dutch adults regarding early detection of cancer (active and passive detection behavior and help-seeking behavior) using data from two studies $(n=431, n=1778)$. Telephone interviews and written questionnaires assessed knowledge of detection methods and cancer symptoms, symptom recognition, detection behaviors, and help-seeking behaviors. Respondents did not have much general knowledge of detection methods and cancer symptoms, but recognized most cancer symptoms. More women than men paid attention to cancer symptoms. For most symptoms, medical help would be sought within the appropriate time by the majority of the respondents. Principal component analyses revealed relations between symptoms pertaining to the 'interior' body and those pertaining to the 'exterior' body. Correlations between symptom recognition, detection behavior and help-seeking behavior were low. Differences in demographic groups and differences in knowledge and behavior require adaptation of future health education on early detection of cancer to different groups.

Manuscript under review as:

De Nooijer, J., Lechner, L. \& De Vries. Early detection of cancer: Knowledge and behaviors among Dutch adults. 
Detecting cancer in the early stages contributes to improved chances for successful treatment and thus for survival (Bailar \& Gornik, 1997; Ruwaard \& Kramers, 1997; American Cancer Society, 1998; Tabar et al., 1985). Three categories of early detection behavior can be distinguished: 1) passive detection behavior, i.e. a person becomes aware of a cancer symptom without a conscious action; 2) active detection behavior, i.e. a conscious action to detect cancer symptoms, such as breast self-examination (BSE); 3) detection behavior by medical professionals, for instance during a screening program or a medical check-up. Early detection of cancer is not one particular behavior, but consists of several separate behaviors. A person has to be able to recognize the different symptoms, and to know how to examine his or her body. In addition to these behaviors, a person has to visit a health care provider when a symptom is found or to participate in screening programs. Although some of these behaviors overlap, the different behaviors require different knowledge, attitudes and skills.

Most studies of early detection of cancer have focused on active detection behaviors, such as performing breast, testicular and skin self-examination, or on detection by medical health care providers, such as participating in screening programs and having yearly check-ups by a physician (Bostick, 1993; Budden, 1995; Friedman et al., 1995; Lechner et al., 1997; Lechner et al., in press; Wardle et al., 1994; Wardle et al., 1995). While active detection contributes to early detection of cancer, a significant contribution can also be made by passive detection and by seeking medical help promptly when potential cancer symptoms are discovered. Qin and colleagues (1996) classifies cancers in three types, to make clear which cancers can be self-detected: 1) cancers of the superficial organs, such as skin, breast and testis, which can be detected by looking for lumps, ulcerations or moles or by palpation; 2) cancers of the hollow organs, such as urinary bladder, lungs, etc, which can be detected by, for instance, blood loss; 3) cancer of deep, solid organs, which does not give any signals in the early development of the cancer and which cannot be detected by palpation.

Few studies have focused on the performance of passive detection behaviors. Knowledge of cancer symptoms is a prerequisite for correct interpretation of symptoms and is associated with help-seeking behavior (Cochran et al., 1986; De Nooijer et al., 2001; Mor et al., 1990; Sheik \& Ogden, 1998). One study found that Dutch adults knew little about cancer symptoms and detection methods (Lechner \& De Vries, 1996). Moreover, there were differences regarding knowledge of cancer symptoms, knowledge of detection methods and passive detection behavior between sexes, age groups, and educational level 
groups. Compared to men, women had greater knowledge of cancer symptoms and detection methods, and checked themselves more often for cancer symptoms. Knowledge of cancer symptoms can be measured by asking open-ended questions about what cancer symptoms are, or in retrospective studies by asking whether the subjects had interpreted symptoms they had experienced as cancer symptoms. A limitation of the first method is that it is not always necessary to be able to actively recall symptoms, since recognition might be sufficient for associating symptoms with a serious health problem and thus seeking help. The second method might be limited by social desirability, resulting in an over-estimation of knowledge.

The aim of the present paper is to describe the knowledge and behavior of the Dutch adult population with regard to cancer symptoms and detection methods, symptom recognition, passive and active detection behavior and help-seeking behavior. The main goal of study 1 was to assess general knowledge about cancer detection methods and cancer symptoms. The main goal of study 2 was to assess to what extent Dutch adults recognized cancer symptoms, participated in detection methods and sought medical help for possible cancer symptoms. Both studies aimed at determining differences in knowledge and behavior in relation to demographic variables. Furthermore, we analyzed the underlying factors linking cancer symptoms, in order to reduce the number of symptoms and to assess the relationship between symptom recognition, passive detection and help seeking.

\section{MetHOdS}

\section{Respondents and procedure}

\section{Study 1}

Data collection was done by means of a telephone questionnaire in 1997. A random sample of 750 address-telephone number combinations was obtained from the Dutch National Telephone Company. All subjects of the sample received a letter which told them that they might be approached in the next few weeks to participate in a survey about the opinions of the Dutch adult population regarding cancer. The telephone interviews were done by professional interviewers. Respondents aged 18 years or over were included.

Of the 750 telephone numbers, 146 could not be reached for various reasons, such as a disconnected line, unanswered calls, or answering machines. For 25 subjects, no appointments could be made within the period of data collection. Of the 579 persons who were 
reached, $431(74 \%)$ completed the interview, while 148 persons $(26 \%)$ were not willing to participate. Reasons for refusing participation were classified under five headings: 'not interested' $(34 \%)$, 'no time' (15\%), 'privacy reasons' (3\%), 'language problems' $(5 \%)$, or 'other reasons' (43\%).

Of the study group, $59 \%$ were female and $41 \%$ were male. The mean age was 48 years $(\mathrm{SD}=16)$. The majority of the respondents had a spouse or partner $(74 \%)$, while $26 \%$ were single or widowed. Education level varied from low (42\%) (including primary school or basic vocational training), via medium (35\%) (including secondary vocational training or high school) and high (23\%) (including higher vocational training or university). The distribution of educational levels was slightly different from that in the general Dutch adult population for 1997 , which was $40 \%, 40 \%$ and $20 \%$ for lower, medium and higher education, respectively (Dutch Central Bureau for Statistics, 2000). Thirty respondents had had cancer at some time in their lives $(7 \%)$ and most of the respondents knew someone with cancer $(85 \%)$.

\section{Study 2}

Data was obtained from 1855 Dutch adults by means of written questionnaires in 1999. Participants were recruited by local newspapers and a national newspaper. Participation was on a voluntary basis. A total of 1778 questionnaires (96\%) were completed and returned.

Respondents of study 2 were predominantly female (80\%). The mean age was 46 years $(\mathrm{SD}=13)$. Most respondents had a spouse or partner $(76 \%)$, while $24 \%$ were single or widowed. Of the respondents $35 \%$ had low education, $36 \%$ had medium education and $29 \%$ had higher education. The higher educated respondents were somewhat overrepresented compared to the Dutch situation in 1998. The distribution of educational levels was 39\%, 40\% and 22\% respectively (Dutch Central Bureau for Statistics, 2000).

Forty-eight respondents (3\%) reported to have cancer, while 173 respondents $(10 \%)$ reported that they had had cancer at some time in their lives. Almost all respondents (92\%) knew someone with cancer. Respondents who were suffering from cancer at the time of data collection were excluded from the analysis.

Approval for both studies was obtained from the university's medical ethical commission. 


\section{Questionnaires}

The questionnaires were based on earlier studies (Berman \& Wandersman, 1991; Lechner \& De Vries, 1996; Lechner et al., 1997) and interviews with cancer patients and physicians (De Nooijer, Lechner \& De Vries, 1997a; 1997b). The questionnaires included questions about general knowledge of detection methods and cancer symptoms (Study 1), recognition of cancer symptoms, detection behaviors, help-seeking behaviors (Study 2), and demographic variables.

\section{Study 1}

General knowledge of detection methods and possible cancer symptoms, i.e., being able to name detection methods and symptoms, was assessed with two open-ended questions: "Which methods do you know that can contribute to detection of cancer?" and "Which symptoms do you think are possibly related to cancer?" Answers were given without reference to a list of methods or symptoms. Answers were categorized into 8 detection methods (Table 4.1) and 9 possible cancer symptoms (Table 4.2). For thickenings or lumps, two separate categories were used, to distinguish between symptoms related to breast cancer and symptoms related to other cancers.

\section{Study 2}

The extent to which possible cancer symptoms were recognized was assessed by a 15 item scale based on the Knowledge of Cancer Warning Signs Inventory (KCWSI) (Berman \& Wandersman, 1991). The scale consisted of 10 correct symptoms and 5 incorrect symptoms, to assess whether respondents were able to distinguish cancer symptoms from non-cancer symptoms. For each symptom, respondents were asked to indicate on a 5-point scale whether they thought this symptom to be a possible cancer symptom (very sure to very unsure). For the analyses, all items were dichotomized into correct (i.e., sure or very sure for cancer symptoms and unsure or very unsure for noncancer symptoms) or incorrect (all other answers), classifying 'don't know' as an incorrect answer. A total knowledge score was computed by counting all correct answers.

Passive detection behavior, i.e. becoming aware of a cancer symptom without a conscious action, was measured by means of 14 questions regarding cancer symptoms. For instance, "How often do you pay attention to ... ?" Answers were given on a 5-point scale (never to always).

Active detection behavior was measured regarding BSE and TSE. For instance "Do you perform breast self-examination?" These questions had to be answered by 'yes' or 'no'. When respondents answered affirmatively, they were asked about the frequency of 
practicing self-examination. Questions on BSE also included whether women performed palpation of the armpit. Correct BSE was defined as performing BSE at least once a month and including palpation of the armpit when doing BSE.

Help-seeking behavior was assessed by 14 questions, for instance: "After what period of time would you consult a physician if you detected a cancer symptom?" Answers were given on a 6-point scale (within one week to never). Data was classified as 'correct helpseeking behavior' (i.e., seeking medical help within one week for blood in stools, coughing up blood, blood in urine, the appearance of warts or new moles or changes in existing moles, swelling or thickening and seeking medical help within four weeks for a nagging cough or hoarseness, a sore that will not heal, indigestion or swallowing problems, changes in bowel habits and unusual weight loss) in accordance with recommendations from the Dutch Cancer Society (Dutch Cancer Society, 1996).

\section{Data analysis}

Descriptive statistics were used to describe the sample with regard to demographics, knowledge, and behavior. Differences between demographic groups were tested by means of Chi-squares, t-tests and analysis of variances with Scheffé multiple comparison tests. An alpha-level of $\mathrm{p}<.01$ was used, to correct for multi-comparisons. To test for differences between age groups, respondents were divided into: 1) 'young' (18-34 years); 2) 'middle aged' ( $35-49$ years): 3) 'old' (> 50 years). The relationship between the various symptoms was analyzed with Pearson's and Spearman's correlations and principal components analysis with orthogonal varimax rotation. All analyses were done with SPSS for Windows 7.5.

\section{RESULTS}

\section{General knowledge}

Study 1

Table 4.1 lists the cancer detection methods mentioned by the respondents. BSE was most frequently mentioned (47\%). Paying attention to cancer symptoms was mentioned by $31 \%$ of the respondents, while consulting a physician was mentioned by $30 \%$ of the respondents. Other detection methods were occasionally mentioned. TSE was mentioned by only one respondent. Ten percent of the respondents were unable to recall any detection methods. 
To determine whether there were significant differences in general knowledge about detection methods between demographic groups, Chi-square tests were performed $(p<.01)$. Detection methods used specifically by women were significantly more often mentioned by women than by men; these included BSE $\left(\chi^{2}=188.18 ; \mathrm{df}=1 ; \mathrm{p}<.001\right)$ and having a Pap smear $\left(\chi^{2}=49.49 ; \mathrm{df}=1 ; \mathrm{p}<.001\right)$, and participating in screening programs $\left(\chi^{2}=4.95 ; \mathrm{df}=1 ; \mathrm{p}<.05\right)$ (Table 4.1). Pap smears were more often mentioned by respondents in the 35-49 age group than in the other age groups $\left(\chi^{2}=17.87 ; \mathrm{df}=2 ; \mathrm{p}<.001\right)$. Checking the skin for possible cancer signals was mentioned more often by younger respondents $\left(\chi^{2}=9.93 ; \mathrm{df}=2 ; \mathrm{p}<.01\right)$ and respondents with a higher educational level $\left(\chi^{2}=12.80 ; \mathrm{df}=2 ; \mathrm{p}<.01\right)$.

Table 4.1 Knowledge of detection methods among all respondents, and differences between women and men (Study 1).

\begin{tabular}{lcccc}
\hline \hline Method & $\begin{array}{c}\text { Total } \\
\mathrm{n}=431\end{array}$ & $\begin{array}{c}\text { Women } \\
\mathrm{n}=256\end{array}$ & $\begin{array}{c}\text { Men } \\
\mathrm{n}=175\end{array}$ & $\mathrm{p}<.01$ \\
\hline Paying attention to cancer symptoms & $30.6 \%$ & $31.3 \%$ & $29.7 \%$ & $\mathrm{~ns}$ \\
BSE & $47.3 \%$ & $74.6 \%$ & $7.4 \%$ & w>m \\
TSE & $0.2 \%$ & - & $0.6 \%$ & - \\
Skin examination & $16.9 \%$ & $15.2 \%$ & $19.4 \%$ & $n s$ \\
Consulting a physician & $29.9 \%$ & $27.0 \%$ & $34.3 \%$ & $n s$ \\
Having a Pap test & $17.2 \%$ & $27.7 \%$ & $1.7 \%$ & w>m \\
Participating in screening programs & $8.8 \%$ & $11.3 \%$ & $5.1 \%$ & w>m \\
Other & $9.5 \%$ & $6.3 \%$ & $14.3 \%$ & $n s$ \\
\hline
\end{tabular}

With regard to general knowledge of cancer symptoms, the analyses showed that the most recalled cancer symptoms were thickenings or lumps in general, which were mentioned by $39 \%$ of the respondents, and changes in the skin, mentioned by $35 \%$ of the respondents (Table 4.2). All other symptoms were less well-known (varying from 26\% for changes in the breast to $2 \%$ for indigestion or swallowing problems).

Some significant differences in general knowledge about cancer symptoms were found between demographic groups: women more often than men mentioned thickenings or lumps in the breast $\left(\chi^{2}=57.09 ; \mathrm{df}=1 ; \mathrm{p}<.001\right)$, thickenings or lumps in general $\left(\chi^{2}=14.34 ; \mathrm{df}=1 ; \mathrm{p}<.001\right)$ and unusual bleeding $\left(\chi^{2}=10.31 ; \mathrm{df}=1 ; \mathrm{p}<.001\right)$ (Table 4.2). Younger respondents more often than older respondents mentioned changes in the skin $\left(\chi^{2}=22.10 ; \mathrm{df}=2 ; \mathrm{p}<.001\right)$, but they less often mentioned unusual bleeding than older respondents $\left(\chi^{2}=10.82 ; \mathrm{df}=2 ; \mathrm{p}<.01\right)$. 
Table 4.2 Knowledge of cancer symptoms among all respondents, and differences between women and men (Study 1).

\begin{tabular}{lcccc}
\hline \hline Symptom & $\begin{array}{c}\text { Total } \\
\mathbf{n}=431\end{array}$ & $\begin{array}{c}\text { Women } \\
\mathbf{n}=\mathbf{2 5 6}\end{array}$ & $\begin{array}{c}\text { Men } \\
\mathrm{n}=174\end{array}$ & $\mathrm{p}<.01$ \\
\hline Nagging cough or hoarseness & $17.2 \%$ & $16.4 \%$ & $18.3 \%$ & $n s$ \\
Sores that do not heal & $2.8 \%$ & $3.5 \%$ & $1.7 \%$ & $n s$ \\
Changes in the skin & $34.6 \%$ & $34.8 \%$ & $34.3 \%$ & $n s$ \\
Indigestion or swallowing problems & $1.6 \%$ & $2.0 \%$ & $1.1 \%$ & $n s$ \\
Thickenings or lumps in the breast & $26.2 \%$ & $39.5 \%$ & $6.9 \%$ & w>m \\
Thickenings or lumps in general & $38.7 \%$ & $46.1 \%$ & $28.0 \%$ & w>m \\
Unusual bleeding & $22.0 \%$ & $27.3 \%$ & $14.3 \%$ & w>m \\
Change in bowel habits & $9.7 \%$ & $11.3 \%$ & $7.4 \%$ & $n s$ \\
Unusual weight loss & $9.5 \%$ & $9.4 \%$ & $9.7 \%$ & $n s$ \\
\hline
\end{tabular}

Table 4.3 Proportion of respondents (\%) thinking that a particular symptom is related to cancer (Study 2).

\begin{tabular}{|c|c|c|c|c|}
\hline Symptom & $\begin{array}{c}\text { Total } \\
n=1710\end{array}$ & $\begin{array}{l}\text { Women } \\
n=1361\end{array}$ & $\begin{array}{c}\text { Men } \\
n=349\end{array}$ & $p<.01$ \\
\hline Nagging cough or hoarseness & $53.1 \%$ & $55.4 \%$ & $44.3 \%$ & $w>m$ \\
\hline Sleeplessness* & $23.0 \%$ & $21.0 \%$ & $30.8 \%$ & $w>m$ \\
\hline Change in bowel habits & $43.1 \%$ & $44.9 \%$ & $36.1 \%$ & $w>m$ \\
\hline Dizziness* & $59.3 \%$ & $60.9 \%$ & $52.9 \%$ & $m>w$ \\
\hline Indigestion or swallowing problems & $41.8 \%$ & $42.3 \%$ & $39.5 \%$ & ns \\
\hline Unusual weight loss & $61.5 \%$ & $62.3 \%$ & $58.6 \%$ & ns \\
\hline Muscle ache* & $28.6 \%$ & $26.4 \%$ & $37.0 \%$ & $w>m$ \\
\hline Unusual bleeding & $59.9 \%$ & $62.7 \%$ & $49.3 \%$ & $w>m$ \\
\hline Heavy feeling in arms and legs* & $37.8 \%$ & $36.0 \%$ & $45.0 \%$ & $w>m$ \\
\hline Heart irregularities* & $23.3 \%$ & $22.1 \%$ & $27.7 \%$ & ns \\
\hline Thickenings or lumps in breast or elsewhere & $54.8 \%$ & $55.7 \%$ & $51.2 \%$ & ns \\
\hline Urinary problems & $34.3 \%$ & $32.5 \%$ & $41.4 \%$ & $m>w$ \\
\hline Appearance of new moles and changes in moles & $79.2 \%$ & $81.9 \%$ & $68.9 \%$ & $w>m$ \\
\hline Sores that do not heal & $37.5 \%$ & $39.4 \%$ & $30.0 \%$ & $w>m$ \\
\hline Appearance of new warts & $56.1 \%$ & $58.7 \%$ & $46.1 \%$ & $w>m$ \\
\hline
\end{tabular}

"incorrect cancer symptom 


\section{Recognition of cancer symptoms}

\section{Study 2}

Table 4.3 lists the percentages of symptoms correctly recognized as cancer or non-cancer symptoms. The appearance of new moles or warts was the most well-known cancer symptom (79\%). Other symptoms were far less often mentioned correctly as cancer symptoms (Table 4.3). Most of the non-cancer symptoms were linked to cancer by fewer than $40 \%$ of the respondents, except dizziness, which was associated with cancer by more than $60 \%$ of the respondents.

Differences in total knowledge scores on correctly recognized symptoms in relation to demographic variables were analyzed with T-tests or analysis of variance. Subjects classified an average of 9 symptoms correctly as a cancer or a non-cancer symptoms $(\mathrm{SD}=3.06)$. Higher educated respondents recognized more symptoms than lower educated respondents ( 9.11 vs 8.11 respectively) $(\mathrm{F}(1572,2)=13.79 ; \mathrm{p}<.001)$.

\section{Passive detection behavior}

In order to assess whether respondents were aware of possible cancer symptoms without conscious actions, respondents were asked how often they paid attention to these symptoms. Many respondents reported to be attentive to unusual blood loss, changes in the skin, thickenings or lumps and changes in bowel habits (Table 4.4), while they were less attentive to indigestion, swallowing problems, unusual weight loss, or urinary problems.

Differences between demographic groups were found for sex and age. More women than men reported paying attention to changes in the skin, thickenings or lumps and changes in bowel habits (Table 4.4). Men more frequently reported paying attention to urinary problems than women. Older respondents reported more attention to indigestion, non-healing sores, the appearance of a wart, unusual weight loss, and a nagging cough or hoarseness (Table 4.4).

\section{Active detection behavior}

To assess the extent to which respondents participated in active detection methods, BSE and TSE were analyzed separately for women and men. Thirty-six percent of the women reported practicing BSE once a month or more, $29 \%$ performed BSE once or twice every 3 months and $35 \%$ performed BSE fewer than twice every six months. Palpation of the armpit to examine the lymph nodes was practiced by $77 \%$ of the women. Thirty-two percent of the women performed BSE correctly, i.e. at least once a month including armpit examination. 
Table 4.4 Passive detection behavior Range 1 (never) to 5 (always) (Study 2).

\begin{tabular}{|c|c|c|c|c|c|c|c|c|}
\hline \multirow[t]{2}{*}{ Paying attention to... } & \multicolumn{5}{|c|}{ Sex } & \multicolumn{2}{|c|}{ Age } & \multirow[b]{2}{*}{$p<.01$} \\
\hline & $\begin{array}{c}\text { Total } \\
n=1710\end{array}$ & $\begin{array}{l}\text { Women } \\
n=1361\end{array}$ & $\begin{array}{c}\text { Men } \\
n=349\end{array}$ & $p<.01$ & $\begin{array}{l}\text { Young } \\
n=342\end{array}$ & $\begin{array}{c}\text { Middle } \\
n=710\end{array}$ & $\begin{array}{c}\text { Old } \\
n=658\end{array}$ & \\
\hline Blood in stool & 3.16 & 3.17 & 3.11 & ns & 3.03 & 3.17 & 3.22 & ns \\
\hline Coughing up blood & 2.73 & 2.72 & 2.77 & ns & 2.67 & 2.68 & 2.82 & ns \\
\hline Swallowing problems & 2.58 & 2.57 & 2.58 & ns & 2.65 & 2.47 & 2.66 & ns \\
\hline Food that does not move normally & 2.14 & 2.14 & 2.10 & ns & 1.97 & 2.06 & 2.30 & $0>y, m$ \\
\hline Sores that do not heal & 2.71 & 2.75 & 2.54 & $w>m$ & 2.55 & 2.68 & 2.83 & $a>y$ \\
\hline Appearance of a wart & 3.18 & 3.24 & 2.94 & $w>m$ & 3.05 & 3.12 & 3.32 & $a>y$ \\
\hline Appearance of a mole & 3.17 & 3.28 & 2.74 & $w>m$ & 3.13 & 3.12 & 3.24 & ns \\
\hline Changes in a mole & 3.39 & 3.54 & 2.80 & $w>m$ & 3.35 & 3.39 & 3.41 & ns \\
\hline Thickenings or lumps & 3.16 & 3.25 & 2.80 & $w>m$ & 3.17 & 3.08 & 3.24 & ns \\
\hline Unusual weight loss & 2.53 & 2.55 & 2.47 & ns & 2.17 & 2.42 & 2.85 & $0>y, m$ \\
\hline Nagging cough or hoarseness & 2.89 & 2.92 & 2.77 & ns & 2.64 & 2.79 & 3.14 & $0>y, m$ \\
\hline Change in bowel habits & 3.01 & 3.06 & 2.83 & $w>m$ & 2.73 & 2.97 & 3.20 & $a>y$ \\
\hline Blood in urine & 3.00 & 2.98 & 3.09 & ns & 2.80 & 2.93 & 3.18 & o>y \\
\hline Urinary problems & 2.58 & 2.51 & 2.88 & $m>w$ & 2.26 & 2.48 & 2.86 & o>y,m \\
\hline
\end{tabular}


Differences between age and educational level groups in correct BSE were analyzed using Chi-square tests. The lower the educational level, the more women performed correct BSE $(44 \%, 35 \%$ and $21 \%$ for women with low, medium and high level education respectively) $\left(\chi^{2}=11,88 ; d f=2 ; p<.01\right)$. No significant differences were found for age groups.

TSE, which was relevant to 50 men from the study group (age 18-35), appeared to be unknown to most men; 32 respondents (64\% of the target group) said they had never heard of TSE, 12 respondents said they had heard of TSE but did not practice it, and 6 respondents said they had practiced TSE. Four of these 6 respondents did this on a regular basis, which is at least once a month. No statistical analysis to test differences between educational levels was performed for TSE, since the target group who performed TSE was too small.

\section{Help-seeking behavior}

Table 4.5 presents percentages of respondents who would seek medical help within the appropriate time with possible cancer symptoms. The results show that the majority of the respondents reported they would consult a physician within the appropriate time, except for changes in the skin and swellings or thickenings (less than 35\% reported that they would seek help in time).

Possible differences between demographic groups in the percentages of correct helpseeking behavior were tested with Chi-square. More women than men reported they would seek help within the appropriate time upon the appearance of warts ( $21 \%$ vs $13 \%)$ $\left(\chi^{2}=13.57 ; \mathrm{df}=1 ; \mathrm{p}<.001\right)$, or changes in a mole $(35 \%$ vs $22 \%)\left(\chi^{2}=23.59 ; \mathrm{df}=1 ; \mathrm{p}<.001\right)$.

Several differences were found between age groups: older respondents seemed to respond more appropriately than younger respondents to the feeling that food does not descend normally from the mouth to the stomach $\left(\chi^{2}=32.61 ; \mathrm{df}=2 ; \mathrm{p}<.001\right)$, to sores that do not heal $\left(\chi^{2}=29.34 ; \mathrm{df}=2 ; \mathrm{p}<.001\right)$, to thickenings or lumps $\left(\chi^{2}=12.35 ; \mathrm{df}=2\right.$; $\mathrm{p}<.01$ ), to unusual weight loss $\left(\chi^{2}=34.80 ; \mathrm{df}=2 ; \mathrm{p}<.001\right)$, to a nagging cough or hoarseness $\left(\chi^{2}=32.29 ; \mathrm{df}=2 ; \mathrm{p}<.001\right)$, and to changes in bowel habits $\left(\chi^{2}=15.86 ; \mathrm{df}=2\right.$; $\mathrm{p}<.001)$.

Compared to respondents with a higher educational level, those with a lower level more frequently reported that they would respond appropriately by consulting a physician upon the appearance of warts $\left(\chi^{2}=25.12 ; \mathrm{df}=2 ; \mathrm{p}<.001\right)$, or new moles $\left(\chi^{2}=10.50 ; \mathrm{df}=2 ; \mathrm{p}<.01\right)$, changes in a mole $\left(\chi^{2}=9.61 ; \mathrm{df}=2 ; \mathrm{p}<.01\right)$, thickenings or lumps $\left(\chi^{2}=27.46 ; \mathrm{df}=2 ; \mathrm{p}<.001\right)$, unusual weight loss $\left(\chi^{2}=16.12 ; \mathrm{df}=2 ; \mathrm{p}<.001\right)$, and nagging cough or hoarseness $\left(\chi^{2}=13.16 ; \mathrm{df}=2 ; \mathrm{p}<.001\right)$. 


\begin{tabular}{ll}
\hline \hline Consulting a physician with... & $\begin{array}{c}\text { Total } \\
n=1710\end{array}$ \\
\hline Blood in stool & $64.0 \%$ \\
Coughing up blood & $70.6 \%$ \\
Swallowing problems & $87.3 \%$ \\
Food does not move normally & $73.7 \%$ \\
Sores that do not heal & $68.5 \%$ \\
Appearance of a wart & $19.6 \%$ \\
Appearance of a mole & $15.6 \%$ \\
Changes in a mole & $32.3 \%$ \\
Thickenings or lumps & $19.4 \%$ \\
Unusual weight loss & $60.8 \%$ \\
Nagging cough or hoarseness & $72.1 \%$ \\
Change in bowel habits & $64.6 \%$ \\
Blood in urine & $70.3 \%$ \\
Urinary problems & $85.1 \%$ \\
\hline
\end{tabular}

\section{Principal component analysis}

Principal component analysis was done to study the relationships between the various symptoms within the three different concepts investigated, viz. recognizing cancer symptoms, passive detection behavior and help-seeking behavior. Cronbach's alphas were used to test whether the variables within the suggested components were correlated. As regards recognizing cancer symptoms, three components with eigenvalues greater than 1 were extracted (Table 4.6). All cancer symptoms, except the skin-related symptoms, loaded on the first component ( 6 items, $\alpha=0.81$ ). All non-cancer symptoms loaded on the second component ( 5 items, $\alpha=0.75$ ). Specific cancer symptoms related to the exterior of the body (i.e. those symptoms which are noticeable at or on the skin) (4 items, $\alpha=0.71$ ) loaded on the third component.

As regards passive detection behavior, two components were extracted (Table 4.6). Symptoms not noticeable on the outside, i.e. 'internal body symptoms', loaded on the first component ( 9 items, $\alpha=0.90$ ). Symptoms noticeable on the outside of the body, i.e. 'external body symptoms', were significant items on the second component (5 items, $\alpha=0.88$ ). Three components were extracted with regard to help-seeking behavior (Table 4.6). The first component consisted of 'internal body' symptoms ( 7 items, $\alpha=0.82$ ). The 
Table 4.6 Principal Component Analysis.

\begin{tabular}{|c|c|c|c|c|c|c|c|c|c|c|}
\hline Symptom recognition items & C1 & C2 & C3 & Passive detection items & C4 & C5 & Help-seeking behavior items & C6 & C7 & C8 \\
\hline Swallowing problems & 0.74 & & & Urinary problems & 0.75 & & Food does not move normally & 0.72 & & \\
\hline Change in bowel habits & 0.73 & & & Blood in urine & 0.73 & & Change in bowel habits & 0.72 & & \\
\hline Nagging cough & 0.72 & & & Swallowing problems & 0.72 & & Nagging cough & 0.70 & & \\
\hline Unusual weight loss & 0.66 & & & Coughing up blood & 0.72 & & Swallowing problems & 0.68 & & \\
\hline Unusual bleeding & 0.59 & & & Food does not move normally & 0.68 & & Sores that do not heal & 0.68 & & \\
\hline Urinary problems & 0.51 & & & Change in bowel habits & 0.68 & & Unusual weight loss & 0.64 & & \\
\hline Heart irregularities & & 0.77 & & Blood in stools & 0.66 & & Urinary problems & 0.57 & & \\
\hline Muscle ache & & 0.76 & & Nagging cough & 0.65 & & Appearance of new moles & & 0.81 & \\
\hline Heavy feeling in arms/legs & & 0.76 & & Unusual weight loss & 0.62 & & Changes in mole & & 0.79 & \\
\hline Sleeplessness & & 0.71 & & Appearance of moles & & 0.90 & Appearance of warts & & 0.78 & \\
\hline Dizziness & & 0.49 & & Changes in mole & & 0.89 & Swellings or thickenings & & 0.52 & \\
\hline Appearance of warts & & & 0.83 & Appearance of warts & & 0.80 & Blood in stools & & & 0.82 \\
\hline New moles or changes in mole & & & 0.69 & Swellings or thickenings & $(0.46)$ & 0.57 & Blood in urine & & & 0.79 \\
\hline Sore that do not heal & & & 0.62 & Sores that do not heal & $(0.50)$ & 0.55 & Coughing up blood & & & 0.76 \\
\hline Thickenings or swellings & $(0.43)$ & & 0.53 & & & & & . & & \\
\hline Variance explained & $21 \%$ & $17 \%$ & $15 \%$ & & $35 \%$ & $26 \%$ & 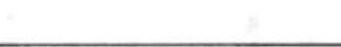 & $24 \%$ & $17 \%$ & $15 \%$ \\
\hline
\end{tabular}

Note. All items loaded >0.40 are depicted. C1='interior body' symptoms, C2=non-cancer symptoms, C3='exterior body' symptoms, C4='interior body' symptoms, C5='exterior body' symptoms, C6='interior body' symptoms, C7='exterior body' symptoms, C8=symptoms concerning unusual bleeding. 
second component consisted of 'external body' symptoms ( 4 items, $\alpha=0.74$ ). The third component consisted of symptoms concerning unusual bleeding ( 3 items, $\alpha=0.77$ ).

\section{Relationships between recognition of cancer symptoms, passive detection behavior and help-seeking behavior}

Relationships between recognition of cancer symptoms, passive detection and helpseeking behavior were studied by analyzing correlations between these variables per symptom. Correlations between recognition of symptoms and passive detection were significant but low (all $\mathrm{r}<0.24$ ). Correlations between recognizing symptoms and consulting a physician for cancer symptoms were significant but low for most symptoms $\left(r_{s}<0.15\right)$, but not significant for swallowing problems, the feeling that the food does not move normally from mouth to stomach, and coughing up blood. Similar results were found in correlations between passive detection and consulting a physician. All correlations were significant but low $(\mathrm{p}<.05$ for blood in stools, and $\mathrm{p}<.01$ for other symptoms).

\section{DISCUSSION}

Two studies were performed to investigate what the Dutch adult population knew about early detection methods and cancer symptoms, and what early detection behaviors they actually engaged in. The results of the first study showed that general knowledge regarding cancer detection methods and cancer symptoms was poor. The second study showed that levels of symptom recognition were higher for most cancer symptoms and that most non-cancer symptoms were recognized correctly as such. Moreover, respondents reported to be fairly attentive to possible cancer symptoms, although attention was higher for some symptoms than for others. Women were more engaged in active detection behaviors (BSE) than men (TSE). The majority of the respondents reported that medical help would be sought within the appropriate time for most symptoms. The results of these studies confirm results of earlier studies, which concluded poor knowledge of cancer symptoms and cancer detection methods (Bostick, 1993; Lechner \& De Vries, 1996; Myhre et al., 1996) but adequate recognition of cancer symptoms (Berman \& Wandersman, 1991; Deliens, 1998; Sheik \& Ogden, 1998). However, passive detection of cancer, which was one of the main topics in this paper, has rarely been measured, and our results are therefore difficult to compare. 
For the purpose of developing health education, target group segmentation is an important issue, since health education is more effective when it is adapted to the characteristics of specific segments of the population. Based on epidemiological data, it is evident that the population can be divided into several subgroups. For instance, BSE is relevant to all women aged 18 years and over, while TSE is relevant to the high risk population, i.e., men aged between 15 and 35 (Dutch Cancer Society, 1996). Thus, men and women of different age groups should be addressed separately in health education on early detection of cancer, to prevent people from receiving redundant information. In addition, the results of these two studies provide relevant new information on how the population can be divided into subgroups based on behavioral aspects. Subgroups can be based on the extent to which they recognize cancer symptoms and perform early detection behaviors. Those who do not recognize cancer symptoms and who do not perform early detection behaviors need different information than those who are already engaged in various early detection behaviors. Moreover, future health education on early detection of cancer should pay special attention to young male subjects, since this group is less commonly involved in early detection behavior or help-seeking behavior than older and female subjects.

Another aim of the present study was to investigate whether the cancer symptoms could be placed under different components. Results of the principal components analysis showed that recognition of symptoms can be divided into cancer symptoms and non-cancer symptoms. This indicates that respondents were able to distinguish between symptoms related to cancer and to other diseases, which is in agreement with Berman \& Wandersman's suggestions (1991). Results also suggested that internal symptoms were not related to external symptoms, since two components for both recognition and passive detection behavior were extracted. Our classification in 'external' and 'internal' symptoms can be compared to Qin's (1996) superficial and hollow organs respectively. As regards seeking medical help, an additional component for unusual bleeding was extracted. Symptoms associated with threatening diseases, like unusual bleeding, often cause a greater concern (Jones, Wiese, Moore \& Haley, 1981) and increase the likelihood of medical help being sought (Byles et al., 1992; De Nooijer et al., 2001; Van de Kar et al., 1992). The fact that respondents regarded internal symptoms and external symptoms as different components could be taken into account in developing health education on early detection of cancer. Information on cancer symptoms should be adapted to the frame of reference of the target population. For instance, health education information should categorize symptoms into internal and external symptoms in order to create a recognizable image of these symptoms in the receivers of the information. Moreover, 
different information can be given about specific aspects of internal and external symptoms. In practice, this means that information should confirm that unusual bleeding is serious, but should also stress that internal symptoms, such as changes in bowel habits, a nagging cough or hoarseness etc., might be caused by serious diseases and thus deserve attention.

The poor associations between symptom recognition, passive detection behavior and seeking medical help indicate that even if a person recognizes cancer symptoms in general, this does not automatically imply awareness of possible cancer symptoms in him- or herself or seeking medical help when a symptom is detected. Anderson and colleagues (1995) argued that delay is most likely to occur between the discovery of an unexplained symptom and inferring illness, especially depending on the interpretation of the unexplained symptom. According to several social psychology models, behavior can be predicted by behavioral determinants, like attitudes, social influences and self-efficacy (Ajzen \& Madden, 1986; De Vries et al., 1988). The gap between recognizing cancer symptoms in general and actual passive detection and help-seeking behavior might be caused by various factors, for example a negative attitude toward early detection of cancer, low self-efficacy for passive detection, or fear of cancer. Bridging this gap between recognition of cancer symptoms and help-seeking behavior requires a better understanding of social psychological determinants and the way these factors influence early detection behavior. Information about these determinants is necessary to develop future health education methods stimulating people to practice early detection behavior. Therefore, further studies of the determinants of early detection behavior are recommended, since it is likely that influencing these factors could improve early detection behavior.

A limitation of the studies presented here could be that selection bias might have occurred, since respondents were included in the study based on voluntary participation. The self-selected respondents might have different characteristics than the total population, for instance, they might be more interested in issues concerning cancer or health in general. The high response rate $(74 \%$ and $96 \%$ for study 1 and study 2 , respectively) confirms this assumption. A limitation of study 2, and to a lesser extent of study 1 , is the overrepresentation of women. Women are apparently more interested in early detection of cancer than men. Therefore, results can be more easily generalized to the female population, since they are more interested in early detection of cancer. Future studies should focus on reaching more men, and the procedure for recruiting respondents should probably involve channels more used by (young) men, such as the Internet, specific magazines or the workplace. 


\section{SOCIAL PSYCHOLOGICAL CORRELATES OF PAYING ATTENTION TO CANCER SYMPTOMS AND SEEKING MEDICAL HELP}

\section{ABSTRACT}

Social psychological correlates of two main aspects of the process of cancer detection, viz. passive detection (i.e., paying attention to cancer symptoms) and help-seeking behavior, were studied among a-symptomatic Dutch adults. Two written questionnaires, with a six-week interval, identified correlates of both behaviors, using the ASE model. Moreover, differences in social psychological correlates were studied among subgroups of the sample. Modeling, intention and past behavior were associated with passive detection. Modeling, moral obligation, self-efficacy, intention and past behavior were correlated with help-seeking behavior. It was concluded that past behavior played an important role in both behaviors, but social psychological correlates did as well. Hence, educational programs need to address the two behaviors separately and also need to tailor the content to the various social psychological correlates of these two behaviors.

Manuscript under review as:

De Nooijer, J., Lechner, L. \& De Vries, H. Social psychological correlates of paying attention to cancer symptoms and seeking medical help. 


\section{INTRODUCTION}

Cancer is one of the most important causes of death in the Netherlands (Van Leer et al., 1999). Successful treatment and survival rates are likely to be improved when cancer is detected in the early stages (Bailar \& Gornik, 1997; Ruwaard \& Kramers, 1997; American Cancer Society, 1998; Tabar et al., 1985). Cancer can be detected by a medical health care provider, or by a person him/herself. Detection can occur without a conscious action, by becoming aware of potential cancer symptoms (i.e., passive detection), or by a conscious action, such as breast self-examination. The process of cancer detection by the person itself consists of several subsequent steps (Andersen et al., 1995), such as the detection of an unexplained symptom, inferring illness, deciding to seek help, and visiting a health care provider. Delay should be avoided, since it may endanger one's health. Therefore, people should pay attention to possible cancer symptoms, and once they face suspicious symptoms, they should response within an appropriate time frame by visiting a medical professional. Paying attention to cancer symptoms and help-seeking behaviors as well as the factors that determine these behaviors are the main focus of this study.

The frequency of occurrence of cancer detection behaviors show large variations. Breast self-examination and participation in screening programs are common (Bostick, 1993; Budden, 1995; Cope, 1992; De Nooijer, Lechner \& De Vries, subm-a; Friedman et al., 1994; Lechner et al., 1997; Persson, Svensson \& Ek, 1997; Wardle et al., 1995), while paying attention to cancer symptoms and testicular self-examination are less common (De Nooijer et al., subm-a; Gascoigne et al., 1999; Katz et al., 1995; Lechner et al., in press; Moore et al., 1998; Thornhill, 1987; Wardle et al., 1994).

In order to be able to know how to encourage early detection behaviors, it is necessary to know the motives of persons (not) to engage in these behaviors. Therefore, it is relevant to study the social psychological correlates of early detection behaviors. The present study used the Attitude - Social influence - self-Efficacy model (ASE) (De Vries et al., 1988) to analyze these motives. The ASE model can be regarded as an elaboration of the Theory of Planned Behavior (TPB) (Ajzen \& Madden, 1986) and has been used for the analysis of various different health behaviors (Brug, Lechner \& De Vries, 1995; Lechner \& De Vries, 1995; Lechner et al., 1997; Lechner et al., in press; Willemsen, De Vries, Van Breukelen \& Oldenburg, 1996). The most important differences with the TPB are that the ASE model includes not only the social norm, but also modeling and social support/pressure to assess the social influence; it adds concepts such as anticipated regret and moral obligation, of which the predictive value in secondary cancer preven- 
tion has been shown (Lechner et al., 1997; Lechner et al., in press); and self-efficacy is measured by the concept of Bandura (Bandura, 1986), while TPB measures the perceived behavioral control. Moreover, the ASE does not assess the central determinants by means of the multiplicative functions of attitudes, social norms and self-efficacy, as in done in TPB. Many studies have shown that the central determinants of TPB or ASE were associated with detection behaviors (Amsel et al., 1985; Barling \& Lehman, 1999; Bostick, 1993, 1994; Champion, 1994; Cochran et al., 1986; De Nooijer et al., 2001; De Nooijer, Lechner \& De Vries, in press; Friedman et al., 1994, 1995; Katz et al., 1995; Lechner et al., 1997; McEvoy-DeVellis et al., 1990; Moore et al., 1998; Mor et al., 1990; Savage \& Clarke, 1996; Skinner et al., 1994; Steffen, 1990; Van Ryn et al., 1996; Wardle et al., 1994). Recently, the role of past behavior in predicting health behaviors has been studied (Eagly \& Chaiken, 1990; Norman \& Conner, 1995) and was found to be associated with participating in screening programs (Lechner et al., 1997). Also other factors, such as the nature of the symptoms, influence help-seeking behavior. Several studies have shown that the more symptoms were associated with threatening diseases, the more likely it was that people sought medical help for these symptoms (Cassileth $e t$ al., 1988; De Nooijer et al., 2001; MacArthur \& Smith, 1981; Smith \& Anderson, 1985).

Most studies in this field used a retrospective study design, and were conducted among cancer patients. Prospective studies have been conducted to assess BSE, TSE and participating in screening programs. Little is known about the combination of passive detection and help-seeking behavior, and the factors associated with the process of cancer detection in a-symptomatic people. Therefore, the purpose of this study was twofold. First, social psychological differences in a-symptomatic subjects who frequently pay attention to cancer symptoms and those who do not are analyzed and factors explaining paying attention to cancer symptoms are identified. Second, social psychological differences in asymptomatic subjects who adequately seek help once they face a cancer symptom and those who do not are analyzed and factors explaining help-seeking behavior are identified. Moreover, implications of the results for health education programs will be discussed.

\section{METHODS}

\section{Subjects and procedures}

This study used a convenience sample consisted of subjects participating in a larger longitudinal study supported by the Dutch Cancer Society on early detection of cancer 
among a-symptomatic Dutch adults. Subjects were recruited via local door-to-door newspapers in 1999. The participants of the control group $(n=618)$ of the larger study were used as the sample for this study. Participants received general information about the study, an informed consent form and the first questionnaire (T1), which assessed determinants and behaviors of passive detection (paying attention to cancer symptoms) and seeking help. This questionnaire (T1) was completed and returned by 588 respondents (95\%). The second questionnaire (T2), assessing passive detection and help-seeking behavior for possible cancer symptoms, was sent to all 588 respondents six weeks after they had returned the first questionnaire. Of these, 534 returned the second questionnaire (86\%).

\section{Questionnaires}

The questionnaires were based on earlier studies (Berman \& Wandersman, 1991; De Nooijer et al., 2001; Lechner et al., 1997). The various concepts assessed in the questionnaire, the number of items, the range, mean score and Cronbach's alpha or Pearson's correlation are described in Table 5.1. Reliability of all scales was sufficiently high (Cronbach's $\alpha=.57-.92)$. Moreover demographic variables were asked for, as well as whether respondents had ever had cancer or had experienced cancer in their immediate environment.

\section{Statistical analysis}

Descriptive statistics were used to describe the sample with regard to demographics, all ASE concepts and behavior. Reliability of the scales was tested with Cronbach's alpha and Pearson's correlations. Group means were compared using analysis of variance or Ttest. For this purpose a 'help-seeking behavior score' was computed. First, data were recoded into 'correct help-seeking behavior' (i.e. seeking medical help within one week for blood in stool, coughing up blood, the appearance of warts or new moles or changes in a mole, thickenings or lumps, blood in urine; and seeking medical help within four weeks for indigestion or swallowing problems, sores that do not heal, unusual weight loss, nagging cough or hoarseness, changes in bowel habits or urinary problems) in accordance with recommendations from the Dutch Cancer Society (Dutch Cancer Society, 1996) and taking diagnostic information into consideration. Second, the 'helpseeking behavior score' was computed by the mean scores of the dichotomized helpseeking behavior items. Thus, a help-seeking score could vary from 0 (no appropriate help-seeking behavior for any of the possible cancer symptoms) to 1 (appropriate helpseeking behavior for all possible cancer symptoms). All respondents who scored a mean 
Table 5.1 Description of the various constructs assessed, number of items, mean (SD), and Cronbach's alpha/Pearson correlation, examples of the questions, answering options and range $(n=534)$.

\begin{tabular}{|c|c|c|c|c|}
\hline & $\begin{array}{l}\text { Number } \\
\text { of items }\end{array}$ & Mean (SD) & $\begin{array}{l}\text { Cronbach's al } \\
\text { Pearson r }\end{array}$ & Examples of the questions, answering options and range \\
\hline \multicolumn{5}{|l|}{ Passive detection } \\
\hline Attitude - Pros & 4 & $3.09(.48)$ & $a=.64$ & To what extent do you think paying attention to cancer symptoms is useful? not useful at all (1) to very useful (4) \\
\hline Attitude - Cons & 3 & $2.08(.70)$ & $a=.75$ & $\begin{array}{l}\text { To what extent do you think paying attention to cancer symptoms is frightening? not frightening at all (1) to very } \\
\text { frightening (4) }\end{array}$ \\
\hline Moral obligation & 1 & $3.43(.60)$ & $\cdot$ & $\begin{array}{l}\text { To what extent do you consider it to be an obligation to yourself and your family to pay attention to cancer } \\
\text { symptoms? no obligation at all (1) to much obligation (4) }\end{array}$ \\
\hline Anticipated regret & 1 & $3.58(.70)$ & $\cdot$ & $\begin{array}{l}\text { To what extent would you feel regret that you had not been more attentive if you did not pay attention to cancer } \\
\text { symptoms and cancer would be diagnosed afterwards? no regret (1) to much regret (4) }\end{array}$ \\
\hline Social norm & 4 & $1.38(.54)$ & $a=.63$ & Does your partner think you should pay attention to cancer symptoms? certainly not (-2) to certainly yes (2) \\
\hline Modeling & 1 & $1.94(1.91)$ & $\cdot$ & $\begin{array}{l}\text { How many people in your immediate environment pay attention to cancer symptoms? almost none (1) to almost } \\
\text { all (5) }\end{array}$ \\
\hline Self-efficacy ability (SE I) & 1 & $.31(1.04)$ & $\cdot$ & Do you think you are able to pay attention to cancer symptoms? certainly not (-2) to certainly yes (2) \\
\hline Self-efficacy difficulties (SE II) & 1 & $-.35(.81)$ & $\cdot$ & To what extent do you find it difficult to pay attention to cancer symptoms? very difficult (-2) to very easy (2) \\
\hline Intention & 14 & $1.49(.93)$ & $a=.92$ & To what extent do you intend to pay attention to each cancer symptom? certainly not (-3) to certainly yes (3) \\
\hline Behavior (T2) & 14 & $2.91(.98)$ & $a=.93$ & How often do you pay attention to each symptom? never (1) to always (5) \\
\hline \multicolumn{5}{|r|}{ T- th } \\
\hline Attitude - Pros & 4 & $3.07(.48)$ & $a=.57$ & $\begin{array}{l}\text { To what extent do you expect certainty about your health if you seek help for cancer symptoms? no certainty at } \\
\text { all (1) to much certainty (4) }\end{array}$ \\
\hline Attitude - Cons & 5 & $2.20(.66)$ & $a=.78$ & $\begin{array}{l}\text { To what extent would you be worried if you would visit a physician with a possible cancer symptom? not worried } \\
\text { at all (1) to very worried (4) }\end{array}$ \\
\hline Moral obligation & 1 & $3.43(.60)$ & $\cdot$ & $\begin{array}{l}\text { To what extent do you consider it to be an obligation to yourself and your family to seek help for cancer } \\
\text { symptoms? no obligation at all (1) to much obligation (4) }\end{array}$ \\
\hline
\end{tabular}




\begin{tabular}{|c|c|c|c|c|}
\hline & $\begin{array}{l}\text { Number } \\
\text { of items }\end{array}$ & Mean (SD) & $\begin{array}{c}\text { Cronbach's al } \\
\text { Pearson } r\end{array}$ & Examples of the questions, answering options and range \\
\hline Anticipated regret & 2 & $3.39(.70)$ & $r=.65$ & 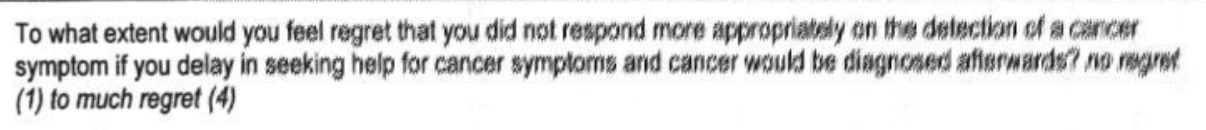 \\
\hline Social norm & 4 & $1.68(.43)$ & $a=.60$ & Does your partner think you should seek help for cancar symptoms? cartainily not ("2) to cartwinily yess (2) \\
\hline Modeling & 1 & $2.45(2.13)$ & $\cdot$ & $\begin{array}{l}\text { How many people in your immediate environmert seak help for cancer symploms? almast nene (1) is aiknuat } \\
\text { all (5) }\end{array}$ \\
\hline Self-efficacy ability (SE III) & 1 & $1.63(.63)$ & $\cdot$ & Do you think you are able to seek help for cancer symptsms? cortainly not (-2) fo certainly yas (2) \\
\hline Self-efficacy difficulties (SE IV) & 1 & $.31(1.12)$ & $\cdot$ & To what extent do you find it difficult to seek help for cancer symplams? vary dificust (-2) fo vary aavy (2) \\
\hline Self-efficacy situations (SE V) & 4 & $1.25(.79)$ & $a=.88$ & 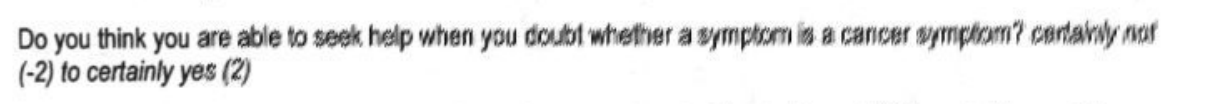 \\
\hline Intention & 14 & $1.66(.85)$ & $a=.92$ & 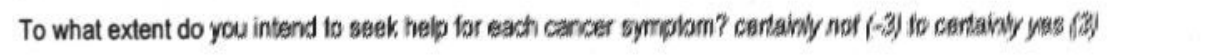 \\
\hline Behavior (T2) & 14 & $.59(.24)$ & $a=.90$ & 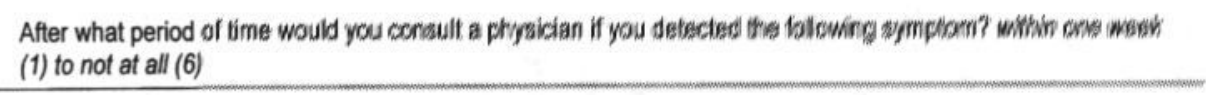 \\
\hline \multicolumn{5}{|l|}{ General concepts } \\
\hline Fatalism & 3 & $-1.45(.65)$ & $a=.70$ & 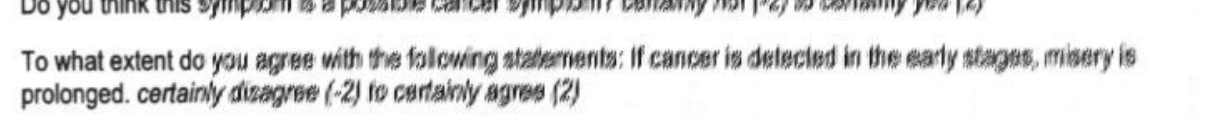 \\
\hline Fear & 5 & $2.69(.74)$ & $a=.72$ & How scared are you of gatting tarower? not at al (t) to very theared (S) \\
\hline
\end{tabular}


of .5 or less on the 'behavioral score' were classified as delayers, because this group would respond too late at least to half of the symptoms. Respondents who scored higher than .5 would respond appropriately at least to half of the symptoms, and were therefore classified as 'appropriate actors'.

Multiple regression analysis (method enter) was used to explain variance in paying attention to cancer symptoms and help-seeking behavior at T2. Demographic variables (sex, age, educational level, marital status, knowing someone with cancer in the environment, cancer history) and ASE variables (attitudes, social influences, self-efficacy expectations) were entered in the first model. Past behavior was included in the second model, to assess the additional explained variance of past behavior and to assess the contribution of social psychological determinants besides past behavior. The assumptions of linearity, normal distribution of residuals and consistent variance of residuals were tested and found to be satisfactory for all regression analysis. All statistical analysis were done with SPSS for Windows (differences were considered significant at $\mathrm{p}<.05$ ).

\section{RESULTS}

\section{Study group}

The study group was predominantly female (77\%), on average 47 years old (SD 12.9), and had a spouse $(78 \%)$. Compared to the Dutch population as a whole, the more highly educated respondents were slightly overrepresented in this study $(33 \%, 38 \%$ and $29 \%$ in our study group for lower, medium and higher level of education, respectively) (Dutch Central Bureau for Statistics, 2000). Nine percent had had cancer at some time in their lives. Almost all respondents (92\%) knew someone in their immediate environment with cancer.

\section{Passive detection}

Analysis of variance was used to assess whether determinants (assessed at T1) of respondents who frequently payed attention to cancer symptoms differed from those of respondents who were less frequently attentive (assessed at T2). Respondents were divided into three groups based on the average degree of attentiveness to cancer symptoms (Table 5.2). No differences were found between the three groups regarding demographics. The exception was for gender: fewer men than women responded that they were sometimes or often attentive to cancer symptoms $\left(\chi^{2}=10.77 ; \mathrm{df}=2 ; \mathrm{p}<.01\right)$. 


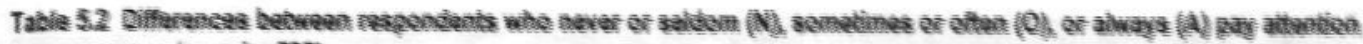
to eancer agngtems lasers.

\begin{tabular}{|c|c|c|c|c|}
\hline 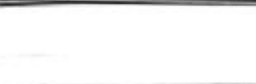 & $\begin{array}{c}\text { Nerwitalden } \\
\text { axis }\end{array}$ & 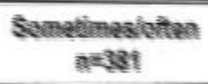 & $\begin{array}{l}\text { Aways } \\
\text { ands }\end{array}$ & $\begin{array}{c}\text { Tuky kso } \\
\text { geas }\end{array}$ \\
\hline intention & 109 & 1.39 & 212 & $N \in O<a$ \\
\hline Koowledge & 708 & 842 & 386 & ase \\
\hline Antude-Pres & 291 & 306 & 330 & Nod \\
\hline Alatude-Cons & 1.99 & 2.09 & 2.10 & 38 \\
\hline Moral otigateen & 3.31 & 341 & 3.38 & Nea \\
\hline Anticipatad negrat & 3.52 & 358 & 320 & as \\
\hline Social nem & 1.25 & 1.36 & 156 & Noa \\
\hline Modeling & 1.11 & 1.92 & 254 & $N=0 A$ \\
\hline Selfefficacy atility & 0.22 & 0.28 & 064 & NOAA \\
\hline Selfefficacy diffculites & -0.46 & -0.44 & 000 & NOSA \\
\hline Fatalism & -1.48 & -1.46 & -1.35 & nst \\
\hline Fear & 2.63 & 2.69 & 274 & as \\
\hline
\end{tabular}

With respect to the social psychological correlates, the results show that respondents who always pay attention to possible cancer symptoms had more positive intentions, attributed more advantages to paying attention to cancer symptoms, felt more morally obliged to be attentive to cancer symptoms, experienced more social influence and had higher levels of self-efficacy than those who were seldom or never attentive.

Multiple linear regression analysis (method enter) was performed to explain paying attention to cancer symptoms at T2. In the first model advantages of paying attention to cancer symptoms, modeling, self-efficacy 'difficulty' concept and intention explained $25 \%$ of the variance in paying attention to cancer symptoms. By adding past behavior in the regression analysis, an additional $30 \%$ of the variance was explained (Table 5.3). Advantages and self-efficacy did not remain significant predictors of paying attention to cancer symptoms when past behavior was added.

\section{Help-seeking for cancer symptoms}

To assess whether there were differences in possible determinants (assessed at T1) between respondents who would seek medical help appropriately and those who were more likely to delay (assessed at T2), respondents were divided into two groups, resulting in 201 delayers and 332 appropriate help seekers (Table 5.4). No differences in demographic variables were found between the two groups. Appropriate help seekers scored 


\begin{tabular}{|c|c|c|}
\hline$\sqrt{20}$ & $\begin{array}{l}\text { Passive detection } \\
\qquad n=477\end{array}$ & $\begin{array}{l}\text { Help-seeking behavior } \\
n=475\end{array}$ \\
\hline & $\beta^{1}$ & $\beta^{1}$ \\
\hline Knowledge of cancer symptoms & 0.04 & 0.03 \\
\hline Attitude - Pros & 0.05 & -0.05 \\
\hline Attitude - Cons & 0.01 & 0.03 \\
\hline Moral obligation & 0.07 & $0.08^{* *}$ \\
\hline Anticipated regret & -0.05 & -0.04 \\
\hline Social norm & 0.02 & 0.04 \\
\hline Modeling & $0.08^{*}$ & $0.09^{*}$ \\
\hline Self-efficacy ability & 0.01 & -0.07 \\
\hline Self-efficacy difficulties & 0.05 & -0.06 \\
\hline Self-efficacy situations & $\cdot$ & $0.19^{* * *}$ \\
\hline Intention & $0.08^{*}$ & $0.10^{*}$ \\
\hline Sex & 0.04 & -0.04 \\
\hline Age & -0.04 & -0.05 \\
\hline Educational level & -0.01 & 0.01 \\
\hline Having a partner & 0.02 & -0.02 \\
\hline Knowing someone with cancer & 0.01 & -0.03 \\
\hline Cancer history & -0.01 & -0.04 \\
\hline Past behavior & $0.64^{* \cdots *}$ & $0.57^{* \cdots *}$ \\
\hline Explained variance $\left(R^{2}\right)$ & 0.55 & 0.51 \\
\hline
\end{tabular}

"p<.05; "* p<.01; "**" p<.001

1 Standardized regression coefficients

higher than delayers on all ASE concepts, except for the perceived disadvantages. The concepts of knowledge, fear and fatalism did not differ between the two groups. Help-seeking behavior at T2 was explained by means of multiple linear regression analysis. Modeling, the self-efficacy concept of different situations, and intention toward help-seeking behavior were found to explain $34 \%$ of the variance in help-seeking behavior. Adding past help-seeking behavior explained an additional $17 \%$ of the variance in help-seeking behavior (Table 5.3). Moral obligation was a significant predictor as well in the second model. All other variables remained significant predictors in the second model. 


\begin{tabular}{lccc}
\hline & $\begin{array}{c}\text { Delay } \\
\mathbf{n}=201\end{array}$ & $\begin{array}{c}\text { Appropriate } \\
\mathrm{n}=332\end{array}$ & $\begin{array}{c}\text { T-test } \\
\mathbf{p}<.05\end{array}$ \\
\hline Intention & 1.26 & 1.90 & $\mathrm{D}<\mathrm{A}$ \\
Knowledge & 8.10 & 8.52 & $n s$ \\
Attitude - Pros & 2.96 & 3.13 & $\mathrm{D}<\mathrm{A}$ \\
Attitude - Cons & 2.13 & 2.24 & $\mathrm{nS}$ \\
Moral obligation & 3.29 & 3.50 & $\mathrm{D}<\mathrm{A}$ \\
Anticipated regret & 3.22 & 3.50 & $\mathrm{D}<\mathrm{A}$ \\
Social norm & 1.58 & 1.74 & $\mathrm{D}<\mathrm{A}$ \\
Modeling & 1.96 & 2.74 & $\mathrm{D}<\mathrm{A}$ \\
Self-efficacy ability & 1.48 & 1.72 & $\mathrm{D}<\mathrm{A}$ \\
Self-efficacy diff. & 0.26 & 0.34 & $\mathrm{nS}$ \\
Self-efficacy sit. & 0.97 & 1.41 & $\mathrm{D}<\mathrm{A}$ \\
Fatalism & -1.43 & -1.46 & $\mathrm{nS}$ \\
Fear & 2.63 & 2.73 & $\mathrm{nS}$ \\
\hline
\end{tabular}

\section{DISCUSSION}

This first aim of this study was to identify social psychological differences between subjects with different degrees of attentiveness to cancer symptoms, and the factors explaining paying attention to cancer symptoms. In general, subjects who were more attentive or were more appropriate help-seekers scored more favorable on advantages, moral obligation, social influences and self-efficacy variables. Several social psychological correlates, such as modeling and intention, as well as past behavior were associated with paying attention to cancer symptoms. Past behavior accounted for the largest variance in paying attention to cancer symptoms. This implies that being used to pay attention to cancer symptoms is of significance in explaining paying attention to cancer symptoms. This is in accordance to results of Lechner's study on participating in cancer screening behavior (Lechner et al., 1997). Lechner stressed the role of past behavior as a predictor of future behavior, conform Norman and Conner (1995). Nevertheless, cognitive correlates are accountable for explaining paying attention to cancer symptoms as well, which means that people who perceive advantages of paying attention to cancer symptoms, who have people in their environment who pay attention to cancer symptoms, who do not perceive difficulties regarding being alert on cancer symptoms and who have 
positive intentions are more likely to pay attention to cancer symptoms. The finding that self-efficacy did not remain significant in the regression model when past behavior was entered might be explained by Bandura's assumption that self-efficacy expectations are partly based on prior experiences (Bandura, 1986).

The second aim of this study was to assess differences in social psychological correlates between subjects who seek help appropriately, and subjects who do not, and to identify factors associated with help-seeking behavior. Similar results were found in social psychological correlates as were found for passive detection. Moreover, moral obligation, modeling, self-efficacy situations and intention were associated with help-seeking behavior beside help-seeking behavior in the past. The results of the regression analysis for both early detection behaviors reveals that although a large proportion of the variance was explained by past behavior, cognitive correlates play an important role as well in explaining these behaviors. The differences between explained variance in both behaviors by cognitive correlates ( 25 and $34 \%$ for paying attention to cancer symptoms and help-seeking behavior respectively) indicated that paying attention to cancer symptoms is probably a less conscious behavior, while help-seeking behavior requires more cognitive skills, because it is a more conscious behavior. This is in line with Andersen (Andersen et al., 1995), according to whom the process of help seeking consists of several steps, which requires a careful consideration about the complaint and the decision to consult a physician. Passive detection, however, is not done by actually searching for possible cancer symptoms, but the behavior is triggered by the occurrence of a symptom. Passive behavior relies probably more on habitual behavior, which is confirmed by the large explained variance of past behavior. The ASE model appeared to be a useful model to understand people's motives to engage in early detection behaviors, while it was traditionally used in explaining primary prevention behaviors or active detection behavior. However, more research on applications of the ASE model on secondary prevention behaviors should be done to improve the predictive value of the model.

In our attempt to study help-seeking behavior for cancer symptoms in a-symptomatic subjects, it appeared to be impossible to measure actual help-seeking behavior. Because of the low prevalence of cancer symptoms, it is unlikely that many respondents would detect actual cancer symptoms and seek medical help in the 6 weeks between $\mathrm{T} 1$ and $\mathrm{T} 2$. The assessment of help-seeking behavior was hypothetical in nature, since respondents were asked what they would expect to do in case they detected a possible cancer symptom. This may have resulted in somewhat socially desirable answers. Assessing actual help-seeking behavior would require either a much larger study population or a much 
larger time frame, since the incidence of cancer symptoms in a general population sample is relatively low. Such a procedure was not realistic in the present study. Another limitation was the overrepresentation of women in the present study. Women were apparently more interested in early detection of cancer than men. Therefore, results may be generalized more easily to the female population. In future studies this may be avoided by recruiting participants via various channels to reach also the people who do not read the local door-to-door newspapers. More research is needed to explore whether results can be generalized to the entire Dutch adult population.

Also the validity of the questionnaire needs further study. Our questionnaire was partly based on other questionnaires, but due to the fact that no validated questionnaires were found to study social psychological correlates of passive detection and help-seeking behavior in 2-symptomatic subjects, we break new grounds with this questionnaire. We therefore recommend that the validity aspects of the questionnaire should be studied in further research.

Our last aim of the present study was to discuss implications for health education on early detection of cancer. We recommend to address both attention to cancer symptoms and help-seeking behavior in health education, since paying attention to cancer symptoms becomes useless if people do not react upon the detection of such symptoms. Furthermore, these two behaviors are partly associated with different factors, so every aspect of the early detection of cancer requires separate attention. Thus, passive detection behavior can be promoted by providing on what the cancer symptoms are, stressing the advantages of passive detection, and discussing possible barriers such as difficulties in interpreting symptoms as possible cancer symptoms or at least as symptoms that need medical attention. Help-seeking behavior can be promoted by more clearly outlining the importance and moral obligation of seeking help, and also by discussing barriers such as being able to consult a physician when in doubt about the seriousness of certain symptoms, or when worrying about a particular diagnosis. 


\section{TAILORED VERSUS GENERAL INFORMATION ON EARLY DETECTION OF CANCER: A COMPARISON OF THE REACTIONS OF DUTCH ADULTS AND THE IMPACT ON ATTITUDES AND BEHAVIORS}

\section{ABSTRACT}

This article describes the process evaluation of two interventions (tailored or general information) to encourage people to engage in behaviors conducive to the early detection of cancer. A total of 1,040 Dutch adults participated in the study. Tailored information is adapted to the characteristics, needs and interest of the individual, and is hence more personally relevant and contains less redundant information. It was therefore hypothesized that tailored information would be better evaluated than general information, influences attitude and behavior change, and that no differences in subgroups would be found in the reactions to the tailored information. The results showed that both kinds of information were read by the large majority of the participants. Recipients of the tailored information saved and discussed the information with others more often, and they were more appreciative of its format and content. Tailored information resulted significantly more often in changes in attitudes and behaviors after the intervention. It is concluded that information adapted to individuals' characteristics is an appreciated method of health education in early detection of cancer.

\section{Accepted for publication as:}

De Nooijer, J., Lechner, L. \& De Vries, H. Tailored vs general information on early detection of cancer: A comparison of the reactions of Dutch adults and the impact on attitudes and behaviors. Health Education Research 
The earlier cancer is detected, the better are the chances for successful treatment and survival (Ruward \& Kramers, 1997; American Cancer Society, 2000b). Encouraging behaviors associated with early detection of cancer allows ureatment and may contribute to reducing cancer morbidity and mortality (Tabar et al, 1985). Farly detection of cancer encompasses various behaviors, such as passive or active selfdetection behavior, helpseeking behavior, and participating in screening programs. Passive detection behavior may be described as becoming aware of cancer symptoms, while no concrete actions have to be undertaken. This assumes correct knowledge and interpretation of cancer symptoms. An example is being attentive to changes in bowel habits or unusual bleeding, Active detection refers to concrete actions to detect cancer symptoms, such as breast selfexamination (BSE). Among the general public knowledge of symptoms and detection methods is not sufficient (Berman \& Wandersman, 1991; Bostick, 1993; Deliens, 1998; Lechner \& De Vries, 1996; Sheik \& Ogden, 1998). Some early detection behaviors, such as paying attention to cancer symptoms, are hardly engaged in, especially by certain subgroups such as young males (De Nooijer et $a l$, subm-2; Lechner, De Nooijer \& De Vries, 1998). In contrast, performing BSE and participating in screening programs are more performed by the target groups (Bostick, 1993; Budden, 1995; Cope, 1992; De Nooijer et al., subm-a; Friedman et al., 1994; Lechner et al., 1997; Persson et al., 1997; Wardle et al., 1995). Various subgroups can be distinguished among the general population, based on cancer incidence (some cancers occur more frequently among specific age groups or gender) (Visser et al., 2000), early detection behaviors (some behaviors are relevant for specific subgroups, for instance BSE for women and TSE for men) (De Nooijer et al., subm-a) and the social psychological correlates of early detection behaviors (some people have for instance higher self-efficacy expectations toward early detection behaviors than others) (De Nooijer, Lechner \& De Vries, subm-b). Hence, it is not easy to simply give one clear general message about early detection of cancer in health education that suits the needs of all these groups.

Interventions to encourage individuals to engage in early detection of cancer mainly focus on participating in screening programs or performing BSE or testicular selfexamination (TSE) (see for instance Friman, 1986; Rakowski et al., 1998). Interventions to encourage individuals to be attentive to cancer symptoms in their own body (passive detection) and to respond appropriately to the detection of a possible cancer symptom are rare. One example was the European Week Against Cancer in 1998 (Dutch Cancer Society, 1998), which focused on men and cancer. The intervention included a brochure, 
targeting men to pay attention to symptoms of common forms of cancer among males. Unfortunately, it was not tested on its format and impact. It is often assumed that these types of interventions increase worries about or fear of cancer. However, various studies on encouraging people to early detection behaviors were found not to enhance fear (Best et al., 1996; Månsson et al., 1999; Weist, 1996).

Recent new approaches in health education allow for the adaptation of health education messages to the individual level. Using computerized tailoring respondents receive health information adapted to their characteristics, needs, and interests. This results in personally relevant information and less redundant information. According to Petty and Cacioppo's Elaboration Likelihood Model (1986) personally relevant information is more likely to be thoughtfully considered via the 'central route'. This is information processing that works by engaging in a subject thoughtfully and that will result in enduring attitude change. It is therefore considered to be more effective in changing attitudes than general information (Brug et al., 1996; Dijkstra, De Vries \& Roijackers, 1999; Kreuter et al., 1999). Subsequently, an enduring, resistant attitude is likely to predict behavior (Eagly \& Chaiken, 1990). Throughout the last decade, computerized tailored health interventions on various health behaviors have been developed, applied and evaluated. These interventions have proven to be effective in changing intentions and behaviors for a number of health behaviors, such as smoking (Dijkstra, De Vries, \& Roijackers, 1998; Strecher et al., 1994), dietary habits (Brug et al., 1999; Brug et al., 1996; Campbell, 1994; De Bourdeaudhuij \& Brug, 2000), mammography (Rakowski et al., 1998; Skinner et al., 1994), and weight loss (Kreuter et al., 1999). Tailored interventions can be distinguished from traditional interventions in that the former are intended for a particular person rather than a group and based on individual level factors related to health or behavior outcome (Kreuter \& Skinner, 2000). Compared to expensive and time-consuming interpersonal communication, computerized tailoring enables us to reach large target groups at relatively low cost (De Vries \& Brug, 1999; Kreuter \& Skinner, 2000; Velicer \& Prochaska, 1999). An example is a computer-tailored smoking cessation intervention, implemented by the Foundation for Smoking and Health. In $2000,15,000$ individuals received a tailored letter about smoking cessation, which cost about $\$ 5$ per letter. After one year, $15 \%$ quitted smoking. In comparison, approximately 200 individuals participated in group sessions to stop smoking, which cost about $\$ 100$ per person (25\% quitters) (Willemsen, 2001).

Dijkstra and De Vries (1999b) identified why tailored messages are likely to increase the effectiveness of the information. First, the message is adapted to foreknowledge. Second, the message contains information that is relevant only to the individual in 
question and thus contains more extensive information. Third, since the message is adapted to the recipient's characteristics and intention to change a behavior, defensiveness to the message, which may lead to counter argumentation, is limited. Fourth, the message is adapted to the phase of the behavior change process and can therefore offer individual behavioral goals.

So far, no tailored interventions have been developed to encourage people to adopt early detection behaviors regarding cancer, with the exception of mammography (Rakowski et al., 1998; Skinner et al., 1994). The present paper describes a tailored intervention aimed at motivating the general public to engage in behavior conducive to the early detection of cancer, and evaluates this intervention on its effects on attitudes, passive detection and help-seeking behavior. The process evaluation was conducted in order to analyze how this tailored intervention was assessed compared to the current information on early detection of the Dutch Cancer Society in terms of use, format and content. Tailored information is adjusted to the characteristics of the recipients and the information is aimed to be more personally relevant to all readers. The present study evaluates therefore four hypotheses. First, tailored information will be more positively evaluated than the general information regarding use (reading, saving and discussing), format aspects (e.g., personally relevant, interesting) and content aspects (e.g., does the information convinces the recipient why $s /$ he should engage in early detection behaviors). Second, tailored information will not result in more worries about complaints or diagnosis, since it discusses personal worries. Third, tailored information will result in a greater influence on attitudes and behaviors of respondents than general information. Fourth, tailored information will not be evaluated differently among subgroups of the recipients of the tailored intervention.

\section{The intervention}

Computerized tailored feedback requires three interrelated elements (De Vries \& Brug, 1999; Dijkstra \& De Vries, 1999b). A screening instrument that enables the researchers to tailor the information to the individual's characteristics, a message source file that provides the feedback messages, and a computer program that connects the screening instrument with the relevant messages and generates the personal feedback. This program consisted mainly of logical ('if-then') statements (Kreuter et al., 2000).

\section{The screening instrument}

The screening instrument consisted of a written questionnaire. The first part of the questionnaire was developed to assess participants' knowledge of cancer symptoms 
(based on the Knowledge of Cancer Warning Signs Inventory (Berman \& Wandersman, 1991)), and early detection behaviors (i.e., paying attention to cancer symptoms, BSE, TSE, help-seeking behavior, and participation in screening programs).

The second part of the screening instrument focused on determinants of early detection behaviors. For this part the Attitude - Social Influence - self-Efficacy (ASE) model (De Vries et al., 1995; De Vries et al., 1988) served as a theoretical framework. This model has proven to be useful in explaining passive detection behavior and help-seeking behavior (De Nooijer et al., subm-b). Attitudes were assessed by asking respondents about the advantages (e.g., important, useful, detection as soon as possible, certainty about health) and disadvantages (e.g., frightening, unpleasant, scary when something is detected) of paying attention to cancer symptoms (passive detection) and seeking help. Anticipated regret and moral obligation were assessed for passive detection behavior and help-seeking behavior. Concerning social influence, the social norms of the partner, family, friends and the family physician with respect to paying attention to and seeking help for cancer symptoms were assessed. Furthermore, possible modeling influences were assessed by asking how many people in the direct environment of the participant were attentive to cancer symptoms and were likely to seek help in the case of cancer symptoms. Self-efficacy was assessed using different concepts: the difficulty of paying attention to and seeking help in the case of cancer symptoms, the ability to pay attention to and seek help in the case of cancer symptoms, and the ability to seek help in four different situations (when people doubt as to whether the symptom is a cancer symptom, when people expect the physician to think the complaint is not serious, when people do not expect the complaint to be serious, and when people experience fear). We also assessed two general concepts that might influence passive detection and help-seeking behavior, i.e., chronic fear for cancer, based on a questionnaire of Jepson and Chaiken (1990) and fatalism.

We asked respondents about demographic variables (gender and age) to facilitate tailoring based on epidemiological data, about their level of education, marital status, cancer history, and about whether they know someone with cancer in their direct environment to provide information for the analyses.

\section{The message source file}

The message source file consisted of 319 feedback messages that could be combined into $1.8^{*} 10^{24}$ different tailored information letters. Each letter consisted of approximately six to eight pages. Positive feedback was given on correct baseline situations, to reinforce the states desired. For instance, a respondent who often paid attention to a cancer symptom 
received information that it was good to be attentive to cancer symptoms. If the baseline situation could be improved, respondents received additional information.

The tailored letter consisted of nine sections. The first section included an introduction about early detection of cancer to explain why it is important that cancer be detected at an early stage. Information about five-year survival rates with and without metastasis was given for the most common types of cancer for both men and women. Furthermore, this section provided information about risk perception, because people might think that cancer is something that would never happen to them (De Nooijer et al., 2001). For this risk perception, role-model stories had been included, adapted to various target groups (for women: a woman who talked about breast cancer; for young men: a young man who talked about testicular cancer; and for men aged 35+: a man who talked about cancer of the colon).

The second section stated the main goal of the letter and contained feedback about knowledge of cancer symptoms and feedback about respondents' behavior (paying attention to cancer symptoms and consulting a physician) for each separate cancer symptom. Feedback differed for respondents that correctly and those that incorrectly identified a symptom as a cancer symptom. Both groups received information on each specific symptom, to ensure a baseline knowledge level. Feedback on paying attention to cancer symptoms was different for various levels of attentiveness (always, often/sometimes, or seldom/never). The first two groups of respondents were encouraged to keep doing so, while the last group received information on the importance of being attentive to the specific symptom. Similar feedback was given for help-seeking behavior for each possible cancer symptom. A distinction was made in the feedback between people who sought medical help within the appropriate time and people that delayed seeking medical help (in accordance with recommendations from the Dutch Cancer Society (Dutch Cancer Society, 1996), see (De Nooijer et al., subm-a, subm-b)).

The third, fourth and fifth sections discussed the determinants of passive detection behavior and help-seeking behavior, including attitudes, social influences and selfefficacy. For instance, respondents with low self-efficacy received information on how they could deal with different situations. These sections also addressed fear of cancer and a fatalistic attitude toward cancer. People who were extremely frightened received information to put this fear into perspectives, whereas people who deny all fears or worries, are warned that sometimes fear or worries are also correct. Anticipating on existing fear is important, because negative affective responses might influence compliance (Millar, 1995). The information emphasized that early detection behaviors may also have positive sides, such as the relief of fear and more certainty about someone's health. 
Sections six and seven were only sent to women and discussed BSE and participation in screening programs for breast and cervix cancer. Feedback on BSE was provided by asking respondents about their intention to perform BSE and included guidelines on how to perform a correct self-examination. It further included tips on how to remember doing BSE every month. Messages were framed negatively, since this was found to be effective in promoting BSE (Meyerowitz \& Chaiken, 1987). An example of a negatively framed message was "If you do not perform BSE, you miss the chance to find cancer in the early stages". Feedback was given to the target groups for breast and cervix screening programs based on the intention to participate the next time the female respondent received an invitation. The advantages of participation were stressed and explained to women who were to receive the first invitation within two years following the research study, and they were encouraged to participate upon receipt of the invitation.

Section eight was only sent to men aged 18-35 and dealt with TSE. Feedback was given on their intention to perform TSE. Since most of the respondents in this target group were unfamiliar with TSE, they all received information on how to perform TSE. Messages on TSE were positively framed, because people with low involvement with the issue appeared to agree more often with its positive aspects (Maheswaran \& MeyersLevy, 1990). For instance "If you perform TSE, you know whether your testicles are bealthy".

Section nine was the closing section, which included a reference to the Dutch Cancer Society for further questions about cancer.

\section{Methods}

\section{Study design and procedures}

Data was obtained from Dutch adults by means of written questionnaires in 1999. A total of 1,855 participants were recruited via local door-to-door newspapers and a national newspaper in the Netherlands. Participation was on a voluntary basis. Participants were randomly assigned to the tailored information group $(n=619)$, the general information group $(n=618)$ or a control group $(n=618)$. Participants received the baseline questionnaire (which is the screening questionnaire for the tailored information group), together with information about the study and an informed consent form. Three weeks after they returned the first questionnaire, participants received either the tailored information, the general information, or no information (in the control group). Again three weeks later, all participants received the second questionnaire. 
The general information, which was an existing brochure of the Dutch Cancer Seciety, dealt with such iscues as the importance of early detection, fear of cancer, the cancer symptoms, screening programs for breast and cervix cancer, early detection of skin cancer, and primary prevention of cancer (Dutch Cancer Society, 1991). The control group was not included in the analysis of the process evaluation, and therefore not included in this study. Approval for the study had been obtained by the university's medical ethics commission.

\section{The questionnaire}

A written questionnaire was used for the evaluation of the intervention. Use was assessed by asking whether the information had been read, saved and discussed with others. These questions could be answered on a dichotomous scale with 'yes' or 'no:'

The format of the information was assessed using six questions (Cronbach's $*=68$ ), such as "Was the information attractive?" or "How understandalle was the information?". Answers were given on one-sided four-point scales, varying from 'not at all' (1) to 'very much* (4).

The content of the information was assessed using five questions (Cronbach's $*=.83$ ), for instance "After reading the letter/folder, did you have sufficient information on bow you can contribute to early detection of cancer?" Answers were given on one-sided four-point scales, varying from 'not sufficient' (1) to 'very sufficient' (4).

The extent to which the information resulted in worries about a particular complaint or diagnosis was assessed using two questions: "After reading the letter/folder, were you worried about a particular complaint (diagnosis)?". One question measured the evaluation of the information in terms of a score on a 1 ('very bad') to 10 ('very good') scale.

For the tailored information group only, three additional questions were asked to evaluate the tailored information on BSE and TSE. These questions assessed whether the instructions on how to perform BSE or TSE were 'very clear' (4) to 'unclear' (1), whether respondents agreed with the importance of BSE or TSE ('very much' (4) to 'not at all' (1)), and how they evaluated the information on BSE or TSE in terms of a score (110).

Attitudes toward early detection behaviors was assessed by asking about the advantages and disadvantages of passive detection and help-seeking behavior. Advantages were assessed using four items for passive detection (Cronbach's $\alpha=.67$ ) and four items for help-seeking behavior (Cronbach's $\alpha=.58$ ), for example, "Do you think paying attention to cancer symptoms is very useful (4) to not useful at all (1)?" Disadvantages were assessed using three items for passive detection (Cronbach's $\alpha=.73$ ) and five items for help-seeking 
behavior (Cronbach's $\alpha=.76$ ), for example, "Would you be hesitant about visiting a family physician if you detected a possible cancer symptom (very much (4) to not at all (1))?"

Passive detection behavior, i.e., becoming aware of cancer symptoms without having undertaken concrete action, was assessed using fourteen questions regarding fourteen cancer symptoms (i.e., blood in stool, coughing up blood, indigestion, swallowing problems, sores that do not heal, appearance of warts, appearance of moles, changes in a mole, thickenings or lumps, unusual weight loss, nagging cough or hoarseness, changes in bowel habits, blood in urine, urinary problems) for instance, "How often do you pay attention to ...?" Questions had to be answered on a five-point scale ('always' to 'never').

Help-seeking behavior was assessed using fourteen items concerning the fourteen cancer symptoms, for instance, "After what period of time would you consult a physician if you detected the following cancer symptom?" Answers were given on a six-point scale (ranging from 'within one week' to 'never'). Data was re-coded into 'appropriate helpseeking behavior' (1) (i.e., seeking medical help within one week for blood in stool, coughing up blood, the appearance of warts or new moles or changes in a mole, thickenings or lumps, blood in urine; and seeking medical help within four weeks for indigestion or swallowing problems, sores that do not heal, unusual weight loss, nagging cough or hoarseness, changes in bowel habits or urinary problems) or 'not appropriate helpseeking behavior' (0) (all other answers) in accordance with recommendations from the Dutch Cancer Society (Dutch Cancer Society, 1996).

\section{Statistical analysis}

Analyses were performed on all respondents who did not suffer from cancer at the time of data collection. Differences between the tailored information group and the general information group at baseline in demographic variables (gender, age, educational level, marital status, knowing someone with cancer, cancer history) were tested with Chisquare tests or analyses of variance. Respondents' reactions to the information received and their opinion about the information were tested using Chi-square tests or T-tests for independent samples. Analyses of covariance were performed to study the effects of the information on attitude and passive detection behavior three weeks after the intervention (T1) between the two study groups. The covariate included was the attitude or the behavior prior to the intervention (assessed in the screening questionnaire at T0). Helpseeking behavior three weeks after the intervention was analyzed using Chi-square tests and logistic regression analysis, since this is a dichotomous variable (yes or no appropriate help seeking). Separate analyses were conducted on the tailored information group to 
study differences in subgroups in the evaluation of the information, using logistic and multiple linear regression analyses. All analyses were carried out with SPSS $(p<.05)$.

\section{RESULTS}

\section{Respondents}

A total of 1,189 screening questionnaires (96\%) were completed and returned. Within three weeks all respondents that had returned the first questionnaire received either the tailored information or the general information, followed by the second questionnaire after three weeks. The response to the second questionnaire was $83 \%(n=516)$ for the tailored information group and $85 \%(n=524)$ for the general information group.

The majority of the respondents was female $(80 \%)$. The average age was 46 years $(\mathrm{SD}=13)$. Most respondents had a spouse or partner $(76 \%), 24 \%$ were single or widowed. Of the respondents $35 \%$ had lower-level education (including primary school or basic vocational school), $36 \%$ had medium-level education (including secondary vocational school or high school), and $29 \%$ had higher-level education (including higher vocational school or university).

Ten percent of the respondents reported that they had had cancer at some time in their lives. Almost all respondents (92\%) knew someone with cancer in their direct environment.

There were no differences between the tailored information group and the general information group in gender, age, educational level, and marital status. In both study groups, respondents had to the same extent experience with cancer in their direct environment or suffered from cancer at some time in their lives.

\section{Evaluation of the information}

Table 6.1 shows that the tailored information and the general information was read by the majority of the respondents. Respondents who received tailored information saved the information $\left(\chi^{2}(982,1)=14.12, \mathrm{p}<.001\right)$ and discussed the information with others $\left(\left(\chi^{2}(983,1)=18.37, \mathrm{p}<.001\right)\right.$ significantly more often compared to respondents who received general information (Table 6.1). 


\begin{tabular}{lccc}
\hline \hline & $\begin{array}{c}\text { Tailored information } \\
(\mathbf{n}=490)\end{array}$ & $\begin{array}{c}\text { General information } \\
(\mathbf{n}=485)\end{array}$ & $\mathrm{p}<.05$ \\
\hline Have you read the entire information? & 95 & 96 & $n s$ \\
Have you saved the information? & 91 & 83 & $\mathrm{~T}>\mathrm{G}$ \\
Have you discussed the information with others? & 50 & 37 & $\mathrm{~T}>\mathrm{G}$ \\
\hline
\end{tabular}

In general, respondents were very positive about the format of both the tailored information and the general information (Table 6.2). T-tests showed significant differences in the total format score $(\mathrm{T}=8.08, \mathrm{df}=979, \mathrm{p}<.001)$, and in the extent to which the information was interesting $(\mathrm{T}=4.86 \mathrm{df}=977, \mathrm{p}<.001)$, new $(\mathrm{T}=7.19, \mathrm{df}=980, \mathrm{p}<.001)$ and attractive $(\mathrm{T}=6.97, \mathrm{df}=969, \mathrm{p}<.001)$; respondents of the tailored information group gave more positive scores on these aspects than respondents of the general information group. Moreover, respondents in the tailored information group felt significantly more personally addressed by the information they had received than respondents in the general information group $(\mathrm{T}=7.85, \mathrm{df}=980, \mathrm{p}<.001)$.

With regard to the content of the information, the responses in the tailored information group were significantly more positive than those in the general information group concerning the total content score $(\mathrm{T}=4.30, \mathrm{df}=972, \mathrm{p}<.001)$, and the advantages $(\mathrm{T}=4.61, \mathrm{df}=973, \mathrm{p}<.001)$ and disadvantages $(\mathrm{T}=3.71, \mathrm{df}=963, \mathrm{p}<.001)$ of paying attention to cancer symptoms (Table 6.2). In addition, respondents that had read the tailored information knew more about what people can do to contribute to early detection of cancer than those that had read the general information $(T=4.53, \mathrm{df}=978$, $\mathrm{p}<.001)$. Neither the tailored information nor the general information resulted in worries about a particular complaint or diagnosis. Overall, the tailored information was evaluated more positively than the general information ( 8 vs 7$)(T=4.73, d f=973$, $\mathrm{p}<.001)$.

The tailored information addressed breast and testicular self-examination, while this was not specifically addressed in the general information. Therefore, only recipients of the tailored information were asked to answer an additional set of questions regarding the tailored information on breast and testicular self-examination. The female respondents reported that the instructions in the tailored information on how to do a breast self-exam were clear (mean score 3.14, SD 0.65). Moreover, they reported understanding the importance of BSE after reading the tailored information (mean score 3.13, $\mathrm{SD}=0.73$ ). On average, the tailored information on BSE was appreciated by the target group with a rate of $8(\mathrm{SD}=1.15)$. 


\begin{tabular}{|c|c|c|c|}
\hline Range $=1$ (negative) tot 4 (pesitive) & $\begin{array}{c}\text { Tallored } \\
\text { information } \\
\text { (nedse) }\end{array}$ & $\begin{array}{l}\text { General } \\
\text { information } \\
(\mathrm{n}=48 \mathrm{~g})\end{array}$ & p<is \\
\hline Format (total score) & $2 \pi(0.41)$ & $2.57(0.40)$ & TिG \\
\hline How interesting was the infermation? & $311(066)$ & $221(0,4)$ & DG \\
\hline How credible was the information? & $312(050)$ & $3.15(0.50)$ & As: \\
\hline How understandabie was the information? & $3.30(0.51)$ & $3.28(0.51)$ & as \\
\hline Was the information new? & $1.91(0.70)$ & $1.60(0.65)$ & $T \geq G$ \\
\hline Was the information attractive? & $266(067)$ & $235(074)$ & TE \\
\hline Did you feel personally addressed by the information? & $2.54(0.35)$ & $2.12(0.83)$ & T26 \\
\hline Content (total score) & $2.82(0.58)$ & $266(0.61)$ & TPG \\
\hline $\begin{array}{l}\text { After reading the letterfolder, do you know why you should pay attention to cancar } \\
\text { symptoms? }\end{array}$ & $2.95(0.67)$ & $2.87(0.74)$ & as \\
\hline $\begin{array}{l}\text { After reading the letterfolder, do you know why you should consult a family physi- } \\
\text { cian when you have cancer symptoms? }\end{array}$ & $3.09(0.73)$ & $300(0.76)$ & as \\
\hline $\begin{array}{l}\text { Do you think the advantages of paying attention to cancer symptoms are sufficiently } \\
\text { discussed in the letterfolder? }\end{array}$ & $2.79(0.78)$ & $2.56(0.79)$ & ग०E \\
\hline $\begin{array}{l}\text { Do you think the disadvantages of paying attention to cancer symptoms are } \\
\text { sufficiently discussed in the letter/folder? }\end{array}$ & $2.52(0.88)$ & $2.32(0.80)$ & $T>G$ \\
\hline $\begin{array}{l}\text { After reading the letter/folder do you have sufficient information on how you can } \\
\text { contribute to early detection of cancer? }\end{array}$ & $2.76(0.80)$ & $2.52(0.83)$ & $T>G$ \\
\hline \multicolumn{4}{|l|}{ Worry } \\
\hline After reading the letter/folder are you worried about a particular complaint? & $1.40(0.61)$ & $1.34(0.57)$ & ns \\
\hline After reading the letter/folder are you worried about a particular diagnosis? & $1.39(0.59)$ & $1.33(0.57)$ & ns \\
\hline Score & $7.73(1.07)$ & $7.39(1.17)$ & $T>G$ \\
\hline
\end{tabular}

The male population younger than 35 was asked to answer questions regarding TSE, since they are the target group for TSE. The number of respondents in the high-risk group for testicular cancer was very limited, only fourteen respondents received the information on TSE. About half of these fourteen respondents said that the instructions on how to perform a TSE were clear, the other half reported that the instructions were not so clear (mean score $2.57, \mathrm{SD}=0.85$ ). Most respondents $(\mathrm{n}=9)$ agreed with the importance of TSE (mean score 2.64, SD 0.63). This part of the tailored information was evaluated with a score of $7(S D=1.49)$. 
Influence of information on attitudes, passive detection behavior and help-seeking behavior Three weeks after the intervention, the effects of tailored vs general information on the attitude toward passive detection and passive detection itself were tested using analyses of covariance. Attitude and behavior at TO were included as covariates to adjust for preexisting attitudes and behaviors. Table 6.3 shows that the tailored information had a significant effect on the advantages of passive detection. Furthermore, significant effects were found for passive detection of all cancer symptoms. This indicates that recipients of the tailored information perceived more advantages of passive detection and paid significantly more attention to cancer symptoms at T1 than recipients of the general information.

Table 6.3 Passive detection: advantages and disadvantages (range 1, 4) and behavior (range 1, 5): Mean scores (standard deviation) at the pretest (TO) and the posttest (T1) and analysis of covariance.

\begin{tabular}{|c|c|c|c|c|c|c|}
\hline & \multicolumn{2}{|c|}{$\begin{array}{l}\text { Tailored information } \\
\qquad(n=494)\end{array}$} & \multicolumn{2}{|c|}{$\begin{array}{l}\text { General information } \\
\qquad(n=496)\end{array}$} & \multirow[b]{2}{*}{$\mathbf{F}$} & \multirow[b]{2}{*}{$p<$} \\
\hline & TO & T1 & TO & T1 & & \\
\hline \multicolumn{7}{|l|}{ Attitude } \\
\hline Advantages & $3.06 \quad(.51)$ & $3.15 \quad(.50)$ & $3.11 \quad(.52)$ & $3.12 \quad(.52)$ & 6.86 & .001 \\
\hline Disadvantages & $2.12(.72)$ & $2.05 \quad(.71)$ & $2.10 \quad(.66)$ & $2.05 \quad(.48)$ & 0.03 & ns \\
\hline \multicolumn{7}{|l|}{ Behavior } \\
\hline Blood in stool & $3.20(1.30)$ & $3.75(1.14)$ & $3.13(1.31)$ & $3.51(1.26)$ & 11.42 & .01 \\
\hline Coughing up blood & $2.71(1.57)$ & $3.66(1.36)$ & $2.69(1.52)$ & $3.23(1.49)$ & 27.79 & .001 \\
\hline Swallowing problems & $2.62(1.22)$ & $3.38(1.12)$ & $2.53(1.20)$ & $2.93(1.17)$ & 38.50 & .001 \\
\hline $\begin{array}{l}\text { Food that does not move } \\
\text { normally }\end{array}$ & $2.13(1.16)$ & $3.06(1.19)$ & $2.07(1.18)$ & $2.59(1.23)$ & 40.13 & .001 \\
\hline Sores that do not heal & $2.75(1.38)$ & $3.72(1.17)$ & $2.65(1.39)$ & $3.34(1.26)$ & 24.80 & .001 \\
\hline Appearance of a wart & $3.22(1.34)$ & $3.97(1.07)$ & $3.13(1.37)$ & $3.62(1.15)$ & 25.32 & .001 \\
\hline Appearance of a mole & $3.21(1.33)$ & $3.93(1.12)$ & $3.17(1.37)$ & $3.64(1.17)$ & 17.89 & .001 \\
\hline Changes in a mole & $3.43(1.34)$ & $4.02(1.12)$ & $3.41(1.32)$ & $3.78(1.19)$ & 14.88 & .001 \\
\hline Thickenings or lumps & $3.19(1.23)$ & $3.88(1.05)$ & $3.21(1.23)$ & $3.56(1.10)$ & 26.87 & .001 \\
\hline Unusual weight loss & $2.52(1.50)$ & $3.53(1.32)$ & $2.52(1.49)$ & $3.03(1.44)$ & 44.80 & .001 \\
\hline $\begin{array}{l}\text { Nagging cough or } \\
\text { hoarseness }\end{array}$ & $2.85(1.38)$ & $3.74(1.16)$ & $2.91(1.38)$ & $3.37(1.26)$ & 33.46 & .001 \\
\hline Change in bowel habits & $3.02(1.27)$ & $3.73(1.14)$ & $2.98(1.28)$ & $3.36(1.19)$ & 28.66 & .001 \\
\hline Blood in urine & $3.00(1.55)$ & $4.00(1.22)$ & $2.98(1.56)$ & $3.58(1.38)$ & 33.03 & .001 \\
\hline Urinary problems & $2.58(1.40)$ & $3.55(1.28)$ & $2.55(1.42)$ & $3.06(1.36)$ & 42.11 & .001 \\
\hline
\end{tabular}


Covariance analyses were performed on the attitude toward help seeking and Ch: square tests were performed to test differences in helpseeking behavior at T1 (Table 6.4), At $\mathrm{Tl}$ an effect was found of the tailored information on the advantages and disadvan tages of help seeking for cancer symptoms, as well as for belp seeking on the majority of cancer symptoms. The recipients of the tailored intervention perceived more positive attitudes toward help seeking and were more likely to respond appropriately to the detection of these particular cancer symptoms than recipients of the general information. Additionally, logistic regression analyses were performed to adjust for preexisting seores on help-seeking behavior. Results were similar for help seeking for all

Table 6.4 Help saeking advantages and disadvantages (range 1,4 mean seeres (standard deviatien) and analysis of covariance; and behavier (W/ agpropriate help seekers) at the pretest (T0) and the pesttest (DI) and Ya tests.

\begin{tabular}{|c|c|c|c|c|c|c|}
\hline & \multicolumn{2}{|c|}{$\begin{array}{l}\text { Tailored infermation } \\
\qquad(\mathrm{n}=494)\end{array}$} & \multicolumn{2}{|c|}{$\begin{array}{l}\text { General information } \\
\qquad(\mathrm{n}=486)\end{array}$} & \multirow[b]{2}{*}{$F$} & \multirow[b]{2}{*}{ pe } \\
\hline & To & $\mathrm{T1}$ & Te & $\mathrm{TH}$ & & \\
\hline Attitude & & & & & & \\
\hline Advantages & $3.03(49)$ & $3.13(.47)$ & $305(53)$ & $304(50)$ & 16.6 & 001 \\
\hline \multirow[t]{2}{*}{ Disadvantages } & $2.20(.65)$ & $208(64)$ & $2.22(.64)$ & $2.15(65)$ & 4.45 & .06 \\
\hline & & & & & $x^{2}{ }^{8}$ & $p s$ \\
\hline Behavior & & & & & & \\
\hline Blood in stool & $65 \%$ & $68 \%$ & $61 \%$ & $57 \%$ & 13.45 & .001 \\
\hline Coughing up blood & $72 \%$ & $74 \%$ & $69 \%$ & $70 \%$ & 1.83 & ns \\
\hline Swallowing problems & $87 \%$ & $94 \%$ & $88 \%$ & $91 \%$ & 4.16 & .05 \\
\hline $\begin{array}{l}\text { Food that does not move } \\
\text { normally }\end{array}$ & $73 \%$ & $87 \%$ & $74 \%$ & $79 \%$ & 10.57 & .001 \\
\hline Sores that do not heal & $70 \%$ & $88 \%$ & $67 \%$ & $78 \%$ & 16.01 & .001 \\
\hline Appearance of a wart & $20 \%$ & $23 \%$ & $20 \%$ & $20 \%$ & 1.12 & ns \\
\hline Appearance of a mole & $16 \%$ & $21 \%$ & $17 \%$ & $20 \%$ & 0.46 & ns \\
\hline Changes in a mole & $34 \%$ & $39 \%$ & $32 \%$ & $38 \%$ & 0.11 & ns \\
\hline Thickenings or lumps & $18 \%$ & $27 \%$ & $21 \%$ & $23 \%$ & 2.78 & ns \\
\hline Unusual weight loss & $61 \%$ & $82 \%$ & $58 \%$ & $68 \%$ & 25.65 & .001 \\
\hline $\begin{array}{l}\text { Nagging cough or } \\
\text { hoarseness }\end{array}$ & $71 \%$ & $88 \%$ & $76 \%$ & $81 \%$ & 10.95 & .001 \\
\hline Change in bowel habits & $62 \%$ & $83 \%$ & $68 \%$ & $75 \%$ & 9.43 & .01 \\
\hline Blood in urine & $70 \%$ & $75 \%$ & $69 \%$ & $66 \%$ & 8.95 & .01 \\
\hline Urinary problems & $83 \%$ & $93 \%$ & $85 \%$ & $88 \%$ & 7.11 & .01 \\
\hline
\end{tabular}


cancer symptoms, with the exception of help-seeking behavior for thickenings or lumps, which did not differ between respondents of the tailored information group and respondents of the general information group when using Chi-square tests, but did differ when using logistic regression (O.R. $=1.44,95 \% \mathrm{CI}=1.054-1.980, \mathrm{p}<.05)$.

\section{Differences among subgroups in the evaluation of the tailored information}

Separate analyses were performed in the tailored information group to test whether various subgroups, based on demographic differences or behavioral differences, influenced the percentage of readers that actually used the material, the evaluation of the format and the evaluation of the content.

Logistic regression analysis was performed to assess the influence of demographics and behavior on reading the information, saving the information and discussing the information with others. The tailored information was read by older respondents more often $(\mathrm{O} . \mathrm{R} .=1.04,95 \% \mathrm{CI}=1.009-1.080, \mathrm{p}<.05)$ and discussed by older respondents more often (O.R. $=.98,95 \% \mathrm{CI}=0.967-0.996, \mathrm{p}<.05)$. The information was discussed more often by respondents with a partner $(\mathrm{O} . \mathrm{R} .=1.87,95 \% \mathrm{CI}=1.225-2.873, \mathrm{p}<.01)$. Other subgroups did not differ in terms of level of use.

Multiple regression analysis was performed in order to see whether demographic variables and early detection behaviors influenced the evaluation of the tailored information with respect to the format. No significant factors could be identified that were related to differences in the evaluations of the format of the tailored intervention.

Multiple regression analysis was also performed to indicate which variables were significantly related to the evaluation of the content of the tailored information. Women $(\beta=.125, p<.01)$, older respondents $(\beta=.179, p<.001)$, respondents who knew someone with cancer in their direct environment $(\beta=.133, p<.01)$, respondents who were attentive to cancer symptoms $(\beta=.097, p<.05)$ and respondents who sought help within the appropriate time $(\beta=.167, \mathrm{p}<.001)$ were significantly more positive about the content of the tailored information.

\section{DISCUSSION}

This paper described the process evaluation of a newly developed tailored intervention designed to encourage people to participate in behaviors related to the early detection of cancer. Our first hypothesis dealt with the evaluation of the information. With respect to use, both types of information were read by the majority of the recipients, but the 
tailored information was saved and discussed with others more often than the general information. This result was also found in previous studies of others (Brug et al., 1996; Campbell, 1994; De Bourdeaudhuij \& Brug, 2000; Skinner et al., 1994) and confirmed in a review on tailored print communications (Skinner et al., 1999). This high level of use provides an important basis in McGuire's assumption that exposure to the message and attention to the message are the first steps for communication to be effective (McGuire, 1989). Further, an active reaction to the information, such as saving and discussing, suggests that the recipient thinks and talks about the information, which is more likely to lead to a greater elaboration of the information (Kreuter et al., 2000).

Additional, the tailored information was more positively evaluated than the general information with respect to aspects of format; for example, it made respondents feel personally addressed, and was considered interesting, new and attractive. With respect to aspects of the content of the tailored information, the information on the advantages and disadvantages of paying attention to cancer symptoms and on what respondents can do to contribute to early detection was viewed as being more sufficient by the recipients of the tailored information. Brug et al. (1998) and De Bourdeaudhuij and Brug (2000) also found that tailored information was more interesting, personally relevant and new compared to general information. Personally relevant and credibility were two factors consistently identified as better for tailored information compared to non-tailored information (Skinner et al., 1999). Credibility in our study was not found to be significantly better. This might be explained by the fact that the non-tailored information was an original brochure of the Dutch Cancer Society, which is considered to be a highly credible organization in the Netherlands.

The second hypothesis addressed increased worries about complaints or diagnosis due to the tailored information. No differences were found between the tailored and the general information regarding worries about a particular complaint or diagnosis, which is consistent with other studies (Best et al., 1996; Månsson et al., 1999; Weist, 1996). This is probably due to the fact that both the tailored information and the general information stressed that fear can be reduced by actively responding to newly detected symptoms and that a physician may take the fear away.

Our third hypothesis stated that, more than general information, tailored information influences changes in attitudes toward passive detection and help seeking, as well as passive detection and help-seeking behaviors. Regarding attitude aspects this was true for three out of four attitude concepts. This indicates that the tailored information, which was based on the ASE model and thus addressed someone's present attitude, was able to establish more positive attitudes. The ASE model seems a helpful model for developing 
feedback messages. Furthermore, the effects of the information on passive detection behaviors in particular, but also on the majority of help-seeking behaviors for cancer symptoms, were due to the tailored information. This may be explained by the fact that the respondents of the tailored information felt significantly more personally addressed than other respondents. According to Petty and Cacioppo (1986), feeling personally addressed is likely to trigger someone's motivation to thoughtfully consider and process the information. Moreover, personally relevant information is more likely to result in changes in attitude and behavior. Compared to the respondents in the general information group, the respondents in the tailored information group also reported that the advantages and disadvantages were addressed more sufficiently, which may have resulted in more favorable attitudes toward passive detection behavior.

We also hypothesized that there would be no differences between subgroups within the tailored information group regarding aspects of use, format and content. Indeed we found that there were no differences between subgroups in the evaluation of the format aspects. This indicates that all respondents were positive about format aspects, which was considered to address respondents personally and offer understandable and interesting information, independent on demographic or behavioral differences. In other words, the format of the tailored information was sufficiently adapted to the characteristics of the target group.

Regarding use and content we did find a number of differences in the evaluation between subgroups. Older respondents were more likely to read and discuss the tailored information. This might be due to the fact that cancer is more likely to occur in older people than in younger people, and thus information on cancer may be more interesting and personally relevant to older respondents. The differences between subgroups in the evaluation of the content might be explained by the fact that the format on how to communicate the information was tailored to the individual level, i.e., personally relevant to the recipient, rather than the content. An example of the first is that the information on the possible cancer symptoms was adjusted to the foreknowledge, while in the latter all respondents received information on the possible cancer symptoms. Alternatively, tailored information might be effective when it fits between behavioral characteristics and the content of the message, but does not have to work when the tailored information does not well-match the characteristics of the recipient, as suggested by Kreuter et al. (2000).

The specific part on TSE was evaluated only by very few people in the target group, as a result of which it is not possible to draw conclusions with confidence. An explanation for the less positive evaluation of the TSE part might be that young and male respon- 
dents gave lower scores in their evaluations on several other aspects as well. This was found in the results of the multiple regression analysis on the evaluation of the general part of the tailored information, where men and younger people were less positive. For TSE, the target group consisted of the young, male respondents, which is also the group that evaluated the information less positively. It is possible that this subgroup does not like the information provided (content aspects), that they do not like the format of the information (format aspects), and that they are not receptive to health information about early detection of cancer at all. These issues should be further studied.

A limitation of the study is the low percentage of male participants. Therefore, the results can be less easily generalized to men than women, among those who are interested in information on early detection of cancer. Young men, the high-risk population for testicular cancer, were underrepresented in our study sample. Future studies should pay attention to the selection of the study group and possibly to the dissemination of the health education information. Further research should explore how to interest this group in health education about early detection of cancer or about health issues in general, and which channels should be used to reach them.

In sum, tailored information seems to be a highly appreciated form of communication about early detection of cancer, both in format and in content. Tailored information also contributes effectively to people's attitudes and early detection behaviors compared to general information. Further research is needed to explore the impact of tailored information on behaviors concerning the early detection of cancer in the long term. 


\section{A RANDOMIZED CONTROLLED STUDY OF SHORT-TERM AND LONG-TERM EFFECTS OF TAILORED INFORMATION VERSUS GENERAL INFORMATION ON DETERMINANTS AND BEHAVIORS RELATED TO EARLY DETECTION OF} CANCER

\section{ABSTRACT}

The effects of computer-tailored information and general information on early detection behaviors were assessed and compared with those in a control group, in a randomized controlled study with a pretest and two posttests. The main outcome variables were passive detection and help-seeking intentions and behavior, as well as social psychological determinants. Possible negative side effects, like increased chronic fear of cancer and more fatalistic attitudes toward cancer, were studied as well. Three weeks after the intervention, significant differences between the study groups were found in behavior, intention, several social psychological determinants and knowledge; the tailored information group showed more knowledge and more favorable intentions and behaviors. Six months after the intervention, there were still differences between the tailored information group and the control group in intentions and passive detection behavior. Furthermore, differences remained between the tailored information group and both other groups with respect to help-seeking behavior. Neither of the interventions resulted in increased chronic fear of cancer or more fatalistic attitudes toward cancer. It is concluded that there were very positive effects of the tailored intervention in the short term, but additional research is needed to assess ways of maintaining these effects in the long-term.

Manuscript submitted for publication as:

De Nooijer, J., Lechner, L., Candel, M. \& De Vries, H. A randomized controlled study of short-term and long-term effects of tailored information versus general information on determinants and behaviors related to early detection of cancer. 


\section{INTRODUCTION}

It is widely accepted that the earlier cancer is detected, the better the chances of treatment and survival (Bailar \& Gornik, 1997; Ruwaard \& Kramers, 1997). In practice, however, cancer detection and diagnosis are often subject to delays (Byles et al., 1992; Cassileth et al., 1988; Cochran et al., 1986; Doherty \& MacKie, 1986; Facione, 1993; Lauver \& Chang, 1993). Therefore, people should be encouraged to engage in early detection behaviors, such as being attentive to cancer symptoms, self-examination, seeking medical help when symptoms are detected, and participating in screening programs.

Many programs have been developed to encourage people to perform breast selfexamination (BSE) or testicular self-examination (TSE) and to participate in screening programs for breast and cervical cancer (Assaf et al., 1985; Best et al., 1996; Friman et al., 1986; Paskett et al., 1998; Rakowski et al., 1998; Skinner et al., 1994; Solomon et al., 1998; Strickland et al., 1997). Far less has been done to enhance attentiveness to general cancer symptoms and to seeking help for these symptoms. A study in Sweden attempted to shorten patient delay by informing patients about cancer symptoms of common forms of cancer by letter. Patients were invited to visit health centers if the symptoms mentioned in the letter were observed (Månsson et al., 1999). This resulted in 234 visits and the detection of 15 cancers, of which 13 were localized. Another study was undertaken to improve specifically the prognosis of melanoma by providing the general public with information on features of early melanoma, and to encourage people to consult a physician if they recognized such lesions on their skin (Doherty \& MacKie, 1986). Very promising results were obtained within a period of six months after the intervention: the proportion of patients diagnosed with 'good prognosis' had increased from $38 \%$ to $62 \%$, while the proportion of patients with 'poor prognosis' had decreased from $34 \%$ to $15 \%$. Unfortunately, no control groups were included in either of these studies, so the value of the conclusions on patient delay or prognosis was limited.

In the Netherlands, the Dutch Cancer Society has developed several brochures informing the general public about early detection of cancer, including the 'warning signs of cancer', BSE, TSE, and participating in screening programs. Furthermore, a mass media campaign was launched a few years ago within the framework of the European Week Against Cancer, attempting to get men to pay attention to symptoms of forms of cancer common among men (Dutch Cancer Society, 1998). Unfortunately, these interventions were not evaluated for their effects. 
It is often questioned whether interventions on early detection of cancer may cause fear. Fear may lead to different coping styles, for instance by avoiding the threatening situation (Sarafino, 1998). This might mean that people who cannot cope with the fear associated with the detection of cancer, and who have little trust in the effectiveness of medical treatment, respond with fatalistic opinions toward cancer, such as 'if you find a cancer symptom, it's too late to do anything about it anyway' and hence do not engage in early detection behaviors (Olson \& Morse, 1996). In the Swedish study the information did not cause anxiety (Månsson et al., 1999), and the same was found in studies providing information about breast self-examination, testicular cancer, and testicular selfexamination (Best et al., 1996; Hobbs et al., 1984; Weist, 1996). Nevertheless, in developing health education interventions on early detection of cancer, the undesirable sideeffect of fear should be very carefully taken into consideration.

A promising and relatively new approach in health education is computerized tailoring, which adapts health education messages to the characteristics, needs and interests of the recipient (De Vries \& Brug, 1999; Dijkstra \& De Vries, 1999b; Kreuter, Strecher et al., 1999). This leads to more personally relevant information, which is more likely to be thoughtfully considered (Petty \& Cacioppo, 1986) and is therefore more effective in changing determinants and behaviors than generic information (Kreuter et al., 1999). Computerized tailoring has been shown to change intentions and behaviors, such as reducing fat intake and stimulating fruit and vegetable intake (Brug et al., 1999; Brug et al., 1996; Campbell et al., 1994), smoking cessation (Dijkstra, De Vries \& Roijackers, 1998; Strecher et al., 1994), losing weight (Kreuter et al., 1999), and participating in mammography screening (Rakowski et al., 1998; Skinner et al., 1994). Computerized tailoring focuses on individuals. Messages are based on individual self-reported behavior and beliefs (Kreuter et al., 2000).

If the goal of an intervention is to encourage healthy behavior, it is necessary to know what the underlying factors are which decide whether a person will engage or not engage in that particular behavior (Rhodes, Fishbein \& Reis, 1997). The Attitude-Social Influence-Self Efficacy (ASE) model (De Vries et al., 1995; De Vries et al., 1988), which can be regarded as an extended version of the Theory of Planned Behavior (Ajzen, 1991), has proven to be a helpful model in understanding various behaviors related to the early detection of cancer (Lechner et al., 1997). This model distinguishes three behavioral determinants, influencing people's motivation or intention to perform a particular behavior. The first determinant, attitude, refers to a person's beliefs about the behavior, for instance the advantages or disadvantages he or she expects from performing the behavior. The attitude concept has recently been supplemented with two affective 
components (Lechner, 1998). The first is anticipated regret, which is the feeling of regret someone expects to experience afterwards if he or she chooses not to perform the behavior. The second is moral obligation, which refers to a personal belief about what ought to be done. Behavior or intentions toward behavior are also influenced by what important people in someone's environment do or think, which refers to the second determinant, social influence. The third determinant is self-efficacy, that is, someone's belief in his or her own capability to perform the behavior. This determinant is closely related to the perceived behavioral control construct in the Theory of Planned Behavior.

So far, no tailored interventions have been developed or evaluated to motivate asymptomatic people to engage in early cancer detection behaviors, except for those stimulating women to have mammography. A randomized controlled study with a pretest and two posttests was conducted to test two different interventions, a computerized tailored intervention and the standard general information currently provided by the Dutch Cancer Society to encourage the Dutch adult population to participate in early detection behaviors. We studied the effects of the two interventions on behaviors, intentions, social psychological determinants of intentions and behaviors, and knowledge, immediately after the intervention and after six months, and compared these with the same parameters in a control group which received no information. It was hypothesized that the changes in social psychological determinants, intentions and behaviors would be significantly more positive for the recipients of the tailored information. Furthermore, we hypothesized that the tailored information would not increase chronic fear of cancer or fatalistic attitudes toward cancer.

\section{METHODS}

\section{Study design and procedures}

A randomized controlled study with a pretest and two posttests to evaluate the impact of a computerized tailored intervention on early detection of cancer was conducted among 1855 Dutch adults. Subjects were recruited in January 1999 by means of an announcement in local door-to-door newspapers throughout the Netherlands and in one national newspaper. Those interested in participation were asked to register by telephone or email. Subjects were randomly assigned to the tailored information group, the general information group or the control group. After registration by telephone or e-mail, subjects received information about the study, an informed consent form and the first questionnaire (TO). Subjects who were cancer patients at TO were excluded from all 
analyses, but they remained included in the sample and, since they had agreed to participate in the study, they received information and the first posttest. The tailored information and the general information were mailed to the subjects within three weeks after the first questionnaire had been returned. The control group did not receive any information, but they were given the general information after completion of the study. Three weeks after the intervention, and for the control group six weeks after the first questionnaire, all subjects received a second questionnaire (T1). All subjects whose second questionnaire was received and who did not suffer from cancer at TO were approached by telephone for a short interview on their behavior and intentions regarding early detection six months after the intervention (T2). The study was approved by the university's medical ethics committee.

\section{Questionnaires}

The ASE model was used as a framework for the questionnaires. Behavior and intentions regarding early detection of cancer were measured at To (screening questionnaire and pretest) and T1 (first posttest) by means of written questionnaires and at T2 (second posttest) by means of a telephone interview. At T0 and T1, social psychological determinants of early detection behaviors were assessed as well. The different concepts assessed are described below.

Behavior was assessed in terms of passive detection and help-seeking behavior: - Passive detection, which is defined as becoming aware of cancer symptoms without having undertaken any concrete action, was assessed using 14 questions regarding 14 cancer symptoms (i.e., blood in stool, coughing up blood, indigestion, swallowing problems, sores that do not heal, appearance of warts, appearance of moles, changes in a mole, thickenings or lumps, unusual weight loss, nagging cough or hoarseness, changes in bowel habits, blood in urine, urinary problems). An example of such a question would be "How often do you pay attention to ...?" Questions had to be answered on a 5point scale (always to never). A passive detection score was computed as the mean score on all 14 items (Cronbach's $\alpha=.93$ ).

- Help-seeking behavior was assessed by means of 14 items relating to the 14 cancer symptoms, for instance, "After what period of time would you consult a physician if you detected the following cancer symptom?" Answers were given on a 6-point scale (within one week to never). Data was recoded into 'correct help-seeking behavior' (i.e., seeking medical help within one week for blood in stool, coughing up blood, the appearance of warts or new moles or changes in a mole, thickenings or lumps or blood in urine; and seeking medical help within four weeks for indigestion or swallowing 
problems, sores that do not heal, musual weight los, ansing cough or hourseness, changes in bowel habits or urinary problensin in accordance with recommendunions of the Dutch Cancer Society (Dutch Cancer Society, 1996) and raking diagnestic inlormation into consideration. A help-secking behavioral score was computed from the mean scores of the dichotomized help-secking behavior items (Crenbach's a $=90$ ). Thus, a helpseeking score could vary from 0 to 1 , where 0 meant incorrect helpseding behavior for any of the possible cancer symptoms and 1 meant correct helpsecking behavior for all possible cancer symptoms.

Intemtion to engage in passive detection behavior and help-secking bohavior was assessed using 1 item for each of the 14 cancer symptoms. Answcring alternatives varied from certainly not $(-3)$ to certainly would (3). Intention scores for passive detection (Cronbach's $\alpha=.93$ ) and help-secking behavior (Cronbach's $\alpha=.92$ ) were computed by calculating the means of each of the scales.

Attitudes toward early detection behaviors were assessed using several coneepts:

- Advantages were assessed by 4 items for passive detection (Cronbach's $\alpha=, 68$ ) and by 4 items for seeking help (Cronbach's $\alpha=.59$ ), for example, "To what cxtent do you think paying attention to cancer symptoms is not useful at all (1) to very useful (4) ?*

- Disadvantages were assessed by means of 3 items for passive detection (Cronbach's $\alpha=.72)$ and 5 items for help seeking (Cronbach's $\alpha=.75$ ), for example, "To what extent would you be worried if you visited a physician with a possible cancer symptom?" Answers ranged from not worried at all (1) to very worried (4).

- Moral obligation was assessed using 1 item for passive detection and 1 item for help seeking, for instance "To what extent do you consider it an obligation to yourself and your family to pay attention to cancer symptoms?" Answers ranged from no obligation (1) to very strong obligation (4).

- Anticipated regret was assessed by means of 1 item for passive detection and 2 items for help seeking behavior $(r=.64)$, for instance, "If you did not pay attention to cancer symptoms and cancer was diagnosed afterwards, would you feel no regret (1) to much regret (4) that you had not been more attentive?"

Social influence was assessed by two concepts:

- Social norm of the partner, family members, friends and the family physician was assessed by means of 4 items on passive detection (Cronbach's $\alpha=.68$ ) and 4 items on help seeking (Cronbach's $\alpha=.61$ ), for instance, "Does your partner think you should pay attention to cancer symptoms?" Answers ranged from certainly not (-2) to certainly does (2). 
- Modeling was assessed by means of 1 item for both passive detection and help seeking, for instance, "How many people in your immediate environment pay attention to cancer symptoms?" Answers ranged from almost none (1) to almost everyone (5).

Self-efficacy regarding passive detection was assessed by 1 item referring to the respondent's general expected ability to pay attention to cancer symptoms and 1 item on the extent to which the respondent found it difficult to pay attention to cancer symptoms. Self-efficacy regarding seeking help for possible cancer symptoms was assessed by 1 item referring to the respondent's general expected ability to seek help for cancer symptoms and 1 item regarding the extent to which the respondent found it difficult to seek help for cancer symptoms. Furthermore, self-efficacy was assessed by 4 situational items (Cronbach's $\alpha=.88$ ), assessing whether the respondents were able to seek help in four different situations (when they doubted whether the symptom was a cancer symptom, when they expected the physician to think the complaint was not serious, when they themselves expected the complaint not to be serious, when they experienced fear).

Three additional concepts that are possibly related to passive detection as well as to help seeking behavior were assessed:

- Knowledge was assessed by means of a 15-item scale adapted from Berman and Wandersman's Knowledge of Cancer Warning Signs Inventory (1991). The scale consisted of 10 correct symptoms and 5 incorrect symptoms, assessing whether respondents were able to distinguish cancer symptoms from non-cancer symptoms. For each symptom, respondents were asked to indicate on a 5-point scale whether they thought these symptoms were possible cancer symptoms (very sure to very unsure). All items were dichotomized for the analysis into correct (i.e., sure or very sure for cancer symptoms and unsure or very unsure for non-cancer symptoms) or incorrect (all other answers). A total knowledge score was computed by adding all correct answers (Cronbach's $\alpha=.70$ ).

- Chronic fear of cancer was assessed using 5 items (Cronbach's $\alpha=.73$ ): "How scared are you of getting cancer?", "How upsetting do you find it when you read or hear something about cancer?", "To what extent do you feel that getting cancer would be devastating to your life?", "If you were to develop cancer, how likely do you think you would be to die from it?", and "How likely do you think it is that you personally will develop cancer at some point in your life?" The concept of chronic fear of cancer was based on a questionnaire by Jepson and Chaiken (1990). The 10-point scale was changed to a 5-point scale.

- Fatalistic attitudes toward early detection were assessed by means of 3 items (Cronbach's $\alpha=.72$ ), using statements like "If cancer is detected in the early stages, misery is even 
prolonged." Respondents had to say whether they disagreed completely $(-2)$ or agreed completely (2) with the statement.

Demographic variables (sex, age, level of education, and marital status) were asked for, as well as whether respondents had ever had cancer or had experienced cancer in their immediate environment.

\section{The intervention}

Three elements are necessary to develop a computer-tailored intervention. First, a screening questionnaire, which provides the data on which the tailored feedback will be based. In our study, the pretest (T0) was used as the screening questionnaire. Second, a message source file, which contains feedback messages for all possible answers included in the screening questionnaire. Third, a computer program to connect the screening questionnaire and the message source file, to facilitate the combining of messages, and to print this as a personal letter.

The message source file consisted of 319 feedback messages. The file contained messages tailored to the individual's knowledge of cancer symptoms and early detection behavior (passive detection, help-seeking behavior, BSE, TSE, participating in screening programs for breast and cervical cancer). Further, messages were included on reasons for early detection of cancer, risk perception, social psychological determinants (attitudes, social influence and self-efficacy), fear of cancer and fatalistic attitudes toward cancer. The tailored information comprised approximately 6 to 8 pages, depending on the messages.

The computer program connects the screening instrument with the right messages and generates the personal letters. The tailoring algorithms were logical statements ('if-then' statements) (Kreuter et al., 2000).

The general information that was used was one of the brochures on early detection currently used by the Dutch Cancer Society (1991). The brochure contained information similar to that in the tailored information and addressed the importance of early detection, fear of cancer, cancer symptoms, screening programs for breast and cervix cancer, early detection of skin cancer and primary prevention of cancer.

\section{Statistical analysis}

Respondents who completed the three questionnaires and who did not suffer from cancer at TO were included in the analysis. All analyses were done with SPSS.

Multivariate analyses of covariance were performed to determine differences in means between study groups regarding knowledge and social psychological determinants at T1, 
adjusting for preexisting knowledge, social psychological determinants and the demographic variables (sex, age, educational level, having a partner, knowing someone with cancer in the immediate environment, and having had cancer in the past). We used Pillai's Trace, which is the most robust criterion to test the significance of the main effect (Tabachnick \& Fidell, 1996). If a main effect of the three study groups on knowledge and determinants was found in the multivariate test, univariate tests were performed for each of the dependent variables. Subsequently, pairwise comparisons were made between the three study groups for the variables that turned out to be significant in the univariate tests, employing the Bonferroni procedure (adjusted for three comparisons $\alpha=0.05 / 3=0.0167$ ).

To investigate the effects of the intervention on (1) passive detection and help-seeking intentions and behavior, (2) chronic fear of cancer and (3) a fatalistic attitude toward cancer in the different study groups, differences between study groups at the first posttest (T1) and the second posttest (T2) were analyzed by means of repeated measures analyses of covariance, adjusting for the scores at the pretest (T0). In the case of a group-time interaction effect, indicating that the mean difference between the two post-tests depended on the study group, separate analyses of covariance were performed to study the effects on T1 and T2. The covariates included in this analysis were the intentions to engage in passive detection and help-seeking behavior, the behavior itself, chronic fear of cancer and fatalistic attitude at the pretest (TO), sex, age, educational level, having a partner, knowing someone with cancer in the immediate environment, and having had cancer in the past. When a group effect was found, pairwise comparisons using Bonferroni (adjusted $\alpha=0.0167$ ) were performed to analyze differences between study groups, based on the estimated marginal means (i.e., corrected for the covariates). In the case of a group-time interaction effect, paired T-tests were also performed to compare means between $\mathrm{T} 1$ and $\mathrm{T} 2$ within each study group.

\section{RESULTS}

\section{Respondents}

Of the initial 1855 volunteers subjects, 1500 met the criteria for being approached for the telephone questionnaire at T2 (i.e., having completed the written questionnaires at T0 and $\mathrm{T} 1$, not having cancer at $\mathrm{T} 0$, having a telephone, and having indicated at $\mathrm{T} 0$ that they were willing to participate in the telephone questionnaire). A total of 1358 (73\%) subjects completed the telephone questionnaire, equally distributed across the tailored 
information group (32\%), the general information group (33\%) and the control group (35\%). The non-response consisted of 109 respondents who were not reached within the time available for the telephone questionnaire for various reasons (unanswered calls, answering machines, or appointments could not be made within the period available for data collection). In two percent of the cases, the subjects $(n-33)$ were reached, but the participant had no time to participate, had moved to another address or was abroad.

The study population was predominantly female $(80 \%)$, on average 47 years old (SD $12.93)$, and most of them had a partner (79\%). Of the respondents, $36 \%$ had completed primary school or basic vocational training, $35 \%$ had completed secondary vocational training or high school and $29 \%$ had a higher vocational or university degree. Most respondents $(92 \%)$ had been confronted with someone with cancer in their immediate environment, while $11 \%$ of the respondents had suffered from cancer themselves at one point in their lives.

\section{Knowledge of cancer symptoms and determinants of passive detection and help-seeking behavior}

The effects of the intervention at the first post-test on knowledge of cancer symptoms and determinants, after adjusting for pre-existing knowledge, attitudes, social influences, self-efficacy expectations, and demographic variables, were tested by means of multivariate analyses of covariance.

Table 7.1 shows the significant values for each of the F-tests of the individual dependent values, as well as the mean scores of knowledge of cancer symptoms, determinants of passive detection and help-seeking behavior at the first posttest (T1) and tests of the pairwise differences in means between the study groups. A main effect of group was found by using Pillai's Trace $(F(36,2246)=3.98, p<.001)$, which means that there was an overall effect of study group on all dependent variables (knowledge and determinants). The univariate test showed that the groups differed significantly for a large number of dependent variables. Pairwise comparisons showed that the tailored information group had a significantly higher level of knowledge than the general information group and the control group, while the general information group knew more cancer symptoms than the control group, while the tailored information group expected more advantages of passive detection and of help-seeking behavior than the two other groups. Compared to the general information group, the tailored information group perceived fewer disadvantages of help-seeking behavior. The tailored information group expected to experience more feelings of regret than the general information group and the control group. Moreover, the tailored information group perceived a more positive social norm toward 
passive detection and help-seeking behavior, and they also perceived more people in their environment who were engaged in passive detection compared to the control group. The tailored information group reported higher self-efficacy expectations regarding their abilities for passive detection than the general information group and the control group. The tailored information group and in the general information group reported higher expectations regarding difficulties of being attentive to cancer symptoms than the control group. Furthermore, the tailored information group had higher self-efficacy expectations about the ability to engage in help-seeking behavior than the control group.

Table 7.1 Knowledge and social psychological determinants of passive detection behavior and help-seeking behavior: range, mean scores (standard deviation) at the first posttest (T1) and analyses of variance results.

\begin{tabular}{|c|c|c|c|c|c|c|}
\hline & Range & $\begin{array}{l}\text { Tailored } \\
\text { information } \\
\text { (T) }(n=430)\end{array}$ & $\begin{array}{l}\text { General } \\
\text { information } \\
\text { (G) }(n=439)\end{array}$ & $\begin{array}{l}\text { Control } \\
\text { group } \\
\text { (C) }(n=462)\end{array}$ & $F$ & $\begin{array}{c}\text { Pairwise } \\
\text { comparisons } \\
\alpha=.0167\end{array}$ \\
\hline Knowledge & $(0,15)$ & $9.85(3.13)$ & $9.26(3.37)$ & $8.21(3.27)$ & $30.28^{m * 1 *}$ & $T>G>C$ \\
\hline \multicolumn{7}{|l|}{ Passive detection } \\
\hline Attitude - advantages & $(1,4)$ & $3.18(0.50)$ & $3.13(0.52)$ & $3.07(0.48)$ & $11.70^{\text {tw* }}$ & $T>G, C$ \\
\hline Attitude - disadvantages & $(1,4)$ & $2.05(0.70)$ & $2.05(0.69)$ & $2.09(0.68)$ & $3.05^{*}$ & ns \\
\hline Moral obligation & $(1,4)$ & $3.43(0.60)$ & $3.41(0.60)$ & $3.40(0.59)$ & 1.10 & ns \\
\hline Anticipated regret & $(1,4)$ & $3.58(0.51)$ & $3.52(0.78)$ & $3.48(0.72)$ & $4.78^{* *}$ & $T>G, C$ \\
\hline Social norm & $(-2,+2)$ & $1.45(0.59)$ & $1.42(0.58)$ & $1.38(0.61)$ & $5.01^{* *}$ & $\mathrm{~T}>\mathrm{C}$ \\
\hline Modeling & $(1,5)$ & $1.95(2.00)$ & $1.76(1.94)$ & $1.67(1.83)$ & $4.75^{* *}$ & $\mathrm{~T}>\mathrm{C}$ \\
\hline Self-efficacy ability & $(-2,+2)$ & $0.60(0.95)$ & $0.48(1.03)$ & $0.31(1.01)$ & $15.38^{m * *}$ & $T>G, C$ \\
\hline Self-efficacy difficulties & $(-2,+2)$ & $-0.16(0.83)$ & $-0.15(0.83)$ & $-0.32(0.78)$ & $8.95^{* \cdots *}$ & $\mathrm{~T}, \mathrm{G}>\mathrm{C}$ \\
\hline \multicolumn{7}{|l|}{ Help seeking } \\
\hline Attitude - advantages & $(1,4)$ & $3.13(0.47)$ & $3.06(0.49)$ & $3.00(0.46)$ & $15.94 \cdots$ & $T>G, C$ \\
\hline Attitude - disadvantages & $(1,4)$ & $2.08(0.64)$ & $2.16(0.66)$ & $2.11(0.61)$ & $4.01^{*}$ & G>T \\
\hline Moral obligation & $(1,4)$ & $3.44(0.55)$ & $3.41(0.57)$ & $3.41(0.55$ & 1.09 & ns \\
\hline Anticipated regret & $(1,4)$ & $3.41(0.68)$ & $3.36(0.76)$ & $3.32(0.70)$ & $4.47^{*}$ & $T>G, C$ \\
\hline Social norm & $(-2,+2)$ & $1.67(0.47)$ & $1.65(0.44)$ & $1.63(0.48)$ & $5.37^{* *}$ & $\mathrm{~T}>\mathrm{C}$ \\
\hline Modeling & $(1,4)$ & $2.31(2.18)$ & $2.28(2.11)$ & $2.15(2.11)$ & 1.28 & ns \\
\hline Self-efficacy ability & $(-2,+2)$ & $1.60(0.62)$ & $1.60(0.60)$ & $1.54(0.65)$ & $3.24^{*}$ & $\mathrm{~T}>\mathrm{C}$ \\
\hline Self-efficacy difficulties & $(-2,+2)$ & $0.31(1.06)$ & $0.23(1.04)$ & $0.26(1.07)$ & 2.15 & ns \\
\hline Self-efficacy situations & $(-2,+2)$ & $1.25(0.73)$ & $1.24(0.73)$ & $1.22(0.76)$ & 2.34 & ns \\
\hline
\end{tabular}

"p<.05; "* $p<.01 ; * \cdots p<.001 ; n s$ not significant

Note. All analyses are based on estimated marginal means. 


\section{Passive detection intention and help-seeking intention}

Effects of the interventions on intentions were measured twice; three weeks after the intervention (T1) and six months after the intervention (T2). Table 7.2 lists the mean scores and standard deviations of the intentions to engage in passive detection and helpseeking behavior at the pretest, the first posttest and the second posttest. Repeated measures analyses of covariance showed significant group-time interactions for the passive detection intention $(\mathrm{F}(2,1289)=18.89, \mathrm{p}<.001)$ and for the help-seeking intention $(\mathrm{F}(2,1288)=14.53, \mathrm{p}<.001)$. This indicates significant differences between study groups in changes in intentions between the first and the second posttest. Table 7.2 reveals that the higher intention scores for passive detection as well as for help-seeking behavior in the tailored information group increased somewhat between the first and the second posttest $(\mathrm{T}=-2.60, \mathrm{df}=434, \mathrm{p}<.01$ for passive detection intention and $\mathrm{T}=-2.94, \mathrm{df}=434$ $\mathrm{p}<.01$ for help-seeking intention), while the lower scores of the general information and control groups increased considerably (general information group: $\mathrm{T}=-7.03, \mathrm{df}=446$, $\mathrm{p}<.001$ for passive detection intention and $\mathrm{T}=-6.80, \mathrm{df}=445, \mathrm{p}<.001$ for help-seeking intention; control group: $\mathrm{T}=-11.17, \mathrm{df}=463, \mathrm{p}<.001$ for passive detection intention and $\mathrm{T}=-9.64, \mathrm{df}=464, \mathrm{p}<.001$ for help-seeking intention).

To test whether mean scores in intentions toward passive detection differed for the two posttests, separate analyses of covariance were performed at the first and second posttests. At the first posttest, a significant group effect was found regarding passive detection intention $(\mathrm{F}(2,1290)=53.58, \mathrm{p}<.001)$. Pairwise comparisons showed significant differences in intention scores toward passive detection for the three groups; the tailored information group scored higher than the general information group and the control group, and the general information group scored higher than the control group on the intention to engage in passive detection measured at T1. At the second posttest, the

Table 7.2 Mean (standard deviation) of passive detection intention (range -3, 3) and help-seeking intention (range -3, 3) at pretest (T0), first posttest (T1) and second posttest (T2).

\section{Tailored information \\ General information \\ Control group}

(T) $(n=434)$

(G) $(n=446)$

$1.42(1.01)$

$1.95(0.87)$

$2.05(0.81)$

T2

Help-seeking intention

TO

T1

T2
$1.57(0.91)$

$2.03(0.79)$

$2.13(0.76)$
$1.48(1.06)$

$1.78(0.91)$

$2.05(0.83)$

$1.62(0.92)$

$1.86(0.83)$

$2.09(0.80)$
(C) $(n=465)$

$1.50(0.92)$

$1.52(0.89)$

$1.96(0.80)$

$1.67(0.83)$

$1.63(0.87)$

$1.99(0.75)$
Pairwise

comparisons

$\alpha=.0167$

Note. All analyses are based on estimated marginal means. 
significant group effect remained $(F(2,1299)=5.90, \mathrm{p}<.01)$, although it had become less significant. Pairwise comparison showed a significant difference in the mean score between the tailored information group and the control group on the intention to engage in passive detection.

Likewise, significant differences in help-seeking intentions were found between the three study groups at the first posttest $(\mathrm{F}(2,1289)=60.71, \mathrm{p}<.001)$ and at the second posttest $(\mathrm{F}(2,1298)=11.81, \mathrm{p}<.001)$. At the first posttest, pairwise comparisons showed significant differences between the three study groups in scores on the intention to engage in help-seeking behavior; the tailored information group scored higher than the general information group and the control group, while the general information group scored higher than the control group. At the second posttest, the tailored information group had higher scores on the intention to engage in help-seeking behavior than the general information group and the control group.

\section{Passive detection and help-seeking behavior}

Table 7.3 lists the mean scores of passive detection and help-seeking behavior at the pretest, first posttest and second posttest. Repeated measures analyses of covariance showed a significant group-time interaction effect for passive detection $(F(2,1283)=12.14$, $\mathrm{p}<.001)$ and help-seeking behavior $(\mathrm{F}(2,1294)=8.51, \mathrm{p}<.001)$, indicating that the three study groups differed significantly in the change in mean scores of passive detection and help-seeking behavior between the first and the second posttest. The high mean scores of the tailored information group on passive detection and on help-seeking behavior at the first posttest remained at the same level at the second posttest (ns), while the lower mean scores of the general information group and the control group continued to increase

Table 7.3 Mean (standard deviation) of passive detection behavior (range 1, 5) and help-seeking behavior (range 0,1$)$ at pretest (TO), first posttest (T1) and second posttest (T2).

Tailored information General information Control group

Pairwise

(T) $(n=431)$

(G) $(n=443)$

(C) $(n=463)$

comparisons

$\alpha=.0167$

\begin{tabular}{lllll} 
Passive detection behavior & & & & \\
T0 & $2.87(0.98)$ & $2.86(0.96)$ & $2.90(0.98)$ & - \\
T1 & $3.70(0.90)$ & $3.34(0.96)$ & $3.18(0.92)$ & T>G>C \\
T2 & $3.70(0.90)$ & $3.57(0.99)$ & $3.47(0.96)$ & T>G,C \\
Help-seeking behavior & & & & \\
T0 & $0.58(0.24)$ & $0.57(0.25)$ & $0.59(0.24)$ & - \\
T1 & $0.68(0.21)$ & $0.61(0.25)$ & $0.59(0.24)$ & T>G>C \\
T2 & $0.69(0.21)$ & $0.66(0.23)$ & $0.65(0.21)$ & T>G,C \\
\hline
\end{tabular}

Note. All analyses are based on estimated marginal means. 
(general information group: $\mathrm{T}=-5.37, \mathrm{df}=444, \mathrm{p}<.001$ for passive detection and $\mathrm{T}=$ 4.86, $\mathrm{df}=448, \mathrm{p}<.001$ for help-seeking behavior; control group: $\mathrm{T}=-6.43, \mathrm{df}=463$, $\mathrm{p}<.001$ for passive detection and $\mathrm{T}=-6.50, \mathrm{df}=464, \mathrm{p}<.001$ for help-seeking behavior) (Table 7.3).

At the first posttest, a group effect was found on passive detection $(F(2,1284)=67.11$, $\mathrm{p}<.001)$. Pairwise comparisons showed significant differences between the three study groups; the tailored information group was more attentive to cancer symptoms than the general information group and the control group, while the general information group was more attentive than the control group. There was also a significant group effect at the second posttest $(\mathrm{F}(2,1297)=11.79, \mathrm{p}<.001)$. Pairwise comparisons showed that the tailored information group was more attentive than the general information group and the control group at the second posttest, but there was no significant difference between the general information group and the control group.

Similar analyses were performed for help-seeking behavior. Analysis of covariance found a significant group effect on the first posttest $(F(2,1294)=36.98, p<.001)$. Pairwise comparisons showed that the tailored information group reported more appropriate help-seeking behavior than the general information group and the control group, while the general information group reported more appropriate help-seeking behavior than the control group. A significant group effect was also found at the second posttest $(F(2,1303)=7.86, p=.001)$. Pairwise comparisons showed a significantly higher score on help-seeking behavior in the tailored group compared to both other groups.

\section{Chronic fear of cancer and fatalistic attitudes toward early detection of cancer}

Table 7.4 presents the mean scores on chronic fear of cancer and fatalistic attitudes toward early detection of cancer at the pretest and both posttests. To determine whether the intervention to motivate people to engage in early detection behavior resulted in negative side-effects, such as increased chronic fear of cancer and more fatalistic attitudes, repeated measures analyses of covariance were performed. No interactions were found between time and group $(F(2,1241)=.67, p=.51$ for fear; $F(2,1286)=.20, p=.82$ for fatalistic attitudes). This implies that the mean differences at the two posttests did not differ significantly between groups. For fatalistic attitudes toward early detection, a group effect was found for the average of $\mathrm{T} 1$ and $\mathrm{T} 2 \quad(\mathrm{~F}=(2,1286)=3.56, \mathrm{p}<.05)$. However, pairwise comparisons did not reveal any differences between the study groups in the mean scores of T1 and T2. No group effect was found for chronic fear of cancer, which means that there were no differences between the study groups in scores on fear of cancer. 
Table 7.4 Mean (standard deviation) of chronic fear of cancer (range 1,5) and fatalistic attitudes toward early detection of cancer (range -2, 2) at pretest (TO), first posttest (T1) and second posttest (T2).

\begin{tabular}{cccc}
\hline \hline & $\begin{array}{c}\text { Tailored information } \\
(\mathbf{n}=415)\end{array}$ & $\begin{array}{c}\text { General information } \\
(\mathbf{n}=431)\end{array}$ & $\begin{array}{c}\text { Control group } \\
(\mathbf{n}=443)\end{array}$ \\
\hline $\begin{array}{c}\text { Chronic fear of cancer } \\
\text { T0 }\end{array}$ & $2.77(0.76)$ & $2.70(0.76)$ & \\
T1 & $2.66(0.73)$ & $2.66(0.76)$ & $2.71(0.73)$ \\
T2 & $2.65(0.75)$ & $2.66(0.76)$ & $2.70(0.73)$ \\
Fatalistic attitudes & & & \\
T0 & $-1.37(0.68)$ & $-1.44(0.63)$ & $-1.44(0.66)$ \\
T1 & $-1.36(0.72)$ & $-1.41(0.64)$ & $-1.34(0.69)$ \\
T2 & $-1.43(0.60)$ & $-1.43(0.58)$ & $-1.38(0.67)$ \\
\hline
\end{tabular}

Note. All analyses are based on estimated marginal means.

\section{DISCUSSION}

The present study tested the impact of a computer-tailored intervention in encouraging people to engage in behaviors associated with the early detection of cancer, and to form positive intentions toward early detection behaviors. Short-term effects showed that the tailored information group had more knowledge of cancer symptoms, more positive expectations of the advantages of early detection behaviors, and higher self-efficacy expectations toward passive detection than the control group and/or the general information group. Additionally, the recipients of the tailored information expressed more positive intentions toward engaging in passive detection and help-seeking behavior, were more attentive to cancer symptoms, and were more likely to seek appropriate help for cancer symptoms than the general information group and the control group after three weeks. After six months, significant differences in intentions and behavior remained between the tailored information group and both of the other groups, except for the intention to engage in passive detection. The tailored information group had more positive intentions toward passive detection than the control group, but the general information group did not differ from either of the other groups. This allows us to conclude that information tailored to the individual seems more effective than general information, which is in line with the findings of previous studies on tailored health information (Brug et al., 1999; Brug et al., 1996; Campbell et al., 1994; Dijkstra, De Vries \& Roijackers, 1998; Kreuter et al., 1999; Rakowski et al., 1998; Skinner et al., 1994; Strecher et al., 1994).

The tailored information group showed a significant increase in the mean scores on intentions and behavior between the pretest and the first posttest, and their scores remained high or did not decrease significantly between the first and the second posttest. 
In the general information group and the control group, the increase in intentions and behavior was significantly less between the pretest and the first posttest, but an additional significant increase occurred between the first and the second posttest. Several explanations can be given for the additional effects between T1 and T2 in the general information group and the control group and for the lack of change in the scores in the tailored information group. First, data at T1 was collected by written questionnaires, while that at T2 was gathered by telephone interviews, which may affect comparisons of mean scores on the first and second posttests. A social desirability effect might have occurred at T2, since the respondents may have tried to please the interviewer, which would not so easily happen with a written questionnaire (Swanborn, 1987). However, respondents who already had high scores at the first posttest, as was the case for the respondents of the tailored information group, might not have felt the same urge to demonstrate improved behavior as did respondents who had low or moderate scores at T1. Second, it is possible that a ceiling effect occurred in the tailored information group. This means that it was more difficult to achieve an improvement in scores on intentions or behaviors which were already high at T1 than in scores which were lower at $\mathrm{T} 1$ (Green \& Lewis, 1986). Third, a testing effect may have occurred, because subjects may have been prepared by earlier tests to perform better on later tests (Green \& Lewis, 1986). For instance, if people are asked to say three times to what extent they are attentive to possible cancer symptoms, they become acquainted with the aims of the questions, and are likely to score better on the third test than on the first two tests, even if their behavior has not actually changed. Moreover, it is likely that repetitive testing makes people aware that they should pay attention to the symptoms mentioned in the questionnaire.

The intervention did not lead to increased chronic fear of cancer, nor to increased fatalistic attitudes toward cancer. This is consistent with results of a Swedish study on informing people about cancer symptoms and stimulating them to seek help (Månsson et al., 1999). Both the tailored information and the general information paid specific attention to the fear that may be caused by detecting a possible cancer symptom. Both types of information emphasized that delay does not lead to less fear, and that the fear may be taken away by consulting a physician. Another explanation can be found in Rogers' (1983) assumption that if the situation is threatening, but at the same time an effective strategy to reduce fear is available, fear will not persist. Information about cancer or cancer symptoms may lead to increased fear, since many people associate cancer with death or unpleasant treatment. Providing effective strategies may help prevent fear. These strategies could include information about symptoms people should 
be attentive to, or information about adequate response to possible cancer symptoms. Since the control group in the present study was not given any potentially fear-inducing information, no changes in fear were expected, and indeed none found.

Our sample included some people who had suffered from cancer at some time in their lives, but who did not indicate that they had cancer at the time of data collection (T0). The reason to keep them in the sample was that their risk of developing a second cancer is comparable to that of the general public, making it equally important for them to engage in early detection behaviors. To correct for possible differences in behavior, intentions and determinants between these two groups, having had cancer in the past was included as a covariate in all analyses.

\section{IMPLICATIONS FOR HEALTH EDUCATION ON EARLY DETECTION OF CANCER}

Although the short-term effects of the study were very much in favor of the tailored information, more research is needed to find out how the effects could be maintained in the long term. To prevent a decline in behavior and intentions toward early detection of cancer in the long term, the effects of multiple tailoring on relevant aspects of early detection should be studied in greater detail. This could be done, for example, by progress or ipsative feedback, which provides feedback on the extent and direction of changes in variables relevant to the long-term effects of tailored information (Dijkstra \& De Vries, 1999b). Positive results with this kind of feedback have been obtained with regard to reducing fat intake (Brug, Glanz, Van Assema, Kok \& Van Breukelen, 1998), accomplishing stages of change transition and increasing intentions to quit smoking (Dijkstra, De Vries, Roijackers \& Van Breukelen, 1998). Furthermore, it should be investigated whether a long-term decline in behavior and intentions could be avoided by for instance, a non-tailored reminder to repeat the message or to maintain alertness. According to a review of studies on the effectiveness of BSE training, positive results on compliance with BSE have been found for various prompts, such as telephone prompts, mailed prompts, personal prompts or calendar stickers (Clarke \& Savage, 1999).

Some other issues should also be addressed in future research. First, the present study showed that it would be better to avoid different methods of collecting data, so as to enhance data comparability. Furthermore, to avoid testing bias, an additional control group could be added at T2, which is not subjected to the pretest and the first posttest. Moreover, although the second posttest was conducted approximately 6 months after the intervention, this period seems too short to investigate whether respondents actually 
detected cancer symptoms and sought medical help for these symptoms. A longer period, or a larger study population, would increase the likelihood that some of the study population might actually find cancer symptoms and might seek medical help for it. It would be interesting to find out whether respondents in the various study groups reacted differently to the detection of new symptoms and what stage of the disease, if it is indeed cancer, is diagnosed.

The encouraging results of the computer-tailored approach suggest that this method is a viable alternative to existing methods. The wide range of possibilities offered by this type of intervention allows it to be implemented in various settings, for instance, as a part of health education at the work place, by District Health Authorities, or by an annual mailing to benefactors of the Dutch Cancer Society. The principles of tailoring can be applied in various interactive forms. During the last decade, very positive results have been obtained with printed health education materials (the first generation of tailored interventions) (Skinner et al., 1999). However, a new era has started with the arrival of the so-called second generation tailored interventions, such as CD-rom, the Internet, or e-mail, which has great potential in view of the rapid ICT developments. Further research should study how this relatively new approach in health education can be integrated into existing approaches. At present, it seems that the new media are used mostly by young people. This could offer a new tool to reach this specific target group, which is often difficult to reach for health education. 


\section{CHAPTER 8}

\section{GENERAL CONCLUSIONS, DISCUSSION AND IMPLICATIONS}

The present thesis reports on the development and evaluation of an intervention to encourage the general public to engage in behaviors conducive to the early detection of cancer. This project included several studies: two predominantly qualitative studies among cancer patients and general practitioners to obtain insight into their experiences with early detection of cancer; two quantitative studies among the general public to provide information on Dutch adults' early detection behaviors and the determinants associated with these behaviors; and two quantitative studies on the development and evaluation of a health education intervention to encourage the general public to engage in early detection behaviors, based on the empirical findings and theoretical insights of behavioral sciences. This final chapter discusses the general conclusions of the different studies and relates and integrates the major findings, addresses the limitations and presents implications for further research and health education on early detection of cancer.

\section{General CONCLUSIONS}

The first chapter of this thesis used a systematic approach to review the extent to which cancer is a health problem and what behaviors and behavioral determinants are related to the detection of cancer. Cancer is a major cause of death and illness in the Netherlands (Visser et al., 2000). The earlier cancer is detected, the better the chances of successful treatment and survival (Bailar \& Gornik, 1997). Chapter 1 provides an overview of the various behaviors conducive to the early detection of cancer. It was concluded that passive detection and help-seeking behavior for possible cancer symptoms in a-symptomatic people has received little attention in health education and behavioral sciences. Nevertheless, it is expected that paying attention to cancer symptoms and seeking medical help as early as possible may contribute to the detection of cancer in its early 
stages (Doherty \& MacKie, 1986; Hakkinen et al., 1997; Månsson et al., 1999; Oliveria et al., 1999). So far, health education for the general public on cancer prevention in the Netherlands has been predominantly focused on primary prevention, or insofar as secondary prevention has been used, on breast self-examination and participation in screening programs for breast and cervix cancer. Additional research was required to systematically plan and evaluate an intervention encouraging the general public to engage in early detection behaviors, such as passive detection and help-seeking behavior for possible cancer symptoms. The results of these studies were the main focus of the research project reported on in this thesis.

\section{Part 1: Perceptions of patients and physicians on early detection of cancer}

The central question of the first part of this thesis is what factors influence detection of cancer symptoms and help-seeking behavior from the perspectives of patients and physicians. To answer this question, two retrospective qualitative studies were conducted among cancer patients and physicians about their experiences of the pre-diagnostic period, using Andersen's model of total patient delay (Andersen et al., 1995) as a framework. We tried to obtain a broad view of the pre-diagnostic period by interviewing both groups. It was found that patients, being lay persons, found it difficult to assess the importance of symptoms, which sometimes resulted in unnecessary visits to health care professionals or, conversely, in the postponement of consulting a medical professional. To minimize delay in the cancer detection process, people need adequate knowledge of cancer symptoms to be able to attribute unexplained symptoms to cancer or at least to a serious complaint needing medical attention. This is consistent with earlier findings, which showed that the greater the perceived severity of a symptom, the more likely it is that people seek help (Cameron et al., 1993; Janz \& Becker, 1984; Van de Kar et al., 1992).

Furthermore, fear appeared to be a significant factor in unnecessary health care visits, delays, and appropriate help-seeking. The way people coped with fear differed per person. Some people used coping strategies by actively addressing a threatening situation, for instance by discussing with others about the detection of symptoms or deciding to seek medical help, and by actually seeking help when they faced a possible cancer symptom, resulting in more appropriate help-seeking behavior. Other people avoided thinking about situations threatening their health, and thus delayed. This is in accordance with the findings of Leventhal (1970), who stated that people handle health threatening situations with either danger control or fear control. If people do not believe that a physician can do something to solve the threatening situation, delays become more 
likely. This is consistent with other findings (Hennrikus et al., 1991; Van de Kar et al., 1992). Based on the first part of this thesis, it was concluded that four different patient groups could be distinguished with regard to reacting to possible cancer symptoms: the worried well, the appropriate help-seekers, those who delay because of lack of knowledge and those who delay because of fear. The factors stimulating or impeding the cancer detection process appeared to be different for each patient group. Each group has different needs and requires different information on early detection of cancer.

\section{Part 2: Determinants and behaviors conducive to early detection among the general public}

The second part of this thesis deals with what a-symptomatic Dutch adults actually do in terms of early detection behaviors. The problem analysis elaborated in the first chapter of this thesis made it clear that little is known about early detection behaviors among asymptomatic people and the determinants influencing these behaviors. Therefore, additional research on these aspects was conducted and the results are presented in chapters 4 and 5.

Our first conclusion was that Dutch adults recognized most cancer symptoms, that they were attentive to some cancer symptoms but not to all, and that they said they would seek medical help within the appropriate time frame for some of the possible cancer symptoms. However, although people recognized cancer symptoms, and although they said they would respond to these symptoms, it was indicated by some patients (Chapter 2) that interpreting symptoms correctly at the time of discovery was difficult. This may be due to people's erroneous tendency to think that their own risk is less than that faced by others, in other words, that once they detect cancer symptoms, they might think that they cannot get cancer. This is called 'unrealistic optimism' (Weinstein, 1984) and is likely to result in a lack of preventive actions.

A second conclusion was that correlations between recognition, attentiveness and help-seeking behavior regarding cancer symptoms were weak (Chapter 4). This suggests that although people know which symptoms are associated with cancer, this does not necessarily mean they are attentive to the presence of these symptoms, nor that they will respond adequately to them should they detect them. If this last step (consulting a physician) does not happen, the first two steps become useless, since they do not result in the early detection of cancer. Other studies have also shown that knowledge about the consequences of unhealthy behaviors does not automatically result in healthy behaviors. For instance, knowledge of the benefits of screening for breast cancer did not result in participation in screening programs (Murray \& McMillan, 1993). In general, knowledge 
results in behavior change only when people are motivated to engage in health behavior, and not because they know what the health behavior is (Conner \& Norman, 1995).

In the next step, we studied people's motives for paying attention to cancer symptoms and engaging in help-seeking behavior, using the ASE model as a theoretical framework (De Vries \& Backbier, 1994; De Vries \& Mudde, 1998). The results, presented in chapter 5 , show that paying attention to cancer symptoms and help-seeking behavior were partly explained by cognitive factors, such as the perceived advantages of the behavior, modeling, self-efficacy expectations, intentions and past behavior. The results of the regression analysis showed that a large part of the variance in passive detection behavior was explained by past behavior (30\%). This suggests that paying attention to cancer symptoms is strongly influenced by habitually being alert to changes in the body rather than by beliefs regarding the behavior. In contrast, half of the variance in help-seeking behavior was explained by cognitive factors, indicating that seeking help for possible cancer symptoms requires substantial cognitive decision making and is less clearly based on prior habits. It was concluded that the ASE model can be successfully applied to passive detection and help-seeking behavior. Traditionally, the model has been applied to behaviors predominantly associated with primary prevention behaviors, active secondary prevention behaviors (breast self-examination and testicular self-examination) and participating in screening programs. Our results show that it can also be applied to secondary prevention behaviors such as passive detection and help-seeking behavior.

The results of chapters 4 and 5 were used to develop a health education intervention encouraging the public to engage in early detection behaviors. The social psychological correlates associated with paying attention to cancer symptoms and seeking help were the starting point for developing a computer-tailored health education intervention. It was intended that influencing these factors would make people more attentive to cancer symptoms and more willing to seek medical help within the appropriate time frame once they detect a cancer symptom. The results of chapter 4 indicated that Dutch adults know the most specific cancer symptoms, such as lumps, changes in the skin and unusual blood loss. However, they did not recognize the a-specific symptoms of cancer, such as changes in bowel habits, indigestion etc. The results also showed that participants indicated they were often alert to the specific cancer symptoms, and would seek medical help for most cancer symptoms within the appropriate time. Differences in knowledge and in passive detection and help-seeking behavior were found for sex, age, and educational level. Chapter 5 concluded that the social psychological determinants of those who were attentive to cancer symptoms were more favorable than those of people who were less attentive or inattentive. Similar differences were found between those who would seek 
help within the appropriate time and those who would delay. Based on these results we concluded that the general population is heterogeneous with respect to early detection of cancer in (1) the incidence of cancer forms among specific groups (compare breast cancer vs testicular cancer); (2) the performance of the desired behaviors (women are more likely to engage in early detection behaviors than men); and (3) the social psychological beliefs people have toward early detection behaviors encounter (for instance, people who have high vs low self-efficacy expectations of their capability to engage in early detection behaviors). In view of the multitude of behaviors involved and the above-mentioned aspects, an approach is required that is adapted to the characteristics and needs of the recipients, and that avoids redundant information (De Vries \& Brug, 1999; Kreuter et al., 2000). Therefore, a tailored health education intervention was developed to meet these requirements.

\section{Part 3: Process and effect evaluation of a computer-tailored intervention}

The last part of this thesis addresses the results of the process and effect evaluation of a computer-tailored intervention encouraging the general public to engage in early detection behaviors, compared to non-tailored or no information. The process evaluation was conducted to answer the question how the tailored intervention was assessed by the target population in terms of use, format and content. It can be concluded that the tailored information did attract the attention of its intended readers and that its format was appreciated. The advantages and disadvantages of paying attention to cancer symptoms were felt to be sufficiently discussed in the letter and the letter provided sufficient information on how individuals can contribute to early detection of cancer. These results are in accordance with those of other studies evaluating tailored interventions, as described in chapter 6.

The effect evaluation involved answering three questions: (1) is the computer-tailored intervention effective?; (2) is the computer-tailored intervention more effective than the current information on early detection currently provided by the Dutch Cancer Society?; and (3) do both kinds of information on early detection of cancer entail negative side effects? Three conclusions were drawn. The first was that compared to the group who received no information, the group who received tailored information showed more positive changes in most ASE determinants and showed more positive intentions and behaviors both three weeks after the intervention and six months after the intervention. This allows us to conclude that the tailored intervention was an effective method to encourage people to engage in behaviors conducive to the early detection of cancer. The second conclusion was that the group who received tailored 
information showed more positive changes in ASE determinants than the group who received general information. Moreover, the tailored information group showed more positive intentions toward seeking help for cancer symptoms, was more likely to pay attention to cancer symptoms, and was more likely to seek help for possible cancer symptoms, both shortly after the intervention and in the long term. Thus, it could be concluded that the tailored intervention was more effective on the majority of the outcome variables than the non-tailored intervention as regards changing determinants, intentions and behaviors conducive to the early detection of cancer. The third conclusion was that no increased chronic fear of cancer or increased fatalistic attitudes were found after the administration of both kinds of information, which allows us to conclude that the interventions do not entail such negative side effects.

Do these statistically significant differences also have practical relevance? Although the results favored tailored information over general information or no information, it should also be concluded that the net effect (second posttest minus pretest) was moderate. It increased from 1.42 to 2.05 and from 1.57 to 2.13 on a seven-point scale for intentions toward passive detection and for help-seeking behavior, respectively. Behavior in terms of paying attention to cancer symptoms improved from 2.78 to 3.70 on a fivepoint scale, while help-seeking behavior increased by $11 \%$ from 0.58 to 0.69 on a scale from 0 to 1 . As regards passive detection, this implies that before the intervention recipients of the tailored information were, on average, 'sometimes' attentive to cancer symptoms, while after the intervention they were 'often' attentive to cancer symptoms. As regards help-seeking behavior, all participants indicated before the intervention that they would seek medical help for about eight symptoms, against about ten symptoms after the intervention in the tailored information group and nine symptoms in both of the other groups. Compared to no or general information, therefore, the tailored intervention resulted in increased knowledge of cancer symptoms, more favorable ASE beliefs about early detection of cancer, more positive intentions and more frequent performance of early detection behaviors, making it likely that this increases the chances of early detection of cancer and thereby improves the chances of successful treatment. In this sense, it may be concluded that, while the effects were moderate, the tailored intervention aimed at encouraging early detection behaviors among the general public is of practical relevance.

Unfortunately, there are not many opportunities to compare our findings with similar studies, since studies of passive detection and help-seeking behavior are hardly available. In contrast to our study, studies of skin awareness (Berwick et al., 1996; Oliveria et al., 1999), awareness of fecal blood (Hakkinen et al., 1997) and awareness of general cancer 
symptoms (Månsson et al., 1999) were able to assess the number of cancer cases diagnosed after an information campaign, but they had limited opportunities to compare the effectiveness of the different interventions. It is also difficult to compare our findings with other computer-tailored interventions, for instance on nutrition habits, smoking cessation, physical activity and participating in mammography screening. Our results are comparable to the extent that tailored health education messages produced significant changes in social psychological determinants, intentions, and behaviors (Brug et al., 1996; Bull, Kreuter, \& Scharff, 1999; Campbell et al., 1994; Dijkstra et al., 1998; Rakowski et al., 1998; Skinner et al., 1994; Strecher et al., 1994). The magnitude of the changes cannot be compared, since the behaviors studied were very different.

\section{MEthodological ISSUES}

Several limitations due to the methodology used and the process of data collection should be considered in interpreting the findings of the studies presented in this thesis. The first issue is that of the operationalization and assessment of early detection behaviors. The second issue is the limitations of the procedures used for the recruitment of participants for the different studies, while the third issue concerns the application of the theoretical models.

\section{Operationalization and assessment of early detection behaviors}

Five issues regarding the operationalization and assessment of early detection behaviors should be discussed: retrospective interviews; self-reported behavior and social desirability; using a combination of written and telephone questionnaires for data collection; multiple data collection; and the assessment of help-seeking behavior. These issues are potential threats to the internal validity of the studies, i.e., the certainty that the results of the evaluation can be attributed to the intervention (Green \& Lewis, 1986). All five are discussed below.

The first limitation of the study described in chapter 2 is that patients were interviewed retrospectively. Patients' retrospective reports on the pre-diagnostic period may be influenced by feelings of guilt about not having detected cancer symptoms earlier, or not having consulted the physician sooner. An attempt was made to limit errors of memory by including only patients who were diagnosed not too long ago. It was impossible to collect complementary information from their physicians, which could confirm the patients' stories. 
Second, self-reports to assess passive detection and help-seeking behavior in a-symptomatic people may be prone to problems of social desirability. Social desirability refers to the tendency among respondents to please the interviewer by answering questions in accordance with perceived norms, and is especially apparent in situations in which the interviewer's opinion is clear (Green \& Lewis, 1986). The present study was supported by the Dutch Cancer Society, whose main concern is cancer prevention, so the respondents' self-reports might have overrated the desired preventive behavior. With respect to paying attention to cancer symptoms, for instance, participants might to some degree have given socially desirable answers, since they might expect that attentiveness to these symptoms is desirable. The situation with regard to help-seeking behavior is perhaps different. Although some people might think "the earlier you visit the physician with a complaint, the better", others might think that they should not bother the physician with futilities. This was indeed mentioned by some patients (Chapter 2), who said they did not want to bother their physician. It could also be argued, however, that people do not know what the cancer symptoms are, and what constitutes an appropriate time frame for consultation (see Chapters 2 and 4). This implies that the results of these helpseeking behaviors may be less prone to social desirability problems. Moreover, an attempt to minimize social desirability was made in the construction of the questionnaires. The written and telephone questionnaires used five-point scales instead of dichotomous scales to assess, for instance, knowledge of cancer symptoms and attentiveness to these symptoms. It was furthermore stressed that answers to questions were not right or wrong, but that they indicated one's opinion, no matter what that opinion was.

The third issue, measuring by means of written questionnaires and telephone interviews, is also related to the social desirability problems. The reason for using telephone interviews at T2 was that they were expected to result in a lower drop-out rate six months after the intervention than another series of written questionnaires. Contrary to our expectations, we had a high response rate, even in the long-term assessment. Whereas social desirability is a problem in all written questionnaires, this might be an even bigger problem in telephone questionnaires, since people are more inclined to please someone when they are speaking to that person directly than when they are filling in a questionnaire. Moreover, it is possible that combining these different data collection methods makes the interpretation of the results less reliable.

The fourth issue concerns a possible testing effect due to the repeated administration of questionnaires. If people are, for instance, asked three times whether they are attentive to cancer symptoms, they are induced to think that they should pay attention to cancer symptoms and may therefore actually start to pay more attention to them. An 
explanation for this phenomenon may be that people become 'test-wise', that is, they become acquainted with the aim of the questions and thus know what to answer (Green \& Lewis, 1986). Another possible explanation is that filling in the questions can be regarded as an intervention in itself. The questionnaire was comprehensive and the fact that respondents in the control group showed improved intentions and behaviors without being exposed to information on early cancer detection may corroborate this assumption.

The last issue concerns the way help-seeking behavior was assessed in a-symptomatic people (Chapter 4 to 7). People were asked what they would do if they experienced cancer symptoms, which assesses hypothetical help-seeking behavior. People might answer these questions based on cognitive expectations. Several studies have revealed that when people actually detect a potential cancer symptom, other factors, like emotions, may influence whether they seek medical help (Chapter 2; Sheik \& Ogden, 1998). However, since the intentions to engage in help-seeking behavior were found to be strong (Chapter 7), and intention is generally one of the most significant predictors of behavior, actual help-seeking for cancer symptoms may be expected. Nevertheless, it is recommended that the way help-seeking is currently being assessed should be studied for its validity with respect to actual behavior by using studies with a longer time frame, for instance using a three-year follow-up. People could then be asked whether they have experienced possible cancer symptoms and how they responded to these symptoms.

\section{Recruitment of participants}

The methods used in the various studies to select the patients, general practitioners and a sample from the general public can be criticized in some respects. Various types of selection bias may threaten the external validity of the studies, that is, the certainty that results can be generalized to other populations (Green \& Lewis, 1986).

The qualitative study among cancer patients (Chapters 2 and 3) included only those patients who had detected their symptoms themselves. This means that patients who died because their cancer was in an advanced or terminal stage at the time of data collection were not included. Their experience may have been different from that of people who had a relatively good prognosis, since they may have interpreted symptoms differently, or may have come to different decisions to postpone consultation. Therefore, it is recommended to study the process of cancer detection among patients who have detected possible cancer symptoms, but did not follow them up by seeking medical help. These persons may have been diagnosed with cancer for instance during a screening program or a medical check-up, but have not taken any action following the earlier 
derestion of a possible cancer symptom. These patients should be questioned about how

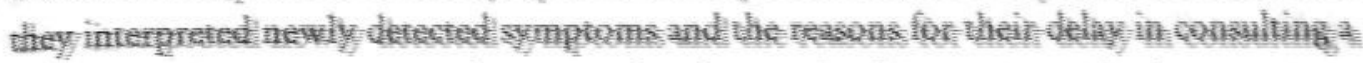
physician. This was to a certain extent allo the case in the present sudy, because some parients had consulted a pilysictant after being urged to do so by other people.

Second the mumber of patiens and physicians involved in the qualitaike sudies was limited and they had net been randomly selected. Only a handful of patients with each of the four selected types of cancer were selected by contact peroons of regional patian groups and were intervicwed. This is certainly not a representaive group of all cancer

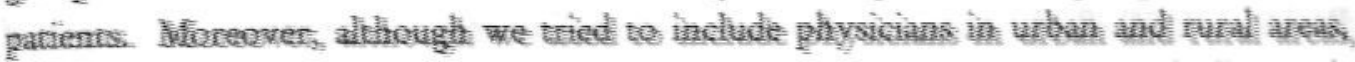
these physicians probably did not constitute a representative sample of all Dutch: physicians. However, the aim of the studies among patients and physicians was not that the reculta stould be generalized to other groups, but to obtain a generdi idea of the perpectives of patients and general practitioners (the gateleepers of the Duteh health care system) in order to genetrate bypotheses.

Third, the selection of the sample of the general public for the evaluation study may have been biased to some extent. The use of announcements in locd doortodoos newspapers and one national newspaper may have resulted in a selected group participatsing in the study, namely those who read these newspapers. in addivion, the method of eurollment wsed (volunteer registration) meant that only those who were already interested in cancer were included in the sample. This may limit the generalizability of the results. An effort was made to reduce this problem by offering those participants who filled in all questionnaires a remuneration of NLG 100 (EUR 45). Dijkstra (1998) suggested that offering a monetary incentive may attract different people and therefore limit selection bias. Although only those people who were interested in or open to information on early detection of cancer were recruited, this does not necessarily mean that we cannot generalize our results to a larger population. However, generalization is only possible to those people who are basically interested in cancer, considering that any kind of information only reaches those who are interested in the topic. Thus, if people do not want to know about early detection of cancer, they will not pick up a brochure from the stand. Moreover, the first goal of the evaluation study was to test the effectiveness of the newly developed materials, rather than to enable generalization to other populations.

One indication that selection bias may have occurred is the overrepresentation of female respondents in the evaluation study. This could be explained by the fact that women are probably more interested in cancer than men and therefore more likely to participate. It might also indicate that (young) males are less interested in participating in 
certain studies or in information on early detection of cancer. Future studies should make an effort to reach underrepresented target groups, but should first study whether these groups are interested in health education at all.

\section{Theoretical models and their limitations}

Two main theories were used in this thesis to analyze the process of cancer detection and seeking medical help, namely Andersen's model of total patient delay (Andersen et al., 1995), and De Vries' Attitude - Social influence - self-Efficacy model (De Vries \& Backbier, 1994). Both models are discussed below. This section ends with a discussion of the possibilities to integrate these models in the application of early cancer detection.

\section{Andersen's model of total patient delay}

The model of total patient delay developed by Anderson was used as a framework for the patient interviews to analyze the process of detecting cancer symptoms and seeking medical help. We concluded that Andersen's model was helpful in structuring the prediagnostic period for research purposes.

However, some aspects of the model should be reconsidered. First, although this model reflects the different phases in detection processes once an unexplained symptom is discovered, it does not pay detailed attention to the behavioral and psychological aspects of these processes. For instance, the detection of unexplained symptoms requires the use of certain detection techniques. Similarly, shortening appraisal delay requires knowledge to interpret the unexplained symptom. Furthermore, people will only decide to consult a physician if they have positive beliefs about deciding to consult a physician and see the relevance of consulting a physician with a particular complaint. Thus, the preconditions for moving from one phase to the next could be elaborated in more detail in future research to enhance insight into the psychological aspects of the cancer detection process.

Second, the model suggests that delays are due to the patient, while in fact the last stages refer to delays caused by the health care system (for instance waiting lists) and the health care provider. Provider delay starts when a person seeks help for a self-discovered symptom and ends at the initiation of the treatment (Facione, 1993). The health care provider may cause delays for instance by misattributing the symptoms, by having waiting lists, or not referring to a specialist. This has often been found to be an important cause of prolonged pre-diagnostic periods (Cassileth et al., 1988; Gascoigne et al., 1999; MacArthur \& Smith, 1981). It is therefore recommended to revise the model for the purpose of research on patient delay in cancer detection. The model should include a 


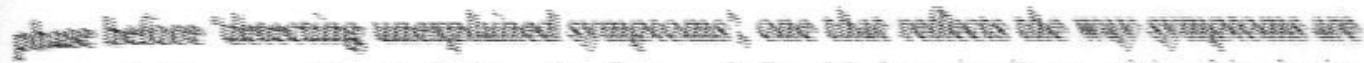

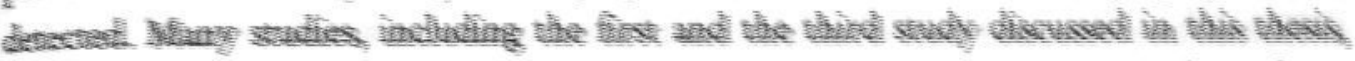

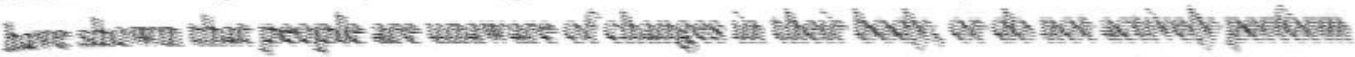

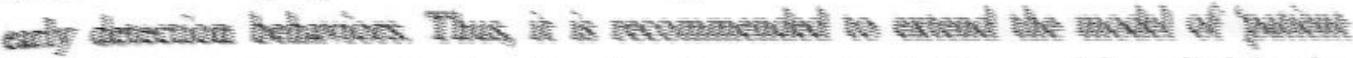

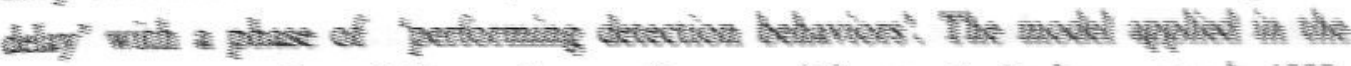

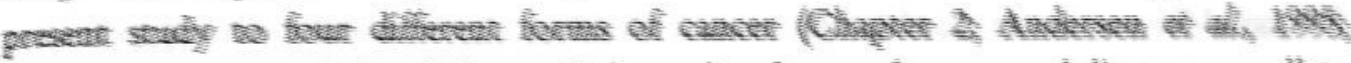

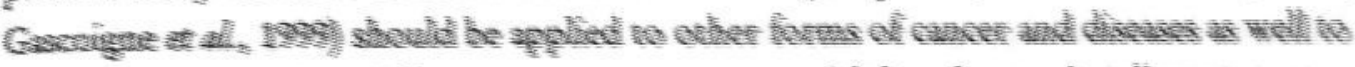

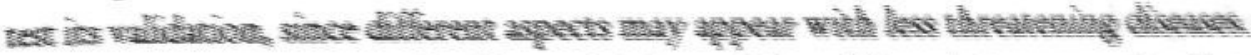

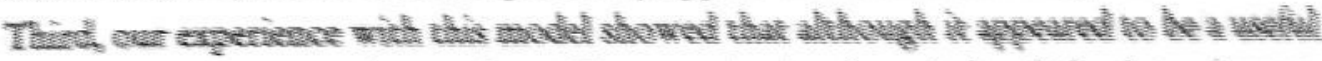

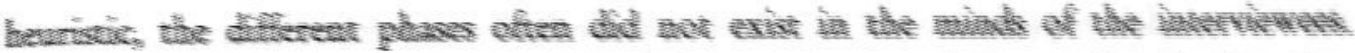

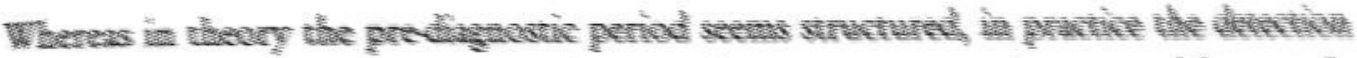

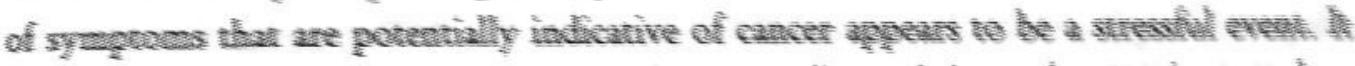

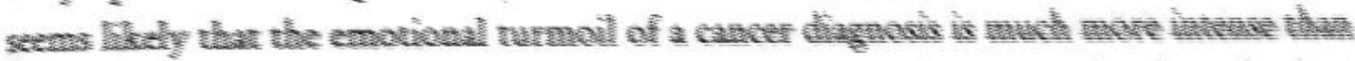
the predizgnadic period. To overcome the limitations of retrogpective intervikwind prospective studies should be conducted. The question then arties whether this would not result in practical problems. For instanct, a large sample of the population woull have to be included in the stody to ensure the indusion of people who detert nowille cancer symptoms

We conclude that Andersen's model of total patient delay provides a wetul strueture for studying the process of cancer detection. Further studies are meeded to explare the psychological aspects accompanying the transition from one phase to the nex and to allow the model to be applied to other forms of cancer and other diseases.

\section{Attitude - Social influence - self Efficacy model}

The ASE model was used to gather information on the social psychological factors associated with the cancer detection process. This model was the basis for the written and telephone questionnaires administered to a sample of the general public (described in Chapters 4 and 5), and as a framework for developing the computer-tailored intervention (Chapters 6 and 7). So far, the ASE model has been applied especially to health related behaviors conducive to the primary prevention of coronary heart diseases and cancer, active detection behaviors (breast and testicular self-examination) and participation in screening for breast cancer (Lechner, 1998). These health related behaviors can be characterized as voluntary (since people are not obliged, for instance, to eat more fruit) and as requiring an action of the individual (for instance, participating in an exercise program). The ASE or similar models, such as TRA and TPB, have to a lesser extent been applied to help-seeking behavior for cancer symptoms, and not at all to passive 
detection. The application of the ASE model to these behaviors was therefore explorative, and future research should validate and fine-tune the questionnaire with regard to the assessment of the ASE concepts.

Moreover, the results should be replicated in future research. The ASE determinants seem relevant in explaining the variance in passive detection and help-seeking behavior (25 and 34\% respectively), although other factors such as past behavior account for a substantial additional proportion of the variance $(30$ and $17 \%$ for passive detection and help-seeking behavior respectively). Passive detection cannot be defined as a conscious action but refers more to awareness, while help-seeking behavior, according to Andersen's model, requires several cognitive considerations (Andersen et al., 1995). This may explain the results of the regression analysis in chapter 5. Passive detection was less adequately explained by the central determinants of the ASE model and is probably more habitual than help-seeking behavior. Thus, ASE seems more relevant in explaining help-seeking behavior than passive detection. This implies that using a predominantly cognitive model to explain health behaviors which are less reasoned and which rely more on habits, as is the case with passive detection, is less successful than explaining behaviors that are primarily reasoned. Emotions involved in the process of detecting cancer symptoms and seeking medical help have also proved to be an important factor in cancer detection behaviors (Katz et al., 1995; Sheik \& Ogden, 1998). One of these emotional factors is fear of cancer. The fact that in our studies fear did not influence paying attention to cancer symptoms, nor help-seeking behavior, may be due to the hypothetical nature of the questions, in which answers are likely to be based on cognitive beliefs. In contrast, retrospective studies have found that fear was indeed one of the factors associated with seeking help for cancer symptoms (see for instance Chapter 2; Gascoigne et al., 1999; Mor et al., 1990).

In view of the above, it can be concluded that social psychological theories, such as ASE, TRA and TPB, can be used to explain or predict behaviors conducive to the early detection of cancer. However, some fine-tuning of the concepts used in the questionnaires, and the factors explaining the unexplained variance, should be attempted in further research.

\section{Integration of the model of patient delay and ASE}

An attempt was made to integrate the model of patient delay and the ASE model in explaining the process of detection of unexplained symptoms potentially indicative of cancer and seeking help for these symptoms. Since these processes encompass various behaviors, more or less under volitional control, it was expected that a combination of 
these models would provide an additional contribution. Moreover, theories about coping with threatening health situations, such as Leventhal's fear and danger control (1970), adaptive or maladaptive coping with health threats as described in Rogers' Protection Motivation Theory (1983; Boer \& Seydel, 1995) and Miller's monitoring and blunting coping styles (1991), are of interest in explaining the successive phases in cancer detection. In each phase of the cancer detection process as described in the model of patient delay, different ASE concepts, but also emotions such as fear or uncertainty, would influence the shift to the next phase. Examples of the ASE concepts involved are beliefs about the outcomes of the health behavior, social influences (for instance whether someone's environment supports help-seeking behavior), and expectations of one's capability to handle a certain situation (for instance performing detection behaviors, deciding to consult or actually consulting a physician). It would furthermore be interesting to study the relative importance of past behavior and habits in these different phases. Integrating the model of patient delay and the ASE model may enable us, on the one hand, to cover the whole process of cancer detection, and on the other hand to obtain insight into the behavioral, psychological and emotional aspects influencing each phase. However, little attention has been paid in quantitative studies to factors influencing appraisal delay, such as attributing symptoms to other diseases. As emphasized by Andersen et al., the most significant delay in the cancer detection process is caused by appraisal delay (Andersen et al., 1995). This is in line with our findings in chapter 2, which suggested that the nature of the newly detected symptoms and a correct attribution of these symptoms by patients were important in making patients aware that something was wrong.

It can be concluded that the integration of the model of total patient delay and the ASE model may provide additional insight into the process of early detection of cancer. In the different phases of the cancer detection process, different factors influenced the transition to the next phase. It seems that the actual detection of cancer symptoms relies to a large extent on habitual behaviors, such as being attentive to changes in the body, while the process from the detection of a possible cancer symptom until the first medical consultation seems more dependent on cognitive and affective factors, such as the interpretation of symptoms as cancer symptoms, fear, and discussing the symptoms with people in one's environment. 
This thesis has presented the development and evaluation of a computer-tailored intervention encouraging people to engage in behaviors conducive to the early detection of cancer. The results have several implications for future research and health education practice. The implications for further research should mainly focus on a theoretical understanding of why tailored health education materials are effective. The implications for practice will focus on whether the newly developed intervention on early detection should be implemented. Both issues are discussed in more detail below.

\section{Implications for future research}

The above discussion of the methodology used in the studies has revealed several recommendations for further research. Briefly, with respect to the operationalization and assessment of early detection behaviors, further research should (1) study prospectively the process from the detection of unexplained symptoms to the moment of seeking medical help, to enable the assessment of actual help-seeking behavior after cancer symptoms have been detected; (2) validate the assessment of passive detection and help-seeking behavior in order to minimize social desirability problems. This could be done by linking these subjective measures to more objective measures, for instance by asking subjects to register their actual detection behaviors in a diary during a certain period. Correlation between these two measures should be assessed to be able to draw conclusions on the validity of the more subjective concepts.

With respect to the recruitment of participants, selection bias should be avoided by including cancer patients who detected cancer symptoms not by coincidence, but by participating in screening programs or during medical check-ups, and by including patients with other forms of cancer, or other diseases, to investigate whether they have different experiences during the pre-diagnostic period. Secondly, it should be studied how underrepresented groups, such as young males, can be reached by health education information and what channels should be used to inform them about how they can contribute to the early detection of cancer.

Furthermore, several recommendations can be formulated regarding the theoretical models used in this thesis. With respect to Andersen's model of total patient delay, it is suggested that future research should (1) focus on the behavioral and psychological factors influencing the transition between the different phases in the cancer detection process; (2) add a phase describing early detection behaviors; and (3) replicate the results in a prospective study design. 
With respect to the ASE model, more research is needed into the assessment of determinants of early detection behaviors and the identification of other factors that influence the cancer detection process. There should also be a more precise elaboration of the behavioral and psychological factors, including cognitive factors, affective factors and past behaviors, that influence passive detection and help-seeking behavior. The contribution of other theories on coping with health threatening situations, such as Leventhal's fear and danger control (1970), Rogers' Protection Motivation Theory (1983; Boer \& Seydel, 1995) and Miller's monitoring and blunting coping styles (1991) should be studied to be better able to explain the decisions to be made to move from one phase to another.

The present effect evaluation revealed very promising results regarding changes in passive detection and help-seeking behavior, but only within a relatively short period (a maximum of six months) after the intervention. In view of the limitations of the present study, further research should be conducted to assess actual changes in help-seeking behavior. A long term follow-up study is recommended to assess whether behavioral changes actually result in appropriate help-seeking behavior and whether, in the case of a cancer diagnosis, the cancer is detected sooner.

Several issues for further research on computer-tailored health education remain. Dijkstra \& De Vries (1999) listed the following topics to be studied: (1) why is tailoring more effective?; (2) for whom is tailoring more effective?; (3) what is bad tailoring?; (4) how tailored does tailoring have to be?; (5) through what media can tailored information best be offered?; and (6) how can tailored interventions be implemented?

As regards the first of these questions, it is still not exactly known why tailored information is more effective than general information in influencing behaviors, in other words, what the working mechanisms of tailored materials are (De Vries \& Brug, 1999; Kreuter et al., 1999; Skinner et al., 1999). It has been suggested that tailored information works better because it is personalized, the content is adapted to prior knowledge, social environment, previous experiences etc., and because it provides feedback on cognitive and behavioral features, reinforces positive feedback and provides normative feedback in a personal tone and with empathy. These aspects are supposed to make the messages more personally relevant, and according to Petty and Cacioppo (1986), personally relevant messages are more likely to result in active and thoughtful information processing. Although we did incorporate these aspects in the present computer-tailored intervention, we did not experimentally vary these factors. Information about risky decisions can be framed in two ways: in terms of potential gains (i.e., benefits or advantages), or in terms of potential losses (i.e., disadvantages or risks). The Prospect Theory (Tversky, 
1981) states that positively framed messages result in risk avoidance, while negatively framed messages result in risk seeking. It suggests that negatively framed messages are more effective than positive framed messages in persuading people to engage in health behaviors that can be considered as risky (for instance, breast self-examination involves a risk of detecting cancer) (Meyerowitz \& Chaiken, 1987; Rothman et al., 1997; Rothman \& Salovey, 1993; Wilson, 1988).

This idea was refined by Maheswaran and Meyers-Levy (1990), who had found that people with low issue involvement were more convinced by positively framed messages, while people with high issue involvement were more persuaded by negatively framed messages. The explanation is that people refrain from information processing when they are not involved in the issue, and in that situation favorable messages lead to information processing following peripheral routes. This type of framing was applied to breast and testicular self-examination in the present tailored intervention (described in Chapter 6), but not tested. Since it was expected that women would be more involved in early detection than men, messages about breast self-examination were framed in more negative terms, while messages about testicular self-examination were framed in more positive terms. For tailored messages on early detection behaviors in general, this implies that people's beliefs about the riskiness of early detection behaviors should be assessed, as well as their issue involvement, for instance in terms of previous experiences with cancer, in order to create more effective messages.

With respect to the second question, it should be investigated whether the tailored information is effective for all segments of the target population, or whether it is more effective for specific subgroups in that population. For instance, Brug and Van Assema (2000) found that tailored feedback on fat intake was more effective than general information in motivating people with no intentions of changing their dietary habits to proceed to more positive stages of change. Moreover, respondents with a lower level of education were more positive about how interesting and how personally relevant the tailored information was, two important aspects of effective communication (McGuire, 1985; Petty \& Cacioppo, 1986). Skinner et al. (1994) concluded that tailored letters encouraging women to have a mammography resulted in more favorable follow-up results than general information among women with low socio-economic status. To assess whether the tailored intervention on early detection of cancer is more effective among specific subgroups of the target population, additional analysis should be performed. Interactions, for instance with educational level, a history of cancer, or being currently engaged in early detection behaviors, should be assessed to identify differences in the use and effects of tailored information. 
As regards the third aspect mentioned by Dijkstra, it has been suggested that 'bad' tailoring may do more harm than good. Bad tailoring is tailoring because computer technologies make it possible to tailor instead of tailoring because of psychological relevance. Thus, when people share the same beliefs and risk factors, experience the same social support and have the same self-efficacy expectations, a single message will be sufficient to address the needs of the target population (Kreuter et al., 2000). Most of the current tailored interventions focus on psychological variables that originate in the Health Belief Model, the Transtheoretical Model or the TRA, TPB and ASE models, such as stages of change, perceived barriers, self-efficacy expectations etc. In the future it can be expected that tailored messages will be adapted to other characteristics of the recipient, such as gender, educational level, or cultural values or beliefs (Kreuter et al., 2000). A shift to these kinds of variables would focus on bow the information is communicated rather than what information needs to be communicated. For the present tailored intervention on early detection of cancer, this means that (depending on the outcomes of the interaction analysis discussed above) the intervention should be adapted to educational levels, for instance by adapting the language or using graphic and audio interfaces for people with limited reading skills. Moreover, it was found that young adults prefer information provided via computers and the Internet rather than via the traditional printed sources such as books or leaflets (Fotheringham, Wonnacot, \& Owen, 2000). According to a study among Dutch adults about the provision of medical information, all people preferred the family physician, but the Internet or books and encyclopedias formed the second and third preferred sources of medical information, especially among people younger than 55 years (Kuijs \& Ehrenhard, 2000). Therefore, further research should investigate whether subgroups of the general public should be approached through different channels. This could include, for instance, providing interactive webbased health education for young people, while older people could be targeted via printed materials.

With respect to Dijkstra's fourth issue, it is not yet known how much tailoring is enough to result in effects. Tailoring can be done at various levels, for instance on behavioral factors or on social psychological factors. What also remains unclear is the impact of the length of tailored messages. For instance, the tailored letters used in the present studies on early detection of cancer ranged from five to eight pages, while other tailored materials tend to be much shorter (Campbell et al., 1999). Since it is assumed that an overload of information does not lead to more attention being paid to the message, a shorter version should be considered. Moreover, the amount of tailored feedback and personalization needs to be studied in further research. It has been sug- 
gested by Kreuter et al. (2000) that appropriate non-tailored materials, that is, those that reflect a person's unique needs purely by chance, performed as well or even better than tailored materials in terms of several cognitive, affective and behavioral outcomes. An explanation might be that the traditional non-tailored health messages also use constructs derived from theories of health behavior change. For instance, the general information on early detection of cancer also addressed fear, a factor known from the literature to influence help-seeking behavior. Since they both anticipate on fear, tailored and nontailored information may be quite similar. Further studies should also investigate the possibilities and effectiveness of ipsative feedback, which was found to be effective in achieving long-term changes in nutritional habits (Brug et al., 1998). Ipsative feedback may prevent a decline in attentiveness to cancer symptoms after a longer period and has the advantage that repetition of the message increases the likelihood of attitude change. Research is needed to investigate whether ipsative feedback could provide additional effects, and what time intervals should be used for this multiple tailoring.

The fifth question is what media are most effective for offering tailored information to the target population. Up to now, most computer-tailored interventions have used printed materials, while the non-print media offer a variety of channels for delivering tailoring programs, such as interactive Internet sites or computer kiosks, tailored e-mails, videotapes and compact discs (Kreuter et al., 2000). Internet-based health education seems a very promising and attractive channel to deliver information, and may attract other people than written materials do. An Internet-based approach has several advantages over the traditional health education interventions, including greater convenience and appeal, flexibility of use, openness of communication and automated data processing and feedback provision (Fotheringham, Owies, Leslie, \& Owen, 2000). However, Internetbased health education also has disadvantages: it should be remembered that the Internet is a very fast medium, and users are easily distracted from the site to other sites. Moreover, the Internet is not yet accessible to all households in the Netherlands, and may be unavailable especially in households in the lower socio-economic categories. Thus, research on the impact of web-based health education is one of the challenges for the coming years. At the same time, advanced computer technology is also making it possible to create new printed materials. It should be investigated which channels are most effective for the specific target groups and whether it is possible to include interactive media in education on early cancer detection.

As a sixth aspect, the implementation of computer-tailored health education in other, large-scale settings should be studied. So far, the available interventions have been tested in research settings. As stated in chapter 1, large-scale implementation and dissemination 
of effective health education interventions should be accomplished by diffusion strategies and supportive policies. The above discussion of practical implications gave two examples of implemented tailored interventions. In view of the positive results of the tailored intervention, implementation on a larger scale should be investigated, for instance via the annual mailing of the Dutch Cancer Society, via regional health authorities etc.

\section{Implications for health education practice}

The research implications discussed above indicate that many aspects remain to be studied before the newly developed intervention on early detection can be implemented in a large-scale setting. However, some recommendations for practice can already be given. These recommendations concern mainly the computer-tailored intervention (Chapters 6 and 7), since the other studies discussed in this thesis were conducted to allow the development of the tailored intervention.

Our patient and physician interviews showed that people often do not interpret potential cancer symptoms as such and that they are often unable to distinguish between sinister and innocuous cancer symptoms. Moreover, a-symptomatic people appeared to be mostly familiar with obvious cancer symptoms such as lumps, changes in the skin, or unusual bleeding, but less so with non-specific cancer symptoms or combinations of symptoms. This was also found by Krige and colleagues (1991) in a study on delays in the diagnosis of melanoma. Few patients recognized early signs of melanoma (changes in the color or diameter of moles), and half of the patients reacted only to late features (bleeding or ulceration). In future health education, therefore, early signs of cancer should be emphasized as specifically as possible. The distinction in internal and external symptoms as suggested in Chapter 4 could be used in health education to categorize symptoms adapted to the frame of reference of the target population. Our computertailored intervention provides one way of emphasizing this message by discussing more details than just the eight cancer symptoms and taking the categories of symptoms into account. For instance, the symptom of 'unusual bleeding' was divided into 'blood in urine', 'coughing up blood' and 'blood in stools'. The combination of non-specific and specific cancer symptoms, for instance unusual weight loss and a lump in the breast, should be stressed as well.

With respect to the practical implications of using the computer-tailored intervention in practice, it can be questioned whether the present intervention should be implemented in large-scale settings and whether it should be implemented in its present form.

As regards the first of these questions, the results of the long-term effect evaluation indicate that this intervention could provide a meaningful addition to current health 
education on early detection of cancer provided by the Dutch Cancer Society. Largescale implementation should be considered, but not without involving all relevant parties in such an implementation process. Successful diffusion is more likely if all participants involved in the implementation process collaborate (Rogers, 1983). This implies a multidisciplinary team including, for instance, the Dutch Cancer Society and other health organizations, as well as an organization responsible for registering recipients, mailing the screening questionnaires, handling returned questionnaires and producing and delivering the tailored letters.

The Dutch Organization for Smoking Cessation (STIVORO) were the first in the Netherlands to implement a computer-tailored intervention for smoking cessation. Their website invited people to fill in a questionnaire. Within a few days, respondents then received a personal written letter by ordinary mail. In 2000, approximately 15,000 persons requested such advice, of whom $15 \%$ had quit smoking after one year (Willemsen, 2001). The regional health authority (GGD-zzL) also adopted and implemented a computer-tailored nutrition education, developed by Brug et al. (1996). Their screening questionnaires were distributed by 'Hartslag Limburg', a community project aimed at the prevention of coronary heart diseases. During the last two years, approximately 3400 screening questionnaires have been handed out, of which $34 \%$ were returned, after which the respondents received a tailored letter. Little information about the impact of the various computer-tailored interventions is currently available. The impact can be calculated from the participation rate (recruited/retention) and the efficacy in percentages (Velicer \& Prochaska, 1999). Velicer and Prochaska concluded that their expert system for smoking cessation was 600 times more effective than a smoking clinic. The impact size of the present intervention on early detection of cancer could only be analyzed after large-scale implementation.

Should the computer-tailored intervention discussed in this thesis be implemented in its present form? The tailored letters we used were quite long (six to eight pages), and provided feedback on the general cancer symptoms for all target groups. A shortened version should be considered. The tailored information could, for example, use an approach that addresses people at high-risk (Jackson, Wilkinson, \& Pill, 1999; Robinson, Rigel, \& Amonette, 1998). For instance, people with a fair skin and many freckles, who are thus at risk of skin cancer, could receive information on early signs of skin cancer, and if so desired, on primary prevention of skin cancer. Such an approach would ignore the fact that all persons are to a certain extent susceptible to these forms of cancer, and that knowledge of cancer symptoms will not only affect the individual itself, but also people in this individual's environment who are not necessarily at risk. This is illustrated 
by examples from the patient interviews (Chapter 2), which showed that the partner played an important role in the detection of symptoms, as well as in stimulating the patient to seek medical help.

With increased access to the new media, cdrom and the Internet, a new generation of computer-tailored interventions, the so-called second generation interventions, are making it possible to reach large target groups. This means that feedback can be provided directly on the computer screen and a continuous interaction between the sender of the message and the target group can be established. One of the first examples of web-based health education is a study by Oenema et al. (Oenema, Brug, \& Lechner, subm), which assessed the impact of a web-based, interactive nutrition education intervention and compared it with general written information. Those who received the computertailored nutrition advice, including computer-illiterate respondents, showed significantly higher levels of awareness and intention to change, as well as greater appreciation of the intervention, and a greater sense of personal relevance. The use of interactive health education is thus a potential tool for educating the general population by enabling direct personal feedback.

\section{CONCLUDING REMARK}

Since no primary preventive actions have been identified for many cancer forms and some forms of cancer are unfortunately not curable, early detection remains an important issue in combating the negative consequences of cancer. Any opportunities to improve early cancer detection should be utilized. Educating the general public about what they can do to increase the chances of early detection of cancer is therefore an essential contribution to early detection processes. The nature and content of cancer prevention education should be a continuous concern of health educators, medical professionals, policymakers, researchers and health organizations, including the Dutch Cancer Society and the regional health authorities. 


\section{REFERENCES}

Ajzen, I. (1988). Attitudes, personality, and behavior. Buckingham: Open University Press.

Ajzen, I. (1991). The Theory of Planned Behavior. Organizational Behavior and Human Decision Processes, 50, 179-211.

Ajzen, I. \& Fisbein, M. (1970). The prediction of behavior from attitudinal and normative variables. Journal of Experimental and Social Psychology, 6, 466-487.

Ajzen, I. \& Fisbein, M. (1980). Understanding attitudes and predicting social behavior. Englewood Cliffs NJ: Prentice Hall.

Ajzen, I. \& Madden, T. J. (1986). Prediction of goal-directed behavior: Attitudes, intention, and perceived behavioral control. Journal of Experimental Social Psychology, 22, 453-473.

Ali, N.S. \& Khalil, H.Z. (1996). Cancer prevention and early detection among Egyptians. Cancer Nursing, 19, 104-111.

Allen, J.D., Sorensen, G., Stoddard, A.M., Colditz, G. \& Peterson, K. (1998). Intention to have a mammogram in the future among women who have underused mammography in the past. Health Education \& Behavior, 25, 474-488.

American Cancer Society (1991). Cancer statistics.CA Cancer Journal of Clinicians, 41, 19-36.

American Cancer Society (1998). Cancer facts \& figures - 1998. Atlanta: American Cancer Society.

American Cancer Society (2000a). Breast cancer facts \& figures 1999-2000. Atlanta: American Cancer Society.

American Cancer Society (2000b). Cancer facts and figures 2000. Atlanta: American Cancer Society.

Amsel, Z., Grover, P. \& Balshem, A.M. (1985). Frequency of breast self-examination practice as a function of physician reinforcement. Patient Education and Counseling, 7, 147-155.

Andersen, B.L., Cacioppo, J. \& Roberts, D.C. (1995). Delay in seeking a cancer diagnosis: Delay stages and psychophysiological comparison processes. British Journal of Social Psychology, 34, 33-52.

Assaf, A.R., Cummings, K.M., Graham, S., Mettlin, C. \& Marshall, J.R. (1985). Comparison of three methods of teaching women how to perform breast self-examination. Health Education Quarterly, 12, 259-272.

Austoker, J. (1994). Cancer prevention in primary care: Screening for ovarian, prostatic, and testicular cancers. British Medical Journal, 309, 315-320.

Auvinen, A., Elovainio, L. \& Hakama, M. (1996). Breast self-examination and survival from breast cancer. A prospective follow-up study. Breast Cancer Research and Treatment, 38, 161-168.

Bailar, J.C. \& Gornik, H.L. (1997). Cancer undefeated. The New England Journal of Medicine, 336, 1569 1574.

Baines, C.J. (1983). Some thoughts on why women don't do breast self-examination. Canadian Medical Association, 128, 255-256.

Baines, C.J., To, T. \& Wall, C. (1990). Women's attitudes to screening after participation in the National Breast Screening Study. Cancer, 65, 1663-1669.

Baker, L. (1982). Breast cancer detection demonstration project: Five-year summary report. CA Cancer Journal of Clinicians, 32, 194-225.

Bandura, A. (1986). Social foundations of thought and action: Englewood Cliffs, NJ: Prentice Hall.

Barling, N.R. \& Lehman, L. (1999). Young men's awareness, attitudes and practice of testicular selfexamination: a Health Action Process Approach. Psychology, Healtb \& Medicine, 4, 255-263. 
Becker, M.H. \& Rosenstock, I.M. (1984). Compliance with medical advise. In A. Steptoe \& A. Mathews (Eds.), Health care and buman bebaviour. London: Academic Press.

Benedict, S., Williams, R.D. \& Hoomani, J. (1996). Method of discovery of breast cancer. Cancer Practice, 4, 147-154.

Berman, S.H. \& Wandersman, A. (1991). Measuring knowledge of cancer. Social Science and Medicine, 32, $1245-1255$.

Berwick, M., Begg, C.B., Fine, J.A., Roush, G.C. \& Barnhill, R.L. (1996). Screening for cutaneous melanoma by skin self-examination. Joumal of the National Cancer Institute, 88, 17-23.

Best, D.L., Davis, S.W., Vaz, R.M. \& Kaiser, M. (1996). Testicular cancer education: A comparison of teaching methods. American Joumal of Health Behavior, 20, 229-241.

Beukema-Siebenga, H.J. (1997). Waarom nooit naar een huisarts? Een exploratief onderzoek naar nonconsultatiegedrag. [Why never visit a general practitioner? An exploration of non-consulting behaviour. Huisarts en wetenschap, 40, 372-375, 395 .

Boer, H. \& Seydel, E.R. (1995). Protection Motivation Theory. In M. Conner \& P. Norman (Eds.), Predicting health behaviour: research and practice with social cognition models. Buckingham, Philadelphia: Open University Press.

Bostick, R.M., Sprafka, J.M., Virnig, B.A. \& Potter, J.D. (1993), Knowledge, attitudes, and personal practices regarding prevention and early detection of cancer. Preventive Medicine, 22, 65-85.

Bostick, R.M., Sprafka, J.M., Virnig, B.A. \& Potter, J.D. (1994). Predictors of cancer prevention attitudes and participation in cancer screening examinations. Preventive Medicine, 23, 816-826.

Boyle, P., Veronesi, U., Tubiana, M., Alexander, F.E., Silva, F.C.D., Denis, L.J., Freire, J.M., Hakama, M., Hirsch, A., Kroes, R., Vecchia, C.L., Maisonneuve, P., Martin-Moreno, J.M., Newton-Bishop, J., Pindborg, J.J., Saracci, R., Scully, C., Standaert, B., Storm, H., Blanco, S., Malbois, R., Bleehen, N., Dicato, M. \& Plesnicar, S. (1995). European School of Oncology advisory report to the European Commission for the "Europe against cancer programme" European code against cancer. European Journal of Cancer, 31A, 1395-1405.

Bracht, N. (1990). Health promotion at the community level. Newbury Park, London, New Delhi: Sage Publications.

Brubaker, R.G. \& Wickersham, D. (1990). Encouraging the practice of testicular self-examination: A field application of the Theory of Reasoned Action. Health Psychology, 9, 154-163.

Brug, J., Campbell, M. \& Assema, P. (1999). The application and impact of computer-generated personalized nutrition education: A review of the literature. Patient Education and Counseling, 36, 145156.

Brug, J., Glanz, K., Van Assema, P., Kok, G. \& Van Breukelen, G.J.P. (1998). The impact of computertailored feedback and iterative feedback on fat, fruit, and vegetable intake. Health Education $\mathcal{E}$ Behavior, 25, 517-531.

Brug, J., Lechner, L. \& De Vries, H. (1995). Psychosocial determinants of fruit and vegetable consumption: Telephone survey. Appetite, 25, 285-296.

Brug, J., Steenhuis, I.H.M., Van Assema, P. \& De Vries, H. (1996). The impact of a computer-tailored nutrition intervention. Preventive Medicine, 25, 236-242.

Brug, J. \& Van Assema, P. (2000). Differences in use and impact of computer-tailored dietary fat-feedback according to stage of change and education. Appetite, 34, 285-293. 
Budden, L. (1995). Young women's breast self-examination knowledge and practice. Journal of Community Health Nursing, 12, 23-32.

Buetow, S.A. (1996). Testicular cancer: to screen or not to screen. Journal of Medical Screening, 3, 3-6.

Byles, J.E., Redman, S., Hennrikus, D., Sanson-Fischer, R.W. \& Dickinson, J. (1992). Delay in consulting a medical practitioner about rectal bleeding. Journal of Epidemiology and Community Health, 46, 241-244.

Calnan, M. (1984). The Health Belief Model and participation in programmes for the early detection of breast cancer: a comparative analysis. Social Science and Medicine, 19, 823-830.

Cameron, L., Leventhal, E.A. \& Leventhal, H. (1993). Symptom representations and affect as determinants of care seeking in a community-dwelling, adult sample population. Health Psuchology, 12, 171179.

Campbell, M.K., Bernhardt, J.M., Waldmiller, M., Jackson, B., Potenziani, D., Weathers, B. \& Demissie, S. (1999). Varying the message source in computer-tailored nutrition education. Patient Education and Counseling, 36, 157-169.

Campbell, M.K., DeVellis, B.M., Strecher, V.J., Ammerman, A.S., DeVellis, R.F. \& Sandler, R.S. (1994). Improving dietary behavior: The effectiveness of tailored messages in primary care settings. American Journal of Public Health, 84, 783-787.

Cassileth, B.P., Temoshok, L. \& Frederick, B.E., et. al. (1988). Patient and physcian delay in melnoma diagnosis. Journal of the American Academy of Dermology, 18, 591-598.

Champion, V.L. (1991). The relationship of selected variables to breast cancer detection behaviors in women 35 and older. Oncology Nursing Forum, 18, 733-739.

Champion, V.L. (1994). Beliefs about breast cancer and mammography by behavioral stage. ONF, 21, 1009-1014.

Clarke, V.A. \& Savage, S.A. (1999). Breast self-examination training: A brief review. Cancer Nursing, 22, 320-326.

Cochran, S.D., Hacker, N.F. \& Berek, J. (1986). Correlates in delay of seeking treatment for endometrial cancer. Journal of Psychosomatic Obstetrics and Gynaecology, 5, 245-252.

Collette, H., Rombach, J.J., De Waard, F. \& Collette, C. (1988). An update of the DOM Project for early detection of breastcancer. In N. Day \& Miller, A. (Eds.), Screening for breast cancer. Toronto.

Conner, M. \& Norman, P. (1995). Predicting bealth behaviour: research and practice with social cognition models. Buckingham, Philadelphia: Open University Press.

Conner, M. \& Sparks, P. (1995). The Theory of Planned Behaviour and health behaviours: Research and practice with social cognition models (pp. 121-162). In M. Conner \& P. Norman (Eds.), Predicting bealth behaviour: Research and practice with social cognition models. Buckingham: Open University Press.

Cope, D.G. (1992). Self-esteem and the practice of breast self-examination. Western Journal of Nursing Research, 14, 618-631.

Corney, R.H. (1990). Sex differences in general practice attendance and help seeking for minor illness. Journal of Psychosomatic Research, 34, 525-534.

Corney, R.H., Everett, H., Howells, A. \& Crowther, M.E. (1992). Psychosocial adjustment following major gynaecological surgery for carcinoma of the cervix and vulva. Journal of Psychosomatic Research, 36, 561-568. 
Crooks, C.E. \& Neutens, J.J. (1993). Prediction and verification of a woman's intention to participate in a mammography screening program. Journal of Healtb Education, 24, 214-218.

Cummings, K.M., Lampone, D., Mettlin, C. \& Pontes, J.E. (1983). What young men know about testicular cancer. Preventive Medicine, 12, 326-330.

Cummings, S.R., Tripp, M.K. \& Herrmann, N.B. (1997). Approaches to the prevention and control of skin cancer. Cancer and Metastasis Reviews, 16, 309-327.

De Boer, M.F. (1998). Physical and psychosocial correlates of rehabilitation, survival and relapse in bead and neck cancer patients. Erasmus Universiteit, Rotterdam.

De Bourdeaudhuij, I. \& Brug, J. (2000). Tailoring dietary feedback to reduce fat intake: An intervention at the family level. Health Education Research, 15, 449-462.

De Haes, J.C.J.M. \& Van Knippenberg, F.C.E. (1989). The quality of life of cancer patients: A review of the literature. Social Science and Medicine, 20, 809-817.

De Koning, H.J. \& Ballegooijen, V. (1997). Screening op kanker [Screening on cancer]. In D. Ruwaard \& P. G. N. Kramers (Eds.), Volksgezondheid Toekomst Verkenning: De gezondheidstoestand van de Nederlandse bevolking in de periode 195-2010 [Public bealth status and forecasts: The bealth status of the Dutch population over the period 1950-2010]. Den Haag: RIVM.

De Nooijer, J., Lechner, L. \& De Vries, H. (1997a). "Dat overkomt mij niet"; Kwalitatieve interviews met patienten over de ontdekking van kanker ["That won't happen to me"; qualitative interviews with patients about the detection of cancer]. Maastricht: Maastricht University.

De Nooijer, J., Lechner, L. \& De Vries, H. (1997b). Kwalitatieve interviews met buisartsen over bet consultatiepatroon van patienten met symptomen van kanker [Qualitative interviews with GPs about consultation behavior of patients with cancer symptoms]. Maastricht: Maastricht University.

De Nooijer, J., Lechner, L. \& De Vries, H. (2001). A qualitative study on detecting cancer symptoms and seeking medical help: An application of Andersen's model of total patient delay. Patient Education and Counseling, 42, 145-157.

De Nooijer, J., Lechner, L. \& De Vries, H. (in press). Help seeking behavior for cancer symptoms: Perceptions of patients and general practitioners. Psycho-Oncology

De Nooijer, J., Lechner, L. \& De Vries, H. (subm-a). Early detection of cancer: Knowledge and behavior of Dutch adults.

De Nooijer, J., Lechner, L. \& De Vries, H. (subm-b). Social psychological correlates of paying attention to cancer symptoms and seeking medical help.

De Vries, H. (1998). Planning and evaluating health promotion. In D. Scott \& R. Weston (Eds.), Evaluating Health Promotion. Cheltenham: Stanley Thornes Ltd.

De Vries, H. \& Backbier, E. (1994). Self-efficacy as an important determinant of quitting among smoking pregnant women: The -pattern. Preventive Medicine, 23, 167-174.

De Vries, H., Backbier, E., Kok, G. \& Dijkstra, M. (1995). The impact of social influences in the context of attitude, self-efficay, intention, and previous behavior as predictors of smoking onset. Journal of Applied Social Psychology, 25, 237-257.

De Vries, H. \& Brug, J. (1999). Computer-tailored interventions motivating people to adopt health promoting behaviours: Introduction to a new approach. Patient Education and Counseling, 36, 99-105.

De Vries, H., Dijkstra, M. \& Kok, G. (1991). De ontwikkeling en evaluatie van een rookpreventieprogramma [The development and evaluation of a smoking cessation program]. Tijdschrift Gezondheidsbevordering, 12, 27-42. 
De Vries, H., Dijkstra, M. \& Kok, G. (1992). A Dutch Smoking Project: An overview. Hygie, 11, $14-18$.

De Vries, H., Dijkstra, M. \& Kuhlman, P. (1988). Self-efficacy: The third factor besides attitude and subjective norm as a predictor of behavioral intentions. Health Education Research, 3, 273-282.

De Vries, H. \& Kok, G. (1996). Gezondheidsbevordering: een toepassing van het ABC-planningsmodel. Gedrag \& Gezondheid, 24, 342-352.

De Vries, H. \& Mudde, A. (1998). Forward and backward stage transitions in the smoking cessation process: A longitudinal report on differences in attitudes, social support and self-effecacy expectations using the ASE-model. Psychology and Health, 13, 369-385.

Deliens, L. (1998). Sociale determinanten van kennis van kankerpreventie in Vlaanderen [Social determi. nants of knowledge of cancer prevention]. Universiteit Maastricht, Maastricht.

Dijkstra, A. (1998). Computer-tailored interventions for smoking cessation: Targeting smokers with low readiness to quit. Universiteit Maastricht, Maastricht.

Dijkstra, A. \& De Vries, H. (1999a). Are computer-tailored interventions more effective than standardized interventions? A critical test. Paper presented at the EHPS, Florence.

Dijkstra, A. \& De Vries, H. (1999b). The development of computer-generated tailored interventions. Patient Education and Counseling, 36, 193-203.

Dijkstra, A., De Vries, H. \& Roijackers, J. (1999). Targeting smokers with low readiness to change with tailored and nontailored self-help materials. Preventive Medicine, 28, 203-211.

Dijkstra, A., De Vries, H., Roijackers, J. \& Van Breukelen, G. (1998). Tailoring information to enhance quitting in smokers with low motivation to quit: Three basic efficacy questions. Health Psychology, 6, 513-519.

Dijkstra, A., De Vries, H. \& Roijackers, J. (1998). Long-term effectiveness of computer-generated tailored feedback in smoking cessation. Health Education Research, 13, 207-214.

Doherty, V.R. \& MacKie, R.M. (1986). Reasons for poor prognosis in British patients with cutaneous malignant melanoma. Britsh Medical Journal, 292, 987-989.

Dutch Cancer Society (1991). Wees wijzer, van doorlopen met klachten wordt $u$ zeker niet beter [Be wise: living with complaints won't make you any better]. Amsterdam: Dutch Cancer Society.

Dutch Cancer Society (1996). Vroege ontdekking van kanker...wat u zelf kunt doen [Early detecton of cancer... what you can you do yourselff. Amsterdam: De Nederlandse Kankerbestrijding/KWF.

Dutch Cancer Society (1998). Mijnheer, sommige kleinigheden kunt $u$ maar beter niet negeren [You would do better not to ignore some lower parts, sir]. Amsterdam: Dutch Cancer Society.

Dutch Central Bureau for Statistics (2000). Statistisch jaarboek [Annual statistical report]. Voorburg/Heerlen: CBS.

Eagly, A.H. \& Chaiken, S. (1990). The psychology of attitudes. Fort Worth (TX): Hartcourt.

Egan, K.J. \& Beaton, R. (1987). Response to symptoms in healthy, low utilizers of the health care system. Journal of Psychosomatic Research, 31, 11-21.

Ersek, M., Ferrell, B.R., Dow, K.H. \& Melancon, C.H. (1997). Quality of life in women with ovarian cancer. Western Journal of Nursing Research, 19, 334-350.

Facione, N.C. (1993). Delay versus help seeking for breast cancer symptoms: A critical review of the literature on patient and provider delay. Social Science and Medicine, 36, 1521-1534.

Felce, D. \& Perry, J. (1995). Quality of life: Its definition and measurement. Research in Developmental Disabilities, 16, 51-74. 
Ferrell, B.R., Grant, M.M., Funk, B., Otis-Green, S. \& Garcia, N. (1997). Quality of life in breast cancer survivors as identified by focus groups. Psycbo-Oncology, 6, 13-23.

Fink, D.G. (1991). Guidelines for the cancer-related checkup: recommendations and rationale. Atlanta: American Cancer Society.

Fletcher, S.W., Black, W., Harris, R., Rimer, B.K. \& Shapiro, S. (1993). Report on the international workshop on screening for breast cancer. Jowrnal of the National Cancer Institute, 85, 1644-1656.

Foster, R.S. \& Constanza, M.C. (1984). Breast self-examination practices and breast cancer survival. Cancer, 53, 999-1005.

Fotheringham, M.J., Owies, D., Leslie, E. \& Owen, N. (2000). Interactive health communication in preventive medicine. Internet-based strategies in teaching and research. American Journal of Preventive Medicine, 19, 113-120.

Fotheringham, M.J., Wonnacot, R.L. \& Owen, N. (2000). Computer-use and physical inactivity in young adults: public health perils and potentials of new information technology. Annual of Behavioral Medicine, 21, 269-275.

Friedman, L.C., Nelson, D.V., Webb, J.A., Hoffman, L.P. \& Baer, P.E. (1994). Dispositional optimism, self-efficacy, and health beliefs as predictors of breast self-examination. American Journal of Preventive Medicine, 10, 130-135.

Friedman, L.C., Webb, J.A., Bruce, S., Weinberg, A.D. \& Cooper, H.P. (1995). Skin cancer prevention and early detection intentions and behavior. American Journal of Preventive Medicine, 11, 59-65.

Friedman, R.J., Rigel, D.S. \& Kopf, A.W. (1985). Early detection of malignant melanoma: The role of physician examination and self-examination of the skin. CA Cancer Journal for Clinicians, 35, 130-151.

Friman, P.C., Finney, J.W., Glasscock, S.G., Weigel, J.W. \& Christophersen, E.R. (1986). Testicular selfexamination: Validation of a training strategy for early cancer detection. Journal of Applied Behavior Analysis, 19, 87-92.

Ganong, L.H. \& Markovitz, J. (1987). Young men's knowledge of testicular cancer and behavioral intentions toward testicular self-exam. Patient Education and Counseling, 9, 251-261.

Gascoigne, P., Mason, M.D. \& Roberts, E. (1999). Factors affecting presentation and delay in patients with testicular cancer: results of a qualitative study. Psycho-Oncology, 8, 144-154.

Giovagnoli, A.R. (1999). Quality of life in patients with stable disease after surgery, radiotherapy, and chemotherapy for malignant brain tumour. Joural of Neurology, Neurosurgery, and Psychiatry, 67, 358363.

Godin, G. \& Kok, G. (1996). The Theory of Planned Behavior: A review of its applications to healthrelated behaviors. American Journal of Health Promotion, 11, 87-98.

Goldenring, J.M. \& Purtell, E. (1984). Knowledge of testicular cancer risk and need for self-examination in college students: A call for equal time for men in teaching of early cancer detection techniques. Pediatrics, 74, 1093-1096.

Green, L.W. \& Kreuter, M.W. (1991). Health promotion planning. An educational and environmental approach. Mountain View: Mayfield Publishing Company.

Green, L.W. \& Lewis, F.M. (1986). Measurement and evaluation in bealth education and bealth promotion. Palo Alto, California: Mayfield Publishing Company.

Greenlee, R. T., Murray, T., Bolden, S. \& Wingo, P.A. (2000). Cancer statistics, 2000. CA Cancer Journal for Clinicians, 50, 7-33. 
Greimel, E.R. \& Popper, V. (1998). The impact of cancer diagnosis on patients quality of life. Cancer Detection and Prevention, 22, S-182.

Hackett, T.P., Cassem, N.H. \& Raker, J.W. (1973). Patient delay in cancer. The New England Journal of Medicine, 289, 14-20.

Hakkinen, I.P.T., Nylamo, E.I. \& Soderstrom, K. (1997). The importance of self-observation of fecal blood in indicating a proper bowel examination. Cancer Detection and Prevention, 21, 267-272.

Hallal, J.C. (1982). The relationship of health beliefs, health locus of control, and self-concept to the practice of breast self-examination of adult women. Nursing Research, 31, 137-142.

Hennrikus, D., Girgis, A., Redman, S. \& Sanson-Fisher, R.W. (1991). A community study of delay in presenting with signs of melanoma to medical practitioners. Archives of Dermatology, 127, 356-361.

Hobbs, P., Haran, D., Pendleton, L.L., Jones, B.E. \& Posner, T. (1984). Public attitudes and cancer education. International Review of Applied Psychology, 33, 565-586.

Holmberg, L., Ekbom, A., Calle, E., Mokdad, A. \& Byers, T. (1997). Breast cancer mortality in relation to self-reported use of breast self-examination. A cohort study on 450,000 women. Breast Cancer Research and Treatment, 43, 137-140.

Huguley, C.M., Brown, R.L., Greenberg, R.S. \& Clark, W.S. (1988). Breast self-examination and survival from breast cancer. Cancer, 62, 1389-1396.

Ingham, J.G. \& Miller, P.McC. (1986). Self-referal to primary care: symptoms and social factors. Journal of Psychosomatic Research, 30, 49-56.

Ingham, J.G. \& Miller, P.McC. (1983). Self-referal: Social and demographic determiants of consulting behaviour. Journal of Psychosomatic Research, 27, 233-242.

Jackson, A., Wilkinson, C. \& Pill, R. (1999). Moles and melanomas - who's at risk, who knows, and who cares? A strategy to inform those at high risk. British Journal of General Practice, 49, 199-203.

Janis, I. \& Mann, L. (1977). Decision making: a psychological analysis of conflict, choice and commitment. New York: Free Press.

Janz, N. \& Becker, M. (1984). The health belief model: A decade later. Health Education Quarterly, 2, 147.

Jepson, C. \& Chaiken, S. (1990). Chronic issue-specific fear inhibits systematic processing of persuasive communications. Journal of Social Behavior and Personality, 5, 61-84.

Jones, R.A., Wiese, H.J., Moore, R.W. \& Haley, J.V. (1981). On the perceived meaning of symptoms. Medical Care, 19, 710-717.

Katz, R.C., Meyers, K. \& Walls, J. (1995). Cancer awareness and self-examination practices in young men and women. Journal of Behavioral Medicine, 18, 377-384.

Kelsey, J.L. \& Gammon, M.D. (1991). The epidemiology of breast cancer. CA Cancer Journal for Clinicians, 41, 146-165.

Koh, H.K., Miller, D.R., Geller, A.C., Clapp, R.W., Mercer, M.B. \& Lew, R.A. (1992). Who discovers melanoma? Patterns from a population-based survey. Journal of the American Academy of Dermatology, 26, 914-919.

Kok, G. (1985). Een model van gedragsverandering via voorlichting. Nederlands Tijdschrift voor de Psychologie, 40, 71-76.

Kreitler, S., Chaitchik, S., Kreitler, H. \& Weissler, K. (1994). Who will attend tests for the early detection of breast cancer? Psychology and Health, 9, 463-483. 
Kreuter, M., Farrell, D., Olevitch, L. \& Brennan, L. (2000). Tailoring bealth messges. Customizing communication with computer technology. Mahwah, New Jersey, London: Lawrence Erlbaum Associates.

Kreuter, M.W., Bull, F.C., Clark, E.M. \& Oswald, D.L. (1999). Understanding how people process health information: A comparison of tailored and non-tailored weight-loss materials. Healtb Psychology, $18,487-494$.

Kreuter, M.W., Oswald, D.L., Bull, F.C. \& Clark, E.M. (2000). Are tailored health education materials always more effective than non-tailored materials? Health Education Research, 15, 305-315.

Kreuter, M.W. \& Skinner, C.S. (2000). Tailoring: what's in a name? Health Education Research, 15, 1-4.

Kreuter, M.W., Strecher, V.J. \& Glassman, B. (1999). One size does not fit all: the case for tailoring print materials. Annual of Behavioral Medicine, 21, 276-283.

Krige, J.E.J., Isaacs, S., Hudson, D.A., King, H.S., Strover, R.M. \& Johnson, C.A. (1991). Delay in the diagnosis of cutaneous melanoma. Cancer, 68, 2064-2068.

Kuijs, C. \& Ehrenhard, M. (2000). Raadplegen van medische informatie [Consulting medical information]. Amsterdam: Nipo het marktonderzoekinstituut.

Kuroishi, T., Tominaga, S., Ota, J., Horinao, T., Taguchi, T., Ishida, T., Yokoe, T., Izuo, M., Ogita, M., Itoh, S., Abe, R., Yoshida, K., Morimot, T., Enomoto, K., Tashiro, H., Kashiki, Y., Yamamoto, S., Kido, C., Honda, K., Sasakawa, M., Fukuda, M. \& Watanabe, H. (1992). The effect of breast selfexamination on early detection and survival. Japanese Journal of Cancer Research, 83, 344-350.

Lauver, D. (1994). Care-seeking behavior with breast cancer symptoms in Caucasian and AfricanAmerican women. Research in Nursing \& Health, 17, 421-431.

Lauver, D. \& Chang, C.H. (1993). Explaining delay in care seeking for breast cancer symptoms. Journal of Applied Social Psychology, 23, 1806-1825.

Lauver, D. \& Chang, A. (1991). Testing theoretical explanations of intention to seek care for a breast cancer symptom. Journal of Applied Social Psychology, 21, 1440-1458.

Lechner, L. (1998). Social psycological determinants of health risk behaviors related to cancer and CVD: Applications and elaborations of the ASE model. Universiteit Maastricht, Maastricht.

Lechner, L., De Nooijer, J. \& De Vries, H. (1998). Vroege ontdekking van kanker: Een gedrags- en determinantenanalyse onder de Nederlandse bevolking [Early detection of cancer: $A$ behavior and determinant analysis among the Dutch population]. Maastricht: Universiteit Maastricht.

Lechner, L. \& De Vries, H. (1995). Participation in an employee fitness program: determinants of high adherence, low adherence and dropout. Journal of Occupational and Environmental Medicine, 37, 429436.

Lechner, L. \& De Vries, H. (1996). Vroege ontdekking van kanker [Early detection of cancer]. Maastricht: Maastricht University.

Lechner, L., De Vries, H. \& Offermans, N. (1997). Participation in a breast cancer screening program: Influence of past behavior and determinants on future screening participation. Preventive Medicine, 26, 473-482.

Lechner, L., Oenema, A. \& De Nooijer, J. (in press). Testicular self-examination (TSE) among Dutch young men aged 15 to 19: Determinants of the intention to practice TSE. Health Education Research Leventhal, H. (1970). Findings and theory in the study of fear communications. In L. Berkowitz L (Ed.), Advances in Experimental Social Psychology. (pp. 119-186). New York, London: Academic Press. 
Li, C., Samsioe, G. \& Iosif, C. (1999). Quality of life in endometrial cancer survivors. Maturitas, 31, 227. 236.

Lipsey, M.W. (1990). Design sensitivity. Statistical power for experimental research. Newbury Park, London, New Delhi: Sage Publications.

MacArthur, C. \& Smith, A. (1981). Delay in breast cancer and the nature of presenting symptoms. The Lancet, 8220, 601-603.

Maheswaran, D. \& Meyers-Levy, J. (1990). The influence of message framing and issue involvement. Journal of Marketing Research, 27, 361-367.

Maibenco, D., Daoud, Y., Phillips, E. \& Saxe, A. (1999). Relationship between method of detection of breast cancer and stage of disease, method of treatment, and survival in women aged 40 to 49 years. The American Surgeon, 65, 1061-1066.

Månsson, J., Marklunc, B., Bengtsson, C. \& Fridlund, B. (1999). Evaluation of an educational programme for the early detection of cancer. Patient Education and Counseling, 37, 231-242.

Marteau, T.M. (1989). Psychological costs of screening. British Medical Journal, 299, 527.

McCance, K.L., Mooney, K.H., Field, R. \& Smith, K.R. (1996). Influence of others in motivating women to obtain breast cancer screening. Cancer Practice, 4, 141-146.

McCaul, K., Sandgren, A., O'Neill, H. \& Hinsz, V. (1993). The value of the theory of planned behavior, perceived control, and self-efficacy for predicting health protective behaviors. Basic and Applied Social Psychology, 14, 231-252.

McEvoy-DeVellis, B., Blalock, S.J. \& Sandler, R.S. (1990). Perceived behavioral control. Journal of Applied Social Psychology, 20, 639-660.

McGuire, W.J. (1985). Attitudes and attitude change. In G. Lindsay \& E. Aronshon (Eds.), The handbook of social psychology (pp. 233-246). New York: Random House.

McGuire, W.J. (1989). Theoretical foundations of campaigns. In E. Atkin \& C. K. Atkin (Eds.), Public communication campaigns (pp. 43-67). Newbury Park: Sage Publications.

Meyerowitz, B.E. \& Chaiken, S. (1987). The effect of message framing on breast self-examination attitudes, intentions, and behavior. Journal of Personality and Social Psychology, 52, 500-510.

Millar, M.G. (1997). The effects of emotion on breast self-examination: Another look at the Health Belief Model. Social Behavior and Personality, 25, 223-232.

Millar, M.G. \& Millar, K. (1995). Negative affective consequences of thinking about disease detection behaviors. Health Psychology, 14, 141-146.

Miller, D.R., Geller, A.C., Wyatt, S.W. et al. (1996). Melanoma awareness and self-examination practices: Results of a United States survey. Journal of the American Academy of Dermatology, 34, 962-970.

Miller, S.M. (1980). When is a little information a dangerous thing?: Coping with stressful life-events by monitoring versus blunting. In S. U. Levine, H. (Ed.), Coping and bealth (pp. 145-169). New York: Plenum Press.

Miller, S.M. (1991). Monitoring and blunting in the face of threat: Implications for adaptation and health. In L. Montada \& S.H. Filipp \& M.J. Lerner (Eds.), Life crises and experiences of loss in adulthood. Engelewood Cliffs, NJ. Erlbaum.

Montano, D.E. \& Taplin, S.H. (1991). A test of an expanded Theory of Reasoned Action to predict mammography participation. Social Science and Medicine, 32, 733-741.

Moore, S.M., Barling, N.R. \& Hood, B. (1998). Predicting testicular and breast self-examination behaviour: A test of the Theory of Reasoned Action. Behaviour Change, 15, 41-49. 
Mor, V. Mastersoan-Allen, S, Goldberg, R., Guadaynoh, E. \& Wod, M.S. (1990), Predikgnastic

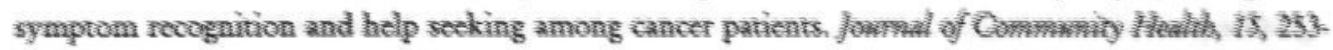
266.

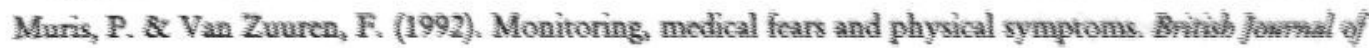
Clinal Pycholegy, $31,360-362$.

Muris, $P_{s}$ Van Zuren, FJ. De Jong, PJ. De Beurs, E. \& Hancwald, G. (1994). Monitoring and blunting coping styles: the Miller behavioural style scale and its correlates, and the development of an

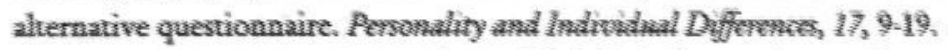

Murray, M. \& McMillan, C. (1993). Health beliefs, locus of control, emotional control and women's cancer screening behaviour. British jowrnal of Clinical Pyololog, 32, 87-100.

Muzzin, L.J. Anderson, N.J. Figueredo, A.T. \& Gudelis, S.O. (1994), The experience of cancer, Social Science and Modicine, $38,1201-1208$.

Myhre, S.I., Li, V.C., Guan, J. \& Wang, ZJ. (1996), Cancer knowledge and perceptions amoñg Chinese factory workers: Implications for cancer control and prevention. Cance Detection and Prewention, 223-233.

Neef, N., Scutchfield, F.D.s Elder, J. \& Bender, S.J. (1991). Testicular self-examination by young men: An analysis of characteristics associated with practice. Joumal of American College Hedh $39,187.190$.

Newcomb, P.A., Weiss, N.S., Storer, B.E., Scholes, D., Young, B.E. \& Voigt, L.F. (1991). Breast silfexamination in relation to the occurence of advanced breast cancer, lowmal of ale National Camer Institute, 83, 260-265.

Nichols, B.S., Misra, R. \& Alexy, B. (1996). Cancer detection: how effective is public education, Cancer Nursing, 19, 98-103.

Norman, P. \& Conner, M. (1993). The role of social cognition models in predicting attendance at health checks. Psychology and Health, 8, 447-462.

Norman, P. \& Conner, M. (1995). The role of social cognition models in predicting health behaviours: future directions. In M. Conner \& P. Norman (Eds.), Predicting bealth behaviour: Research and practice with social cognition models. Buckingham: Open University Press.

Oenema, A., Brug, J. \& Lechner, L. (subm). Web-based tailored nutrition education: Results of a randomized controlled trial.

Oliveria, S.A., Christos, P.J., Halpern, A.C., Fine, J.A., Barnhill, R.L. \& Berwick, M. (1999). Patient knowledge, awareness, and delay in seeking medical attention for malignant melanoma. Journal of Clinical Epidemiology, 52, 1111-1116.

Olson, K.L. \& Morse, J.M. (1996). Explaining breast self-examination practice. Health Care for Women International, 17, 575-591.

Ostwald, S.K. \& Rothenberger, J. (1985). Development of a testicular self-examination program for college men. Journal of American College Health, 33, 234-239.

Parker, S.L., Tong, T., Bolden, S. \& Wingo, P.A. (1996). Cancer Statistics, 1996. CA Cancer Journal for Clinicians, 46, 5-27.

Paskett, E.D., McMahon, K., Tatum, C., Velez, R., Shelton, B., Case, L.D., Wofford, J., Moran, W. \& Wymer, A. (1998). Clinic-based interventions to promote breast and cervical cancer screening. Preventive Medicine, 27, 120-128.

Pennebaker, J.W. (1982). The psychology of physical symptoms. New York: Springer-Verlag. 
Persson, K., Johansson, I. \& Ek, A.C. (1995). Breast self-examination among Swedish women: A survey of frequency, knowledge and attitudes. Journal of Cancer Education, 10, 163-167.

Persson, K., Svensson, P. \& Ek, A.C. (1997). Breast self-examination: An analysis of self-reported practice. Journal of Advanced Nursing, 25, 886-892.

Petty, R.E. \& Cacioppo, J.T. (1986). The elaboration likelihood model of persuasion. In L. Berkowitz (Ed.), Advances in Experimental Social Psychology (Vol. 19). London: Academic Press.

Philip, J., Harris, W.G., Flaherty, C., Joslin, C.A.F., Rustage, J.H. \& Wijesinghe, D.P. (1984). Breast selfexamination: clinical results from a population-based prospective study. British Journal of Cancer, $50,7$. 12.

Pinto, B. \& Fuqua, R.W. (1991). Training breast self-examination: a research review and critique. Health Education Quarterly, 18(4), 495-516.

Qin, D.X., Wang, G.Q., Zhang, X.H., Zuo, J.H. \& Yuan, F.L. (1996). New concept for cancer screening. European Journal of Cancer Prevention, 5, 121-124.

Rakowski, W., Dube, C.E., Marcus, B.H., Prochaska, J.O., Velicer, W.F. \& Abrams, D.B. (1992). Assessing elements of women's decisions about mammography. Health Psychology, 11, 111-118.

Rakowski, W., Ehrich, B., Goldstein, M., Rimer, B.K., Pearlman, D.N., Clark, M.A., Velicer, W.F. \& Woolverton, H. (1998). Increasing mammography among women aged $40-74$ by use of a stagematched, tailored intervention. Preventive Medicine, 27, 748-756.

Rampen, R.H.J., R.umke, P.H. (1984). Patients' and doctors' delay in diagnosing and treating malignant melanoma of the skin. In D.J. Ruiter, Welvaart, K., Ferrone, S. (Ed.), Cutaneous Melanoma and Precursor Lesions. Amsterdam: Martinus Nijhoff Publishers.

Reno, D.R. (1988). Men's knowledge and health beliefs about testicular cancer and testicular selfexamination. Cancer Nursing, 11, 112-117.

Rhodes, A.R. (1995). Public education and cancer of the skin. What do people need to know about melanoma and nonmelanoma skin cancer? Cancer, 75, 613-636.

Rhodes, F., Fishbein, M. \& Reis, J. (1997). Using behavioral theory in computer-based health promotion and appraisal. Health Education \& Behavior, 24, 20-34.

Richard, R., Van der Pligt, J. \& De Vries, N. (1995). Anticipated affective reactions and prevention of AIDS. British Journal of Social Psychology, 34, 9-21.

Ries, L.A.G., Eisner, M.P., Hankey, B.F., Miller, B.A., Clegg, L., Edwards, B.K. \& eds. (2000). SEER Cancer Statistics Review, 1973-1997. Bethesda, MD: National Cancer Institute.

Ringdal, G.I., Ringdal, K., Kvinnsland, S. \& Gotestam, K.G. (1994). Quality of life of cancer patients with different prognoses. Quality of Life Research, 3, 143-154.

Robinson, J.K., Rigel, D.S. \& Amonette, R.A. (1998). What promotes skin self-examination? Journal of the American Academy of Dermatiology, 38, 752-757.

Robinson, J.O. \& Granfield, A.J. (1986). The frequent consulter in primary medical care. Journal of Psychosomatic Research, 30, 589-600.

Rogers, E.M. (1983). Diffusion of innovations. New York: The Free Press.

Rogers, R.W. (1983). Cognitive and physiological processes in fear appeals and attitude change: a revised theory of protection motivation. In J.T. Cacioppo \& R.E. Petty (Eds.), Social Psychophysiology - A source book (pp. 153-176). New York: Guilford Press.

Rothman, A.J. \& Salovey, P. (1997). Shaping perceptions to motivate healthy behavior: The role of message framing. Psychological Bulletin, 121, 3-19. 
Rothman, A.J., Salovey, P., Antone, C., Keough, K. \& Drake Martin, C. (1993). The influence of message framing on intentions to perform health behaviors. Journal of Experimental Social Psychology, 29, 408-433.

Ruwaard, D. \& Kramers, P.G.N. (1997). Volksgezondheid Toekomst Verkenning: De gezondheidstoestand van de Nederlandse bevolking in de periode 195-2010 [Public bealth status and forecasts: The bealth status of the Dutch population over the period 1950-2010]. Den Haag: Elsevier/De Tijdstroom.

Safer, M.A., Tharps, Q.J., Jackson, B.A. \& Leventhal, H. (1979). Determinants of three stages of delay in seeking care at a medical clinic. Medical Care, 17, 11-29.

Salander, P., Bergenheim, A.T., Hamberg, K. \& Hendriksson, R. (1999). Pathways from symptoms to medical care: a descriptive study of symptom development and obstacles to early diagnosis in brain tumour patients. Family Practice, 16, 143-148.

Sarafino, E.P. (1998). Health Psychology. Biopsychosocial Interactions. New York: John Wiley \& Sons, Inc. Savage, S.A. \& Clarke, V.A. (1996). Factors associated with screening mammography and breast selfexamination intentions. Health Education Research, 11, 409-421.

Shapiro, S., Coleman, E.Z., Broeders, M., Codd, M., De Koning, H., Fracheboud, J., Moss, S., Paci, E., Stachenko, S. \& Ballard-Barbash, R. (1998). Breast cancer screening programmes in 22 countries: current policies, administration and guidelines. International Journal of Epidemiology, 27, 735-742.

Sheeran, P. \& Abraham, C. (1995). The Health Belief Model. In M. Conner \& P. Norman (Eds.), Predicting bealth behaviour: Research and practice with social cognition models. Buckingham: Open University Press.

Sheik, I. \& Ogden, J. (1998). The role of knowledge and beliefs in help seeking behaviour for cancer: a quantitative and qualitative approach. Patient Education and Counseling, 35, 35-42.

Shugg, D., Hill, D., Cooper, D. \& Shepherd, J. (1990). Practice of breast self-examination and the treatment of primary breast cancer. Australian and New Zealand Journal of Surgery, 60, 455-462.

Skinner, C.S., Campbell, M.K., Rimer, B.K., Curry, S. \& Prochaska, J.O. (1999). How effective is tailored print communication? Annals of Behavioral Medicine, 21, 290-298.

Skinner, C.S., Strecher, V.J. \& Hospers, H. (1994). Physicians' recommendations for mammography: Do tailored messages make a difference? American Journal of Public Health, 84, 43-48.

Smith, E.M. \& Anderson, B. (1985). The effects of symptoms and delay in seeking diagnosis on stage of disease at diagnosis among women with cancers of the ovary. Cancer, 56, 2727-2732.

Smith, E.M. \& Burns, T.L. (1985). The effects of breast self-examination in a population-based cancer registry. A report of differences in extent of disease. Cancer, 55, 432-437.

Solomon, L.J., Flynn, B.S., Worden, J.K., Mickey, R.M., Skelly, J.M., Geller, B.M., Peluso, N.W. \& Webster, J.A. (1998). Assessment of self-rewarded strategies for maintenance of breast self-examination. Journal of Behavioral Medicine, 21, 83-102.

Soost, H.J., Lange, H.J., Lehmacher, W. \& Ruffing-Kullmann, B. (1991). The validation of cervical cytology. Sensitivity, specificity and predictive values. Acta Cytology, 35, 8-14.

Spielberger, C.D. (1979). Understandig stress and anxiety. New York: Harper and Row.

Steckler, A., McLeroy, K.R., Goodman, R.M., Bird, S.T. \& McCormick, L. (1992). Toward integrating qualitative and quantitative methods: An introduction. Health Education Quarterly, 19, 1-8.

Steffen, V.J. (1990). Men's motivation to perform the testicle self-exam: Effects of prior knowledge and an educational brochure. Journal of Applied Social Psychology, 20, 681-702. 
Steffen, V.J. \& Gruber, V.A. (1990). Direct experience with a cancer self-exam: Effects on cognitions and behavior. The Journal of Social Psychology, 131, 165-177.

Stein, J.A., Fox, S.A., Murata, P.J. \& Morisky, D.E. (1992). Mammography usage and the Health Belief Model. Health Education Quarterly, 19, 447-462.

Strecher, V.J., Kreuter, M.W., Boer, D.D., Kobrin, S.C., Hospers, H.J. \& Skinner, C.S. (1994). The effects of computer tailored smoking cessation messages in family practice settings. Journal of Family Practice, 39, 262-270.

Strecher, V.J. \& Rosenstock, I.M. (1996). The Health Belief Model. In K. Glanz, F.M. Lewis \& B.K. Rimer (Eds.), Health behavior and bealth education: theory, research and practice. San Francisco, CA: Jossey-Bass.

Strickland, C.J., Feigl, P., Upchurch, C., King, D.K., Pierce, H.I., Grevstad, P.K., Bearden, J.D., Dawson, M., Loewen, W. C. \& Meyskens, F.L. (1997). Improving breast self-examination compliance: a Southwest oncology group randomized trial of three interventions. Preventive Medicine, 26, 320-332. Swanborn, P.G. (1987). Methoden van sociaal-wetenschappelijk onderzoek. Meppel, Amsterdam: Boon.

Tabachnick, B.G. \& Fidell, L.S. (1996). Using multivariate statistics. New York: HaarperCollins College Publishers.

Tabar, L., Fagerber, C.J., Gad, A., Baldetorp, L., Holmberg, L.H., Grontoft, O., Ljungquist, U., Lundstrom, B., Manson, J. C. \& Eklund, G. (1985). Reduction in mortality from breast cancer after mass screening with mammography. Randomised trial from the Breast Cancer Screening Working Group of the Swedish National Board of Health and Welfare. The Lancet, 1, 829-832.

The Skin Cancer Foundation (1992). Simple steps to sun safety. New York: The Skin Cancer Foundation.

Thomas, D.B., Gao, D.L., Self, S.G., Allison, C.J., Tao, Y., Mahloch, J., Ray, R., Qin, Q., Presley, R. \&

Porter, P. (1997). Randomized trial of breast self-examination in Shanghai: Methodology and preliminary results. Journal of the National Cancer Institute, 89, 355-365.

Thornhill, J.A., Conroy, R.M., Kelly, D.G., Walsh, A., Fennelly, J.J. \& Fitzpatrick, J.M. (1986). Public awareness of testicular cancer and the value of self-examination. Britsh Medical Journal, 293, 480-481.

Thornhill, J.A., Fennelly, J.J., Kelly, D.G. et al. (1987). Patients' delay in the presentation of testis cancer in Ireland. British Journal of Urology, 59, 447-451.

Tversky, A. \& Kahneman, D. (1981). The framing of decisions and the psychology of choice. Science, 211, 453-458.

United States Department of Health and Human Services (1988). The bealth consequences of smoking: Nicotine Addiction. A report of the surgeon general. (DHHS Publication No. 88-8406). Washington, DC: U.S. Government Printing Office.

United States Preventive Services Task Force (1996). Guide to clinical preventive services: Second Edition (1996). Baltimore: Williams \& Wilkins.

Van de Kar, A.G.A., Knottnerus, J.A., Meertens, R.M., Dubois, V. \& Kok, G.J. (1992). Why do patients consult the general practitioner? Determinants of their decision. British Journal of General Practice, 42, 313-316.

Van Duijn, N.P., De Haes, J.C.J.M., Heerma van Vos, G.J.J., Koedoot, C.G., Schade, E., Schornagel, J.H. \& Spelten, E. (2000). Signaleringsrapport kanker 1999. Deelrapport zorg. Amsterdam: Nederlandse Kankerbestrijding/KWF.

Van Leer, E.M., Cleton, F.J. \& van Leeuwen, F.E. (1999). Signaleringsrapport kanker 1999 [Cancer Registry report 1999]. Amsterdam: Nederlandse Kankerbestrijding/KWF. 
Van Ryn, M., Lytle, L.A. \& Kirscht, J.P. (1996). A test of the theory of planned behavior for two healthrelated practices. Journal of Applied Social Psychology, 26, 871-883.

Van Zuuren, F.J. \& Dooper, R. (1999). Coping style and self-reported health promotion and disease detection behaviour. British Journal of Health Psychology, 4, 81-89.

Vaz, R.M., Best, D.L. \& Davis, S.W. (1988). Testicular cancer. Adolescent knowledge and attitudes. Journal of Adolescent Health Care, 9, 474-479.

Velicer, W.F. \& Prochaska, J.O. (1999). An expert intervention for smoking cessation. Patient Education and Counseling, 36, 119-129.

Vernon, S., Lavill, E. \& Jackson, G. (1990). Participation in breast screening programmes: A review. Social Science and Medicine, 30, 1107-1118.

Visser, O., Coebergh, J.W.W., Schouten, L.J. \& Van Dijck, J.A.A.M. (2000). Incidence of cancer in the Netherlands 1996. Utrecht: Comprehensive Cancer Centres.

Wagle, A., Komorita, N.I. \& Lu, Z.J. (1997). Social support and breast self-examination. Cancer Nursing, $20,42-48$.

Wardle, J., Steptoe, A., Burckhardt, R., Vogele, C., Vila, J. \& Zarczynski, Z. (1994). Testicular selfexamination: Attitudes and practices among young men in Europe. European Journal of Cancer Prevention, 4, 61-68.

Wardle, J., Steptoe, A., Smith, H., Groll-Knapp, E., Koller, M., Smith, D. \& Brodziak, A. (1995). Breast self-examination: Attitudes and practices among young women in Europe. European Journal of Cancer Prevention, 4, 61-68.

Weinstein, N.D. (1984). Why won't it happen to me: Perspectives of risk factors and susceptibility. Health Psychology, 3, 431-457.

Weist, M.D., Finney, J.W. (1996). Training in early cancer detection and anxiety in adolescent males: a preliminary report. Developmental and Behavioral Pediatrics, 17, 98-99.

Willemsen, M. (2001). Personal communication.

Willemsen, M.C., De Vries, H., Van Breukelen, G. \& Oldenburg, B. (1996). Determinants of intention to quit smoking among Dutch employees: The influence of the social environment. Preventive Medicine, 25, 195-202.

Wilson, D.K., Purdon, S.E. \& Wallston, K.A. (1988). Compliance to health recommendations: a theoretical overview of message framing. Health Education Research, 3, 161-171.

Wool, M.S. (1986). Extreme denial in breast cancer patients and capacity for object relations. Psychotber. apy Psychosomatic, 46, 196-204. 


\section{SUMMARY}

This thesis describes the development and evaluation of an intervention aimed at encouraging Dutch adults to engage in behaviors conducive to the early detection of cancer. It is widely accepted that the earlier cancer is detected, the better chances on successful treatment and survival are. Chapter 1 provides an overview of cancer as a health problem and the behaviors associated with early detection of cancer. This chapter focuses on the detection of potential cancer symptoms, as well as on consulting a physician if such symptoms are detected. Detection of cancer can be done in two ways: actively, for instance by performing breast or testicular self-examination, or passively, by being alert on potential cancer symptoms without a conscious action. Little is known about passive detection and help-seeking behavior for these symptoms among a-symptomatic people. It is expected that this may contribute to the early detection of cancer, and is therefore the main focus of this thesis.

This thesis consists of three parts. The first part (Chapter 2 and 3) describes two qualitative studies to obtain insight into the cancer detection process from the perspectives of patients and physicians. In the second part (Chapter 4 and 5) the behaviors conducive to early detection of cancer and the determinants associated with these behaviors among a-symptomatic Dutch adults are presented. The last part (Chapter 6 and 7) describes the process and effect evaluation of a newly developed computer-tailored intervention aimed at stimulating people to engage in early detection behaviors. The three parts of the thesis end with a general discussion (Chapter 8).

Delay in cancer diagnosis should be prevented. Unfortunately, delay often occurs in the period between someone's first awareness of an unexplained symptom and the day he/she receives medical attention. In Chapter 2 a model to study delay is described and applicated. This model describes that the pre-diagnostic period is comprised of several stages in which delay might occur. First, when a person detects an unexplained symptom he/she should recognize this symptom as a possible cancer symptom or at least as a symptom serious enough to consult a physician. Then, he/she has to decide to consult a physician. Subsequently, an appointment with the medical professional should be made, which in some cases may take a while before actual consultation takes place. Lastly, delay can occur between the first medical attention and the beginning of the treatment. During these phases delay can occur due to the patient and in the last phases also due to the medical professionals. The cancer detection process was studied among 23 cancer patients, using semi-structured interviews. The factors influencing this process were identified. Among the factors stimulating this process were attributing the newly 
detected symptom to cancer and discussing the detection of the symptoms with others. Being ashamed by the nature of the symptoms and attributing the symptom to common ailments were among the impeding factors. One of the conclusions of this first chapter is that health education should focus on increasing knowledge about the cancer symptoms and providing information about early detection of cancer in a positive way. Other channels than just the medical circuit to disseminate health education on early detection of cancer should be studied, since especially young people do not frequently visit medical professionals.

Chapter 3 describes the early detection process from patients' and physicians' perspectives. This chapter describes the role of knowledge and symptom interpretation, fear and trust in the medical professionals at the one hand, and consulting the physician with cancer symptoms on the other. Twenty-three patients and ten physicians were asked about their experiences with the cancer detection process by means of semi-structured interviews. It was found that patients who postpone consultation of a medical professional did this because of fear or lack of knowledge and misinterpretation of cancer symptoms. Implications for health education are that this should be focused on improving knoweldge and interpretation of cancer symptoms, decreasing feelings of unrealistic fear, helping patients to cope with realistic fear, and convincing patients of the relevance of consulting a physician. Suggestions are given of how these results can be tested using various social psychological theories.

Chapter 4 presents the results of two quantitative studies $(N=431, n=1778)$ on knowledge and behavior among Dutch adults regarding early detection of cancer. Telephone interviews were used to assess knowledge of cancer symptoms and detection methods. In the second study a written questionnaire was used to assess symptom recognition, detection behaviors and help-seeking behaviors. The findings showed that respondents did not have much general knowledge of detection methods and cancer symptoms, but recognized most cancer symptoms. For most symptoms, medical help would be sought within the appropriate time by the majority of the respondents. Correlations between recognition of cancer symptoms, paying attention to cancer symptoms and help-seeking behavior were significant but low. This means that although people in general recognize the symptoms as cancer symptoms, this does not automatically result in being alert on these symptoms in themselves or that they would seek help once they face such symptoms. More research is required to study the factors explaining this gap.

In Chapter 5 the social psychological factors associated with paying attention to cancer symptoms and help-seeking behavior were studied. Two written questionnaires with a 
six-week time interval, were administerd by approximately 600 Dutch adults. Correlates of both behaviors with other factors were studied by means of the Attitude - Social influence - self-Efficacy (ASE) model. Modeling, intention and past behavior were associated with passive detection. Modeling, moral obligation, self-efficacy, intention and past behavior were correlated with help-seeking behavior. It was concluded that past behavior played an important role in especially paying attention to cancer symptoms, while help-seeking behavior was more influenced by cognitive and affective determinants. Hence, educational programs need to address the two behaviors separately and also need to tailor the content to the various social psychological correlates of these two behaviors.

Chapter 6 describes the process evaluation of the computer-tailored intervention aimed at encouraging Dutch adults to engage in early detection behaviors and short-term effects on attitudes and behaviors. The tailored information was compared with the current (non-tailored) information on early detection of cancer of the Dutch Cancer Society on its use, format and content. A total of 1040 Dutch adults participated in the study. Results showed that both kinds of information were often read by the recipients, but the recipients of the tailored information more often saved and discussed the information. Moreover, the tailored information was perceived as more interesting, attractive, new, and personnally relevant. Also the content of the tailored letter was more positively evaluated by the recipients compared to the non-tailored information. The tailored as well as the non-tailored information did not increase feelings of worry about particular symptoms or complaints. Short-term effects showed that tailored information resulted significantly more often in changes in attitudes and behaviors after the intervention. It was concluded that information adapted to individuals' characteristics is an appreciated and effective method of health education in early detection of cancer.

Chapter 7 deals with the short-term (three weeks after the intervention, T1) and longterm (six months after the intervention, T2) effect evaluation of a computer-tailored intervention aimed at encouraging Dutch adults $(n=1855)$ to engage in early detection behaviors. In a randomized controlled trial the tailored information was compared with non-tailored information on early detection of cancer and with no information to study effects on ASE determinants, intentions toward early detection behaviors and early detection behaviors. Possible negative side effects, such as chronic fear for cancer and fatalistic attitudes toward cancer were studied as well. The main conclusions were that the tailored intervention is effective, since positive changes were found on ASE determinants, intentions and behaviors at T1 and T2 compared to the control group. Moreover, 
the tailored intervention is more effective than the non-tailored information in changing some of the ASE determinants, almost all intentions (except for the intention to pay attention to cancer symptoms at T2) and all behaviors. The results showed furthermore that no adverse side-effects on fear or fatalism occured in both interventions. This allows us to conclude that there were very positive effects of the tailored intervention. However, research is needed how these effects can be maintained over longer time periods.

The last chapter (Chapter 8) discusses the main findings of the emperical studies. This chapter futhermore discusses the methodology used in the different studies with respect to the operationalization and assessment of the behaviors and ASE concepts, the recruitment of the participants and the theories which were the basis for these studies. The thesis ends with recommendations for further research and practice. 
Dit proefschrift beschrijft de ontwikkeling en evaluatie van een advies-op-maat gericht op het stimuleren van de vroege ontdekking van kanker door Nederlandse volwassenen. Het is algemeen bekend dat de kansen op een succesvolle behandeling en overleving groter worden wanneer kanker in een vroeg stadium ontdekt wordt. In hoofdstuk 1 wordt een overzicht gegeven van kanker als gezondheidsprobleem en van de gedragingen die met de vroege ontdekking van kanker samenhangen. Daarbij gaat het zowel om de ontdekking van bepaalde symptomen die op kanker kunnen wijzen, als om het zoeken van adequate medische hulp in het geval dergelijke symptomen zich voordoen. De ontdekking van kankersymptomen vindt enerzijds plaats door actieve opsporing, zoals borstzelfonderzoek en zaadbalzelfonderzoek, anderzijds door passieve opsporing, waarbij iemand bepaalde kankersymptomen gewaar wordt door daar alert op te zijn, zonder specifieke acties daartoe te ondernemen. Vanuit gezondheidsvoorlichting en de gedragswetenschappelijke hoek is tot op heden weinig onderzoek verricht naar met name de passieve ontdekking van kanker door a-symptomatische personen en hun daaropvolgende hulpzoekgedrag. Omdat verwacht mag worden dat beide gedragingen een bijdrage aan de vroege ontdekking en overleving van kanker kunnen leveren, vormen ze de kern het onderzoek dat beschreven is in dit proefschrift.

De empirische studies in dit proefschrift kunnen worden onderverdeeld in drie delen. Het eerste deel (hoofdstuk 2 en 3) geeft op basis van twee kwalitatieve studies inzicht in het proces van het ontdekken van kanker symptomen tot het eerste medische consult om een diagnose te kunnen stellen. Deze studies zijn verricht vanuit het perspectief van zowel patiënten als van huisartsen. In het tweede deel (hoofdstuk 4 en 5) worden twee studies gepresenteerd die ingaan op de opvattingen van a-symptomatische volwassen Nederlanders aangaande de vroege ontdekking van kanker en hun feitelijke gedrag in dezen. Het laatste deel (hoofdstuk 6 en 7) beschrijft eerst de ontwikkeling van een adviesop-maat dat beoogt de passieve opsporing van kanker en adequaat hulpzoekgedrag in geval van kankersymptomen te bevorderen. Van het experimentele onderzoek dat met dit voorlichtingsinstrument werd verricht, beschrijft dit deel zowel een procesevaluatie als een evaluatie van de korte- en langetermijneffecten. Het proefschrift eindigt met een algemene discussie van de belangrijkste conclusies, methodologische aspecten van de studies en aanbevelingen voor verder onderzoek en de praktijk (hoofdstuk 8).

Vaak genoeg wordt een symptoom van kanker pas in een laat stadium ontdekt, of wordt een bezoek aan de huisarts om een diagnose te kunnen stellen en een behandeling in gang te kunnen brengen uitgesteld. Hoofdstuk 2 presenteert een model om dit 
uitstelgedrag in kaart te brengen. Dit model beschrijft dat de pre-diagnostische periode van ontdekken en hulpzoeken uit verschillende fases bestaat. Zo moet men eerst een symptoom ontdekken, en erkennen dat dit een symptoom van kanker is - of tenminste een symptoom dat medisch advies nodig heeft. Vervolgens moet men de beslissing nemen om medische hulp te zoeken, een afspraak maken met de huisarts en die ook daadwerkelijk consulteren. Vervolgens moet de huisarts een behandeling instellen. In al deze fases kan vertraging optreden. In de eerdere fases is dat voornamelijk te wijten aan de patiënt, in de latere met name aan de huisarts. Met semi-gestructureerde interviews onder 23 kankerpatiènten werd nagegaan hoe het pre-diagnostische proces voor hun was verlopen en welke factoren een rol hadden gespeeld bij het al dan niet consulteren van de huisarts. Het proces van passieve detectie en hulpzoeken verliep sneller indien een symptoom met kanker werd geassocieerd en als de symptomen werden besproken met anderen. Schaamte door de aard van het symptoom of de toeschrijving van het symptoom aan een gewone ziekte, bleken juist een remmende invloed in het proces te hebben. Angst bleek zowel een rol te spelen bij onnodig hulpzoeken, als bij uitstelgedrag, als bij adequaat hulpzoekgedrag. Geconcludeerd werd dat gezondheidsvoorlichting over vroege ontdekking zich zou moeten richten op het overbrengen van kennis over symptomen van kanker. Om mensen met symptomen te stimuleren tijdig een huisarts te consulteren, zou de voorlichting bovendien in moeten gaan op mogelijke angstgevoelens en positieve informatie moeten bevatten over de behandeling en overlevingskansen. Omdat vooral jonge mensen nauwelijks bij een huisarts terecht komen, maar wel met kanker geconfronteerd kunnen worden, zullen ook andere kanalen dan het medische circuit aangeboord moeten worden om deze informatie over te brengen.

Hoofdstuk 3 doet verslag van semi-gestructureerde interviews met 23 kankerpatiënten en tien huisartsen naar hun ervaringen met het zoeken van medische hulp voor symptomen van kanker. Centraal daarbij stonden de kennis en de interpretatie van symptomen, de angst en het vertrouwen dat men had in de behandeling van de huisarts enerzijds en de beslissing de huisarts te consulteren anderzijds. Patiënten die een bezoek aan de huisarts uitstellen, bleken dit mogelijk om twee redenen te doen: vanwege gebrek aan kennis en/of de misinterpretatie van symptomen of vanwege angst voor de diagnose, de ernst van de ziekte, de behandeling of overlijden. De huisartsen onderschreven de invloed van onvoldoende kennis en angst op het uitstelgedrag. Voorlichting zou een positieve bijdrage aan de vroege ontdekking van kanker kunnen leveren door zich te richten op een verbetering van de kennis en de interpretatie van symptomen en een afname van onrealistische angstgevoelens. Vanwege de rol van angst zou voorlichting 
bovendien effectief copinggedrag moeten aanreiken en patiënten moeten overtuigen van het belang tijdig een huisarts te consulteren. Het hoofdstuk sluit af met suggesties om deze resultaten met behulp van sociaal psychologische theorieën verder te onderzoeken.

Het vierde hoofdstuk beschrijft twee kwantitatieve studies onder Nederlandse volwassenen $(n=431, n=1778)$ naar de kennis van kankersymptomen en methoden om kanker of de symptomen daarvan te ontdekken en naar de mate waarin deze methoden daadwerkelijk werden gebezigd. De eerste studie bestond uit telefonische interviews. Daarin werd gevraagd welke symptomen van kanker en welke methoden om kanker in een vroeg stadium te ontdekken men spontaan kon noemen. In de tweede studie werden schriftelijke vragenlijsten gebruikt. Daarmee werd gemeten of men bepaalde symptomen herkende als kankersymptomen, welke methoden van vroege opsporing van kanker men uitvoerde, en of men met bepaalde symptomen naar de huisarts zou gaan. Uit deze studies bleek dat de respondenten weinig symptomen van kanker en slechts een gering aantal methoden voor de vroege ontdekking van kanker spontaan konden opnoemen. Wel wist men wel de meeste kankersymptomen te herkennen en te kunnen onderscheiden van symptomen die niet op kanker duiden. Bovendien bleek men redelijk alert te zijn op mogelijke kankersymptomen bij zichzelf. Verder gaven de meeste respondenten aan op tijd naar de huisarts te zullen gaan indien zij een mogelijk symptoom van kanker zouden ontdekken. Per symptoom was de samenhang tussen het herkennen van dat symptoom, het vertonen van passief ontdekkingsgedrag en het voorgenomen adequate hulpzoekgedrag laag. Dat betekent dat wanneer iemand in zijn algemeenheid symptomen van kanker herkent, dit niet automatisch inhoudt dat diegene daar ook bij zichzelf alert op is, of, in geval van ontdekking van een van die symptomen bij zichzelf, daar ook tijdig mee naar de huisarts zal gaan. Meer onderzoek is nodig om deze kloof tussen het herkennen van kankersymptomen in het algemeen en het daadwerkelijke opsporings- en hulpzoekgedrag te kunnen verklaren.

Hoofdstuk 5 gaat nader in op de rol van verschillende sociaal-psychologische factoren bij twee gedragingen die de vroege ontdekking van kanker kunnen bevorderen, namelijk de passieve detectie van symptomen en het tijdig consulteren van de huisarts als een symptoom van kanker is ontdekt. Onder ruim 600 volwassen Nederlanders werd op twee meetmomenten met behulp van schriftelijke vragenlijsten gemeten hoe men dacht over de vroege ontdekking van kanker (TO) en wat men daadwerkelijk aan vroege ontdekking deed (T1). Het ASE-model werd gebruikt om de mogelijke determinanten van vroege opsporing in kaart te brengen. De mate waarin respondenten bij zichzelf letten op symptomen van kanker was geassocieerd met soortgelijk gedrag van anderen in hun omgeving, de intentie om op symptomen te letten en de mate waarin men dat in het 
verleden al deed. Of mensen met hun symptomen tijdig hun huisarts zouden consulteren, hing eveneens samen met voorbeeldgedrag van anderen in hun omgeving en de intentie om het gedrag te vertonen, maar minder sterk met de mate waarin men dat in het verleden gewoon was te doen. Daarnaast speelde bij het tijdig consulteren van de huisarts de morele verplichting tegenover zichzelf en de familie een rol, alsmede de mate waarin men zichzelf in staat achtte om in diverse situaties ook daadwerkelijk hulp te zoeken. Geconcludeerd werd dat hetgeen men gewend is om te doen vooral van belang is voor de passieve detectie van kankersymptomen, terwijl cognitieve en affectieve factoren een grotere rol spelen bij de beslissing om de huisarts te consulteren. In interventies zouden beide gedragingen en de determinanten die daarbij een rol spelen apart aandacht moeten krijgen.

Hoofdstuk 6 beschrijft allereerst de ontwikkeling van een advies-op-maat gericht op het stimuleren van gedragingen die leiden tot de vroege ontdekking van kanker. Dit advies-op-maat werd vergeleken met de brochure over de vroege ontdekking van kanker die in gebruik was bij de Nederlandse Kankerbestrijding. Duizendveertig volwassen Neder-landers namen aan deze studie deel. In de procesevaluatie werden deze twee voorlichtingsmethoden vergeleken wat betreft het gebruik, de vorm en de inhoud. Beide vormen van informatie werden door de meerderheid van de respondenten gelezen, maar het advies-op-maat werd vaker bewaard en met anderen besproken dan de algemene brochure. Mensen die het advies-op-maat hadden ontvangen vonden de informatie ook interessanter, geloofwaardiger, nieuwer en aantrekkelijker. Verder was men van mening dat het advies-op-maat voldoende informatie bevatte over de voordelen van de vroege ontdekking van kanker en over hetgeen men daar zelf aan bij zou kunnen dragen. Van belang was tevens dat het advies-op-maat geen extra angst opriep bij de respondenten. De effectevaluatie drie weken na de interventie wees uit dat de attitudes en gedragingen aangaande het letten op kankersymptomen en het tijdig consulteren van de huisarts, meer in positieve zin waren veranderd door het advies-op-maat dan door de algemene brochure. Geconcludeerd werd dat informatie die aansluit bij de kenmerken van de ontvanger een gewaarde en effectieve methode is om volwassen Nederlanders te stimuleren tot de vroege ontdekking van kanker.

Hoofdstuk 7 gaat nader in op de korte en lange termijn effectevaluatie van het adviesop-maat. In dit onderzoek werden ruim 1800 mensen op basis van toeval toegewezen aan drie verschillende condities: het advies-op-maat, een algemene brochure of (in eerste instantie) geen informatie. $\mathrm{Bij}$ de respondenten vonden een schriftelijke voormeting, een schriftelijke nameting op de korte termijn ( 3 weken na de interventie) en een telefonische nameting op de lange termijn (6 maanden na de interventie) plaats. Geconcludeerd werd 
dat (1) het advies-op-maat effectief is in het veranderen van de determinanten, de intenties en de gedragingen; (2) het advies-op-maat gedeeltelijk effectiever is dan de bestaande algemene voorlichting; (3) deze voorlichting over kanker niet leidt tot een toegenomen angst voor of toegenomen fatalistische opvattingen over kanker. Het verdient aanbeveling om te onderzoek of deze effecten over een langere tijdsperiode eveneens gehandhaafd blijven.

Tot slot worden in hoofdstuk 8 de belangrijkste conclusies nog eens weergegeven. Vervolgens wordt ingegaan op de methodologie van het onderzoek: de wijze van operationalisatie en meting van de gegevens, de methode van werving van de onderzoekspersonen, en het theoretisch kader waarbinnen het onderzoek is uitgevoerd. Het hoofdstuk sluit af met implicaties voor verder onderzoek en toekomstige voorlichting over vroege ontdekking van kanker. 


\section{ACKNOWLEDGMENTS}

My great thanks go to the following people for making this dissertation possible: My advisors Lilian Lechner and Hein de Vries, for guiding me through the process of starting the project and finishing it; Karel van Koppen, Cora Honing and the Dutch Cancer Society, for giving me the opportunity to conduct this project and providing financial support; Jack Berben, Math Candel, Janneke Harting, Jan Klerkx, Ineke Stolte, and MEMIC for their contributions to this thesis; the cancer patients, physicians and volunteers, for participating in the studies; my colleagues within the Department of Health Education and Promotion, for all their professional and social support; my parents and Ton, for all the things you can't write down in one page.

Allen hiervoor mijn dank. 


\section{CURRICULUM VitAE}

Jascha de Nooijer was born in Dordrecht on March 5, 1970. She received her HAVO diploma at the Scholengemeenschap de Breul in Zeist, in 1987. She started with a higher vocational training on Food and Dietetics at the Hogeschool in Nijmegen, from which she graduated in 1991. She continued with Health Promotion and Education at the Universiteit Maastricht. After graduation in 1994 she worked as a volunteer on an AIDS project in Chiang Mai, Thailand. In 1995 she participated in a project funded by the Dutch Heart Foundation as a research assistant at the Department of Health Promotion and Education, Universiteit Maastricht. After a year, she spent four months at the National Institute of Health Promotion and Disease Prevention (NIGZ) in Woerden, before starting as a $\mathrm{PhD}$ fellow, again in Mastricht. For four years she worked on the project Early detection of cancer, which is described in this thesis. Since December 2000 she has continued her work at the same department as an assistant professor in the field of communication and genetics. 

